\title{
INDICAÇÕES PARA O EMPREGO DA MADEIRA DE ESPÉCIES TROPICAIS DO BRASIL
}

\author{
Eng ${ }^{a}$ Marcela Paula Grobério
}

Dissertação apresentada à Área de Interunidades, em Ciência e Engenharia de Materiais, como parte dos requisitos para obtenção

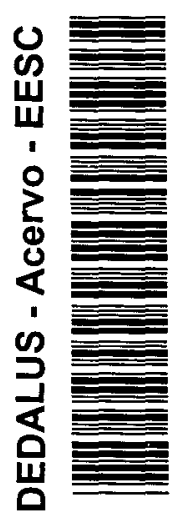
do título de Mestre em Ciência e Engenharia dos Materiais.

Orientador: Prof. Titular Francisco Antonio Rocco Lahr

São Carlos

2000

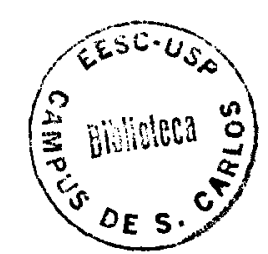


Class.

$\frac{1.50}{2654}$

$\cos 1013401$

2190950

Ficha catalográfica preparada pela Seção de Tratamento da Informação do Serviço de Biblioteca - EESC/USP

\begin{tabular}{|c|c|}
\hline \multirow[t]{3}{*}{ G873i } & $\begin{array}{l}\text { Grobério, Marcela Paula } \\
\quad \text { Indicações para o emprego da madeira de espécies } \\
\text { tropicais do Brasil / Marcela Paula Grobério. -- São } \\
\text { Carlos, } 2000 \text {. }\end{array}$ \\
\hline & $\begin{array}{l}\text { Dissertação (Mestrado) -- Escola de Engenharia de São } \\
\text { Carlos/Instituto de Física de São Carlos/Instituto de } \\
\text { Química de são Carlos-Universidade de são Paulo, } 2000 . \\
\text { Área Interunidades: Ciência e Engenharia de Materiais. } \\
\text { Orientador: Prof. Dr. Francisco Antonio Rocco Lahr. }\end{array}$ \\
\hline & $\begin{array}{l}\text { 1. Madeiras tropicais. 2. Propriedades físicas e } \\
\text { mecânicas. 3. Critérios para classificação. I. Título. }\end{array}$ \\
\hline
\end{tabular}


MEMBROS DA COMISSÃO JULGADORA DA DISSERTAÇÃO DE MESTRADO DE MARCELA PAULA GROBÉRIO, APRESENTADA AO PROGRAMA DE PÓS-GRADUAÇÃO INTERUNIDADES, ÁREA EM CIÊNCIA E ENGENHARIA DE MATERIAIS, DA UNIVERSIDADE DE SÃO PAULO, EM 28/11/2000.

\section{COMISSÃO JULGADORA:}

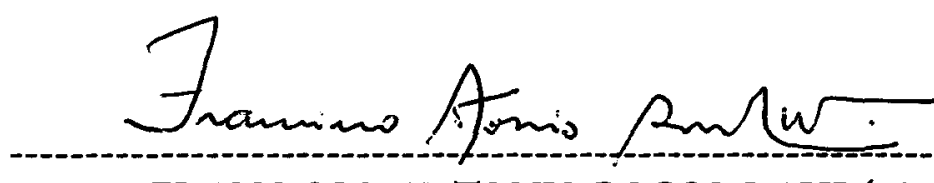

Prof. Dr. FRANCISCO ANTONIO ROCCO LAHR(orientador) - EESC/USP

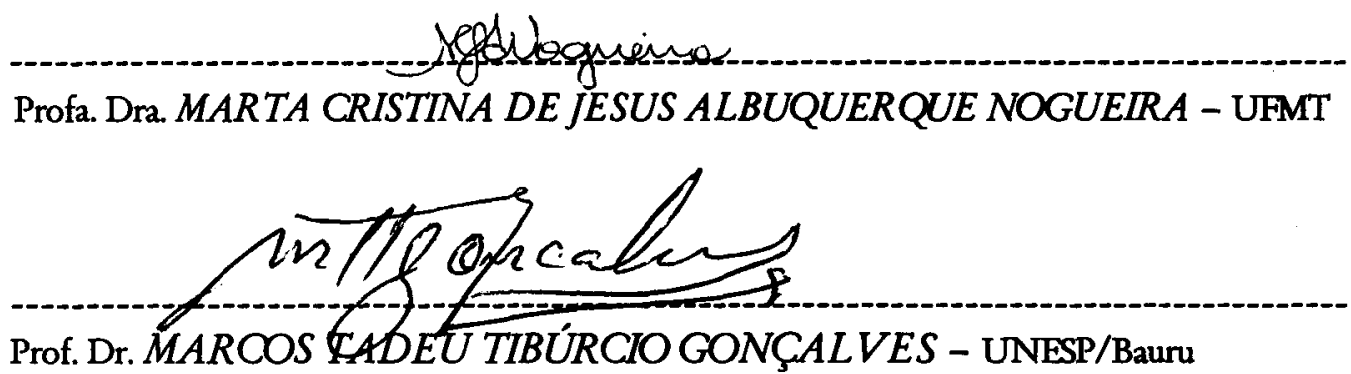




\section{DEDICATÓRIA}

Ao Racional Superior e em respeito à Natureza que rege seres e sistemas

Em especial, pelo amor e carinho, a meu marido Geraldo e à fi tha Nayara 
HOMENAGEM

A meus Pais e irmãos,

pela formação moral e acadêmica 


\section{AGRADECIMENTOS}

Ao Professor Francisco Antonio Rocco Lahr, pela oportunidade de sua orientação, constante manifestação de amizade e de estímulo profissional.

À Coordenadoria de Aperfeiçoamento de Pessoal de Nível Superior - CAPES, pela bolsa de estudo concedida.

A todos os colegas, professores e funcionários do Laboratório de Madeíras e de Estrutura de Madeira, Universidade de São Paulo, pela colaboração e boa vontade na prestação de serviços.

A todos os colegas, professores e funcionários da Área de Interunidades em Ciência e Engenharia de Materiais, Universidade de São Paulo, pela colaboração e boa vontade na prestação de serviços.

A minha irmã sílvia, em especial, pela força do bem querer.

À cunhada Cristina e familiares, também meus, pela leal presença e amizade.

Aos amigos Lédia, Celina, Elza, Nilton, pela vibração racional. 


\section{SUMÁRIO}

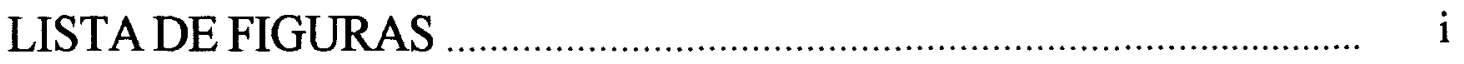

LISTA DE TABELAS _................................................................. ii

LISTA DE ABREVIATURAS OU SIGLAS ….................................... vi

LISTA DE SÍMBOLOS ..................................................................... viii

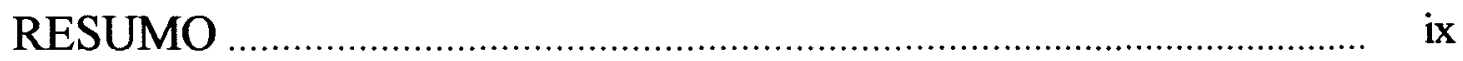

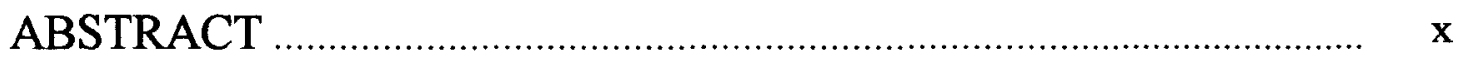

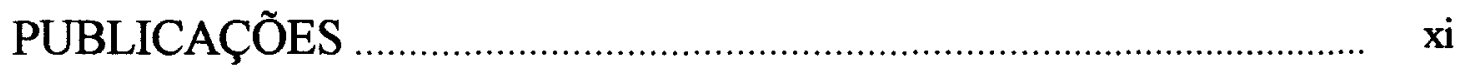

1 - INTRODUÇÃO ............................................................................. 1

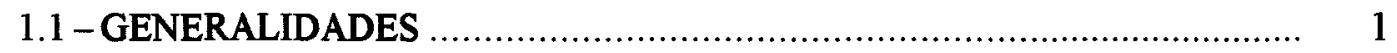

1.2 -OBJETIVOS ......................................................................... 2

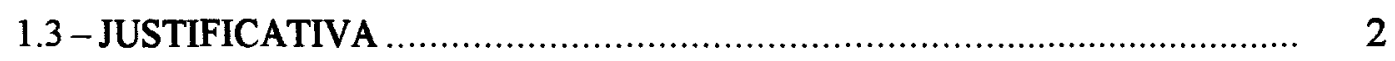

2 - REVISÃO BIBLIOGRÁFICA ………......................................... 5

2.1 - GENERALIDADES ................................................................... 5

2.2 - ASPECTOS HISTÓRICOS DO ESTUDO DA MADEIRA ........................... 6

2.3 - COMENTÁRIOS SOBRE A REVISÃO BIBLIOGRÁFICA ..................... 11

2.3.1 - Considerações bibliográficas sobre as propriedades da madeira 11

2.3.2 - Secagem da madeira ............................................................. 14

2.3.3 - Considerações finais .............................................................. 18

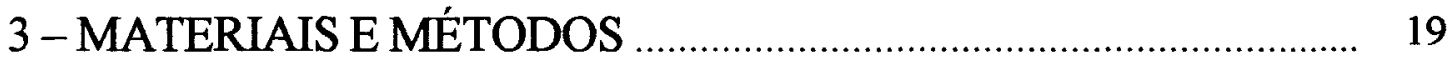

3.1 - CONSIDERAÇÕES INICIAIS....................................................... 19

3.2 -ESPÉCIES ESTUDADAS ............................................................. 19

3.3 - MÉTODOS DE ENSAIOS ............................................................. 56

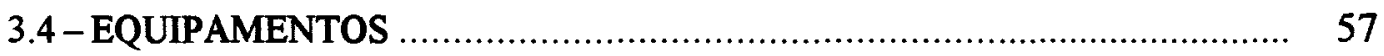

3.5 - CRITÉRIOS ADOTADOS PARA A CLASSIFICAÇÃO E INDICAÇÕES DAS ESPÉCIES DEMADEIRA ……………………...................... 59

3.5.1 - Considerações iniciais ............................................................. 59 
3.5.2 - Critérios de Sallenave

3.5.3 - Critérios de Nahuz ........................................................ 63

3.5.4 - Critérios de Nogueira .......................................................... 66

3.5.5 - Classificação geral das aplicações na construção civil em função dos requisitos técnicos .......................................... 68

4 - APRESENTAÇÃO DOS RESULTADOS ….................................. 72

4.1 - ANÁLISE DOS RESULTADOS ................................................ 76

4.1.1 - Características de secagem ............................................. $\quad 80$

4.1.2 - Características de trabalhabilidade .................................... 80

4.2 - CLASSIFICAÇÃO FINAL DAS TRINTA E QUATRO ESPÉCIES DE

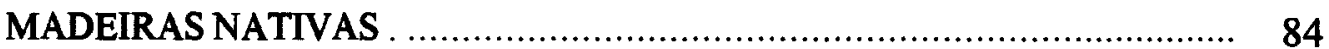

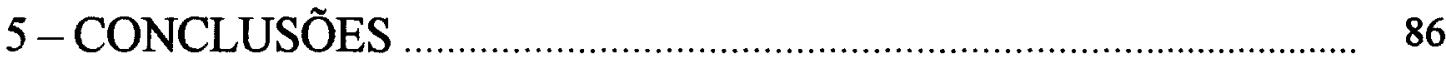

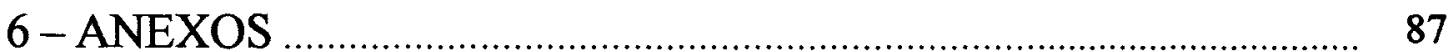

7 - REFERÊNCIAS BIBLIOGRÁFICAS .................................. 125

7.1 - BIBLIOGRAFIA CONSULTADA _............................................... 125

7.2 - BIBLIOGRAFIA COMPLEMENTAR .......................................... 129 


\section{LISTA DE FIGURAS}

Figura 2.1 - Diagrama de Kollmann - (variação da densidade aparente $\times$ teor de umidade). Fonte: KOLLMANN \& COTÉ (1968)

Figura 2.2 - Diagramas de inchamento para a Itaúba (Mezilaurus itauba). Fonte:LOGSDON (1998)

Figura 2.3 - Efeito da severidade do processo de secagem sobre a resistência à flexão $\left(1 \mathrm{kgf} / \mathrm{cm}^{2} \cong 0,10 \mathrm{MPa}\right)$. Fonte: KOLLMANN \& COTÉ (1968)

Figura 2.4 - Teor de umidade de equilíbrio da madeira em diversos ambientes de utilização. Fonte: LOGSDON (1998)

Figura 3.1 - a) Máquina universal de ensaio - AMSLER, b) Detalhe de ensaio e relógio comparador.

Figura 3.2 - a) Máquina Tipo FPL, de tenacidade, b) Detalhe da máquina,

c) Detalhe de ensaio para determinação da tenacidade. 


\section{LISTA DE TABELAS}

Tabela 2.1 - Alguns aspectos da evolução das pesquisas a respeito da madeira

Tabela 3.1 - Nomenclatura das espécies …………….................................... 20

Tabela 3.2 - Características gerais ........................................................... 21

Tabela 3.3 - Condições de tratamento químico da madeira ………………....... 22

Tabela 3.4 - Descrição da espécie Angelim-Amargoso ……………………..... 22

Tabela 3.5 - Descrição da espécie Angelim-Araroba ......................................... 23

Tabela 3.6 - Descrição da espécie Angelim-Ferro ………………………........ 24

Tabela 3.7 - Descrição da espécie Angelim-Pedra. ………………………...... 25

Tabela 3.8 - Descrição da espécie Angelim-Pedra-Verdadeiro ……………..... 26

Tabela 3.9 - Descrição da espécie Angelim-Saia ................................................ 27

Tabela 3.10 - Descrição da espécie Angico Preto ……………………….......... 28

Tabela 3.11 - Descrição da espécie Branquilio ………….................................. 29

Tabela 3.12 - Descrição da espécie Cafearana ………...................................... 30

Tabela 3.13 - Descrição da espécie Canafistula ................................................. 31

Tabela 3.14 - Descrição da espécie Casca Grossa …………………................ 32

Tabela 3.15 - Descrição da espécie Castelo ……………................................. 33

Tabela 3.16 - Descrição da espécie Catanudo …………….............................. 34

Tabela 3.17 - Descrição da espécie Cedro Amargo …………......................... 35

Tabela 3.18 - Descrição da espécie Cedrorana ……………………………….. 36

Tabela 3.19 - Descrição da espécie Champanhe ………………………………. 37

Tabela 3.20 - Descrição da espécie Cupiúba ……………………………....... 38

Tabela 3.21 - Descrição da espécie Cutiúba ………………………………….... 39

Tabela 3.22 - Descrição da espécie Garapa ...................................................... 40

Tabela 3.23 - Descrição da espécie Goiabão .................................................... 41

Tabela 3.24 - Descrição da espécie Guaiçara …………....................................... 42

Tabela 3.25 - Descrição da espécie Guarucaia .................................................... 43

Tabela 3.26 - Descrição da espécie Itaúba …………………………………….. 44 
Tabela 3.27 - Descrição da espécie Louro Preto …………………………........ 45

Tabela 3.28 - Descrição da espécie Mandioqueira ………………………........ 46

Tabela 3.29 - Descrição da espécie Oiticica Amarela ......................................... 47

Tabela 3.30 - Descrição da espécie Oiuchu ..................................................... 48

Tabela 3.31 - Descrição da espécie Parinari ..................................................... 49

Tabela 3.32 - Descrição da espécie Piolho ………………………………......... 50

Tabela 3.33 - Descrição da espécie Quarubarana ............................................. 51

Tabela 3.34 - Descrição da espécie Rabo de Arraia …………………………... 52

Tabela 3.35 - Descrição da espécie Tachi ......................................................... 53

Tabela 3.36 - Descrição da espécie Tatajuba .................................................. 54

Tabela 3.37 - Descrição da espécie Umirana ................................................... 55

Tabela 3.38 - Classes de umidade ................................................................. 58

Tabela 3.39 - Densidade aparente - Sallenave ……………………………...... 60

Tabela 3.40 - Retratibilidade - Sallenave ....................................................... 60

Tabela 3.41 - Dureza JANKA normal às fibras - Sallenave .............................. 61

Tabela 3.42 - Cota de dureza - Sallenave .................................................... 61

Tabela 3.43 - Resistência ao fendilhamento - Sallenave .................................. 61

Tabela 3.44 - Resistência à tração normal às fibras - Sallenave …………......... 62

Tabela 3.45 - Resistência ao cisalhamento - Sallenave …………………….... 62

Tabela 3.46 - Resistência à compressão paralela às fibras - Sallenave ............. 62

Tabela 3.47 - Resistência convencional na flexão estática - Sallenave ............. 62

Tabela 3.48 - Densidade aparente - Nahuz …………………........................ 64

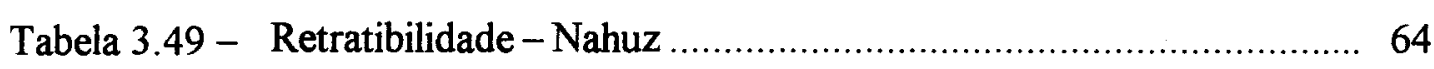

Tabela 3.50 - Dureza JANKA paralela às fibras - Nahuz …………………..... 64

Tabela 3.51 - Resistência à compressão paralela às fibras - Nahuz ………….... 65

Tabela 3.52 - Resistência ao cisalhamento - Nahuz …………………………... 65

Tabela 3.53 - Resistência convencional na flexão estática - Nahuz ………….... 65

Tabela 3.54 - MOE - flexão estática - Nahuz ………………………………...... 65

Tabela 3.55 - Tenacidade - Nahuz ……………………............................ 66

Tabela 3.56 - Trabalhabilidade - Nahuz …………………………………..... 66

Tabela 3.57 - Resistência à tração paralela às fibras - Nogueira ……………..... 67

Tabela 3.58 - MOE na tração paralela às fibras - Nogueira …………………... 67

Tabela 3.59 - MOE na compressão paralela às fibras - Nogueira …………....... 67 
Tabela 3.60 - Construção civil pesada externa ......................................... 69

Tabela 3.61 - Construção civil pesada interna ............................................. 69

Tabela 3.62 - Construção civil leve externa ................................................ 69

Tabela 3.63 - Construção civil leve interna - Decorativa .............................. 70

Tabela 3.64 - Construção civil leve interna - Utilidade Geral ....................... 70

Tabela 3.65 - Construção civil leve interna - Estrutural ............................. 70

Tabela 3.66 - Assoalhos Domésticos .................................................... 71

Tabela 3.67 - Assoalhos Industriais .................................................... 71

Tabela 4.1 - Propriedades Físicas de Resistência e Rigidez consideradas ....... 72

Tabela 4.2 - Propriedades Físicas de Resistência e Rigidez das espécies

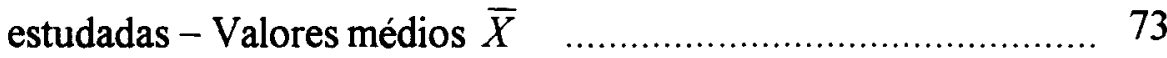

Tabela 4.3 - Intervalos correspondentes ao somatório dos valores numéricos dos símbolos - classificação ............................................. 76

Tabela 4.4 - Classificação - Propriedades de Resistência ............................ 77

Tabela 4.5 - Classificação - Propriedades de Rigidez ................................ 78

Tabela 4.6 - Classificação - Propriedade Física - Densidade aparente Sallenave e Nahuz .................................................................... 79

Tabela 4.7 - Classificação - \% de Defeitos no Aplainamento - Nahuz .......... 81

Tabela 4.8 - Classificação - Cota de Dureza - Sallenave ............................ 82

Tabela 4.9 - Classificação final e indicações das trinta e quatro espécies

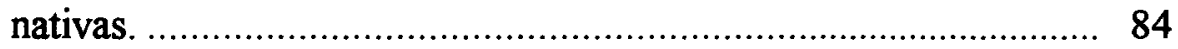

Tabela 6.1 - Ensaios - Angelim Amargoso ................................................ 88

Tabela 6.2 - Ensaios - Angelim Araroba ................................................. 89

Tabela 6.3 - Ensaios - Angelim Ferro ...................................................... 90

Tabela 6.4 - Ensaios - Angelim Pedra ....................................................... 91

Tabela 6.5 - Ensaios - Angelim Pedra Verdadeiro .................................... 93

Tabela 6.6 - Ensaios - Angelim Saia ...................................................... 94

Tabela 6.7 - Ensaios - Angico Preto …..................................................... 95

Tabela 6.8 - Ensaios - Branquilio ........................................................... 96

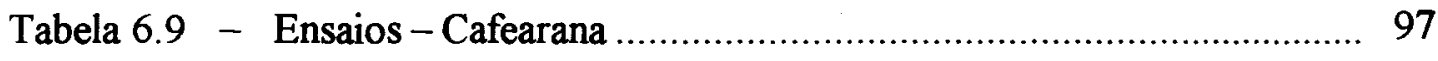

Tabela 6.10 - Ensaios - Canafistula ..................................................... 98

Tabela 6.11 - Ensaios - Casca Grossa ......................................................... 99

Tabela 6.12 - Ensaios - Castelo ........................................................ 101 
Tabela 6.13 - Ensaios - Catanudo ............................................................ 102

Tabela 6.14 - Ensaios - Cedro Amargo ….................................................... 103

Tabela 6.15 - Ensaios - Cedrorana _........................................................... 104

Tabela 6.16 - Ensaios - Champanhe ………………………….................... 105

Tabela 6.17 - Ensaios - Cupiúba ................................................................. 106

Tabela 6.18 - Ensaios - Cutiúba _............................................................... 108

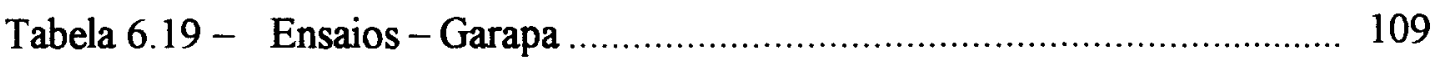

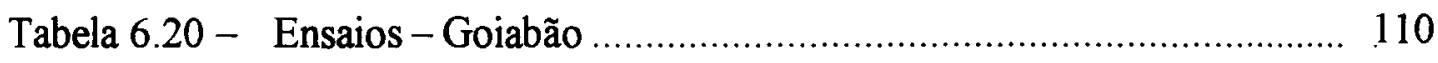

Tabela 6.21 - Ensaios - Guaiçara ............................................................... 111

Tabela 6.22 - Ensaios - Guarucaia ……………………………………..... 112

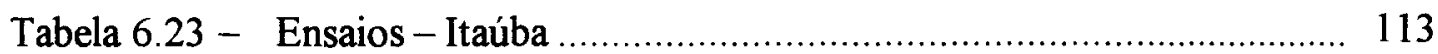

Tabela 6.24 - Ensaios - Louro Preto …...................................................... 114

Tabela 6.25 - Ensaios - Mandioqueira …………………….......................... 115

Tabela 6.26 - Ensaios - Oiticica Amarela …………………........................ 116

Tabela 6.27 - Ensaios - Oiuchu .............................................................. 117

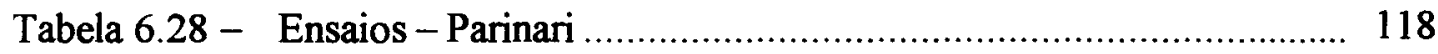

Tabela 6.29 - Ensaios - Piolho ………….................................................... 119

Tabela 6.30 - Ensaios - Quarubarana _...................................................... 120

Tabela 6.31 - Ensaios - Rabo de Arraia ……………….............................. 121

Tabela 6.32 - Ensaios - Tachi ............................................................... 122

Tabela 6.33 - Ensaios - Tatajuba …………………………...................... 123

Tabela 6.34 - Ensaios - Umirana _........................................................... 124 


\section{LISTA DE ABREVIATURAS OU SIGLAS}

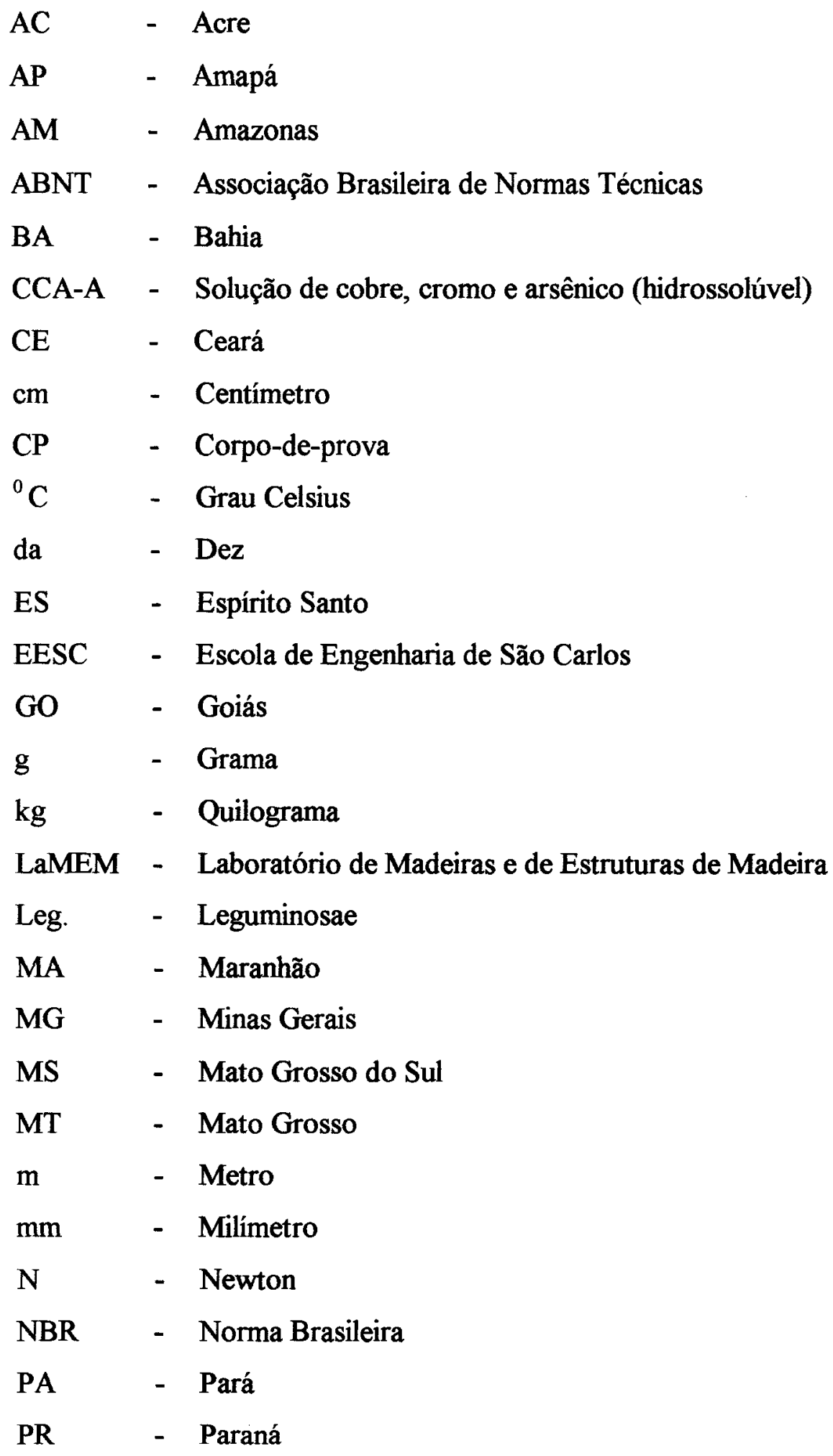




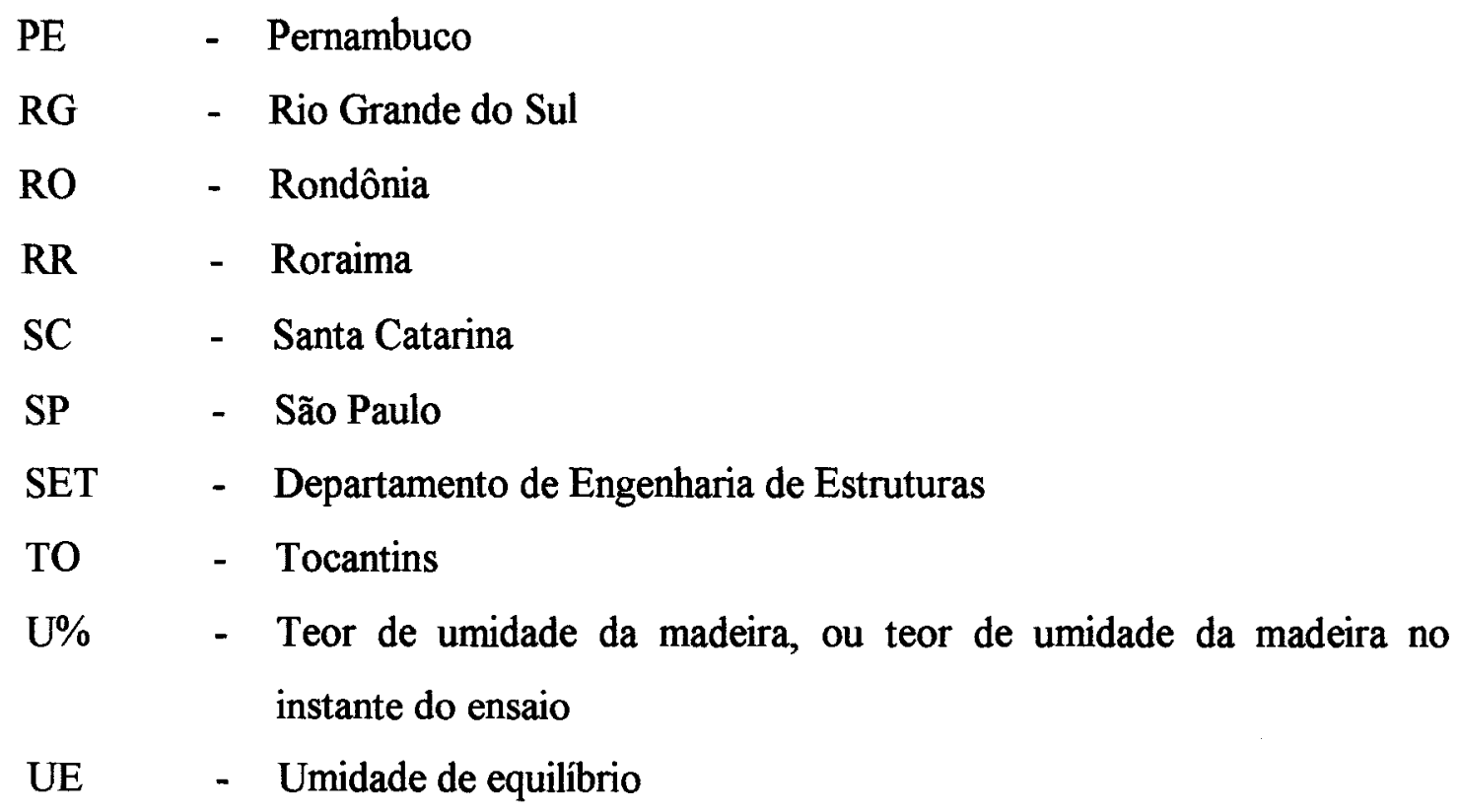




\section{LISTA DE SÍMBOLOS}

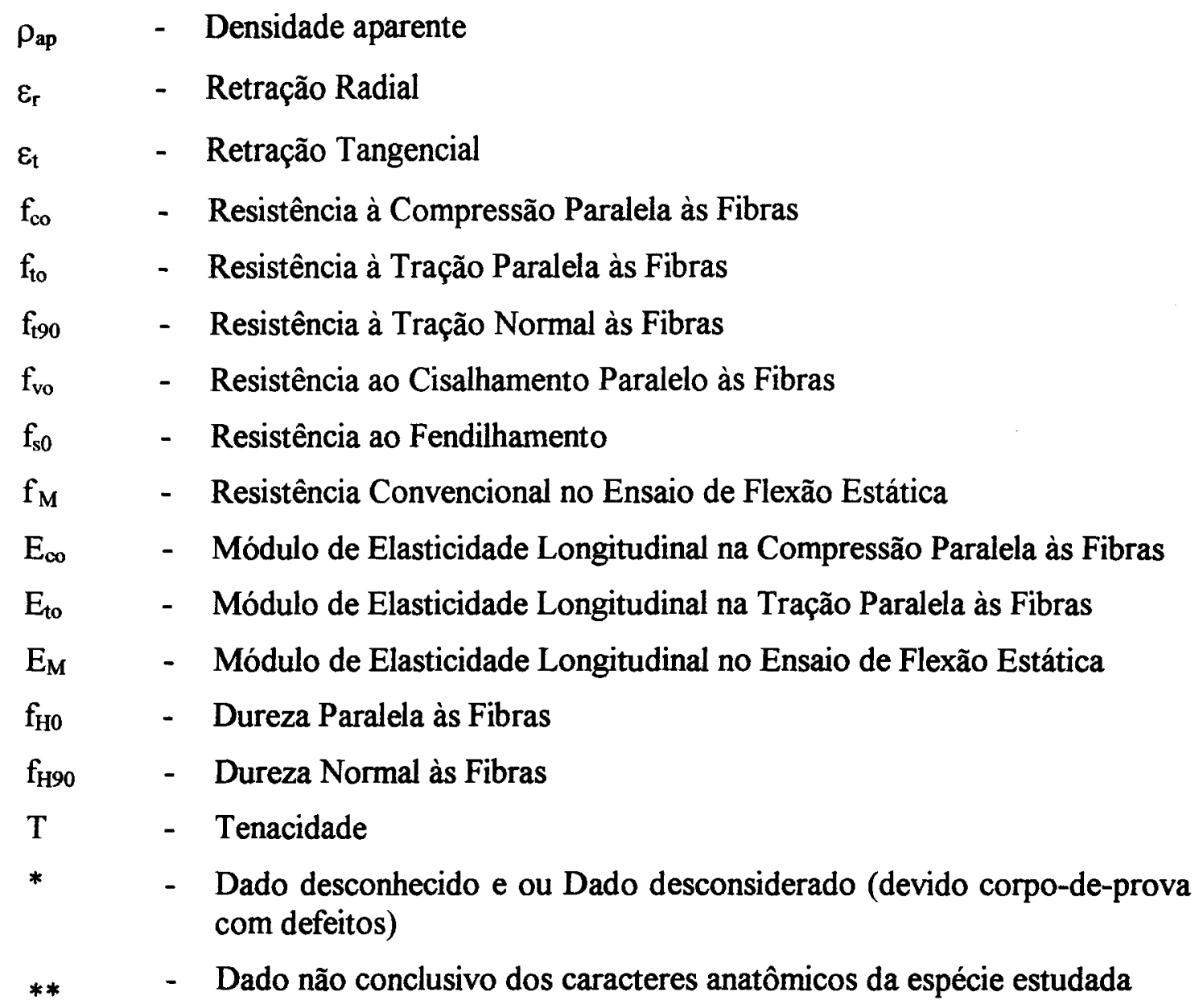




\section{RESUMO}

Realizou-se, no contexto deste trabalho, o estudo de espécies tropicais de madeira e a qualificação destas a partir de suas características físicas, de resistência e rigidez. Os ensaios para a determinação das propriedades foram realizados no Laboratório de Madeiras e de Estruturas de Madeira, do Departamento de Engenharia de Estruturas, Escola de Engenharia de São Carlos, seguindo as recomendações do anexo B da NBR 7190/1997 - Projeto de Estruturas de Madeira. O objetivo fundamental é gerar informações que possam fornecer suporte para um direcionamento e perspectiva de novas possibilidades de aplicação na construção civil: construção de estruturas para diferentes finalidades (coberturas, pontes, cimbramentos); industriais para componentes de edificações (pisos, caixilhos); armazenamento; obras portuárias; entre outras.

Palavras-chave: madeiras tropicais, propriedades fisicas e mecânicas, critérios para classificação. 


\begin{abstract}
It was realized, in the context of this work, a study about tropical wood species and their qualification, based on the physical and mechanical properties. The tests to the determination of such properties were realized in Wood and Timber Structures Laboratory, Structural Engineering Departament, São Carlos Engineering School, according to the recommendations of the Annex B, NBR 7190/1997 - Timber Structures Design. The mean subject is to generate information to permit new application in civil construction: structures for different purposes (roofs, bridges, formwork); industrial to building components; storage; among others.
\end{abstract}

Keywords: tropical timber, mechanical and physical properties, criteria to classification. 


\section{PUBLICAÇÕES} publicação:

A relação seguinte, apresenta os artigos publicados e encaminhados à

- GROBÉRIO, M.P.; LAHR, F.A.R. (1999). Indicações para o emprego da madeira de espécies tropicais brasileiras. SICEM 99, realizado em São Carlos, SP, no período de 11 e 12 de novembro de 1999. in: Simpósio Interunidades de Ciência e Engenharia de Materiais,2. São Carlos, 1999. Anais, São Paulo, USPIQSC. SICEM 99, pg 29.

- LAHR, F.A.R.; GROBÉRIO, M.P. (2000). Indicações para o emprego estrutural da madeira de espécies nativas do noroeste do Brasil [CD-ROM]. In: JORNADAS SUDAMERICANAS DE INGENIERÍA ESTRUCTURAL, 29. / JUBLEO PROF. JULIO RICALDONI, Punta Del Este, Uruguay, 13-17 noviembre, 2000. Memorias. Montevideo, Instituto de Estructuras y Transporte / ASAIE. 10p.

- GROBÉRIO, M.P.; LAHR, F.A.R. (2000). Indicações para o emprego da madeira de espécies tropicais do noroeste do Brasil [CD-ROM]. In: ENCONTRO BRASILEIRO EM MADEIRAS E EM ESTRUTURAS DE MADEIRA, 7. São Carlos, 12-14 de julho de 2000. São Carlos, EESC-USP. 9p.

- LAHR, F.A.R.; GROBÉRIO, M.P. (2000). indications for the structural employment of the wood of native species of the northwest of brazil [CD-ROM]. In REUNION DE DESAROLLO DE PRODUCTOS FORESTALES, 9. Concepción, Chile, 16 a 20 de outubro de 2000. Concepcion, Universid Del Biobio. 7p.

- LAHR, F.A.R.; GROBÉRIO, M.P.; DIAS, F. M. (2000) - Physical and mechanical properties of two tropical wood species [CD-ROM]. In REUNION DE DESAROLLO DE PRODUCTOS FORESTALES, 9., Concepción, Chile, 16 a 20 de outubro de 2000. Concepcion, Universid Del Biobio. 6p.

- LAHR, F.A.R.; GROBÉRIO, M.P. (2000) - Desempenho térmico de painéis de vedação produzidos a partir de produtos derivados da madeira - "REVISTA BRASILEIRA DE ENGENHARIA AGRÍCOLA E AMBIENTAL" DE CAMPINA GRANDE, SP (PB), Artigo aceito e em fase de correção para posterior publicação. 


\section{1 - INTRODUÇÃo}

\section{1 - GENERALIDADES}

A madeira, produto de um sistema biológico, é um compósito com estrutura celular que conduz a elevada resistência mecânica relativamente ao peso específico, superando muitos materiais de uso consagrado na construção civil. De múltiplas aplicações estruturais, por consumir pouca energia no processo envolvido, apresenta outras particularidades muito interessantes no que concerne à sua trabalhabilidade e versatilidade. Além da vantagem de ser matéria prima renovável, se reintegra ao meio ambiente num processo simbiótico natural com o apodrecimento, sem causar danos ambientais. $\mathrm{O}$ mesmo não acontece com outros materiais alternativos à madeira como o plástico, o concreto, o aço etc.

A indústria madeireira brasileira no setor da construção civil ainda é carente de informações seguras referentes à qualidade e ao desempenho, particularmente de espécies tropicais nativas, que possam orientar sua melhor utilização, como material de construção. A falta de tais informações tecnológicas acaba conduzindo ao emprego de processos construtivos de pequena eficiencia, comprometendo, muitas vezes, o produto final desejado, seja na indústria, seja na obra.

No tópico relacionado à caracterização tecnológica de espécies, alguns estudos vêm sendo realizados com $\mathrm{o}$ intuito de melhorar o potencial de comercialização das essências tropicais alternativas, um passo fundamental não apenas para a exploração sustentada dos recursos florestais nativos, como também para o uso racional dos produtos fornecidos, a partir da aplicação de conceitos silviculturais compatíveis com o desenvolvimento científico, já experimentado pelo setor. $O$ adequado aproveitamento da madeira assim obtida passa, necessariamente, 
pelo conhecimento de suas propriedades físico-mecânicas.

Os critérios de classificação atualmente disponíveis na literatura são pouco numerosos, vale ressaltar, em geral baseadas em características como massa específica aparente, umidade, características de resistência, cor do cerne, durabilidade natural, e usos finais.

Classes de densidade são conceitos muito importantes para agrupar espécies, à vista da sua alta correlação com as propriedades mecânicas.

A partir da constatação da lacuna de informações que permitam o emprego racional da madeira no Brasil, em particular das milhares de espécies presentes nas florestas tropicais, há algum tempo vem sendo desenvolvido no Laboratório de Madeiras e de Estruturas de Madeira (LaMEM), do Departamento de Engenharia de Estruturas (SET), da Escola de Engenharia de São Carlos (EESC), Universidade de São Paulo (USP), um projeto de pesquisa objetivando a caracterização de espécies tropicais brasileiras. Estão sendo utilizadas para tal fim as recomendações metodológicas propostas no anexo B da Norma NBR 7190/1997: Projeto de Estruturas de Madeira, da Associação Brasileira de Normas Técnicas (ABNT).

Para alcançar os objetivos mencionados, alguns critérios reconhecidos nacional e internacionalmente estão sendo utilizados, especialmente os desenvolvidos por Sallenave (1955) e Nahuz (1974).

Os critérios de Sallenave estabelecem a classificação de espécies voltadas para a aplicação na construção civil, feita considerando as suas propriedades fisicas e mecânicas, bem como parâmetros relativos a defeitos no processo de secagem, orientação das fibras, especificidades decorrentes da anisotropia e outras características orgânicas.

Os critérios propostos por Nahuz, baseados num estudo efetuado para as essências da região amazônica, estabelecem que a classificação das espécies pode ser feita a partir dos valores das propriedades fisicas e mecânicas, da durabilidade natural e da tratabilidade contra a demanda biológica.

Algumas considerações adotadas por Nogueira (1991), colaboram para complementar a classificação das espécies, considerando requisitos de resistência e rigidez. 


\section{2 - OBJETIVO}

O objetivo deste trabalho é a indicação para o emprego de trinta e quatro espécies tropicais nativas na construção civil e áreas afins, partindo-se dos correspondentes valores de suas propriedades fisicas, de resistência e de rigidez.

\section{3 - JUSTIFICATIVA}

Os constantes avanços da tecnologia de produtos florestais, que tem a origem de seu desenvolvimento em centros de pesquisa, vêm influindo decisivamente na qualidade que pode ser agregada a essa matéria prima e em seu processamento industrial. A finalidade é sempre melhorar o desempenho do produto final e ampliar sua vida útil depois de aplicado.

Apesar de o Brasil deter grandes reservas de floresta tropical, sua exploração necessita estar fundamentada em conceitos silviculturais adequados, de modo a se impedir os lamentáveis procedimentos seletivos e predatórios, tão em evidência nas últimas décadas. De acordo com os dados publicados pelo Instituto Nacional de Pesquisas Espaciais - INPE (1998), da área original de dois milhões e oitocentos mil quilômetros quadrados da Floresta Amazônica, perto de quinze por cento já haviam sido devastados de modo irreversível até 1997.

É evidente que a possibilidade de aproveitamento comercial não é alcançada pelas mais de quatro mil espécies arbóreas existentes na Amazônia. Entretanto é viável ampliar o leque restrito a pouco mais de vinte espécies que integram a lista das preferidas pelo mercado consumidor nacional e internacional, segundo informações do IBAMA. Para isto, deve-se aplicar os procedimentos de exploração ecologicamente orientados, na busca da valorização econômica das espécies, com suficiente potencial de disponibilidade, e com algumas informações tecnológicas já geradas pelos centros de pesquisa que se dedicam ao assunto, melhorando os conhecimentos que possam levar à uma utilização mais racional, proporcionando condições para a necessária regeneração em ciclos de tempo compatíveis com a capacidade vital da floresta. 
Estudos voltados à indicação das aplicações mais convenientes para as espécies ainda não consagradas aos usuários, como o aqui apresentado, se constituem em importantes referências para assegurar melhor aproveitamento da produção das florestas nativas, com muitas outras conseqüências positivas, como a conservação ambiental e a adoção de conceitos de planejamento silvicultural, a longo prazo.

À vista do exposto, entende-se como plenamente justificada a realização deste trabalho, direcionado aos engenheiros, arquitetos e outros profissionais ligados ao emprego da madeira, em particular na solução dos mais variados problemas ligados à construção civil. 


\section{2 - REVISÃO BIBLIOGRÁFICA}

\section{1 - GENERALIDADES}

Produto de um sistema biológico, a madeira possui características específicas que a diferenciam diante de outros materiais de construção, privilegiando-a em muitos aspectos.

Proveniente das árvores, que são seres vivos, a madeira tem estrutura anatômica com elevado grau de complexidade, heterogeneidade que conduz à anisotropia, fatores que provocam significativa variabilidade dos valores representativos de suas propriedades fisicas, de resistência e de elasticidade.

As árvores que produzem madeira de interesse comercial são provenientes das coníferas ou das dicotiledôneas. As coníferas apresentam estrutura constituída de um menor número de elementos anatômicos, enquanto as dicotiledôneas, consideradas os vegetais mais desenvolvidos do planeta, têm ampla diferenciação entre seus constituintes.

Neste trabalho, a revisão bibliográfica abrangerá os tópicos necessários ao adequado embasamento para alcançar os objetivos mencionados no item 1. Registrase que aspectos relacionados à configuração anatômica da madeira e a outros pormenores de sua estrutura interna não serão abordados neste trabalho, podendo ser encontrados com detalhes nas publicações de Mainieri (1956), Harlow e Harrar (1958), Rawitscher (1964), Foeckel (1977), Morey (1980), Gemmel (1980), Hellmeister (1983), Rocco Lahr (1990), entre outros. 


\section{2 - ASPECTOS HISTÓRICOS DO ESTUDO DA MADEIRA}

A madeira sempre esteve presente no centro dos interesses de muitos pesquisadores. Na seqüência deste item estão registradas algumas das contribuições bibliográficas referentes ao objetivo específico do presente trabalho. Observa-se também que as obras apresentadas na tabela 2.1 não se restringem apenas à caracterização fisico-mecânica da madeira.

Tabela 2.1 - Alguns aspectos da evolução das pesquisas a respeito da madeira

\begin{tabular}{c|l}
\hline \hline Pesquisador(es) / Ano & \multicolumn{1}{|c}{ Observações sobre os trabalhos realizados } \\
\hline \hline (1564-1642) & $\begin{array}{l}\text { Referência aos primeiros estudos publicados, de autoria } \\
\text { de Galileu Galilei, iniciando o desenvolvimento da } \\
\text { ciência dos materiais.. Foram experimentadas vigas de } \\
\text { madeira e de outros materiais, e os resultados são hoje } \\
\text { reconhecidos como fundamentais para a compreensão do } \\
\text { comportamento dos materiais de aplicação estrutural. }\end{array}$ \\
\hline (1635-1703) & $\begin{array}{l}\text { Robert Hooke apresenta os resultados dos estudos } \\
\text { realizados na tentativa de estabelecer uma relação entre a } \\
\text { força aplicada e deformação decorrente em amostras de } \\
\text { materiais estruturais. }\end{array}$ \\
\hline (1905) & $\begin{array}{l}\text { Publicação da obra "Manual de Resistência dos } \\
\text { Materiaes", pela "Escola Polytécnica de São Paulo". } \\
\text { Neste trabalho estão apresentados os primeiros } \\
\text { resultados a respeito das propriedades fisicas e } \\
\text { mecânicas de espécies de madeiras brasileiras. }\end{array}$ \\
\hline (1955) & $\begin{array}{l}\text { Proposição de critérios estabelecendo que a classificação } \\
\text { das madeiras pode ser feita através da análise das suas } \\
\text { propriedades fisicas e mecânicas, cujos valores tenham } \\
\text { sido obtidos a partir de ensaios padronizados de } \\
\text { laboratório. Neste caso, o autor partiu dos métodos de } \\
\text { ensaio propostos pela Associação Francesa de Normas - } \\
\text { AFNOR, e considera importantes os fatores relativos ao } \\
\text { teor de umidade, à anisotropia, aos defeitos da madeira } \\
\text { decorrentes do processo de secagem, entre outros. A } \\
\text { classificação ou ordenação das madeiras segundo seu } \\
\text { comportamento mecânico deve ainda considerar a sua } \\
\text { natureza particular e outras caracteristicas devidas à sua } \\
\text { constituição orgânica. }\end{array}$ \\
\hline \hline
\end{tabular}


Tabela 2.1 - (continuação) - Alguns aspectos da evolução das pesquisas a respeito da madeira

\begin{tabular}{|c|c|}
\hline Pesquisador(es) / Ano & Observações sobre os trabalhos realizados \\
\hline $\begin{array}{c}\text { IPT } \\
(1956)\end{array}$ & $\begin{array}{l}\text { Publicação do Boletim } 31 \text {, do Instituto de Pesquisas } \\
\text { Tecnológicas do Estado de São Paulo (IPT). Trata-se de } \\
\text { uma obra histórica, que apresenta as propriedades fisicas } \\
\text { e mecânicas de mais de duzentas espécies brasileiras, } \\
\text { além dos métodos para a respectiva determinação. }\end{array}$ \\
\hline $\begin{array}{c}\text { KOLLMANN, CÔTÉ } \\
\text { (1968) }\end{array}$ & $\begin{array}{l}\text { Estes autores publicaram a obra Principles of Wood } \\
\text { Science and Technology, resultado de um vasto trabalho } \\
\text { voltado à explicação do comportamento da madeira e } \\
\text { derivados, apresentam a madeira desde sua constituição } \\
\text { molecular, anatômica, propriedades e aspectos gerais da } \\
\text { tecnologia de sua utilização para diferentes finalidades. } \\
\text { Trata-se de um dos mais significativos trabalhos sobre o } \\
\text { assunto publicado no mundo ocidental. }\end{array}$ \\
\hline $\begin{array}{c}\text { HELLMEISTER } \\
\text { (1973) }\end{array}$ & $\begin{array}{l}\text { Pesquisador brasileiro, foi um dos pioneiros na pesquisa } \\
\text { sistemática da madeira voltada para aplicação na } \\
\text { construção civil, em especial em estruturas, neste } \\
\text { trabalho o autor apresenta ampla abordagem histórica, } \\
\text { buscando registrar a cronologia da evolução da pesquisa } \\
\text { sobre as propriedades fisicas e mecânicas da madeira. }\end{array}$ \\
\hline $\begin{array}{c}\text { NAHUZ } \\
(1974)\end{array}$ & $\begin{array}{l}\text { A partir de estudos efetuados em madeiras tropicais, } \\
\text { provenientes da Floresta Amazônica, propôs critérios } \\
\text { para a classificação de espécies, com base em } \\
\text { parâmetros de resistência, potencial de durabilidade } \\
\text { natural e também de trabalhabilidade contra a demanda } \\
\text { biológica. }\end{array}$ \\
\hline $\begin{array}{c}\text { FINDLAY } \\
\text { (1975) }\end{array}$ & $\begin{array}{l}\text { Como resultado de suas pesquisas, o autor fornece } \\
\text { informações interessantes a respeito da variação das } \\
\text { propriedades de resistência e rigidez, para madeira em } \\
\text { diversos níveis de umidade. }\end{array}$ \\
\hline $\begin{array}{c}\text { FREITAS } \\
\text { (1978) }\end{array}$ & $\begin{array}{l}\text { Foi o primeiro a dedicar-se aos procedimentos para } \\
\text { agrupar espécies tropicais de madeira provenientes da } \\
\text { Floresta Amazônica, a partir de valores numéricos de } \\
\text { suas propriedades de resistência e de rigidez, } \\
\text { considerando sua variabilidade já visando o projeto } \\
\text { estrutural. }\end{array}$ \\
\hline
\end{tabular}


Tabela 2.1 - (continuação) - Alguns aspectos da evolução das pesquisas a respeito da madeira

\begin{tabular}{|c|c|}
\hline Pesquisador(es) / Ano & Observações sobre os trabalhos realizados \\
\hline $\begin{array}{l}\text { FURIATI } \\
(1981)\end{array}$ & $\begin{array}{l}\text { Propôs uma sistemática para a classificação de peças } \\
\text { estruturais de madeira, com ensaios não destrutivos de } \\
\text { flexão estática, a partir dos quais eram estimados os } \\
\text { valores do módulo de elasticidade longitudinal. }\end{array}$ \\
\hline $\begin{array}{c}\text { PIGOZZO } \\
(1982)\end{array}$ & $\begin{array}{l}\text { Apresentou estudos pioneiros avaliando conjuntamente a } \\
\text { influência da umidade e da densidade na resistência à } \\
\text { compressão paralela às fibras de espécies brasileiras. }\end{array}$ \\
\hline $\begin{array}{r}\text { MELO } \\
(1984)\end{array}$ & $\begin{array}{l}\text { Fez um estudo comparando os valores do módulo de } \\
\text { elasticidade longitudinal obtidos de dois modos } \\
\text { distintos, um a partir de ensaios convencionais de flexão } \\
\text { estática e outro empregando equipamento mecânico de } \\
\text { classificação de peças estruturais. Trabalhou com } \\
\text { espécies tropicais provenientes da Floresta Amazônica. }\end{array}$ \\
\hline $\begin{array}{c}\text { SIQUEIRA } \\
(1986)\end{array}$ & $\begin{array}{l}\text { Projetou e instrumentou uma máquina de ensaios para a } \\
\text { determinação da propriedade mecânica tenacidade } \\
\text { madeira. Tal equipamento, primeiro de fabricação } \\
\text { nacional, está em utilização até esta data no } \\
\text { LaMEM/SET. }\end{array}$ \\
\hline $\begin{array}{c}\text { CHAHUD } \\
\text { (1989) }\end{array}$ & $\begin{array}{l}\text { Apresentou trabalho, no qual ficou demonstrada pela } \\
\text { primeira vez, a equivalência estatística entre valores do } \\
\text { módulo de elasticidade longitudinal, obtidos nos ensaios } \\
\text { de compressão paralela às fibras, de tração paralela às } \\
\text { fibras e de flexão estática. Trabalhou com espécies } \\
\text { tropicais da Floresta Amazônica. }\end{array}$ \\
\hline $\begin{array}{c}\text { PRATA } \\
(1989)\end{array}$ & $\begin{array}{l}\text { Baseado em dados experimentais apresentou parâmetros } \\
\text { para cálculo, projeto e execução de peças estruturais de } \\
\text { madeira submetidas à compressão paralela às fibras, } \\
\text { investigando as influências do tamanho do corpo de } \\
\text { prova na resistência obtidas nos ensaios. }\end{array}$ \\
\hline $\begin{array}{c}\text { CARVALHO et al } \\
\text { (1989) }\end{array}$ & $\begin{array}{l}\text { Iniciou uma série de trabalhos importantes, realizados } \\
\text { com o objetivo de caracterizar espécies alternativas para } \\
\text { substituir o Mogno (Swietenia macrophylla), essência } \\
\text { muito requisitada na indústria moveleira. }\end{array}$ \\
\hline
\end{tabular}


Tabela 2.1 - (continuação) - Alguns aspectos da evolução das pesquisas a respeito da madeira

\begin{tabular}{|c|c|}
\hline Pesquisador(es) / Ano & Observações sobre os trabalhos realizados \\
\hline $\begin{array}{l}\text { SOUZA } \\
(1989)\end{array}$ & $\begin{array}{l}\text { Apresentou interessante trabalho, fornecendo subsídios } \\
\text { técnicos para qualificar diversas espécies alternativas } \\
\text { que possam substituir, em suas múltiplas aplicações, a } \\
\text { madeira da Castanheira (Bertholletia excelsa Humb\& } \\
\text { Bonpl). }\end{array}$ \\
\hline $\begin{array}{c}\text { ROCCO LAHR } \\
(1990)\end{array}$ & $\begin{array}{l}\text { Apresentou estudos para quantificar a variabilidade das } \\
\text { propriedades de resistência e de elasticidade da madeira, } \\
\text { bem como para a definição de função densidade de } \\
\text { probabilidade mais conveniente para representar os } \\
\text { resultados obtidos. Trabalhou com espécies tropicais } \\
\text { nativas e espécies de reflorestamento. }\end{array}$ \\
\hline $\begin{array}{c}\text { MASCIA } \\
(1991)\end{array}$ & $\begin{array}{l}\text { Definiu, com base experimental de laboratório, as } \\
\text { constantes elásticas da madeira, considerada como } \\
\text { material anisotrópico com comportamento elástico que } \\
\text { evidencia sua ortotropia. Mascia foi o primeiro } \\
\text { pesquisador a estabelecer tais parâmetros para espécies } \\
\text { tropicais brasileiras. }\end{array}$ \\
\hline $\begin{array}{c}\text { NOGUEIRA } \\
(1991)\end{array}$ & $\begin{array}{l}\text { A partir dos resultados de ensaios para determinação de } \\
\text { propriedades fisicas, de resistência e de elasticidade, esta } \\
\text { autora classificou e indicou as aplicações mais } \\
\text { convenientes na construção civil, para a madeira de } \\
\text { dezesseis espécies de eucalipto, utilizando os critérios de } \\
\text { Sallenave e Nahuz. }\end{array}$ \\
\hline $\begin{array}{c}\text { TANAAMI } \\
(1993)\end{array}$ & $\begin{array}{l}\text { Apresenta os primeiros estudos sistematizados } \\
\text { objetivando estabelecer parâmetros sobre o } \\
\text { comportamento da madeira quando submetida à tração } \\
\text { normal às fibras. Trabalhou com espécies tropicais } \\
\text { brasileiras. }\end{array}$ \\
\hline $\begin{array}{c}\text { BORTOLETTO Jr. } \\
(1993)\end{array}$ & $\begin{array}{l}\text { Apresentou resultados das propriedades fisicas, de } \\
\text { resistência e de rigidez de seis espécies-de Pinus, tendo } \\
\text { como objetivo a recomendação dos usos mais adequados } \\
\text { da madeira destas espécies na construção civil, } \\
\text { utilizando os critérios de Sallenave, Nahuz e Nogueira. }\end{array}$ \\
\hline $\begin{array}{l}\text { DIAS } \\
(1994)\end{array}$ & $\begin{array}{l}\text { Apresentou um estudo teórico experimental a respeito da } \\
\text { solicitação da compressão normal às fibras, propondo } \\
\text { uma metodologia original de ensaio a ser empregada } \\
\text { para a caracterização da madeira quando solicitada à } \\
\text { compressão normal às fibras. }\end{array}$ \\
\hline
\end{tabular}


Tabela 2.1 - (continuação) - Alguns aspectos da evolução das pesquisas a respeito da madeira

\begin{tabular}{c|l}
\hline Pesquisador(es) / Ano & \multicolumn{1}{|c}{ Observaçóes sobre os trabalhos realizados } \\
\hline ROCHA & $\begin{array}{l}\text { Apresentou estudo sobre as propriedades fisicas, de } \\
\text { resistência e de rigidez, de 150 espécies arbóreas de } \\
\text { várias regiões da Floresta Amazônica. Trabalho este, de } \\
\text { expressivo significado para potencializar o emprego } \\
\text { racional de espécies nativas menos conhecidas. }\end{array}$ \\
\hline NBR & $\begin{array}{l}\text { Ano de entrada em vigor do texto revisado da NBR } \\
\text { 7190/1997 - Projeto de Estruturas de Madeira. } \\
\text { Fundamentado no Método dos Estados Limites, tal } \\
\text { documento normativo constitui num grande avanço na } \\
\text { área de madeiras, no Brasil. Além das recomendações } \\
\text { para a verificação do desempenho estrutural, a NBR } \\
7190 / 1997 \text { contém a nova proposta de metodologia para } \\
\text { a determinação de propriedades fisicas, de resistência e } \\
\text { de rigidez da madeira, em substituição à NBR 6230, } \\
\text { originalmente adotada em 1940. Os resultados } \\
\text { considerados na presente dissertação foram obtidos } \\
\text { adotando-se as recomendações da NBR 7190/1997. }\end{array}$ \\
\hline LOGSDON & $\begin{array}{l}\text { Trabalho pioneiro no emprego da conceituação } \\
\text { introduzida pela NBR 7190 para quantificar a influência } \\
\text { da umidade em propriedades de resistência e de } \\
\text { elasticidade da madeira. Utilizou espécies tropicais } \\
\text { nativas e de reflorestamento. }\end{array}$ \\
\hline 1998$)$
\end{tabular}

As informações contidas na Tabela 2.1 são referências da trajetória dos trabalhos de pesquisa desenvolvidos no sentido de se melhorar o conhecimento da madeira, à vista de suas variadas formas de aproveitamento. Indicam também as iniciativas, embora pouco numerosas, já efetuadas para se ampliar o leque de espécies, em particular das tropicais brasileiras, que podem ser utilizadas alternativamente àquelas de uso consagrado e que vem alcançando niveis próximos ao esgotamento.

Com isto, espera-se deixar evidenciado que o trabalho aqui apresentado contribui para preencher uma lacuna muito ampla no que se refere à adequada aplicação de espécies tropicais de madeira. 


\section{3 - COMENTÁRIOS SOBRE A REVISÃO BIBLIOGRÁFICA}

Neste item é feita uma síntese a respeito da importância do conhecimento das especificidades da madeira, a partir do embasamento teórico adquirido em pesquisa bibliográfica, citada na tabela 2.1, do item 2.2 - ASPECTOS HISTÓRICOS DO ESTUDO DA MADEIRA, tendo em vista as diversas finalidades que se pode propor para essa matéria prima, partindo-se dos resultados experimentais de suas propriedades físicas, de resistência e de rigidez.

\subsection{1 - Algumas considerações sobre propriedades da madeira}

O conhecimento das propriedades físicas, de resistência e de elasticidade da madeira define substancialmente sua aplicação nas diferentes áreas da construção civil.

A umidade traz grande influência no comportamento de elementos da madeira. Sua redução para níveis inferiores ao ponto de saturação faz com que a sua resistência e sua rigidez adquiram valores mais elevados. Entretanto, cuidados especiais devem ser tomados para que a secagem seja bem conduzida, minorando os problemas e os defeitos decorrentes de processos não controlados.

A umidade não apenas provoca variações nas propriedades mecânicas, como também é parâmetro fundamental para outras quantificações. Diversos autores se ocuparam em quantificar a influência da umidade na densidade da madeira. Um dos diagramas mais utilizados para a estimativa da densidade, nos diversos níveis de umidade, é o construído por Kollmann, a partir do estudo de espécies de clima temperado. Tal diagrama está apresentado, a título de ilustração, na Figura 2.1. 


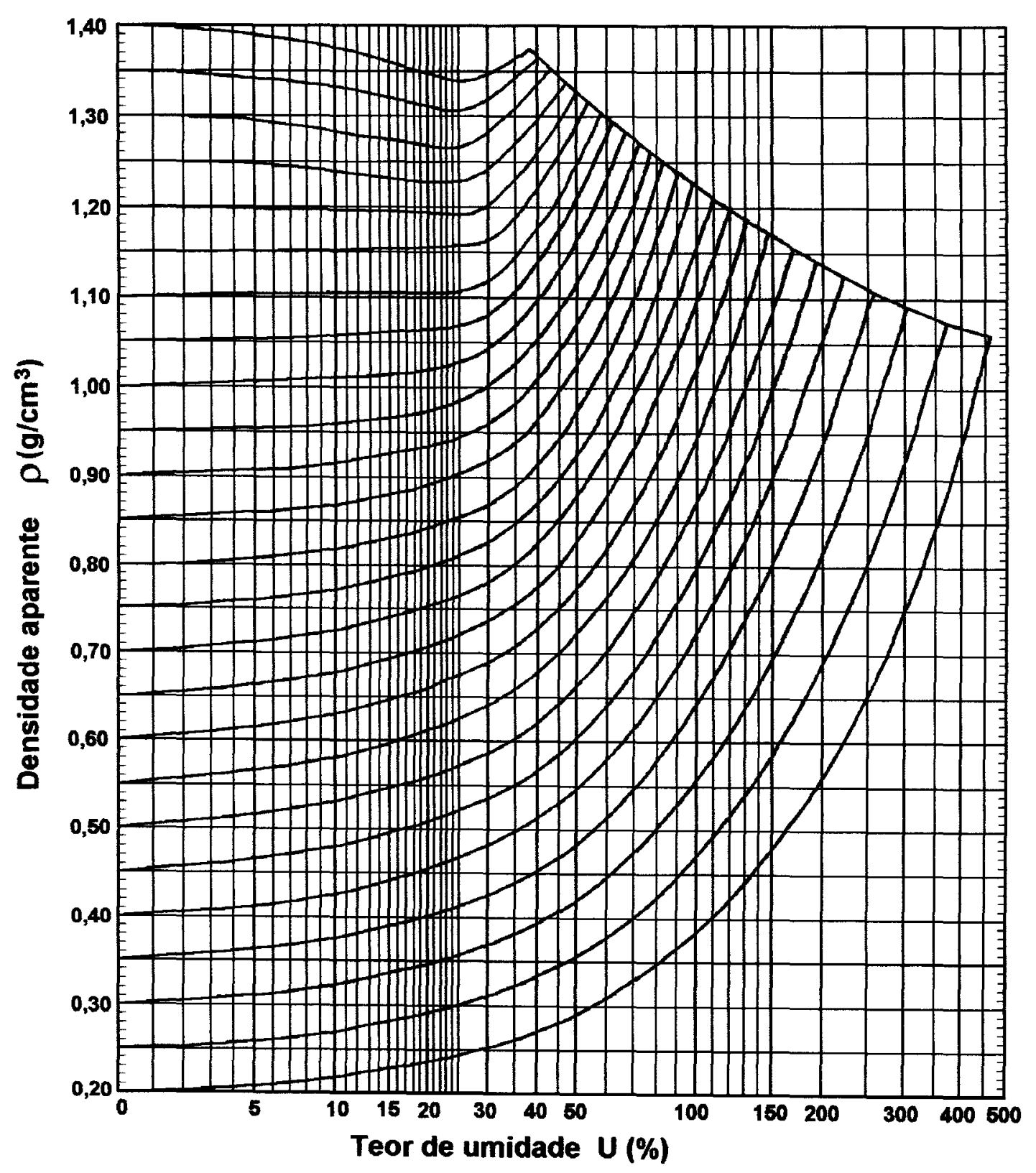

Figura 2.1 - Diagrama de Kollmann (variação da densidade aparente $x$ teor de umidade). Fonte: KOLLMANN \& COTÉ (1968).

Além da umidade, as propriedades fisicas e mecânicas da madeira são influenciadas pelos mais variados fatores, entre eles a sua estrutura anatômica, a quantidade de extrativos, e a densidade, além das condições de clima e solo nas quais as árvores se desenvolveram. Outro parâmetro que influi nas propriedades mecânicas diz respeito à direção da solicitação, relativamente à posição das fibras. 
A relação entre resistência e umidade pode ser expressa por diferentes modelos matemáticos, dependendo da solicitação considerada. Algumas propriedades são muito sensíveis à variação da umidade, por exemplo, a resistência à compressão paralela às fibras. No caso da tenacidade, cujo valor é determinado a partir do ensaio de flexão dinâmica, a influência da umidade é muito pequena e não existe um padrão único, para a respectiva representação gráfica ou numérica.

Muitas das propriedades de resistência se correlacionam diretamente com a densidade. São bem conhecidos os modelos matemáticos que descrevem os respectivos fenômenos, permitindo a estimativa dos valores da resistência para, praticamente, todos os níveis de umidade. Ganham maior importância os níveis de umidade entre $12 \%$ e o ponto de saturação, uma vez que a quase totalidade das aplicações da madeira, na construção civil, é feita nas condições mencionadas.

A questão da ortotropia da madeira fica mais evidente quando são avaliadas as propriedades de resistência e de rigidez. Em diversas situações, é importante conhecer as proporções da mencionada diferença para melhor aplicação da matéria prima.

Existem também correlações bem claras entre propriedades de resistência e de rigidez da madeira. A NBR 7190/1997, que considera a resistência à compressão paralela às fibras como referência, preconiza uma série de expressões que permitem estimar a resistência à tração paralela às fibras e a resistência ao cisalhamento, por exemplo, a partir da propriedade de referência. Desta forma, a NBR 7190/1997 acaba sugerindo algumas classes de resistência da madeira para estruturas, o que viabiliza $o$ emprego até de lotes de espécies pouco conhecidas.

Os valores da resistência da madeira na direção perpendicular às fibras são significativamente inferiores se comparados aos da direção paralela às fibras. Neste sentido, a NBR 7190/97 registra que deve ser desprezada, para efeito de projeto, a resistência da madeira à tração normal às fibras.

Outras fontes de variabilidade das propriedades fisicas e mecânicas da madeira são inerentes às características de crescimento das árvores, da existência e da freqüência de nós e de fibras retorcidas. Estes aspectos, em geral, provocam redução sensível nos valores que representam as citadas propriedades. 


\subsection{2 - Secagem da madeira}

A madeira das árvores vivas ou recentemente derrubadas apresenta alto teor de umidade. Nestas condições, diz-se que a madeira está saturada ou "verde". A umidade, logo após o abate, tende a diminuir com a evaporação das moléculas de água para o ambiente, enquanto as toras aguardam o desdobro.

A redução da umidade prossegue após o desdobro, a taxas dependem da espécie vegetal considerada, do ambiente a que a peças estejam expostas, das respectivas dimensões, do tipo de empilhamento efetuado. $O$ processo de secagem se verifica, inicialmente, com a evaporação das moléculas de água livre, que se encontram nos lúmens dos elementos anatômicos. Depois de algum tempo, atinge-se o chamado ponto de saturação, quando tem início a saída das moléculas de água que impregnam as paredes celulares. Abaixo do ponto de saturação, a saída das moléculas de água é acompanhada da retração da madeira, ao mesmo tempo em que as propriedades de resistência e de rigidez atingem valores superiores aos da madeira saturada. A saída das moléculas de água de impregnação se dá mais lentamente, até ser atingido a chamada umidade de equilíbrio (UE). Esta umidade eqüivale a $12 \%$, à temperatura de $20^{\circ} \mathrm{C}$ e umidade relativa do ar $65 \%$. Abaixo da UE, a saída das moléculas de água somente ocorrerá com o fornecimento artificial de energia (estufas ou climatizadoras). Entre os fatores que influem no movimento da água no interior da madeira podem ser citados: a permeabilidade, a densidade, o volume e a localização dos extrativos.

As dimensões das peças de madeira, em decorrência dos fenômenos de retração e inchamento, se alteram significativamente. $O$ gráfico apresentado na Figura 2.2 ilustra o fenômeno do inchamento. A função linear é satisfatória para representá-lo, de umidade $0 \%$ até o ponto de saturação. Acima disto, uma reta paralela à abscissa mostra a não dependência entre as variáveis umidade e inchamento. Em razão da anisotropia da madeira, a retração se manifesta em taxas diferentes, se consideradas as três direç̃es principais: axial, radial e tangencial. A retração volumétrica é consequência das retrações lineares consideradas. 


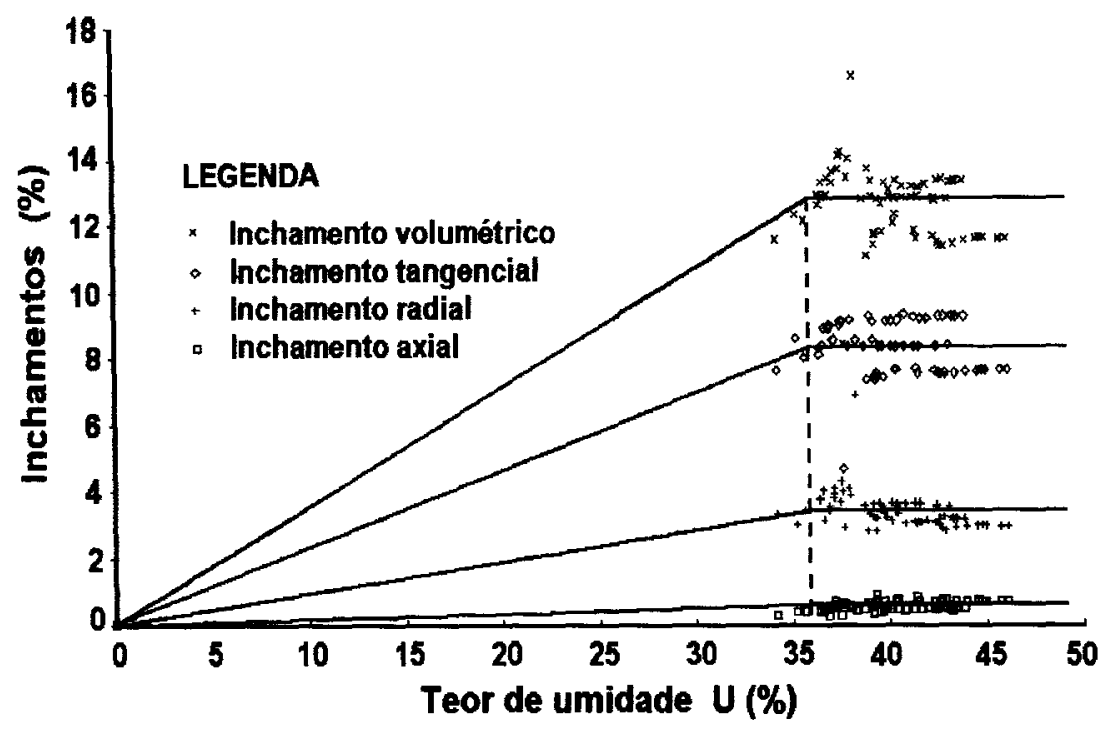

Figura 2.2 - Diagramas de inchamentos para a Itaúba (Mezilaurus itauba). Fonte: LOGSDON (1998).

A transformação racional da madeira bruta em produtos serrados requer, obrigatoriamente, a adoção de processos controlados de secagem. Desta forma, além do ganho em resistência e rigidez, garante-se que será proporcionada a melhor condição para a aplicação de acabamentos ou da impregnação com substâncias preservativas contra a demanda biológica

A resistência à flexão de madeiras cuja secagem foi acelerada, normalmente, é muito mais alto que o obtido com uma secagem que garanta distribuição uniforme do teor de umidade (Figura 2.3). A razão é evidente: devido ao elevado gradiente de umidade, do interior para o exterior, as camadas mais externas da madeira estão mais secas e assim mais resistentes, afetando sensivelmente a resistência à flexão. 


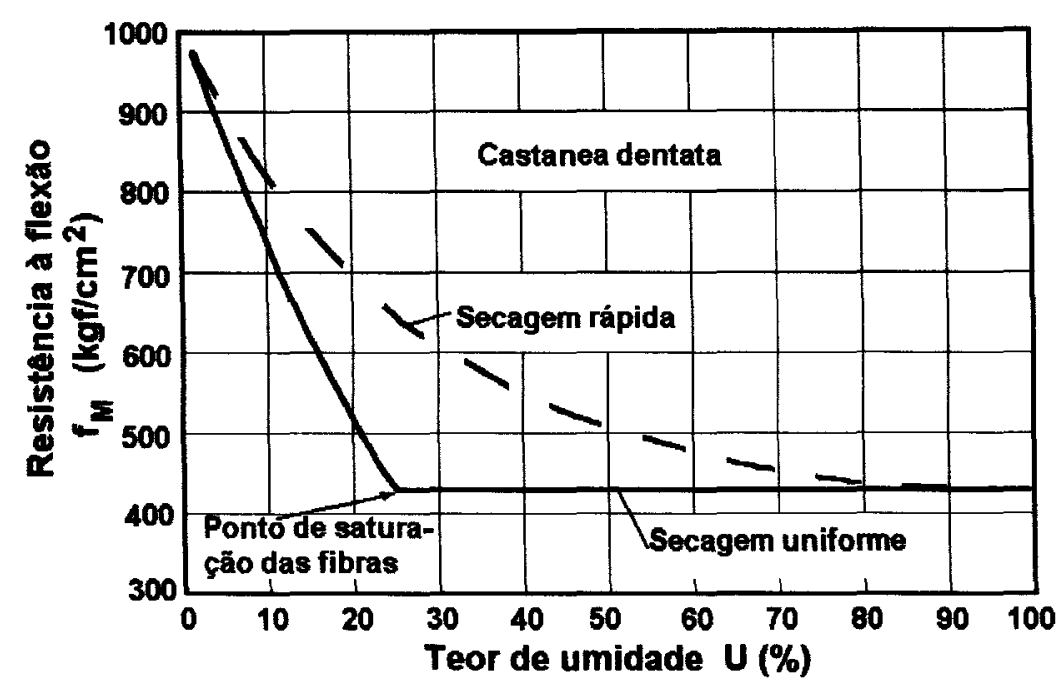

Figura 2.3 - Efeito da severidade do processo de secagem sobre a resistência à flexão da espécie Castanea dentata $(1 \mathrm{kgf} / \mathrm{cm} 2 \cong 0,10 \mathrm{MPa})$. Fonte: KOLLMANN \& COTÉ (1968).

$\mathrm{O}$ uso de programas de secagem controlada, efetuada através de secadores ou estufas com o equipamento adequado, permitem ajustar o teor de umidade da madeira de acordo com as condições climáticas do local de uso do produto final, em qualquer época do ano. Além disto, reduz a incidência de defeitos como rachaduras, empenamentos, encanoamentos, bem como elimina os fungos eventualmente presentes nas peças. Em linhas gerais, os programas de secagem consistem numa seqüência pré-determinada de temperaturas e umidade relativa do ar no interior dos secadores, estabelecida para cada espécie, visando proporcionar a redução da umidade de acordo com o comportamento da espécie considerada. Na etapa final do processo, uma vez atingida a umidade média do lote, é previsto um período de climatização propriamente dita da madeira, no qual se permite que o gradiente de umidade das peças seja minimizado, garantindo que o desempenho final será de acordo com o esperado.

$\mathrm{Na}$ Figura 2.4, a seguir, estão apresentados os valores médios da umidade de equilíbrio da madeira em diversos ambientes de utilização. Esta figura é interessante para se ilustrar a conveniência de se estabelecer, nos processos de secagem, as umidades finais de acordo com o tipo e local da aplicação do produto de madeira considerado. 


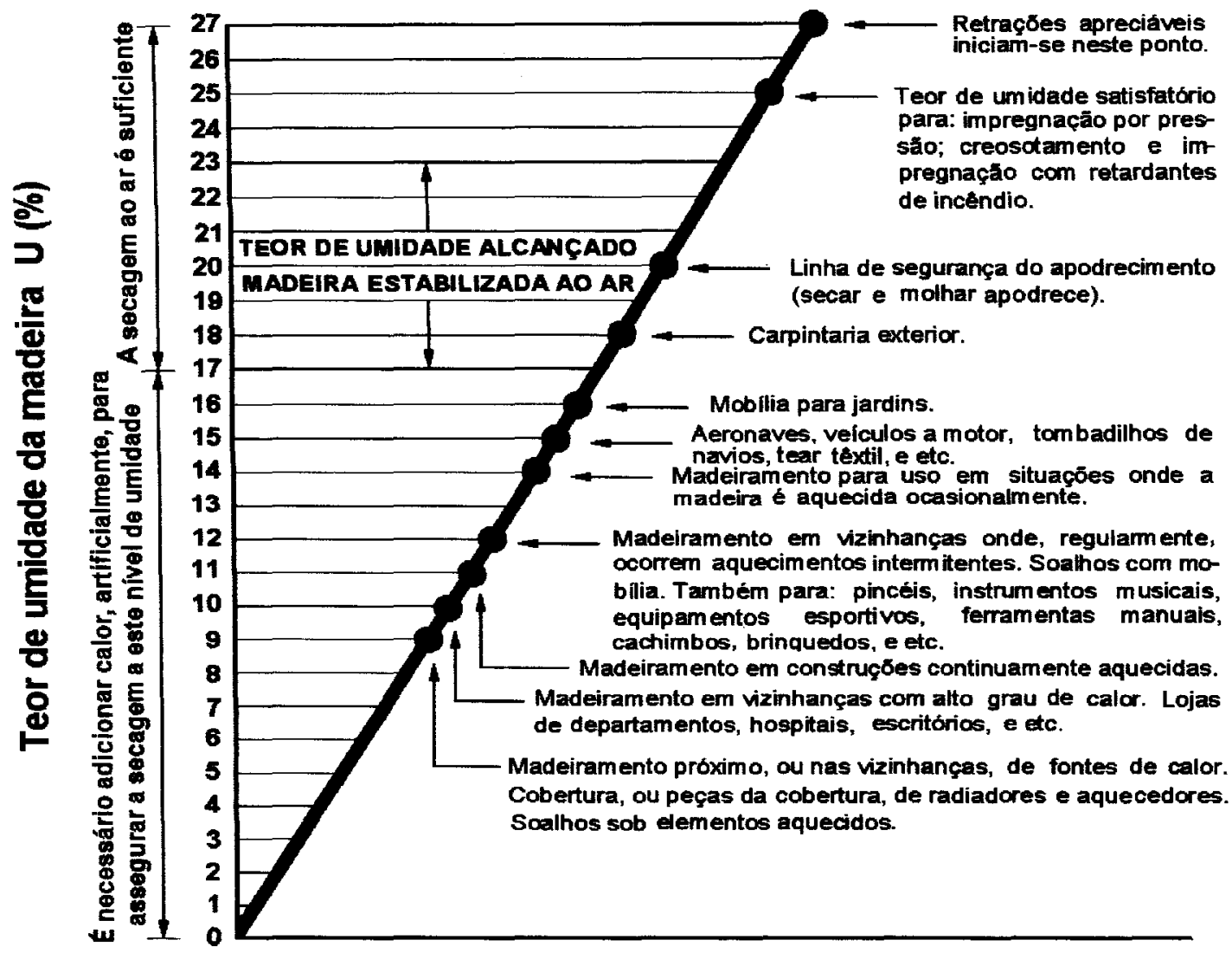

Figura 2.4 - Teor de umidade de equilíbrio da madeira em diversos ambientes de utilização. Fonte: LOGSDON (1998).

Destaca-se que o texto da NBR 7190/1997, no anexo B: Determinação de propriedades da madeira, recomenda expressamente a realização dos ensaios tendo como umidade de referência o valor de $12 \%$. Neste sentido, observa-se a grande importância na adoção de adequados procedimentos para a secagem da madeira, objetivando a obtenção dos corpos-de-prova a empregar na caracterização das espécies.

Registra-se que, no trabalho aqui apresentado, todos os valores das propriedades consideradas estão referidos à umidade de $12 \%$. 


\subsection{3 - Considerações finais}

A síntese bibliográfica apresentada serve não somente para deixar registrados aspectos relevantes do comportamento da madeira, mas também para evidenciar a importância de serem adotados procedimentos adequados para a preparação do material a ser empregado nos ensaios, visando a determinação de propriedades físicas, de resistência e de rigidez das espécies a estudar.

As recomendações contidas no texto do item 2.3.2 se constituíram nos pontos básicos a partir dos quais se processou todo o estudo das espécies tropicais alternativas, com o intuito de serem propostas suas aplicações mais convenientes nos diversos segmentos da construção civil.

Desta forma é possível assegurar a validade dos resultados diante da documentação normativa vigente, permitindo que as sugestões de emprego, apresentadas ao final da dissertação, sejam respaldadas por experimentação adequadamente conduzida. 


\section{3 - MATERIAL E MÉTODOS}

\section{1 - CONSIDERAÇÕES INICIAIS}

Neste capítulo são apresentados os seguintes itens:

- Informações gerais a respeito da madeira das espécies consideradas;

- Generalidades a respeito dos métodos de ensaio utilizados para a determinação das propriedades fisicas, de resistência e de rigidez da madeira das espécies consideradas;

- Dados básicos sobre os equipamentos utilizados na parte experimental do trabalho;

- Informações sobre os critérios utilizados para a indicação dos usos mais adequados das espécies consideradas.

\section{2 - ESPÉCIES ESTUDADAS}

Toda madeira apresenta-se constituída de tecidos lenhosos com características próprias e que, permanecendo constantes em seus arranjos, definem uma espécie. Assim, através de amostras autênticas de lenho provenientes de árvores classificadas botanicamente, pelos caracteres de observação macroscópica, é possível fazer-se a diferenciação entre espécies.

A Tabela 3.1 mostra a nomenclatura das espécies de madeira em estudo.

As características gerais foram descritas a partir de pesquisa bibliográfica, através de literatura especializada, dentro deste contexto, a Tabela 3.2 ilustra um modelo de como as demais Tabelas foram elaboradas, para uma melhor visualização das espécies em estudo e a Tabela 3.3 apresenta as condições de tratamento químico da madeira.

As Tabelas apresentadas na seqüência ( 3.4 a 3.38) mostram as descrições dos aspectos peculiares de cada espécie em estudo. 
Tabela 3.1 - Nomenclatura das espécies

\begin{tabular}{|c|c|c|}
\hline \multicolumn{3}{|c|}{ ESPÉCIES } \\
\hline NOME POPULAR & NOME CIENTÍFICO & FAMÍLIA \\
\hline Angelim Amargoso & Vatairea fusca & Leg. Papilionoideae \\
\hline Angelim Araroba & Vataireopsis araroba & Fabaceae \\
\hline Angelim Ferro & Hymenolobium sp & Leg. Papilionoideae \\
\hline Angelim Pedra & Hymenolobium petraeum & Leg. Papilionoideae \\
\hline Angelim Pedra Verdadeiro & Dinizia excelsa & Mimosaceae \\
\hline Angelim Saia & Vatairea $s p$ & Mimosaceae \\
\hline Angico Preto & Piptadenia macrocarpa & Mimosaceae \\
\hline Branquilho & Terminalia sp & Combraceae \\
\hline Cafearana & Andira sp & Leguminoseae \\
\hline Canafistula & Cássia ferruginea & Caesalpiniaceae \\
\hline Casca Grossa & ** & $* *$ \\
\hline Castelo & Gossypiospermun praecox & Flacourtiaceae \\
\hline Catanudo & Calophyllum sp & Clusiaceae \\
\hline Cedro Amargo & Cedrela odorata & Meliaceae \\
\hline Cedrorana & Cedrelinga catenaeformis & Leguminosae \\
\hline Champanhe & Dipteryx $s p$ & Leg. Papilionoideae \\
\hline Cupiúba & Goupia glabra & Goupiaceae \\
\hline Cutiúba & Qualea paraensis & Vochysiaceae \\
\hline Garapa & Apuleia leiocarpa & Caesalpiniaceae \\
\hline Goiabão & Planchonella pachycarpa & Sapotaceae \\
\hline Guaiçara & Luetzelburgia sp & Leguminosae \\
\hline Guarucaia & Peltophorum vogelianum & Caesalpiniaceae \\
\hline Itaúba & Mezilaurus itauba & Lauraceae \\
\hline Louro Preto & Ocotea sp & Lauraceae \\
\hline Mandioqueira & Qualea albiflora & Moraceae \\
\hline Oiticica Amarela & Clarísia racemosa & Moraceae \\
\hline Oichu & Pradozia sp & Sapotaceae \\
\hline Parinari & Parinari excelsa sabine & Crysobalanaceae \\
\hline Piolho & Tapirira sp & Anacardiaceae \\
\hline Quarubarana & Erisma uncinatum & Vochysiaceae \\
\hline Rabo de Arraia & Vochysia sp & Vochysiaceae \\
\hline Tachi & Sclerolobium sp & Caesalpiniaceae \\
\hline Tatajuba & Bagassa guianensis & Moraceae \\
\hline Umirana & Qualea retusa & Vochysiaceae \\
\hline
\end{tabular}

\footnotetext{
"* Dado não conclusivo dos caracteres anatômicos da espécie estudada.
} 
Tabela 3.2 - Características gerais

Zona de coleta: Estado procedente do material lenhoso.

Outros nomes comuns: A sinonímia ou o nome comum utilizado neste trabalho é advindo da zona de coleta do material lenhoso para os estudos tecnológicos. Os outros nomes apresentados foram obtidos em pesquisa bibliográfica. Devido à grande variabilidade e inexistência da padronização destes nomes, recomenda-se não dissocia-los dos seus respectivos nomes botânicos ou científicos.

Zonas de maior ocorrência: Regiões ou Estados de provável ocorrência da espécie.

\section{Caracteres gerais:}

- Cerne/alburno: Foram verificados pela presença de cores em distintos, indistintos ou pouco distintos.

- Anéis de crescimento: Destacados pela observação a olho nu.

- Grã: Pode ocorrer mais de um tipo de grã em árvores de uma mesma espécie, em diferentes amostras de uma mesma árvore, ou ainda numa mesma amostra. Foi empregada como referência, a direção dos elementos celulares constituintes da madeira em relação ao eixo longitudinal do tronco. A grã foi classificada em: direita, revessa.

- Textura: As diferenças no aparecimento dos anéis de crescimento, que resultam das variações em tamanho e uniformidade das dimensões das células, constituem a textura da madeira. A classificação da textura usada baseia-se no tamanho dos poros e na visibilidade do parênquima e foi considerada: grossa - com poros de diâmetros acima de 300 micra e parênquima abundante visível a olho nu; média - com poros de diâmetro entre 100 a 300 micra e parênquima visível sem auxílio de lentes; e fina - com poros de diâmetro menor do que 100 micra e parênquima visível apenas com o auxílio de lentes.

- Brilho: Ausente, brilho moderado ou brilho acentuado.

- Cheiro: Imperceptível, perceptível ou característico, agradável, desagradável.

- Gosto: Perceptível ou imperceptível.

Durabilidade natural: Os dados foram retirados de diversas referências bibliográficas e, portanto, não seguem uma padronização de nomenclatura Entretanto, os conceitos utilizados como durável, moderadamente durável, resistente, suscetível, vulnerável, etc, dão uma idéia da durabilidade natural da madeira.

Tratamento preservante: Segundo a bibliografia consultada, os dados de preservação de madeira foram obtidos por meio do tratamento, em separado, de peças medindo $5 \mathrm{~cm} \times 5 \mathrm{~cm}$ de seção transversal e $60 \mathrm{~cm}$ de comprimento, com creosoto (oleossolúvel) e com solução de cobre, cromo e arsênico - CCA-A (hidrossolúvel), em base óxida a 3\% (volume/volume), pelo processo de célula cheia, de acordo com as condições de tratamento apresentadas na Tabela 3.3.

Dados segundo autor: Citação autoral, segundo pesquisa bibliográfica.

Textura da espécie: Corte longitudinal proveniente do lenho da espécie ensaiada, disponível em amostras no LaMEM/SET. 
Tabela 3.3 - Condições de tratamento químico da madeira

\begin{tabular}{|c|c|c|c|c|}
\hline \multicolumn{5}{|c|}{ CONDIÇŌES DE TRATAMENTO } \\
\hline Preservativos & $\begin{array}{l}\text { Vácuo inicial } \\
\text { durante } 45 \text { min. }\end{array}$ & $\begin{array}{l}\text { Pressão de } \\
\text { trabalho } \\
\text { durante } 4 \mathrm{~h}\end{array}$ & $\begin{array}{c}\text { Vácuo final } \\
\text { durante } 30 \\
\text { min. }\end{array}$ & Temperatura \\
\hline Solução & (mm Hg) & $\left(\mathrm{kg} / \mathrm{cm}^{2}\right)$ & (mm Hg) & $\left({ }^{0} \mathrm{C}\right)$ \\
\hline CREOSOTO & 600 & 12 & 600 & $80-90$ \\
\hline CCA-A & 600 & 12 & 600 & 23 \\
\hline
\end{tabular}

Fonte: CAMARGOS et al (1997).

Tabela 3.4 - Descrição da espécie Angelim Amargoso

\begin{tabular}{|c|c|}
\hline \multicolumn{2}{|c|}{$\begin{array}{l}\text { ANGELIM AMARGOSO } \\
\text { Nome comum }\end{array}$} \\
\hline OUTROS NOMES COMUNS & $\begin{array}{l}\text { Amargoso, angelim-amargoso, faveira (PA); } \\
\text { faveira-amargosa, faveira-bolacha (AM). }\end{array}$ \\
\hline ZONAS DE MAIOR OCORRÊNCIA & Estados do AM, PA, AC, RO. \\
\hline CARACTERES GERAIS & $\begin{array}{l}\text { A madeira apresenta cerne marrom-oliva, quando } \\
\text { recém-cortada, tornando-se marrom-avermelhado } \\
\text { com listas amarelo-amarronzadas, distinto do } \\
\text { alburno marrom muito pálido ou cinza rosado; } \\
\text { anéis de crescimento indistintos; grã revessa; } \\
\text { textura grossa; cheiro imperceptível. }\end{array}$ \\
\hline DURABILIDADE NATURAL & $\begin{array}{l}\text { O cerne é moderadamente durável a durável, } \\
\text { baseado em teste de campo. }\end{array}$ \\
\hline TRATAMENTO PRESERVANTE & $\begin{array}{l}\text { Cerne não é tratável com CCA-A, mesmo em } \\
\text { tratamento sob pressão. }\end{array}$ \\
\hline DADOS SEGUNDO AUTOR & CAMARGOS et al (1997). \\
\hline
\end{tabular}

TEXTURA DA ESPÉCIE

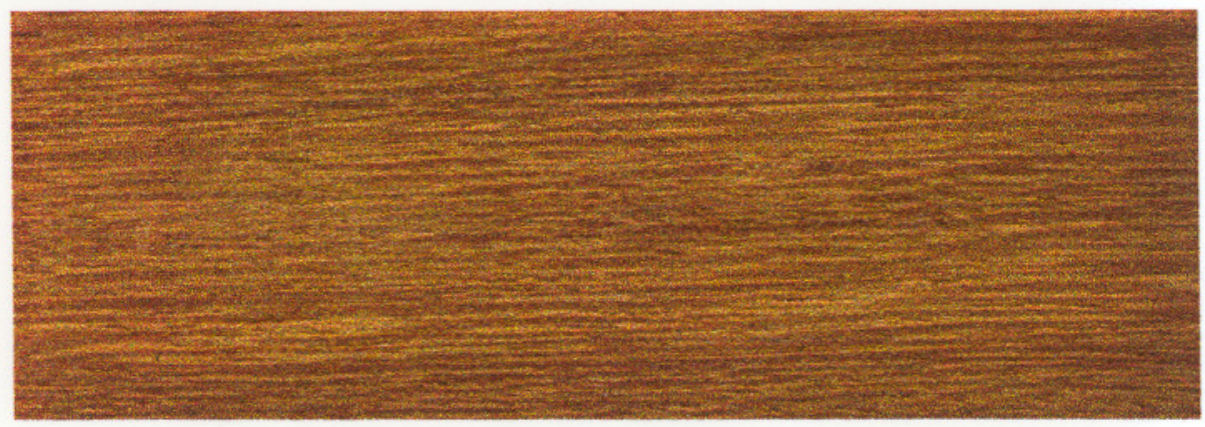

Corte Longitudinal. 
Tabela 3.5 - Descrição da espécie Angelim Araroba

\begin{tabular}{l|l}
\hline $\begin{array}{l}\text { Vataireopsis araroba } \\
\text { Nome científico }\end{array}$ & $\begin{array}{l}\text { ANGELIM ARAROBA } \\
\text { Nome comum } \\
\text { Fabaceae } \\
\text { Fália }\end{array}$ \\
\hline \hline OUTROS NOMES COMUNS & $\begin{array}{l}\text { Angelim-pedra (MG), angelim-amarelo, moina, } \\
\text { araroba, angelim-amargoso. }\end{array}$ \\
\hline ZONAS DE MAIOR OCORRÊNCIA & $\begin{array}{l}\text { Estado de RR, sul do Estado da BA, norte do } \\
\text { Estado do ES, vale do Rio Doce, Estado de MG, } \\
\text { norte do Estado do RJ. }\end{array}$ \\
\hline CARACTERES GERAIS & $\begin{array}{l}\text { As árvores atingem 30m } \times 120 \mathrm{~cm} \text { comumente } \\
\text { com fustes de 12-20 m } \times \text { co-70cm. Cerne } \\
\text { apresenta cor uniforme, amarelo a amarelo- } \\
\text { queimado, quando recém-cortado, passando para } \\
\text { castanho-amarelado após exposição ao ar; } \\
\text { camadas de crescimento pouco distintas; raios } \\
\text { notados a olho nu no topo e na face tangencial só } \\
\text { sob lente; grã direita; textura grossa; superficie de } \\
\text { pouco brilho, áspera ao tato, de aspecto fibroso } \\
\text { destacado; cheiro acentuadamente amargo. }\end{array}$ \\
\hline DURABILIDADE NATURAL & $\begin{array}{l}\text { Alta resistência ao apodrecimento e à ação de } \\
\text { cupins devido ao seu abundante conteúdo } \\
\text { amarelado, de "Pó-de-Araroba". }\end{array}$ \\
\hline TRATAMENTO PRESERVANTE & * \\
\hline DADOS SEGUNDO AUTOR & CHIMELO \& MAINIERI (1989); RIZZINI (1971) \\
\hline \hline
\end{tabular}

TEXTURA DA ESPÉCIE

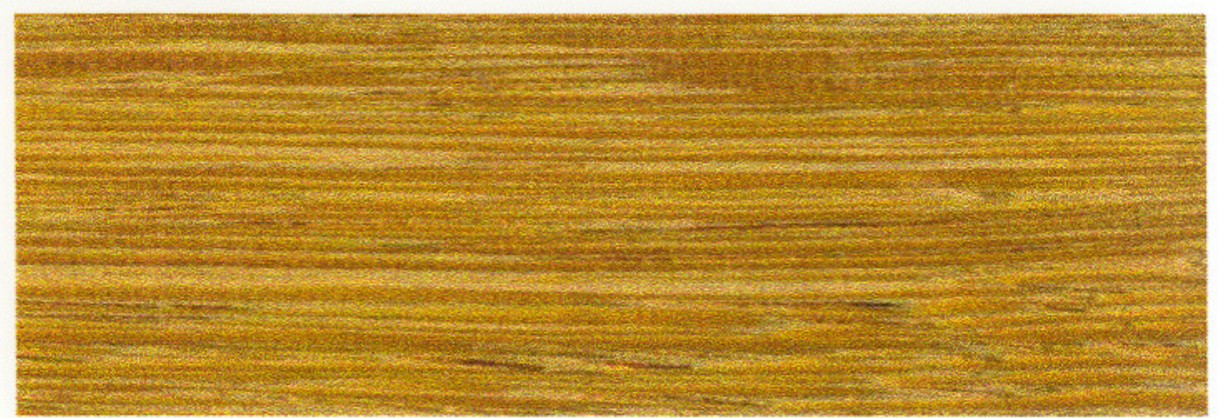

Corte Longitudinal.

"Dado desconhecido. 
Tabela 3.6 - Descrição da espécie Angelim Ferro

\begin{tabular}{|c|c|}
\hline \multicolumn{2}{|c|}{$\begin{array}{c}\text { ANGELIM FERRO } \\
\text { Nome comum } \\
\text { Leg. Papilionoideae } \\
\text { Familia } \\
\end{array}$} \\
\hline OUTROS NOMES COMUNS & $\begin{array}{l}\text { Angelim, angelim-amarelo, angelim-amargoso, } \\
\text { angelim-comum, angelim-do-pará, angelim-doce, } \\
\text { angelim-fava, angelim-pedra, angelim-da-mata, } \\
\text { angelim-rosa, mirarema. }\end{array}$ \\
\hline ZONAS DE MAIOR OCORRÊNCIA & Estados do AM, PA, RR. \\
\hline CARACTERES GERAIS & $\begin{array}{l}\text { A altura comercial da árvore é de } 13,50 \mathrm{~m} \text {; tronco } \\
\text { retilíneo. A madeira apresenta cerne e alburno } \\
\text { distintos, cerne de cor castanho a castanho rosado } \\
\text { a marrom-avermelhado-claro, alburno de cor } \\
\text { marrom-muito-pálido e espessura de } 2,5 \mathrm{~cm} \text { a } \\
4,5 \mathrm{~cm} \text {; camadas de crescimento distintas; grã } \\
\text { revessa; textura grossa; brilho ausente; cheiro } \\
\text { imperceptível. }\end{array}$ \\
\hline DURABILIDADE NATURAL & $\begin{array}{l}\text { Alta durabilidade, quando exposto a fungos da } \\
\text { podridão-branca e parda, resistente a cupins de } \\
\text { madeira seca e moderadamente resistente a brocas } \\
\text { marinhas. }\end{array}$ \\
\hline TRATAMENTO PRESERVANTE & $\begin{array}{l}\text { A preservação do alburno mostra-se muito fácil e } \\
\text { o cerne é de baixa permeabilidade a soluções } \\
\text { preservantes, creosoto e CCA-A. }\end{array}$ \\
\hline DADOS SEGUNDO AUTOR & CAMARGOS et al (1997). \\
\hline
\end{tabular}

TEXTURA DA ESPÉCIE

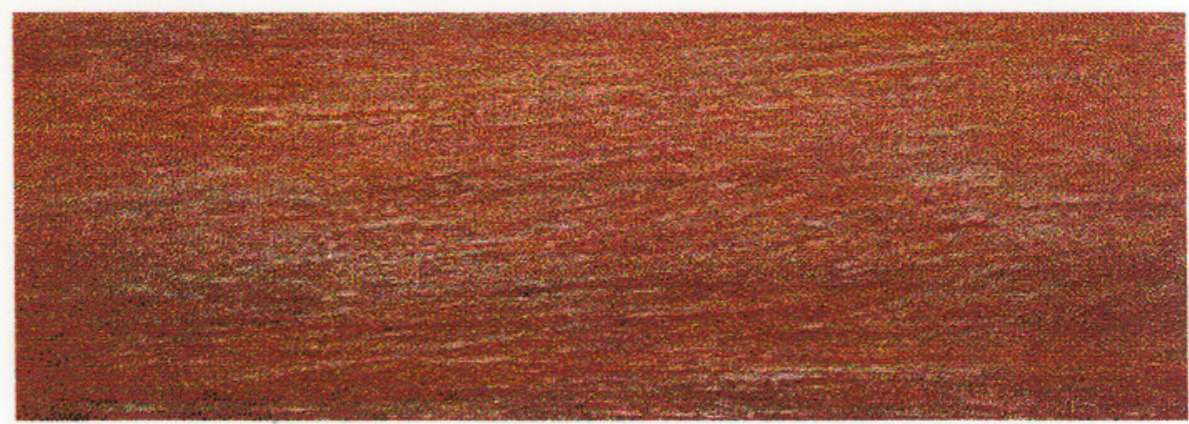

Corte Longitudinal 
Tabela 3.7 - Descrição da espécie Angelim Pedra

\section{ANGELIM PEDRA}

Nome comum

\section{Hymenolobium petraeum Leg. Papilionoideae}

Sul de Roraima

Família

Zona de coleta

\begin{tabular}{l|l}
\hline OUTROS NOMES COMUNS & $\begin{array}{l}\text { Angelim, angelim-amarelo, angelim-aroeira, } \\
\text { angelim-comum, angelim-da-mata, angelim-do- } \\
\text { pará, angelim-macho, angelim-branco-pedra, } \\
\text { angelim-rosa, angelim-grande, mirarema, } \\
\text { murarema, sucupira-amarela. }\end{array}$ \\
\hline ZONAS DE MAIOR OCORRÊNCIA & $\begin{array}{l}\text { Presente desde o Atlântico até a parte oriental do } \\
\text { estado do AM (Parintins), PA, AM, RR. }\end{array}$ \\
\hline CARACTERES GERAIS & $\begin{array}{l}\text { As árvores, na mata são de 50 m e tronco retilíneo, } \\
\text { sendo uma das mais altas da floresta Amazônica, } \\
\text { nas matas secas e campos mostram-se bem } \\
\text { menores. As proporçóes comerciais são de 9,70 m } \\
\times 65,3 \text { cm. A madeira apresenta-se distinta por } \\
\text { veios finos e pela presença de manchas irregulares } \\
\text { da mesma cor que os veios, devido a exudação de } \\
\text { óleo-resina. Crne marrom-amarelado-claro, } \\
\text { distinto do alburno marrom-pálido; camadas de } \\
\text { crescimento distintas; grã revessa; textura grossa; } \\
\text { brilho ausente e cheiro imperceptivel. }\end{array}$ \\
\hline DURABILIDADE NATURAL & $\begin{array}{l}\text { Cerne muito durável, quando exposto a fungos da } \\
\text { podridão parda e branca; moderada resistencia a } \\
\text { brocas marinhas; resistente a cupins de madeira } \\
\text { seca. }\end{array}$ \\
\hline TRATAMENTO PRESERVANTE & $\begin{array}{l}\text { Alburno apresenta alta permeabilidade de creosoto } \\
\text { (oleossolúvel) e CCA-A (hidrossolúvel), o cerne é } \\
\text { de baixa permeabilidade, mesmo em tratamento } \\
\text { sob pressão. }\end{array}$ \\
\hline DADOS SEGUNDO AUTOR & $\begin{array}{l}\text { RIZZINI (1971); IBAMA (1997); CAMARGOS et al } \\
\text { (1997). }\end{array}$ \\
\hline
\end{tabular}

TEXTURA DA ESPÉCIE

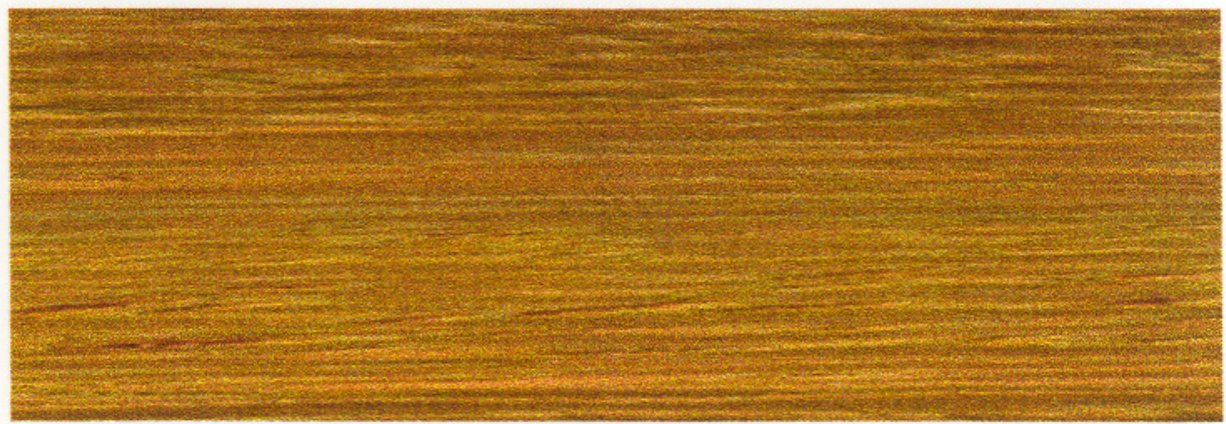

Corte Longitudinal 
Tabela 3.8 - Descrição da espécie Angelim Pedra Verdadeiro

\begin{tabular}{|c|c|}
\hline \multicolumn{2}{|c|}{$\begin{array}{l}\text { ANGELIM PEDRA VERDADEIRO } \\
\text { Nome comum }\end{array}$} \\
\hline $\begin{array}{c}\text { Dinizia excelsa } \\
\text { Nome científico }\end{array}$ & $\begin{array}{l}\text { Mimosaceae } \\
\text { Família }\end{array}$ \\
\hline OUTROS NOMES COMUNS & $\begin{array}{l}\text { No Brasil, angelim-vermelho, angelim-falso, } \\
\text { faveira-grande, faveira-dura, faveira-ferro. Na } \\
\text { Guiana Francesa, faveira-preta, kuraru, parakwa. }\end{array}$ \\
\hline ZONAS DE MAIOR OCORRÊNCIA & $\begin{array}{l}\text { Região Amazônica, principalmente nos Estados } \\
\text { de AC, RO, AM, PA e RR; Guiana Francesa. }\end{array}$ \\
\hline CARACTERES GERAIS & $\begin{array}{l}\text { As árvores desta espécie são de porte gigante, } 55- \\
60 \mathrm{~m} \times 2 \mathrm{~m} \text {, ocorre em terrenos sílico-argilosos ou } \\
\text { argilosos. O cerne e alburno são pouco } \\
\text { diferenciados, cerne de cor castanho rosado, } \\
\text { adquire coloração avermelhada quando em } \\
\text { contato com a luz solar; grã direita a irregular; } \\
\text { textura média a grossa; superficie lisa ao tato e } \\
\text { sem brilho; cheiro característico de madeira verde } \\
\text { e gosto quase imperceptível. }\end{array}$ \\
\hline DURABILIDADE NATURAL & Apresenta alta resistência a organismos xilófagos. \\
\hline TRATAMENTO PRESERVANTE & $\begin{array}{l}\text { Baixa permeabilidade às soluções preservantes, } \\
\text { creosoto e CCA-A, mesmo em tratamento sob } \\
\text { pressão. }\end{array}$ \\
\hline DADOS SEGUNDO AUTOR & $\begin{array}{l}\text { LOUREIRO \& SILVA (1968); CHIMELO \& } \\
\text { MAINIERI (1989). }\end{array}$ \\
\hline
\end{tabular}

TEXTURA DA ESPÉCIE

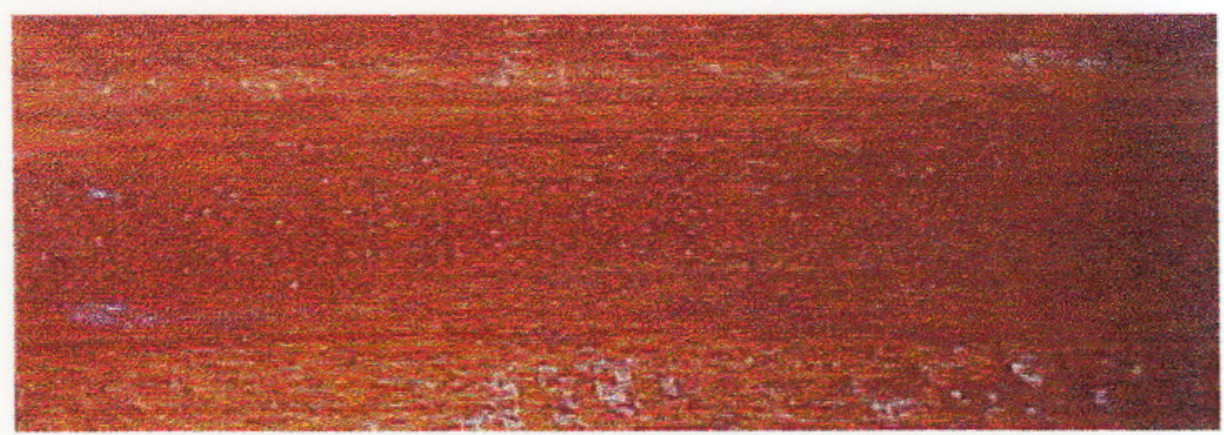

Corte Longitudinal 
Tabela 3.9 - Descrição da espécie Angelim Saia

\begin{tabular}{|c|c|}
\hline $\begin{array}{l}\text { Vatairea guianensis } \\
\text { Nome científico }\end{array}$ & $\begin{array}{l}\text { ANGELIM SAIA } \\
\text { Nome comum } \\
\begin{array}{c}\text { Leguminosae } \\
\text { Família }\end{array} \\
\text { Nordeste do Mato Grosso } \\
\text { Zona de coleta }\end{array}$ \\
\hline OUTROS NOMES COMUNS & $\begin{array}{l}\text { Fava, fava-bolacha, faveira, faveira-de- } \\
\text { impingem, faveira-grande-do-igapó. }\end{array}$ \\
\hline ZONAS DE MAIOR OCORRÊNCIA & $\begin{array}{l}\text { Estados do AM e PA, indo até a fronteira da } \\
\text { Guiana Francesa e Venezuela, parte Amazônica, } \\
\text { podendo também ocorrer em outras regiões. }\end{array}$ \\
\hline CARACTERES GERAIS & $\begin{array}{l}\text { E árvore de grande porte, sendo freqüente nos } \\
\text { igapós e nas margens dos rios. A madeira } \\
\text { apresenta cerne amarelo-vivo quando recém- } \\
\text { cortado, escurecendo para castanho-amarelado ou } \\
\text { castanho-claro rosado; alburno esbranquiçado ou } \\
\text { cinza; raios no topo finos e numerosos, visíveis a } \\
\text { olho nu; na face tangencial são baixos e } \\
\text { irregularmente dispostos; grã um tanto regular; } \\
\text { superficie lustrosa quando polida; gosto amargo. }\end{array}$ \\
\hline DURABILIDADE NATURAL & $\begin{array}{l}\text { O cerne é considerado como durável a } \\
\text { moderadamente durável. }\end{array}$ \\
\hline TRATAMENTO PRESERVANTE & $\begin{array}{l}\text { Apresenta boa permeabilidade em tratamento de } \\
\text { CAA-A, sob pressão. }\end{array}$ \\
\hline DADOS SEGUNDO AUTOR & LOUREIRO (1968); CAMARGOS et al (1997). \\
\hline \multicolumn{2}{|l|}{ TEXTURA DA ESPÉCIE } \\
\hline \multicolumn{2}{|r|}{ Corte Longitudinal } \\
\hline
\end{tabular}


Tabela 3.10 - Descrição da espécie Angico-Preto

\begin{tabular}{|c|c|}
\hline $\begin{array}{c}\text { Piptadenia Macrocarpa } \\
\text { Nome científico } \\
\end{array}$ & $\begin{array}{c}\text { ANGICO PRETO } \\
\text { Nome comum } \\
\text { Mimosaceae } \\
\text { Família } \\
\end{array}$ \\
\hline OUTROS NOMES COMUNS & $\begin{array}{l}\text { Angico, angico-bravo, angico-vermelho, cambuí- } \\
\text { ferro, angico-preto-rajado, angico-rajado, } \\
\text { guarapiraca; na região oeste do Paraguai é } \\
\text { conhecida por cebil-colorado, curupay. }\end{array}$ \\
\hline ZONAS DE MAIOR OCORRÊNCIA & $\begin{array}{l}\text { De ampla distribuição geográfica, desde o Estado } \\
\text { do MA até SP, incluindo o nordeste (caatinga) e } \\
\text { Brasil central, Estado de MG, oeste de SP, sul do } \\
\text { Estado do MS, MT e RO. Também é de ocorrência } \\
\text { no Peru, Bolívia, na região norte da Argentina e } \\
\text { oeste do Paraguai. }\end{array}$ \\
\hline CARACTERES GERAIS & $\begin{array}{l}\text { As árvores atingem na mata } 30 \mathrm{~m} \times 90 \mathrm{~cm} \text {. É } \\
\text { pequena no cerrado e caatinga, com ca. } 3-10 \mathrm{~m} \text {, } \\
\text { podendo atingir } 15 \mathrm{~m} \times(30-50 \mathrm{~cm}) \text {, fuste retilíneo. } \\
\text { A madeira tem cerne castanho-amarelado quando } \\
\text { recém-cortado, passando pela cor castanho- } \\
\text { avermelhado, escurecendo para vermelho- } \\
\text { queimado, apresenta abundantes veios ou manchas } \\
\text { arroxeadas; grã irregular a revessa; textura média; } \\
\text { superficie pouco lustrosa e irregularmente áspera; } \\
\text { cheiro imperceptível; gosto ligeiramente } \\
\text { adstringente. }\end{array}$ \\
\hline DURABILIDADE NATURAL & Apresenta alta resistência ao apodrecimento. \\
\hline TRATAMENTO PRESERVANTE & $\begin{array}{l}\text { Em tratamento sob pressão demonstrou ter baixa } \\
\text { permeabilidade às soluções preservantes. }\end{array}$ \\
\hline DADOS SEGUNDO AUTOR & CHIMELO \& MAINIERI (1989); RIZZINI (1971). \\
\hline
\end{tabular}

TEXTURA DA ESPÉCIE

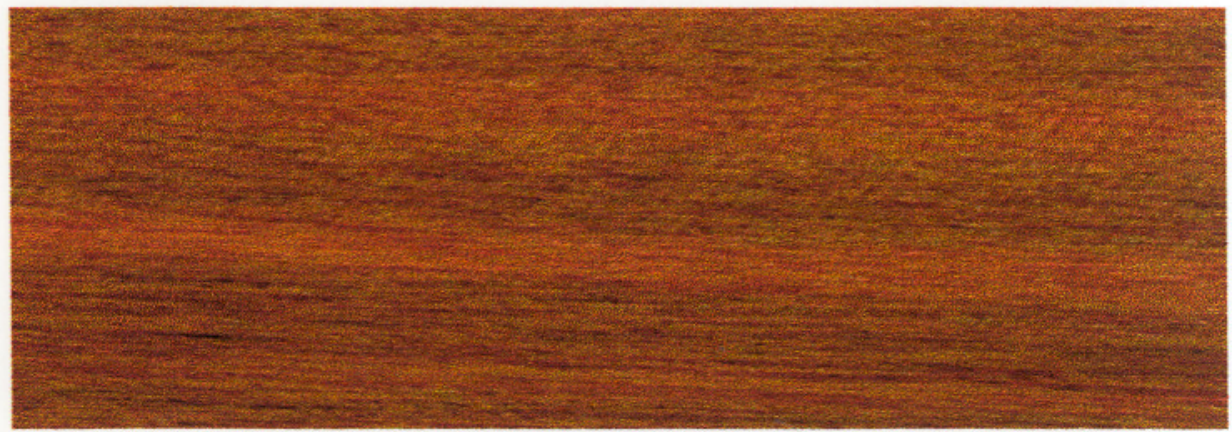

Corte Longitudinal 
Tabela 3.11 - Descrição da espécie Branquilho

\begin{tabular}{l|l}
\hline $\begin{array}{l}\text { Terminalia sp } \\
\text { Nome científico }\end{array}$ & $\begin{array}{l}\text { BRANQUILHO } \\
\text { Nome comum } \\
\text { Combretaceae } \\
\text { Família }\end{array}$ \\
\hline \hline OUTROS NOMES COMUNS & $\begin{array}{l}\text { Cuiarana taninbuca, tanibuca, periquiteira, } \\
\text { mirindinga, carará. }\end{array}$ \\
\hline ZONAS DE MAIOR OCORRENCIA & $\begin{array}{l}\text { Estados do AM, PA, MT. } \\
\text { Zona de coleta }\end{array}$ \\
\hline CARACTERES GERAIS & $\begin{array}{l}\text { Cerne de coloração pardo-claro-olivácea ou } \\
\text { amarelo-claro-oliváceo, com veios mais escuros } \\
\text { presentes; camadas de crescimento demarcadas por } \\
\text { zonas fibrosas mais escuras; raios visíveis só sob } \\
\text { lente no topo e na face tangencial; grã direita ou } \\
\text { revessa; textura fina a média; brilho moderado; } \\
\text { cheiro agradável quando recém-cortado e } \\
\text { imperceptível após secagem. }\end{array}$ \\
\hline DURABILIDADE NATURAL & $\begin{array}{l}\text { Alta resistência a cupins, resistência moderada ao } \\
\text { ataque de fungos apodrecedores e a brocas } \\
\text { marinhas. }\end{array}$ \\
\hline DADOS SEGUNDO AUTOR & $\begin{array}{l}\text { Alburno de moderada permeabilidade ao creosoto, } \\
\text { cerne apresenta impermeabilidade ao CCA-A, } \\
\text { mesmo em tratamento sob pressão. }\end{array}$ \\
\hline \hline & \begin{tabular}{l} 
MAINIERI (1983); CAMARGos et al (1997). \\
\hline TRATENTO PRESERVANTE
\end{tabular} \\
\hline
\end{tabular}

TEXTURA DA ESPÉCIE

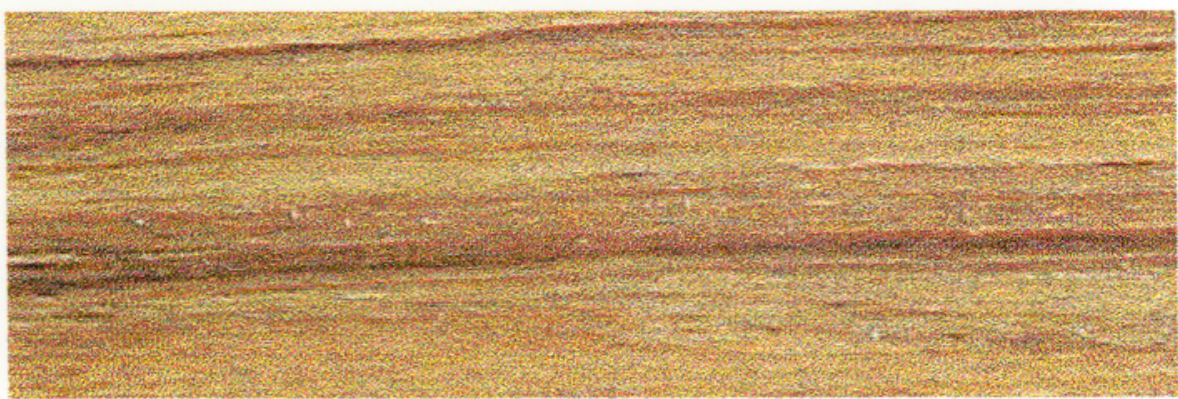

Corte Longitudinal 
Tabela 3.12 - Descrição da espécie Cafearana

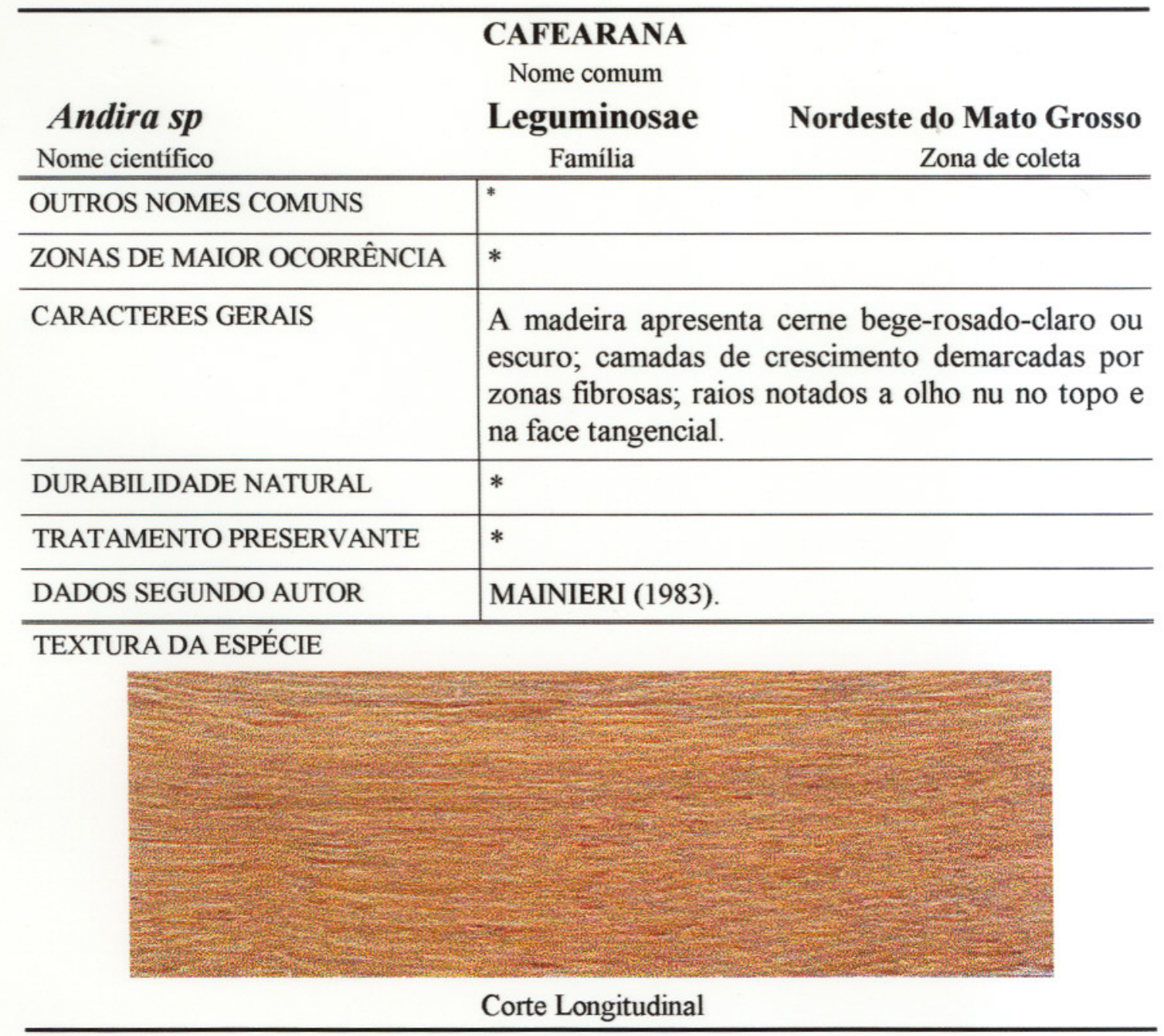

"Dado desconhecido. 
Tabela 3.13 - Descrição da espécie Canafístula

\begin{tabular}{|c|c|}
\hline $\begin{array}{l}\text { Cássia ferruginea } \\
\text { Nome científico }\end{array}$ & $\begin{array}{l}\text { CANAFÍSTULA } \\
\text { Nome comum } \\
\text { Caesalpiniaceae } \\
\text { Família } \\
\end{array}$ \\
\hline OUTROS NOMES COMUNS & $\begin{array}{l}\text { O nome canafistula, no setor comercial é } \\
\text { comumente aplicado à madeira de guarucaia, } \\
\text { peltophorum vogelianum walp, principalmente na } \\
\text { região do oeste do Estado do PA, devido à } \\
\text { provável influência do Paraguai, onde a espécie p. } \\
\text { dubium (spreng.) taub é conhecida por canafistula } \\
\text { ou ibirapitá. Em estudos realizados demonstram } \\
\text { que estas duas espécies têm a estrutura anatômica } \\
\text { muito semelhante, o que ocorre também com os } \\
\text { caracteres gerais: peso, cor, aspecto, grã, etc. }\end{array}$ \\
\hline ZONAS DE MAIOR OCORRÊNCIA & $\begin{array}{l}\text { Estados do CE até o PA; Estado do MT e no } \\
\text { interior dos Estados de MG, SP e PA. }\end{array}$ \\
\hline CARA CTERES GERAIS & $\begin{array}{l}\text { As árvores atingem } 10-20 \mathrm{~m} \text { e fornece toras de } \\
8-10 \mathrm{~m} \times 50-70 \mathrm{~cm} \text {. Cerne variável do bege- } \\
\text { rosado-claro ao escuro, e do castanho-claro ao } \\
\text { avermelhado; alburno diferenciado, branco, } \\
\text { levemente rosado; grã irregular; textura média; } \\
\text { superficie lustrosa medianamente lisa; cheiro e } \\
\text { gosto imperceptíveis. }\end{array}$ \\
\hline DURABILIDADE NATURAL & $\begin{array}{l}\text { Moderada resistência ao ataque de organismos } \\
\text { xilófagos. }\end{array}$ \\
\hline TRATAMENTO PRESERVANTE & $\begin{array}{l}\text { Baixa permeabilidade às soluções preservantes, } \\
\text { mesmo sob pressão, devido à presença de poros } \\
\text { parcialmente obstruídos por óleo e resina. }\end{array}$ \\
\hline DADOS SEGUNDO AUTOR & CHIMELO \& MAINIERI (1989); RIZZINI (1971). \\
\hline
\end{tabular}

TEXTURA DA ESPÉCIE

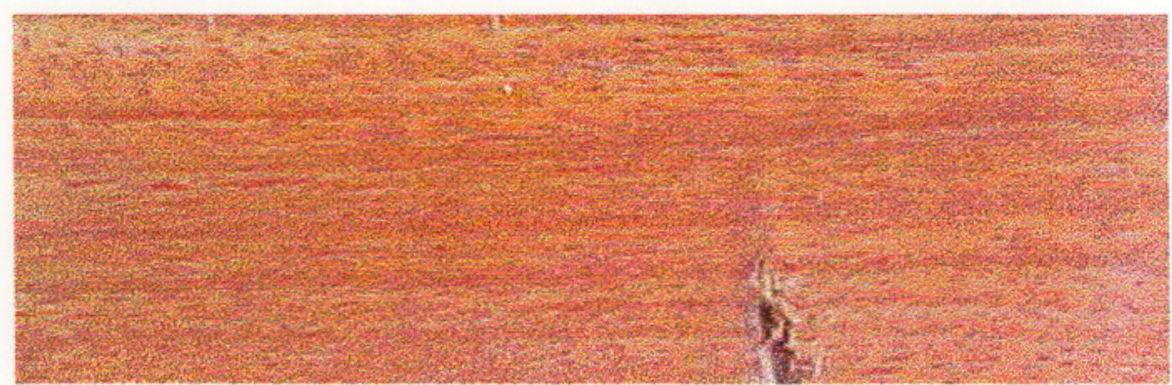

Corte Longitudinal 
Tabela 3.14 - Descrição da espécie Casca Grossa

\begin{tabular}{|c|c|c|}
\hline$\stackrel{\left({ }^{* *}\right)}{\text { Nome científico }}$ & $\begin{array}{c}\text { ASCA GROSSA } \\
\text { Nome comum } \\
(* *) \\
\text { Família }\end{array}$ & $\begin{array}{c}\text { Nordeste do Mato Grosso } \\
\text { Zona de coleta }\end{array}$ \\
\hline OUTROS NOMES COMUNS & ${ }^{*}$ & \\
\hline ZONAS DE MAIOR OCORRÊNCIA & $*$ & \\
\hline CARACTERES GERAIS & * & \\
\hline DURABILIDADE NATURAL & $*$ & \\
\hline TRATAMENTO PRESERVANTE & $*$ & \\
\hline DADOS SEGUNDO AUTOR & * & \\
\hline \multicolumn{3}{|l|}{ TEXTURA DA ESPÉCIE } \\
\hline 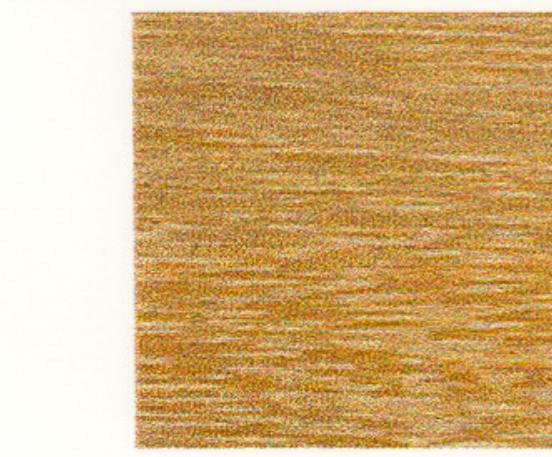 & 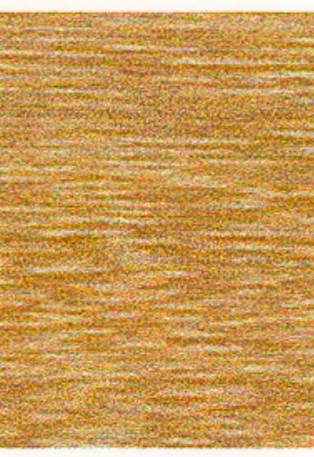 & (2) \\
\hline \multicolumn{3}{|c|}{ Corte Longitudinal } \\
\hline
\end{tabular}

\footnotetext{
"* Dado não conclusivo dos caracteres anatômicos da espécie estudada.

"Dado desconhecido.
} 
Tabela 3.15 - Descrição da espécie Castelo

\section{CASTELO}

Nome comum

Gossypiospermun praecox Flacourtiaceae Nordeste do Mato Grosso Nome científico

Família

Zona de coleta

\begin{tabular}{l|l}
\hline OUTROS NOMES COMUNS & $*$ \\
\hline ZONAS DE MAIOR OCORRENCIA & Estados do MT e MS. \\
\hline CARACTERES GERAIS & $\begin{array}{l}\text { Cerne amarelo-claro a pardo-claro levemente } \\
\text { amarelado; em algumas espécies podem ocorrer } \\
\text { manchas irregulares de cor pardo-escura; } \\
\text { camadas de crescimento indistintas, demarcadas } \\
\text { por zonas fibrosas. }\end{array}$ \\
\hline DURABILIDADE NATURAL & $*$ \\
\hline TRATAMENTO PRESERVANTE & $*$ \\
\hline DADOS SEGUNDO AUTOR & MAINIERI (1983). \\
\hline \hline
\end{tabular}

TEXTURA DA ESPÉCIE

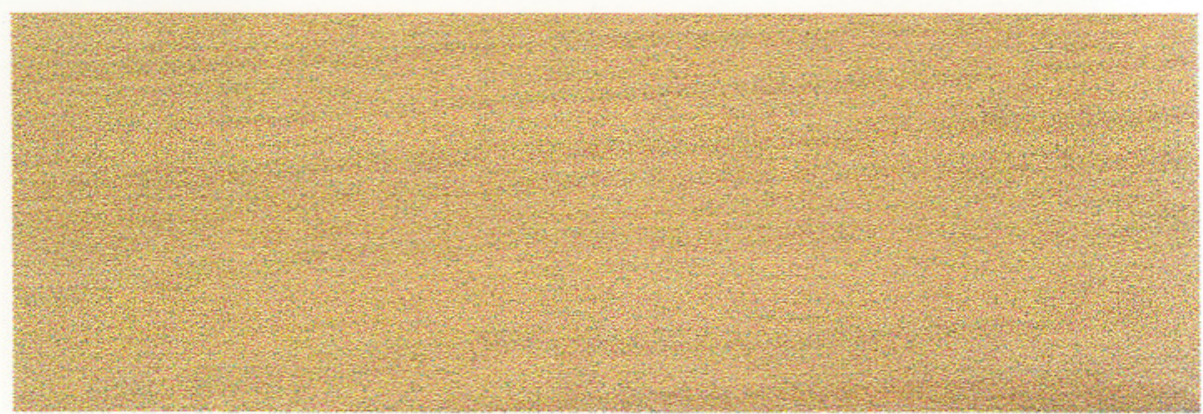

Corte Longitudinal

"Dado desconhecido. 
Tabela 3.16 - Descrição da espécie Catanudo

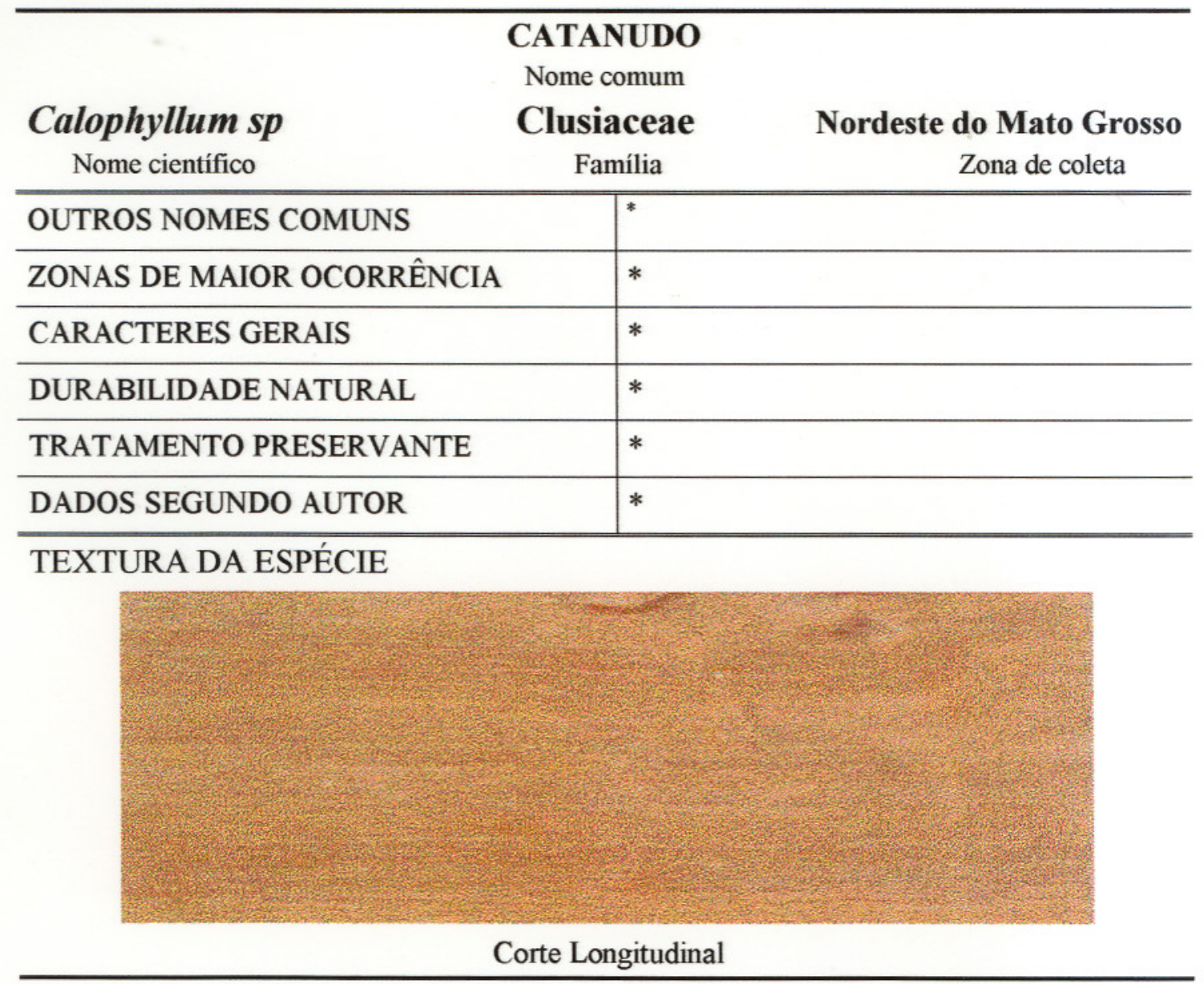

"Dado desconhecido. 
Tabela 3.17 - Descrição da espécie Cedro-Amargo

\section{CEDRO-AMARGO}

Nome comum

Cedrella sp

Nome científico

OUTROS NOMES COMUNS

\section{Meliaceae}

Família
Sul de Roraima

Zona de coleta

Conforme a variação do tom da cor castanha, será especificados por cedro-branco, cedro-rosa, cedrovermelho. No comércio internacional, as madeiras do Cedrela são conhecidas por Cedar, Ceder ou Cedro.

ZONAS DE MAIOR OCORRÊNCIA

O gênero Cedrela, no Brasil é representado por variadas espécies, mas apenas três se destacam como principais: - C. odorata 1., comum na floresta Amazônica, estendendo até o norte do Estado do ES; - C. angustifólia S. \& Moc. na região costeira, desde o Estado do ES até a região sul do País; - C. fissilis Vell., em matas do interior, desde o Estado de MG até o Estado do RS.

É comum em terra firme e várzeas altas, em florestas úmidas da região costeira. A madeira apresenta cerne variando do bege-rosado-escuro a castanho-claro-rosado, indo até o castanhoavermelhado; textura grossa; grã direita ou ligeiramente ondulada; superficie lustrosa e com reflexos dourados; cheiro característico, agradável, gosto ligeiramente amargo.

\begin{tabular}{l|l}
\hline DURABILIDADE NATURAL & $\begin{array}{l}\text { Resistência moderada ao ataque de organismos } \\
\text { xilófagos. }\end{array}$ \\
\hline TRATAMENTO PRESERVANTE & $\begin{array}{l}\text { Em tratamento sob pressão, em ensaios de } \\
\text { laboratório, demonstrou ser de baixa } \\
\text { permeabilidade às soluções preservantes. }\end{array}$ \\
\hline DADOS SEGUNDO AUTOR & CHIMELO \& MAINIERI (1989). \\
\hline \hline
\end{tabular}


Tabela 3.18 - Descrição da espécie Cedrorana

\section{CEDRORANA}

Nome comum

\section{Cedrelinga Catenaeformis Legumin. Mimosoideae Sul de Roraima \\ Nome científico \\ Família \\ Zona de coleta}

\begin{tabular}{l|l}
\hline OUTROS NOMES COMUNS & $\begin{array}{l}\text { Cedrarana, cedro-branco, cedroarana, cedromara, } \\
\text { taperibá-açu, tornillo. }\end{array}$ \\
\hline ZONAS DE MAIOR OCORRÊNCIA & $\begin{array}{l}\text { No Brasil esta espécie é presente nos Estados do } \\
\text { AM e do PA, RO, MT, MA, AP. Também é } \\
\text { presente no Peru e Colômbia. }\end{array}$ \\
\hline CARACTERES GERAIS & $\begin{array}{l}\text { Árvore de grande porte da Amazônia, com } \\
\text { diâmetro de fuste de até 2 m. A madeira apresenta } \\
\text { cerne vermelho róseo; alburno mais claro e } \\
\text { lustroso; grã direita; textura grossa; lisa ao tato; } \\
\text { pouco lustrosa; cheiro desagradável quando úmida; } \\
\text { gosto indistinto. }\end{array}$ \\
\hline DURABILIDADE NATURAL & $\begin{array}{l}\text { É moderadamente resistente a ataques de fungos e } \\
\text { insetos. }\end{array}$ \\
\hline TRATAMENTO PRESERVANTE & $\begin{array}{l}\text { Cerne e alburno dificeis de tratar com produtos } \\
\text { preservativos hidrossolúveis, mesmo em } \\
\text { tratamento sob pressão. }\end{array}$ \\
\hline DADOS SEGUNDO AUTOR & LOUREIRO (1968); CAMARGOS et al (1997). \\
\hline
\end{tabular}

TEXTURA DA ESPÉCIE

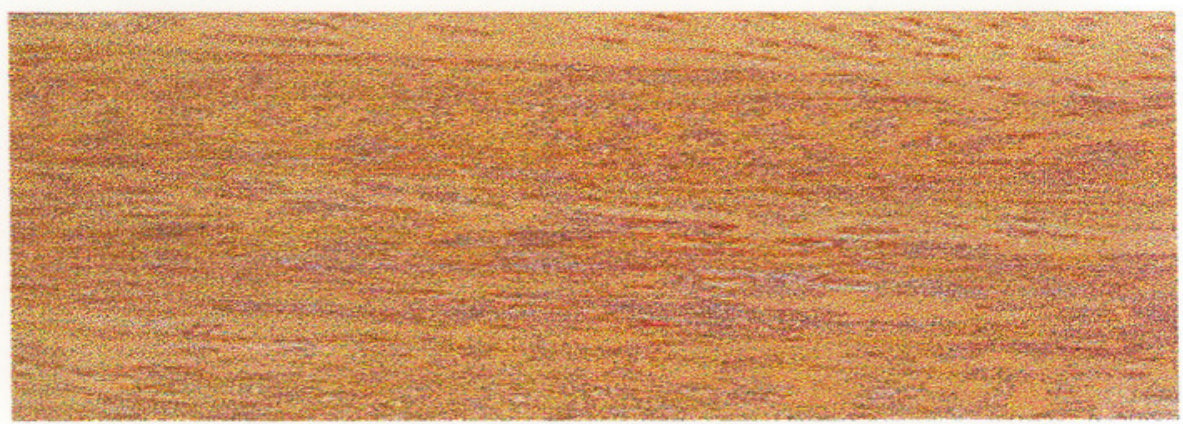

Corte Longitudinal 
Tabela 3.19 - Descrição da espécie Champanhe

\begin{tabular}{|c|c|}
\hline $\begin{array}{l}\text { Dipteryx sp } \\
\text { Nome científico }\end{array}$ & $\begin{array}{l}\text { CHAMPANHE } \\
\text { Nome comum } \\
\text { inosae Papilionoideae } \\
\quad \text { Família }\end{array}$ \\
\hline OUTROS NOMES COMUNS & $\begin{array}{l}\text { Baru, cumbari (AM), cumaru.amarelo, champagne, } \\
\text { cumaru-verdadeiro, cumaru da folha grande, ipê- } \\
\text { cumaru, muimapagé, sarrapia (AM). }\end{array}$ \\
\hline ZONAS DE MAIOR OCORRÊNCIA & É presente desde os Estados do AM, AC até o MA. \\
\hline CARACTERES GERAIS & $\begin{array}{l}\text { Árvore de } 30 \mathrm{~m} \text { de altura, na mata de várzea alta e } \\
\text { terra firme. Cerne diferenciado do alburno, de cor } \\
\text { mais clara, variando do bege-amarelado, } \\
\text { eventualmente rosado a castanho-claro-amarelado; } \\
\text { camadas de crescimento pouco distintas, } \\
\text { demarcadas por zonas fibrosas; grã revessa; textura } \\
\text { média a fina; superficie de pouco brilho e lisa ao } \\
\text { tato; aspecto fibroso atenuado; cheiro e gosto } \\
\text { imperceptíveis. }\end{array}$ \\
\hline DURABILIDADE NATURAL & $\begin{array}{l}\text { Resistente a fungos apodrecedores, cupins, brocas } \\
\text { marinhas. Em solos bem drenados sua durabilidade } \\
\text { varia de } 10 \text { a } 22 \text { anos. }\end{array}$ \\
\hline TRATAMENTO PRESERVANTE & $\begin{array}{l}\text { Baixa permeabilidade ao creosoto e CCA-A, } \\
\text { mesmo em tratamento sob pressão. }\end{array}$ \\
\hline DADOS SEGUNDO AUTOR & $\begin{array}{l}\text { MAINIERI, C. (1983); CHIMELO \& MAINIERI } \\
\text { (1989); CAMARGOS et al (1997). }\end{array}$ \\
\hline
\end{tabular}

TEXTURA DA ESPÉCIE

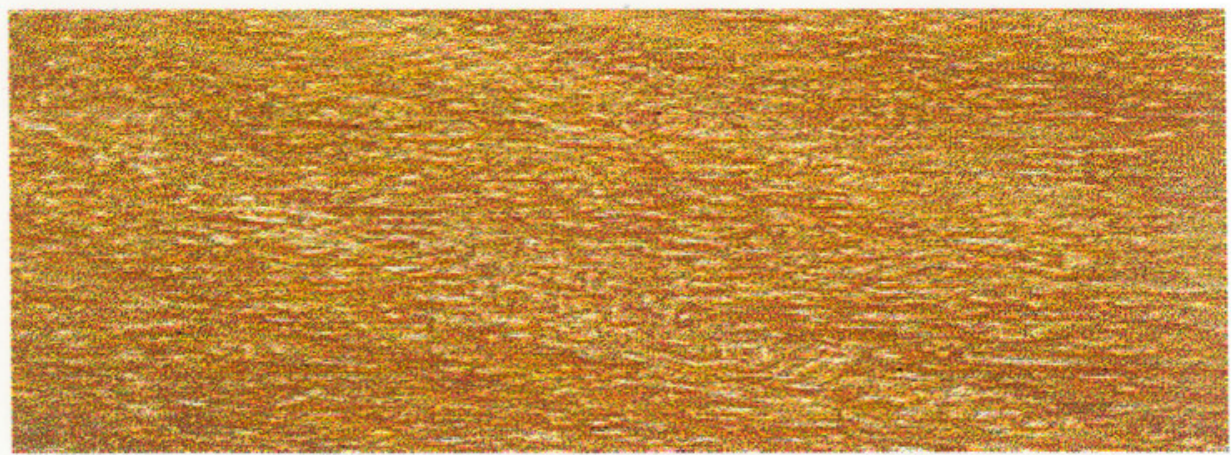

Corte Longitudinal 
Tabela 3.20 - Descrição da espécie Cupiúba

\begin{tabular}{l|l}
\hline $\begin{array}{l}\text { Goupia glabra } \\
\text { Nome científico }\end{array}$ & \multicolumn{1}{c}{$\begin{array}{l}\text { CUPIÚBA } \\
\text { Nome comum } \\
\text { Goupiaceae } \\
\text { Familia }\end{array}$} \\
\hline \hline OUTROS NOMES COMUNS & $\begin{array}{l}\text { Cachaceiro, copiúba, cupiúba-rosa, peniqueiro, } \\
\text { peroba-fedida peroba-do-norte (MT), kopei, } \\
\text { cabukalli. }\end{array}$ \\
\hline ZONAS DE MAIOR OCORRÊNCIA & $\begin{array}{l}\text { Sul de Roraima } \\
\text { Éna de coleta }\end{array}$ \\
\hline CARACTERES GERAIS & $\begin{array}{l}\text { A madeira apresenta cerne e alburno pouco } \\
\text { distintos, marrom-avermelhado-claro a castanho- } \\
\text { rosado; anéis de crescimento pouco distintos; grã } \\
\text { revessa; textura média; brilho ausente e cheiro } \\
\text { desagradável, quando úmida. }\end{array}$ \\
\hline DURABILIDADE NATURAL & $\begin{array}{l}\text { Resistente a ataque de cupins de madeira seca e } \\
\text { pouco resistente a brocas marinhas. Testes de } \\
\text { laboratório indicaram boa resistência ao } \\
\text { apodrecimento. }\end{array}$ \\
\hline TRATAMENTO PRESERVANTE & $\begin{array}{l}\text { Apresenta moderada permeabilidade ao creosoto } \\
\text { e CCA-A, quando tratada sob pressão. }\end{array}$ \\
\hline \hline
\end{tabular}

TEXTURA DA ESPÉCIE

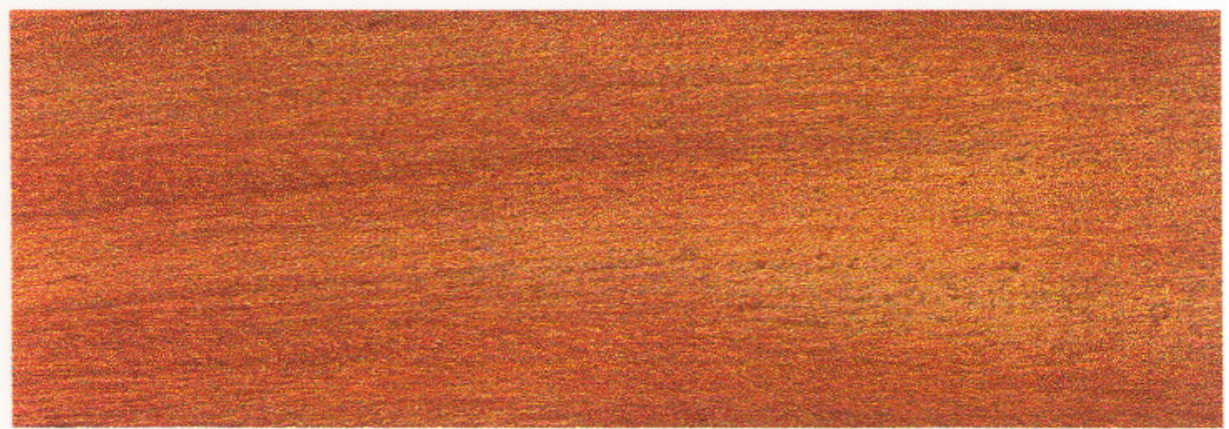

Corte Longitudinal 
Tabela 3.21 - Descrição da espécie Cutiúba

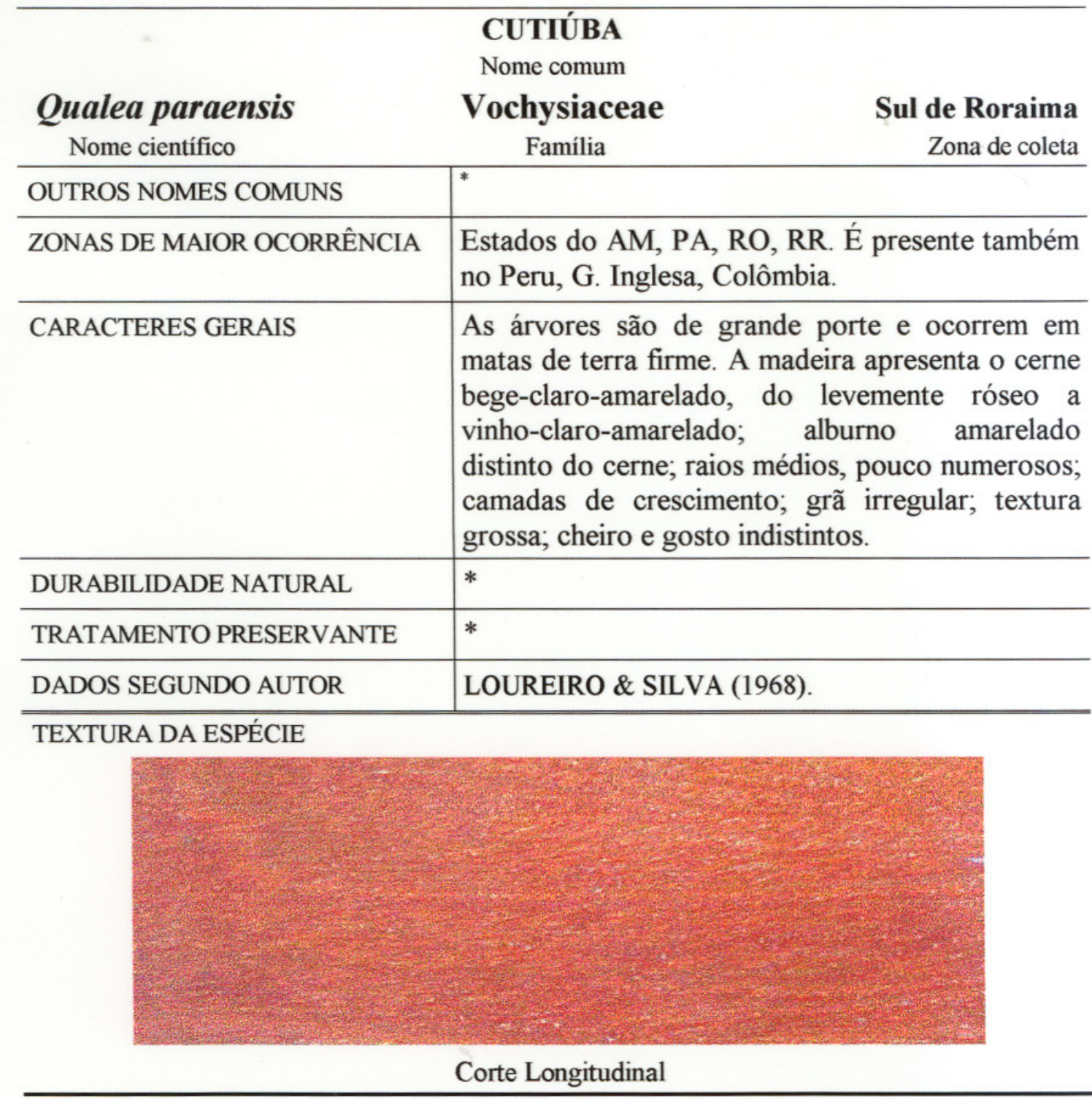

"Dado desconhecido. 
Tabela 3.22 - Descrição da espécie Garapa

\begin{tabular}{|c|c|}
\hline $\begin{array}{l}\text { Apuleia leiocarpa } \\
\text { Nome científico }\end{array}$ & $\begin{array}{cc}\text { GARAPA } & \\
\text { Nome comum } & \\
\text { Caesalpiniaceae } & \text { Norte do Mato Grosso } \\
\text { Família } & \text { Zona de coleta }\end{array}$ \\
\hline OUTROS NOMES COMUNS & $\begin{array}{l}\text { Amarelinho, grapiapunha, gema-de-ovo, grápia, } \\
\text { jataí-amarelo. }\end{array}$ \\
\hline ZONAS DE MAIOR OCORRÊNCIA & $\begin{array}{l}\text { As espécies do gênero Apuleia leiocarpa são } \\
\text { presentes em toda mata brasileira, desde o Estado } \\
\text { do AM até o Estado do RS. Estados do PA, MT, } \\
\text { MS, RO, GO, sul do Estado da BA, norte do } \\
\text { Estado do PR, Estado de SC. Também é presente } \\
\text { no Uruguai, Argentina, e Paraguai. }\end{array}$ \\
\hline CARACTERES GERAIS & $\begin{array}{l}\text { A madeira apresenta cerne que vai do amarelado, } \\
\text { bege-amarelado ou amarelo levemente rosado, até } \\
\text { ao róseo-acastanhado, uniforme; alburno } \\
\text { diferenciado, branco-amarelado; grã irregular para } \\
\text { revessa; superficie lustrosa e lisa ao tato; cheiro e } \\
\text { gosto imperceptíveis. }\end{array}$ \\
\hline DURABILIDADE NATURAL & $\begin{array}{l}\text { Em observações práticas, nas zonas de ocorrência, } \\
\text { apresenta moderada resistência ao apodrecimento e } \\
\text { baixa resistência ao ataque de cupins de madeira } \\
\text { seca. }\end{array}$ \\
\hline TRATAMENTO PRESERVANTE & $\begin{array}{l}\text { Em ensaios de laboratório, demonstrou ter baixa } \\
\text { permeabilidade às soluções preservantes, mesmo } \\
\text { quando submetida à impregnação, em tratamento } \\
\text { sob pressão. }\end{array}$ \\
\hline DADOS SEGUNDO AUTOR & CHIMELO \& MAINIERI (1989). \\
\hline
\end{tabular}

TEXTURA DA ESPÉCIE

Corte Longitudinal 
Tabela 3.23 - Descrição da espécie Goiabão

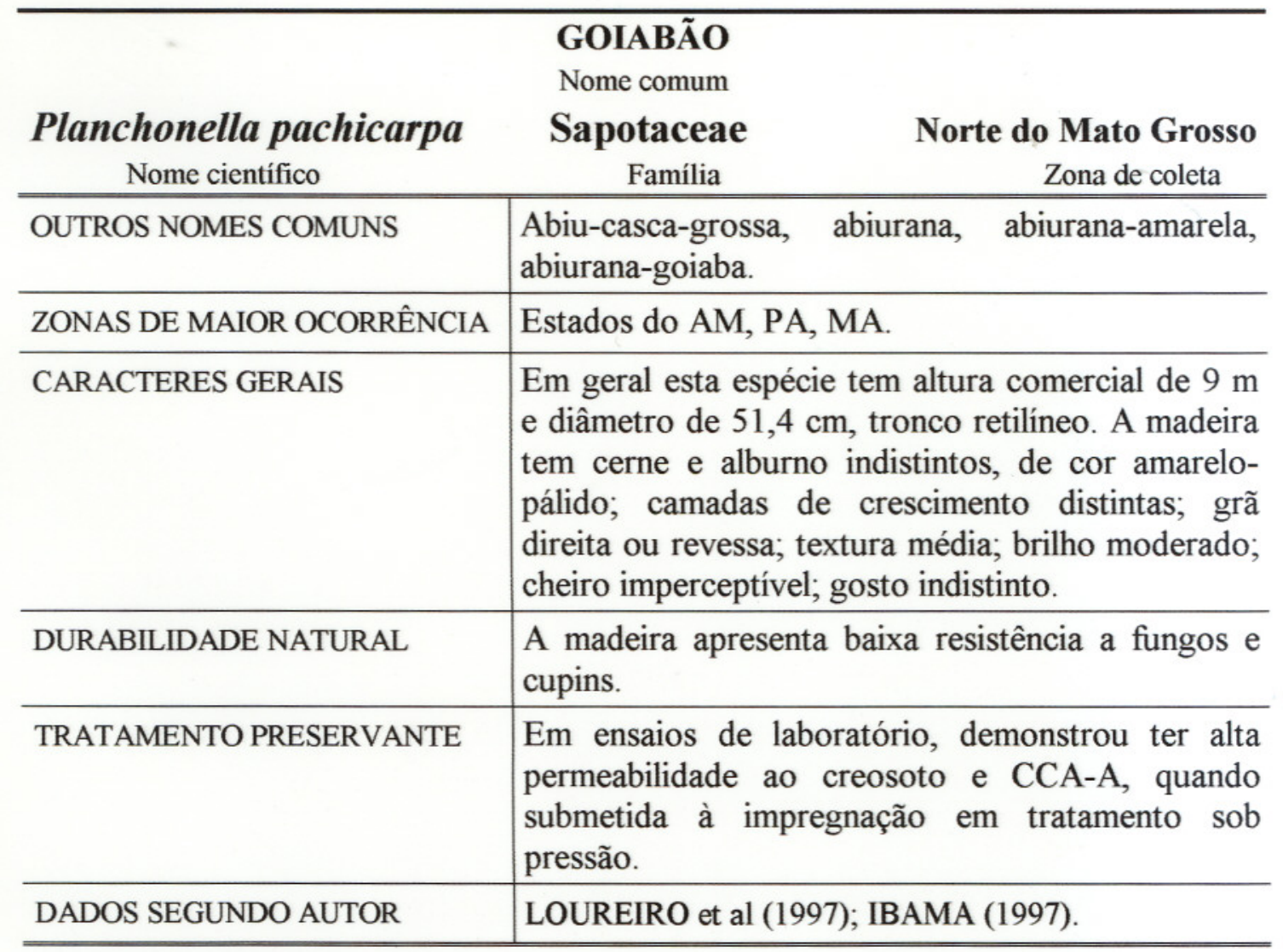

TEXTURA DA ESPÉCIE

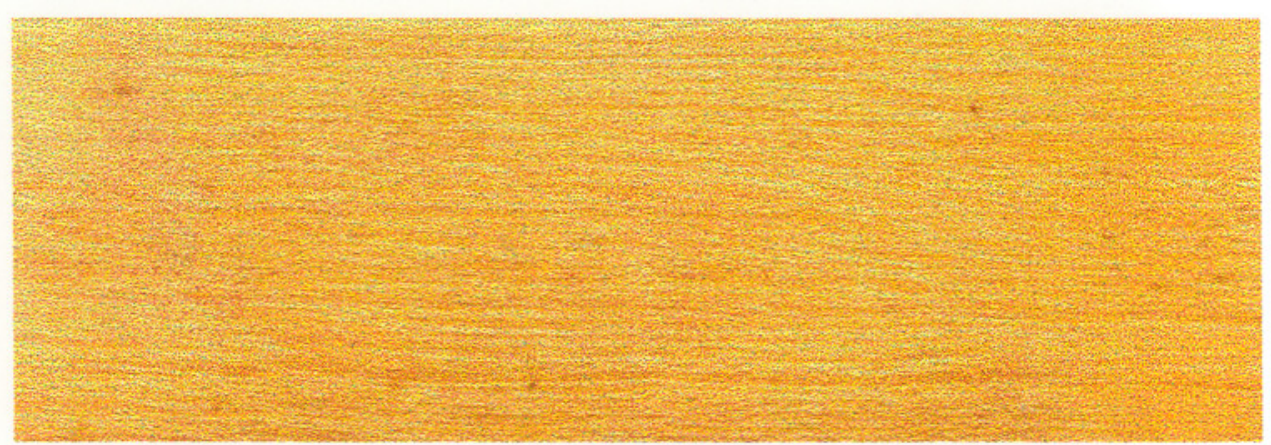

Corte Longitudinal 
Tabela 3.24 - Descrição da espécie Guaiçara

\begin{tabular}{|c|c|}
\hline $\begin{array}{l}\text { Ferreirea spectabilis } \\
\text { Nome científico }\end{array}$ & $\begin{array}{c}\text { GUAIÇARA } \\
\text { Nome comum } \\
\text { Leguminosae } \\
\text { Família }\end{array}$ \\
\hline OUTROS NOMES COMUNS & $\begin{array}{l}\text { Guaiçara (SP), (MT), (MS), (GO); macanaíba- } \\
\text { amarela (ES), BA). No Paraguai, taperyva-guasu. }\end{array}$ \\
\hline ZONAS DE MAIOR OCORRÊNCIA & $\begin{array}{l}\text { Estados do MT e sul do Estado do MS, sul de GO, } \\
\text { oeste do Estado de SP, norte e oeste do Estado do } \\
\text { PA atingindo até o oeste do Paraguai. Ocorre } \\
\text { ainda no Vale do Rio Doce, Estado de MG, } \\
\text { estendendo-se para o norte do Estado do ES e sul } \\
\text { da BA. }\end{array}$ \\
\hline CARACTERES GERAIS & $\begin{array}{l}\text { A madeira recém-cortada apresenta cerne amarelo- } \\
\text { dourado, passando a amarelo-claro e escurecendo } \\
\text { para o castanho com numerosas estrias mais } \\
\text { claras, às vezes apresentando vivos reflexos } \\
\text { alaranjados; grã irregular; superficie } \\
\text { irregularmente lustrosa, medianamente lisa ao tato, } \\
\text { de aspecto fibroso; cheiro imperceptível; gosto } \\
\text { ligeiramente amargo. }\end{array}$ \\
\hline DURABILIDADE NATURAL & $\begin{array}{l}\text { Boa resistência ao apodrecimento e ao ataque de } \\
\text { cupins de madeira seca. }\end{array}$ \\
\hline TRATAMENTO PRESERVANTE & ${ }^{*}$ \\
\hline DADOS SEGUNDO AUTOR & CHIMELO \& MAINIERI (1989). \\
\hline
\end{tabular}

TEXTURA DA ESPÉCIE

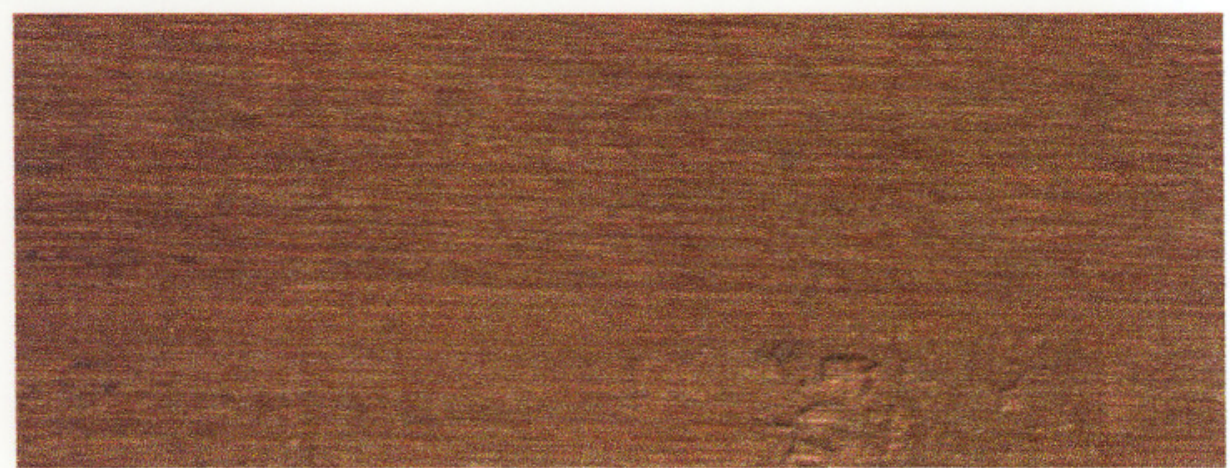

Corte Longitudinal

"Dado desconhecido. 
Tabela 3.25 - Descrição da espécie Guarucaia

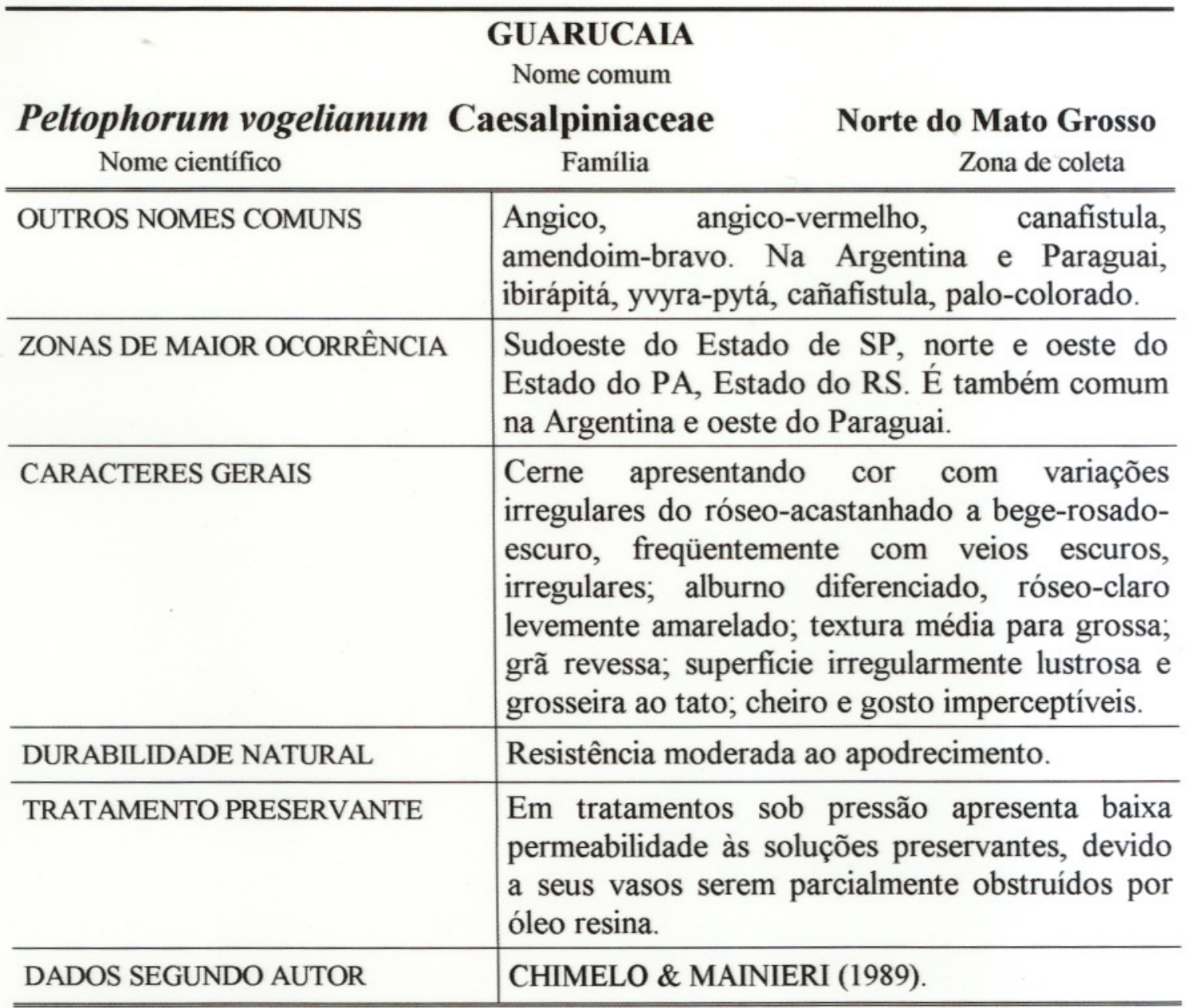

TEXTURA DA ESPÉCIE

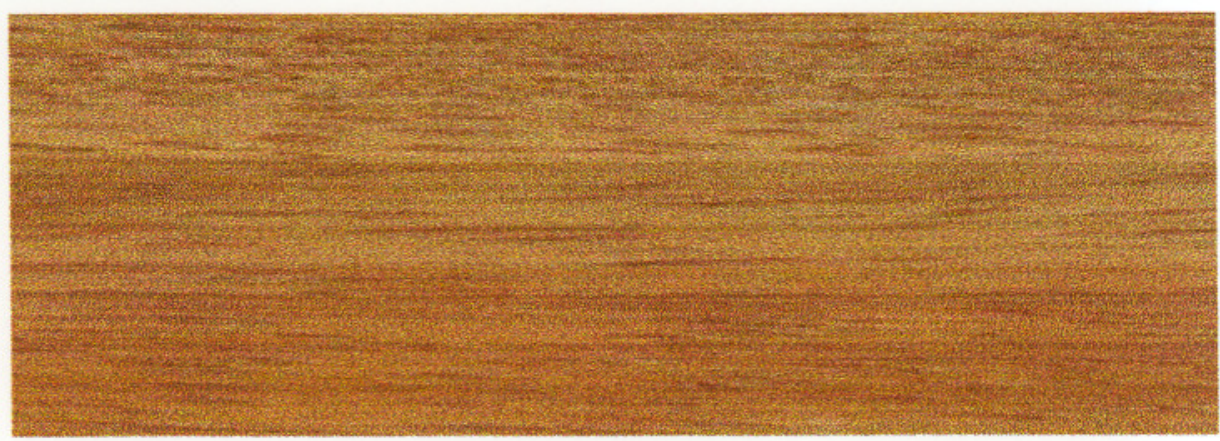

Corte Longitudinal 
Tabela 3.26 - Descrição da espécie Itaúba

\begin{tabular}{|c|c|}
\hline 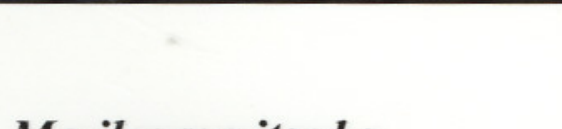 & $\begin{array}{l}\text { ITAÚ BA } \\
\text { Nome comum }\end{array}$ \\
\hline Mezilaurus itauba & Norte do Mato Grosso \\
\hline Nome científico & Zona de coleta \\
\hline OUTROS NOMES COMUNS & Itaúba, louro-itaúba, itaúba-vermelha. \\
\hline ZONAS DE MAIOR OCORRÊNCIA & $\begin{array}{l}\text { As espécies do gênero Mezilauros itauba ocorre no } \\
\text { Estado do AM, região do Rio Negro. Estado do PA, } \\
\text { região do Tocantins, estendendo ao norte até o } \\
\text { território do AP e Guianas e ao sul, a região norte } \\
\text { do Estado do MT e RO. }\end{array}$ \\
\hline CARACTERES GERAIS & $\begin{array}{l}\text { As árvores chegam a atingir } 40 \mathrm{~m} \times 80 \mathrm{~cm} \text {, quando } \\
\text { em floresta. Ocorre na terra firme, em solos } \\
\text { silicosos e argilo-silicosos não inundáveis. Em } \\
\text { locais arenosos ou pedregosos, não passa de uma } \\
\text { árvore pequena. A madeira apresenta cerne } \\
\text { amarelo-oliváceo quando recém-polido, tornando- } \\
\text { se pardo-havana-claro, escurecendo para pardo- } \\
\text { havana-escuro, uniforme; alburno pardo-amarelado; } \\
\text { grã ondulada ou revessa; superficie irregularmente } \\
\text { lustrosa e lisa ao tato; cheiro ligeiramente } \\
\text { adocicado; gosto imperceptível. }\end{array}$ \\
\hline DURABILIDADE NATURAL & $\begin{array}{l}\text { Em condições adversas é considerada de alta } \\
\text { resistência ao ataque de organismos xilófagos. }\end{array}$ \\
\hline TRATAMENTO PRESERVANTE & $\begin{array}{l}\text { Quando em tratamento sob pressão apresenta baixa } \\
\text { permeabilidade à impregnação e retenção de } \\
\text { soluções preservativas, devido aos poros serem } \\
\text { obstruídos por óleo-resina e tilos. }\end{array}$ \\
\hline DADOS SEGUNDO AUTOR & $\begin{array}{l}\text { RIZZINI (1971); SUDAM (1979); CHIMELO \& } \\
\text { MAINIERI (1989). }\end{array}$ \\
\hline
\end{tabular}

TEXTURA DA ESPÉCIE

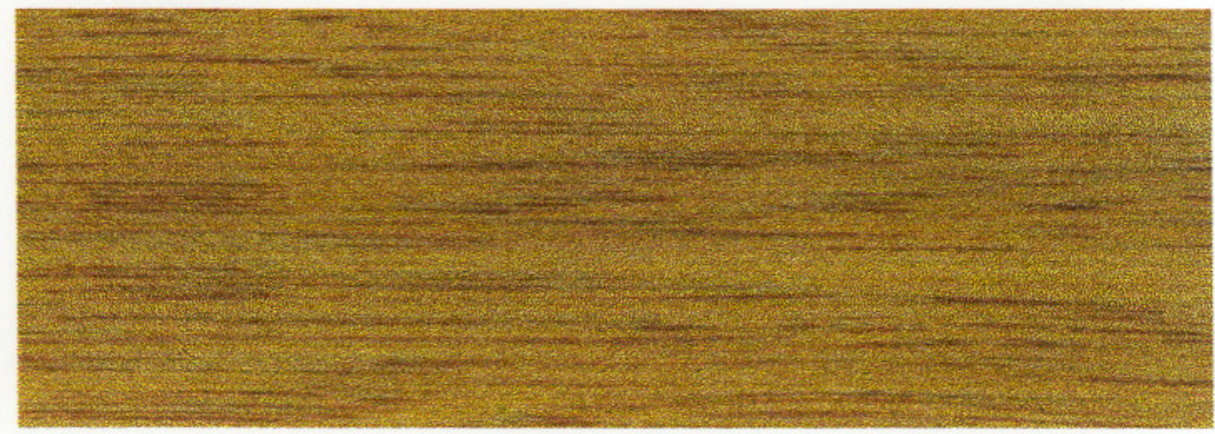

Corte Longitudinal 
Tabela 3.27 - Descrição da espécie Louro-Preto

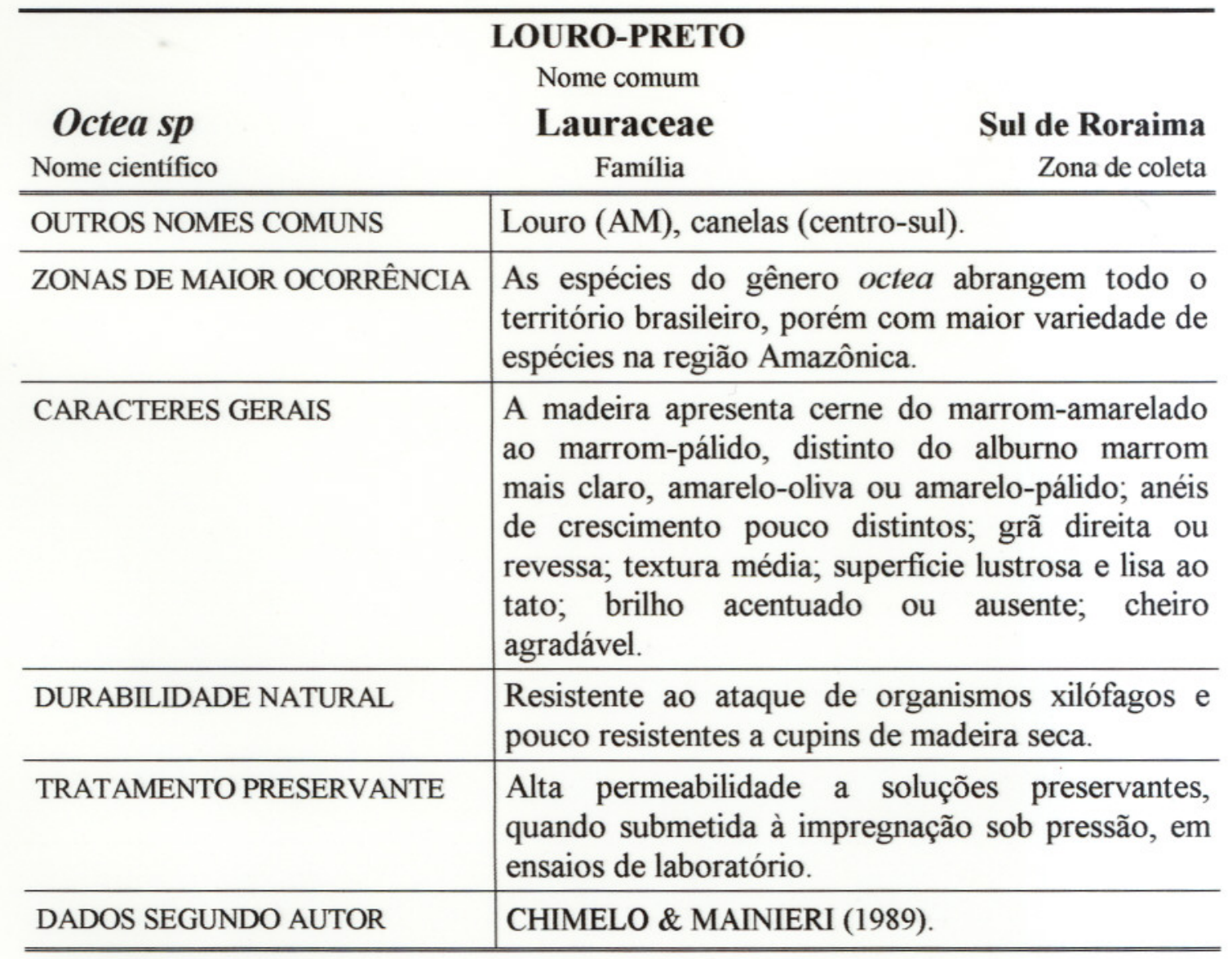

TEXTURA DA ESPÉCIE

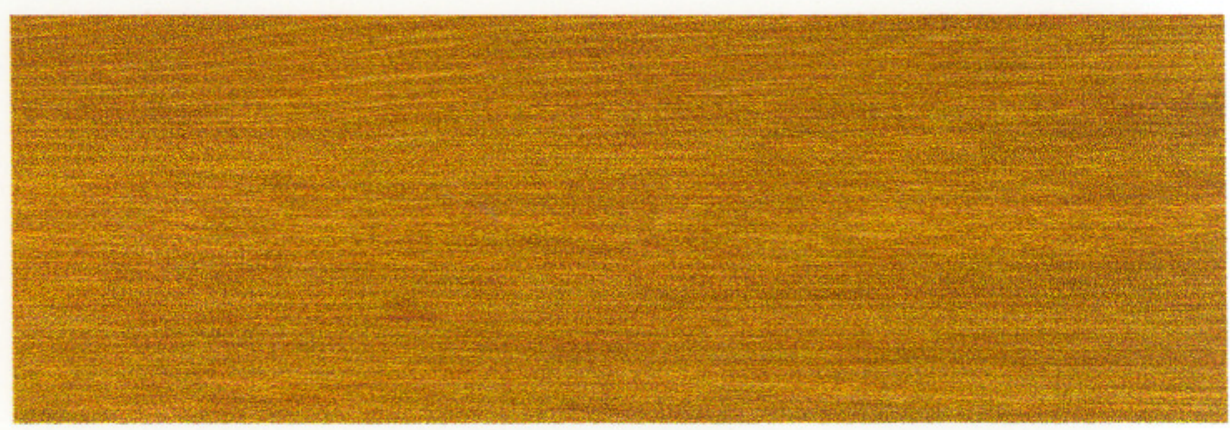


Tabela 3.28 - Descrição da espécie Mandioqueira

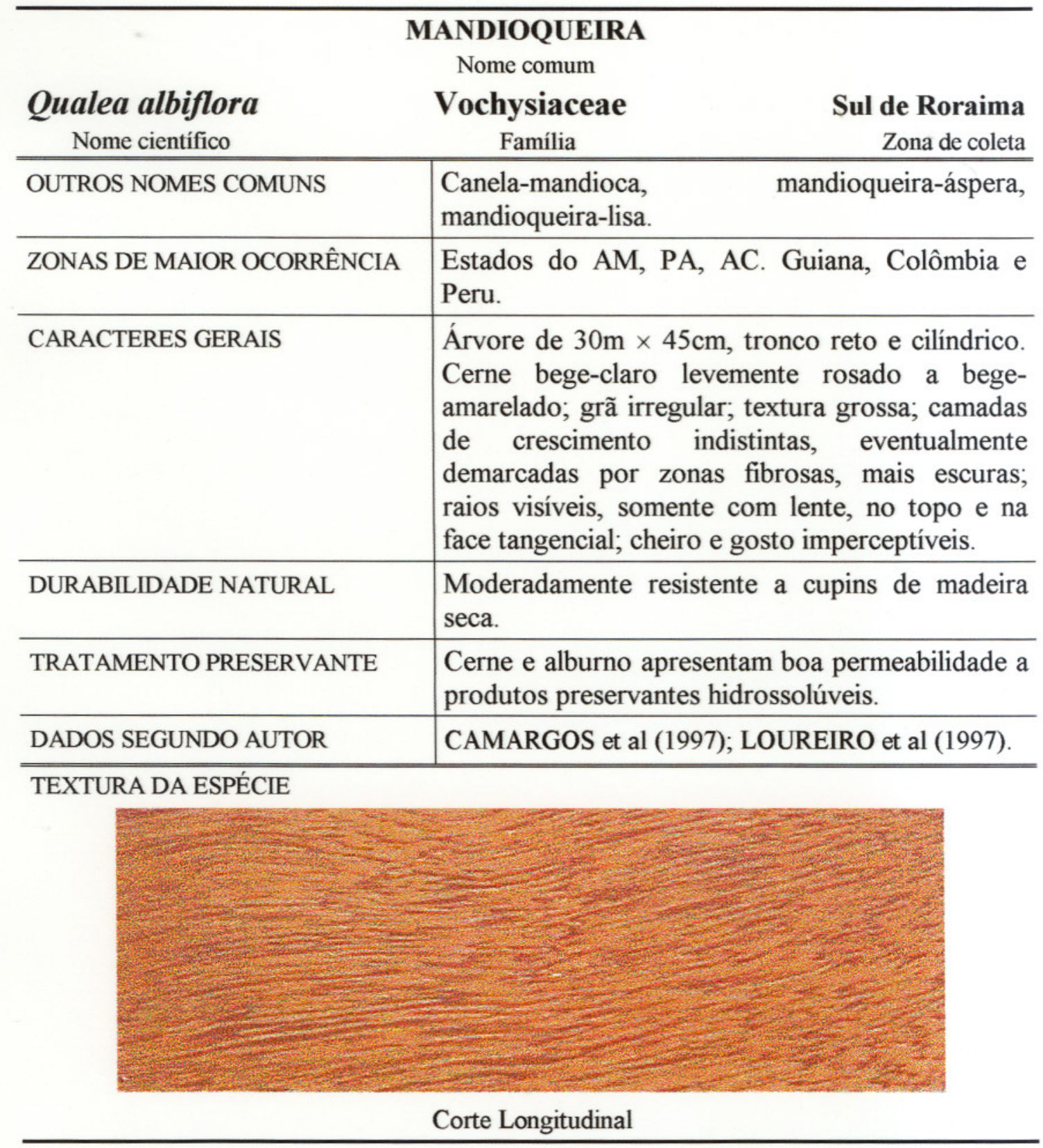


Tabela 3.29 - Descrição da espécie Oiticica-Amarela

\begin{tabular}{|c|c|}
\hline \multicolumn{2}{|c|}{$\begin{array}{l}\text { OITICICA-AMARELA } \\
\text { Nome comum }\end{array}$} \\
\hline Clarísia racemosa & Nordeste do Mato Grosso \\
\hline Nome científico & Zona de coleta \\
\hline OUTROS NOMES COMUNS & $\begin{array}{l}\text { É conhecida no Brasil por oiticica (BA), oiticica- } \\
\text { da-mata (PE ), guariúba-amarela (AM), recebe o } \\
\text { nome ainda de catruz, janitá, tatajuba-amarela. No } \\
\text { Equador, por moral-babo, moral-comida-de-mono, } \\
\text { sota, zota; no Peru, por capinuri, guariuba, tulpay. }\end{array}$ \\
\hline ZONAS DE MAIOR OCORRÊNCIA & $\begin{array}{l}\text { É freqüente em toda a Amazônia (mata de terra } \\
\text { firme argilosa, poucas vezes na várzea), no sul da } \\
\text { BA e norte do ES. Ocorre ainda, no vale do Rio } \\
\text { Doce e na zona da mata do Estado de MG e do } \\
\text { Estado de PE; rara no Estado do RJ. Estende-se até } \\
\text { o Equador, Bolívia e Peru. }\end{array}$ \\
\hline CARACTERES GERAIS & $\begin{array}{l}\text { Árvore de grande porte } 25-30 \mathrm{~m} \times 60-100 \mathrm{~cm} \text {, } \\
\text { podendo chegar a } 40 \mathrm{~m} \text { em matas virgens. O cerne } \\
\text { é amarelo-vivo quando verde, passando a castanho- } \\
\text { amarelado-escuro com o tempo de secagem, o } \\
\text { cerne é bem distinto do alburno que é amarelo- } \\
\text { claro; grã regular; textura média uniforme; } \\
\text { superficie lustrosa; ligeiramente áspera ao tato; sem } \\
\text { sabor, insípida; inodora. }\end{array}$ \\
\hline DURABILIDADE NATURAL & $\begin{array}{l}\text { Bastante durável quando não em contacto com o } \\
\text { solo. Baixa resistência a fungos e cupins de } \\
\text { madeira seca. }\end{array}$ \\
\hline TRATAMENTO PRESERVANTE & $\begin{array}{l}\text { Cerne não é tratável com creosoto e CCA-A, } \\
\text { mesmo sob pressão. }\end{array}$ \\
\hline DADOS SEGUNDO AUTOR & RIZZINI (1971); CHIMELO \& MAINIERI (1989). \\
\hline
\end{tabular}

TEXTURA DA ESPÉCIE

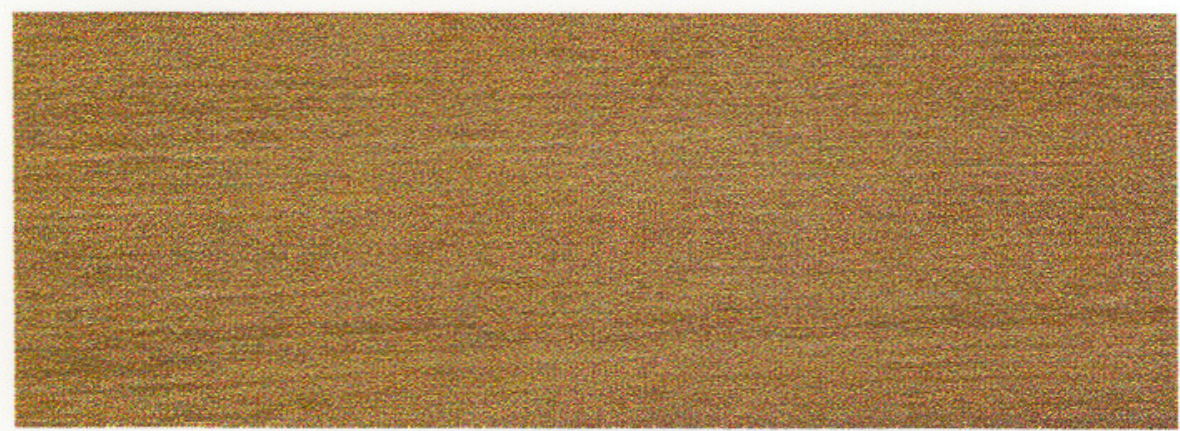

Corte Longitudinal 
Tabela 3.30 - Descrição da espécie Oiuchu

\begin{tabular}{l|l}
\hline $\begin{array}{l}\text { Pradosia sp } \\
\text { Nome científico }\end{array}$ & $\begin{array}{l}\text { OIUCHU } \\
\text { Nome comum } \\
\text { Sapotaceae } \\
\text { Família }\end{array}$ \\
\hline \hline OUTROS NOMES COMUNS & $\begin{array}{l}\text { Buranhém-de-casca-doce, } \\
\text { guranhém, ibiracém, imiracém, mantegueira, } \\
\text { merecem, pau-doce. }\end{array}$ \\
\hline ZONAS DE MAIOR OCORRÊNCIA & Estados do PA, AL, MG, ES, SP. \\
\hline CARACTERES GERAIS & $\begin{array}{l}\text { A madeira apresenta cerne pardo cinzentado } \\
\text { com nuanças róseas a pardo rosadas; camadas de } \\
\text { crescimento quase indistintas, demarcadas por } \\
\text { zonas fibrosas; sabor adocicado, adstringente. }\end{array}$ \\
\hline DURABILIDADE NATURAL & $*$ \\
\hline TRATAMENTO PRESERVANTE & $*$ \\
\hline DADOS SEGUNDO AUTOR & MAINIERI (1983). \\
\hline \hline TEXTURA DA ESPÉCIE &
\end{tabular}

"Dado desconhecido. 
Tabela 3.31 - Descrição da espécie Parinari

\begin{tabular}{|c|c|}
\hline $\begin{array}{l}\text { Parinari excelsa sabine } \\
\text { Nome científico }\end{array}$ & $\begin{array}{c}\text { PARINARI } \\
\text { Nome comum } \\
\text { Crysobalanaceae } \\
\text { Família }\end{array}$ \\
\hline OUTROS NOMES COMUNS & $\begin{array}{l}\text { Bafo-de-boi-mirim, farinha-seca, pajurá-da-mata, } \\
\text { paranari, pranari. }\end{array}$ \\
\hline ZONAS DE MAIOR OCORRÊNCIA & Encontra-se também no Estado do PA e AP. \\
\hline CARACTERES GERAIS & $\begin{array}{l}\text { A altura comercial do tronco é de } 13,30 \mathrm{~m} \text { com } \\
\text { diâmetro de } 62,53 / 56,20 \mathrm{~cm} \text {; sendo este retilínio. } \\
\text { A madeira apresenta o cerne e alburno } \\
\text { indistintos, cerne bege-rosado, indo do } \\
\text { amarelado ou marrom-claro, ao castanho-escuro } \\
\text { levemente arroxeado; camadas de crescimento } \\
\text { praticamente indistintas; raios indistintos a olho } \\
\text { nu no topo, na face tangencial são pouco visíveis } \\
\text { mesmo sob lente; grã direita; textura média; } \\
\text { ausência de brilho; cheiro imperceptível. }\end{array}$ \\
\hline DURABILIDADE NATURAL & ${ }^{*}$ \\
\hline TRATAMENTO PRESERVANTE & $\begin{array}{l}\text { A madeira é de fácil tratamento com creosoto } \\
\text { (oleossolúvel) e com CCA-A (hidrossolúvel). }\end{array}$ \\
\hline DADOS SEGUNDO AUTOR & MAINIERI (1983); IBAMA (1997). \\
\hline
\end{tabular}

TEXTURA DA ESPÉCIE

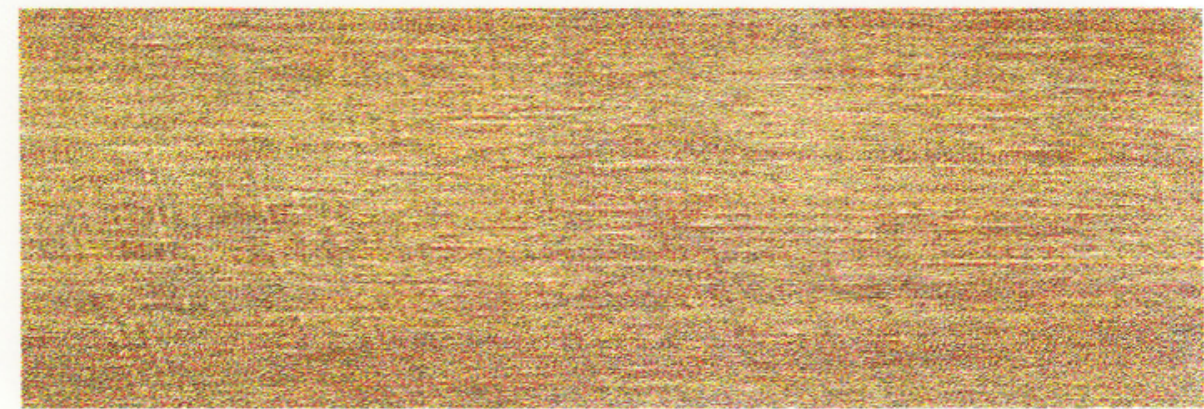

Corte Longitudinal

"Dado desconhecido. 
Tabela 3.32 - Descrição da espécie Piolho

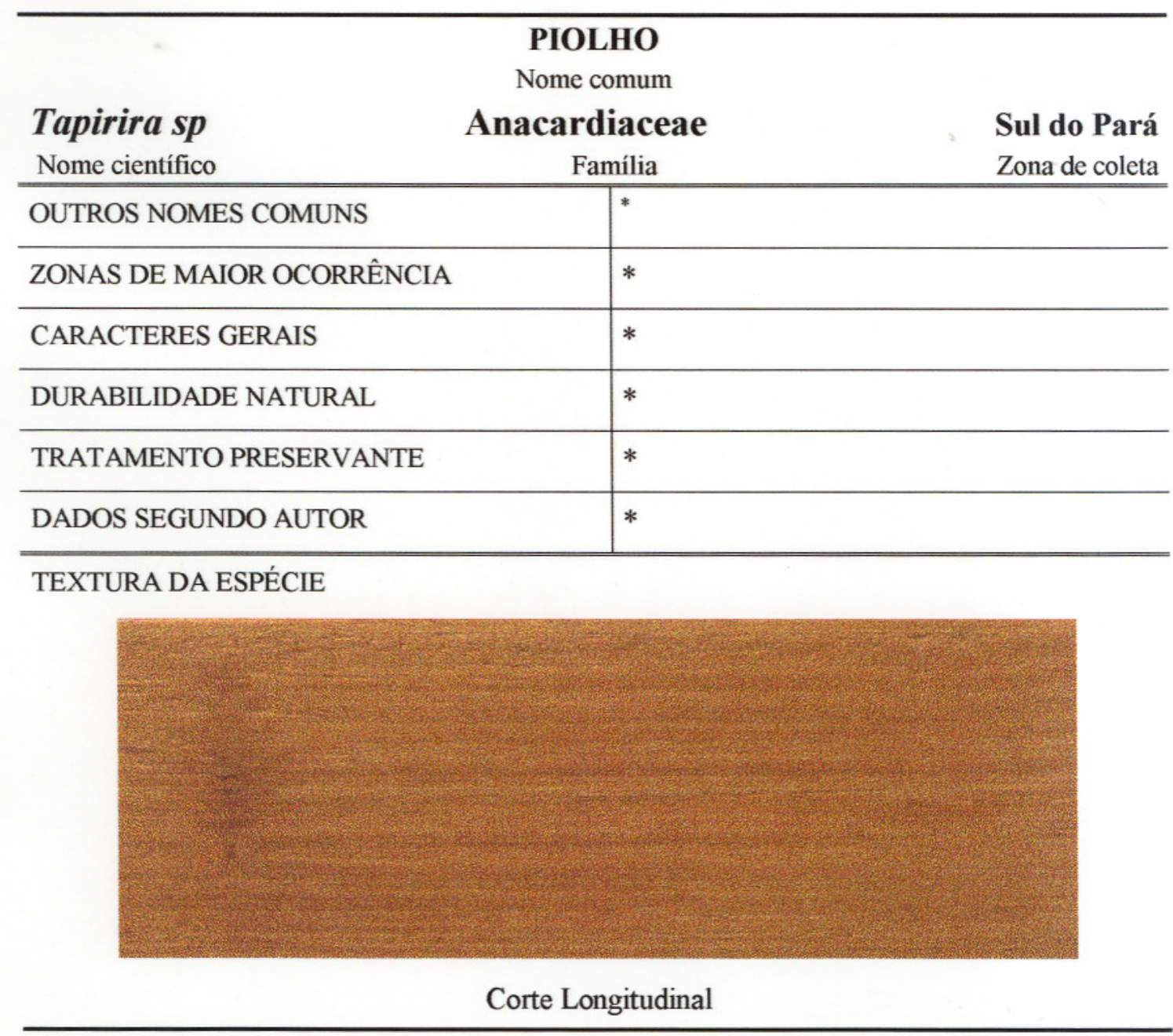

* Dado desconhecido. 
Tabela 3.33 - Descrição da espécie Quarubarana

\begin{tabular}{l|l}
\hline $\begin{array}{l}\text { Erisma uncinatum } \\
\text { Nome científico }\end{array}$ & $\begin{array}{l}\text { QUARUBARANA } \\
\text { Nome comum } \\
\text { Vochysiaceae } \\
\text { Familia }\end{array}$ \\
\hline \hline OUTROS NOMES COMUNS & $\begin{array}{l}\text { Bruteiro, cedrinho, cedrilho, cambará, cachimbo- } \\
\text { de-jaboti, jaboti-da-terra-firme, quaruba-vermelha, } \\
\text { verga-de-jaboti. }\end{array}$ \\
\hline ZONAS DE MAIOR OCORRENCIA de coleta
\end{tabular}

TEXTURA DA ESPÉCIE

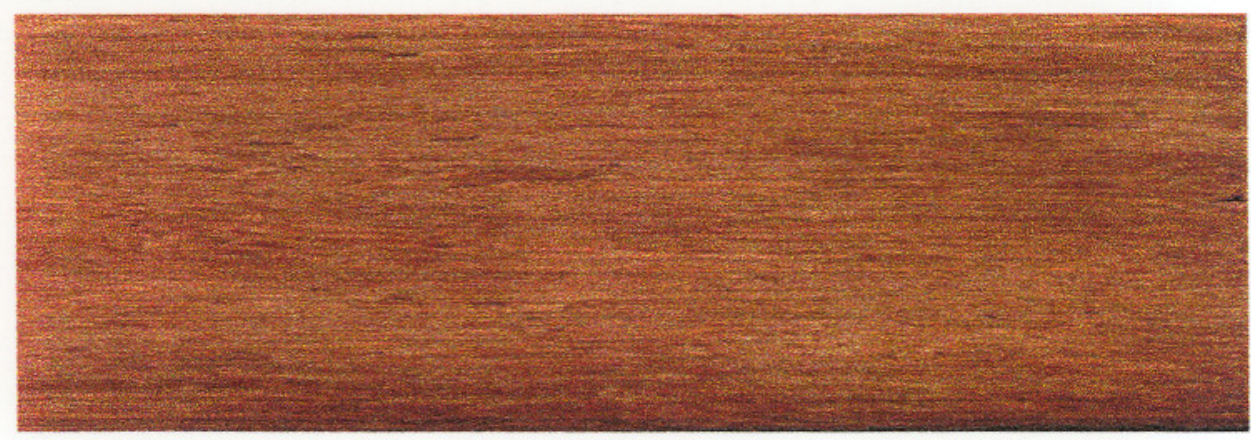

Corte Longitudinal 
Tabela 3.34 - Descrição da espécie Rabo de Arraia

\begin{tabular}{|c|c|}
\hline \multicolumn{2}{|r|}{$\begin{array}{l}\text { RABO DE ARRAIA } \\
\text { Nome comum }\end{array}$} \\
\hline Vochysia sp & Vochysiaceae \\
\hline Nome científico & Zona de coleta \\
\hline OUTROS NOMES COMUNS & Quaruba-jasmineira. \\
\hline ZONAS DE MAIOR OCORRÊNCIA & $\begin{array}{l}\text { As espécies do gênero Vochysia sp ocorrem em } \\
\text { toda a região Amazônica brasileira. }\end{array}$ \\
\hline CARACTERES GERAIS & $\begin{array}{l}\text { A madeira apresenta cerne bege-rosado; raios } \\
\text { visíveis a olho nu na face transversal (topo) e na } \\
\text { face tangencial só sob lente. Camadas de } \\
\text { crescimento indistintas. }\end{array}$ \\
\hline DURABILIDADE NATURAL & $\begin{array}{l}\text { Apresenta baixa resistência ao ataque fúngico, } \\
\text { quando em contacto com o solo, em ensaios de } \\
\text { laboratório. }\end{array}$ \\
\hline TRATAMENTO PRESERVANTE & ${ }^{*}$ \\
\hline DADOS SEGUNDO AUTOR & MAINIERI (1983). \\
\hline \multicolumn{2}{|l|}{ TEXTURA DA ESPÉCIE } \\
\hline & Corte Longitudinal \\
\hline
\end{tabular}

"Dado desconhecido. 
Tabela 3.35 - Descrição da espécie Tachi

\begin{tabular}{|c|c|}
\hline $\begin{array}{c}\text { Sclerolobium sp } \\
\text { Nome científico }\end{array}$ & $\begin{array}{c}\text { TACHI } \\
\text { Nome comum } \\
\text { Caesalpiniaceae } \\
\text { Família }\end{array}$ \\
\hline OUTROS NOMES COMUNS & $\begin{array}{l}\text { As espécies do gênero sclerolobium na Amazônia, } \\
\text { são chamadas indistintamente de tachi, nome este } \\
\text { também aplicado às espécies do gênero Tachigalia } \\
\text { (Caesalpiniaceae), em outros Estados é chamada } \\
\text { de angá, caingá, canela-freijó, ingauçu, apapaçu, } \\
\text { bascuaré, paçariuva, paçuaré. }\end{array}$ \\
\hline ZONAS DE MAIOR OCORRÊNCIA & $\begin{array}{l}\text { Nos Estados da AM, PA, AC, Estados de MG, ES } \\
\text { e RJ, nas matas da costa atlântica, Estados de SP, } \\
\text { PR e SC. }\end{array}$ \\
\hline CARACTERES GERAIS & $\begin{array}{l}\text { A madeira apresenta cerne muito irregular quanto } \\
\text { à cor, do róseo-claro ao castanho-claro rosado, e } \\
\text { do bege-pardacento ao pardo-claro-amarelado, ou } \\
\text { acinzentado, com reflexos róseos ou arroxeados; } \\
\text { alburno pouco diferenciado, bege-claro levemente } \\
\text { rosado; grã tipicamente revessa; superficie } \\
\text { irregularmente lustrosa e ligeiramente áspera ao } \\
\text { tato; cheiro suave, desagradável; gosto } \\
\text { imperceptível. }\end{array}$ \\
\hline DURABILIDADE NATURAL & $\begin{array}{l}\text { Quanto à resistência natural, a madeira apresenta } \\
\text { baixa resistência ao apodrecimento, porém boa } \\
\text { resistência a cupins de madeira seca. }\end{array}$ \\
\hline TRATAMENTO PRESERVANTE & * \\
\hline DADOS SEGUNDO AUTOR & CHIMELO \& MAINIERI (1989). \\
\hline
\end{tabular}

\section{TEXTURA DA ESPÉCIE}

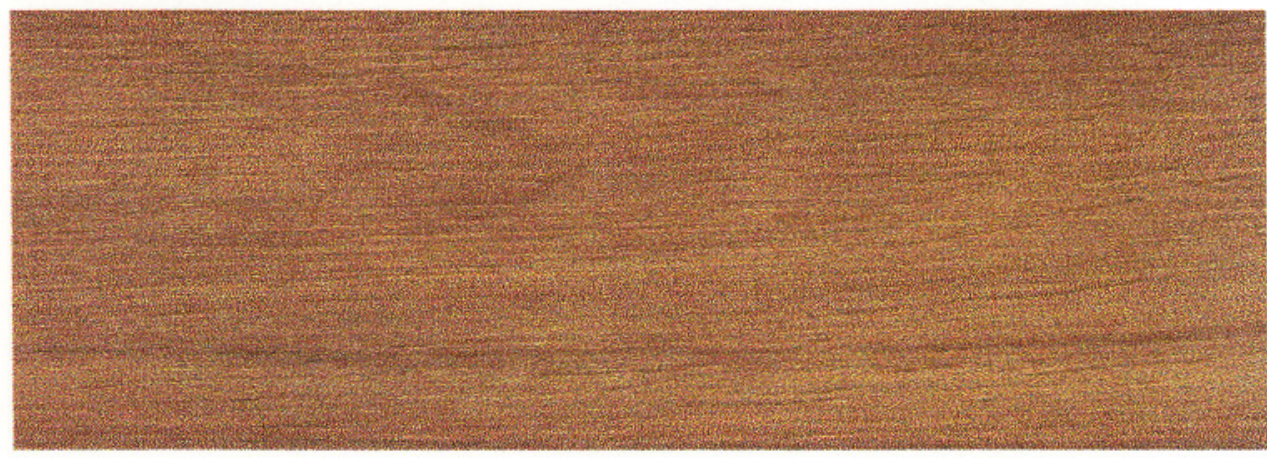

Corte Longitudinal

\footnotetext{
"Dado desconhecido.
} 
Tabela 3.36 - Descrição da espécie Tatajuba

\begin{tabular}{|c|c|}
\hline \multicolumn{2}{|r|}{$\begin{array}{l}\text { TATAJUBA } \\
\text { Nome comum }\end{array}$} \\
\hline Bagassa guianensis & Sul de Roraima \\
\hline Nome científico & Local de origem \\
\hline OUTROS NOMES COMUNS & $\begin{array}{l}\text { No Brasil é conhecida como bagaceira, } \\
\text { amaparriana, amarelão, cachaceiro e garrote. Na } \\
\text { Guiana Francesa por bagasse, bois bagasse, bois } \\
\text { jaune; no Suriname, gale bagesse. }\end{array}$ \\
\hline ZONAS DE MAIOR OCORRÊNCIA & $\begin{array}{l}\text { Estados do AM, AC, RO, PA, e MA. Encontra-se } \\
\text { também na Guiana Francesa e no Suriname. }\end{array}$ \\
\hline CARACTERES GERAIS & $\begin{array}{l}\text { Ocorre nas matas em terra firme e em solo } \\
\text { argiloso. As árvores são de grande porte, } 25 \mathrm{~m} \text {. } \\
\text { Fuste reto e cilíndrico, casca com superficie } \\
\text { escamosa espessa que produz látex branco } \\
\text { adocicado que logo se coagula. O cerne apresenta- } \\
\text { se na cor amarelo-dourado quando recém-cortado, } \\
\text { escurecendo para amarelo-queimado ou castanho- } \\
\text { amarelado; alburno amarelo-pálido, quase branco; } \\
\text { textura grossa; grã direita a irregular; superficie } \\
\text { lustrosa; cheiro e sabor imperceptíveis. }\end{array}$ \\
\hline DURABILIDADE NATURAL & $\begin{array}{l}\text { A madeira apresenta uma resistência natural de um } \\
\text { período superior a } 7 \text { anos, em ensaios de campo na } \\
\text { Amazônia. Cerne resistente ao ataque de fungos da } \\
\text { podridão-branca e podridão-parda. }\end{array}$ \\
\hline TRATAMENTO PRESERVANTE & $\begin{array}{l}\text { De baixíssima permeabilidade á impregnação com } \\
\text { soluções preservantes, mesmo em tratamento sob } \\
\text { pressão. }\end{array}$ \\
\hline DADOS SEGUNDO AUTOR & SUDAM (1979); CHIMELO \& MAINIERI (1989). \\
\hline
\end{tabular}

TEXTURA DA ESPÉCIE

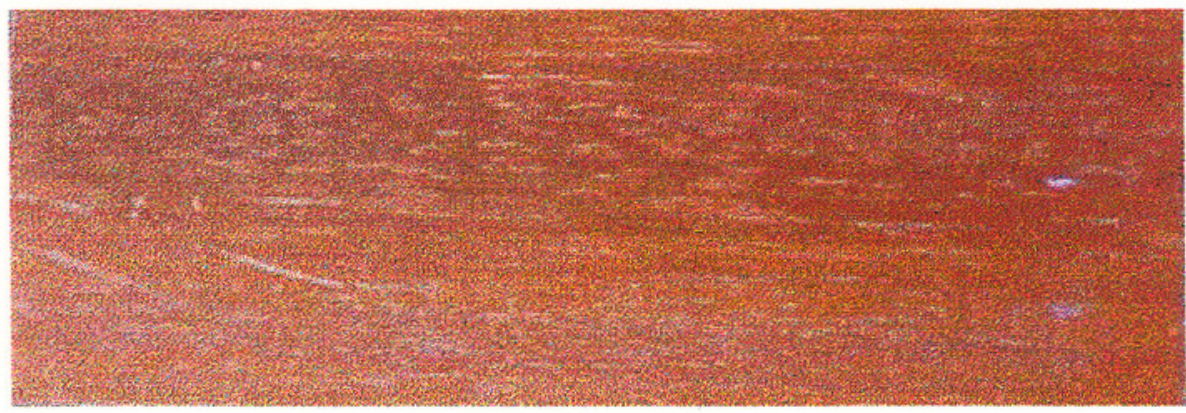

Corte Longitudinal 
Tabela 3.37 - Descrição da espécie Umirana

\begin{tabular}{l|l}
\hline $\begin{array}{l}\text { Qualea retusa } \\
\text { Nome científico }\end{array}$ & \multicolumn{1}{c}{$\begin{array}{l}\text { UMIRANA } \\
\text { Nome comum } \\
\text { Vochysiaceae }\end{array}$} \\
\hline \hline OUTROS NOMES COMUNS & $\begin{array}{r}\text { Sul de Roraima } \\
\text { Zona de coleta }\end{array}$ \\
\hline ZONAS DE MAIOR OCORRÊNCIA & $\begin{array}{l}\text { Esta espécie é presente também no Estado do } \\
\text { PA. }\end{array}$ \\
\hline CARACTERES GERAIS & $\begin{array}{l}\text { Apresenta o cerne pardo-escuro-avinhado com } \\
\text { veios pouco ondulados; raios pouco visíveis a } \\
\text { olho nu no topo e na face tangencial, finos, } \\
\text { pouco numerosos; anéis de crescimento bem } \\
\text { distintos; grã irregular; textura média, um pouco } \\
\text { fibrosa com nuances escuras; cheiro e sabor } \\
\text { leve; brilho acentuado; superficie pouco lisa. }\end{array}$ \\
\hline DURABILIDADE NATURAL & $*$ \\
\hline TRATAMENTO PRESERVANTE & $*$ \\
\hline DADOS SEGUNDO AUTOR & FARIA (1981). \\
\hline
\end{tabular}

\section{TEXTURA DA ESPÉCIE}

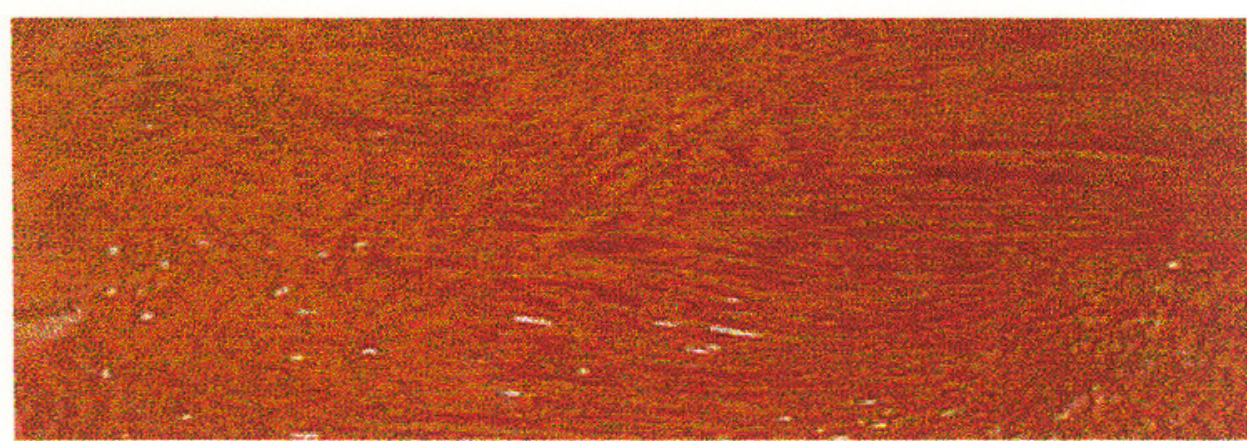

Corte Longitudinal

* Dado desconhecido. 


\section{3 - MÉTODOS DE ENSAIO}

Os ensaios para determinação das propriedades fisicas e mecânicas foram realizados de acordo com as recomendações do Anexo B da NBR 7190/97. O número de corpos-de-prova foi, para a grande maioria das espécies, no mínimo doze, configurando a caracterização completa das espécies, uma vez tendo sido garantida a aleatoriedade da obtenção das peças para a confecção dos corpos-de-prova.

Foram determinadas as seguintes propriedades:

a. Densidade aparente $\left(\rho_{\text {ap }}\right)$;

b. Retração Radial $\left(\varepsilon_{\mathbf{r}}\right)$;

c. Retração Tangencial $\left(\varepsilon_{t}\right)$;

d. Resistência à Compressão Paralela às Fibras $\left(\mathbf{f}_{\text {wco }}\right)$;

e. Resistência à Tração Paralela às Fibras $\left(\mathbf{f}_{\mathbf{t o}}\right)$;

f. Resistência à Tração Normal às Fibras ( $\left.\mathbf{f}_{\mathbf{t g 0}}\right)$;

g. Resistência ao Cisalhamento Paralelo às Fibras $\left(\mathbf{f}_{v o}\right)$;

h. Resistência ao Fendilhamento $\left(\mathbf{f}_{\mathbf{s}}\right)$;

i. Resistência Convencional no Ensaio de Flexão Estática $\left(\mathbf{f}_{\mathbf{M}}\right)$;

j. Módulo de Elasticidade Longitudinal na Compressão Paralela às Fibras $\left(\mathbf{E}_{\mathbf{c o}}\right)$;

k. Módulo de Elasticidade Longitudinal na Tração Paralela às Fibras $\left(\mathbf{E}_{\mathbf{t o}}\right)$;

1. Módulo de Elasticidade Longitudinal no Ensaio de Flexão Estática $\left(\mathbf{E}_{\mathbf{M}}\right)$;

m. Dureza Paralela às Fibras $\left(\mathbf{f}_{\mathbf{H}}\right)$;

n. Dureza Normal às Fibras $\left(\mathbf{f}_{\mathbf{H 9 0}}\right)$;

o. Tenacidade (T).

Os valores especificados nesta Norma para as propriedades de resistência e elasticidade correspondem à classe 1 de umidade (Tabela 3.38), definida no referido documento normativo pelo teor de umidade de referência adotado para a madeira (12\%). 


\section{4 - EQUIPAMENTOS}

$\mathrm{Na}$ realização da parte experimental deste trabalho foram utilizados os equipamentos listados a seguir.

a. Paquímetro digital, de sensibilidade $0,1 \mathrm{~mm}$;

b. Balança analítica com sensibilidade $0,01 \mathrm{~g}$;

c. Estufa de esterilização e secagem, para temperaturas em torno de $103 \pm 2{ }^{\circ} \mathrm{C}$;

d. Relógios comparadores, de sensibilidade $0,01 \mathrm{~mm}$ e $0,001 \mathrm{~mm}$;

e. Máquina universal de ensaio - AMSLER - capacidade $250 \mathrm{kN}$;

f. Máquina tipo FPL, para a determinação da tenacidade.

Nas Figuras 3.1 e 3.2 são apresentados alguns dos equipamentos empregados.
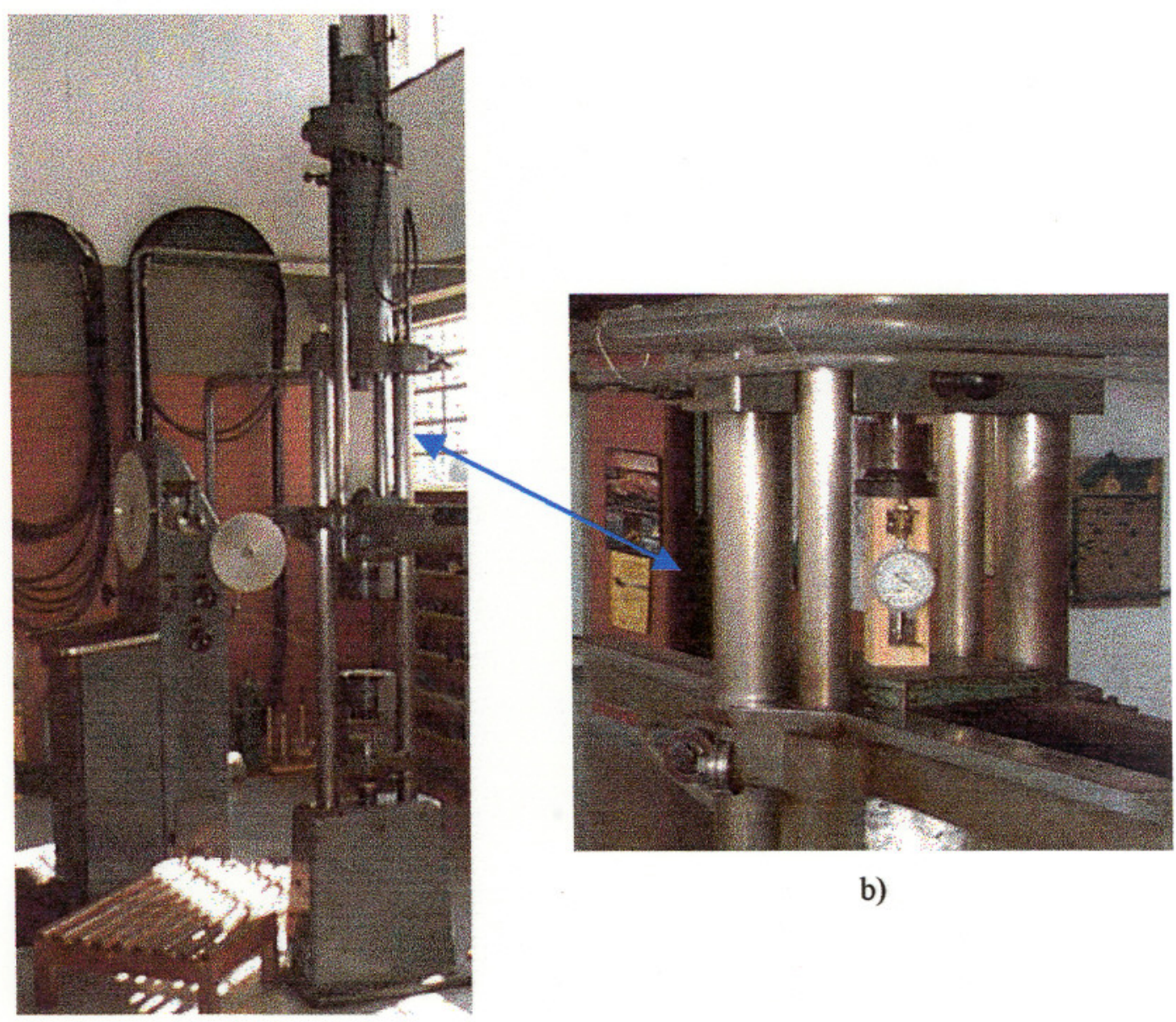

b)

a)

Figura 3.1 - a) Máquina universal de ensaio - AMSLER, b) Detalhe de ensaio e relógio comparador. 


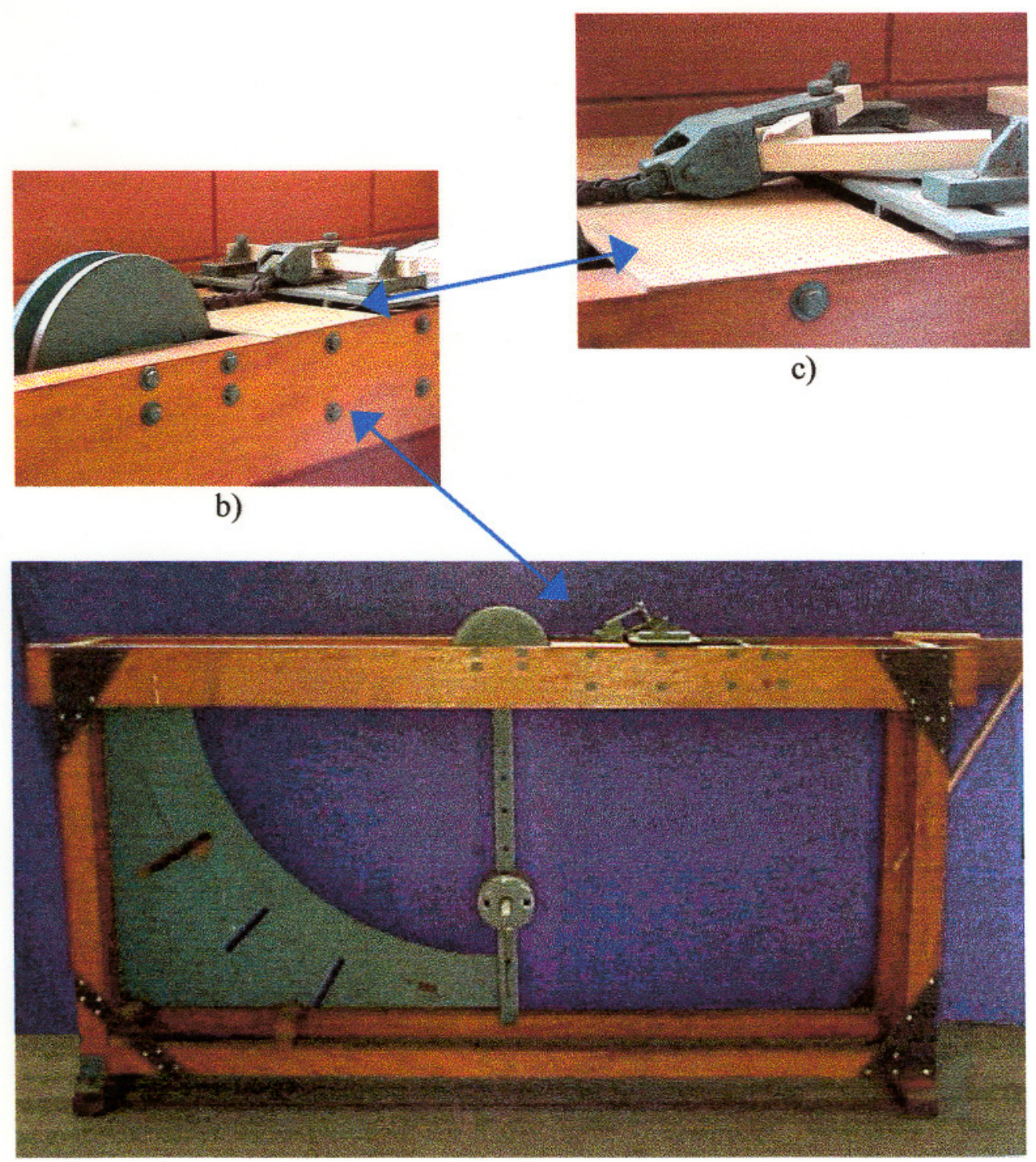

a)

Figura 3.2 - a) Máquina Tipo FPL, de tenacidade, b) Detalhe da máquina, c) Detalhe de ensaio para determinação da Tenacidade.

Tabela 3.38 - Classes de Umidade

\begin{tabular}{c|c|c}
\hline $\begin{array}{c}\text { Classes } \\
\text { de umidade }\end{array}$ & $\begin{array}{c}\text { Umidade relativa } \\
\text { do ambiente } \mathbf{U}_{\text {amb }}\end{array}$ & $\begin{array}{c}\text { Umidade de equilíbrio } \\
\text { da madeira } \mathbf{U}_{\text {eq }}\end{array}$ \\
\hline 2 & $\leq 65 \%$ & $12 \%$ \\
\hline 3 & $65 \%<\mathrm{U}_{\mathrm{amb}} \leq 75 \%$ & $15 \%$ \\
\hline 4 & $75 \%<\mathrm{U}_{\mathrm{amb}} \leq 85 \%$ & $18 \%$ \\
\hline $\mathrm{U}_{\mathrm{amb}}>85 \%$ & $\geq 25 \%$ \\
\hline
\end{tabular}

Fonte: NBR 7190/97 - ABNT. 


\section{5 - CRITÉRIOS ADOTADOS PARA CLASSIFICAÇÃO E INDICAÇÕES DAS ESPÉCIES DE MADEIRA}

\subsection{1 - Considerações iniciais}

Dentro dos procedimentos para o conhecimento tecnológico da madeira, alguns estudos foram realizados para se classificar madeiras a partir de critérios baseados em parâmetros físicos, de resistência e rigidez.

O agrupamento de espécies tem o objetivo de minimizar a variação dentro do grupo e maximizar a variação entre os grupos. $O$ agrupamento de espécies a partir de suas propriedades fisicas e mecânicas apresenta-se como um dos procedimentos mais adequados para a indicação dos usos finais da madeira.

Neste trabalho, cujos objetivos estão registrados no capítulo 1, foram utilizados os critérios de Sallenave, Nahuz e Nogueira. Estes critérios foram definidos a partir de estudos realizados em madeiras européias e brasileiras, das Coníferas e das Dicotiledôneas. Para usos finais baseou-se na proposição do IPT-SUDAM, (1981).

\subsection{2 - Critérios de Sallenave}

Sallenave (1955) e (1971) propôs critérios estabelecendo que a classificação das madeiras pode ser feita através da análise das suas propriedades fisicas e mecânicas. Seu ponto de partida fora os resultados de ensaio obtidos de acordo com as prescrições contidas nos métodos de ensaio da AFNOR (Associação Francesa de Normas). Considerou, também, fatores relativos a: defeitos da madeira, teor de umidade, orientação das fibras e anisotropia.

A classificação ou ordenação das madeiras segundo seu comportamento mecânico deve ainda considerar a sua natureza particular e outras características devidas à sua constituição orgânica. A determinação das propriedades mecânicas foi feita em estado seco $(U=12 \%)$. Sallenave, propôs as seguintes propriedades fisicas para a classificação das madeiras:
a. Densidade aparente, contendo umidade a $12 \%$;
b. Retratibilidade radial, tangencial e volumétrica;
c. Dureza JANKA normal às fibras. 
Dentre as propriedades mecânicas que permitem qualificar o comportamento das madeiras por Sallenave, foram selecionadas as de maior interesse para este estudo:

a. Resistência à compressão paralela às fibras;

b. Resistência convencional na flexão estática;

c. Resistência ao cisalhamento;

d. Resistência ao fendilhamento;

e. Resistência à tração normal às fibras.

Foi selecionada também, como de interesse para o estudo, a característica de trabalhabilidade "cota de dureza", calculada a partir da propriedade dureza JANKA normal às fibras, apresentada na Tabela 3.42 , a seguir.

A classificação através das propriedades a serem analisadas pelos critérios propostos por Sallenave (1955), para as Dicotiledôneas, dispõe-se na seqüência das Tabelas a seguir:

Tabela 3.39 - Densidade Aparente - Sallenave

\begin{tabular}{c|c}
\hline CLASSE & $\begin{array}{c}\text { DENSIDADE APARENTE A 12\% DE UMIDADE } \\
\left(\mathbf{g} / \mathbf{c m}^{\mathbf{3}}\right)\end{array}$ \\
\hline Muito leve & $\rho_{12}<0,50$ \\
\hline Leve & $0,50 \leq \rho_{12} \leq 0,64$ \\
\hline Semipesada & $0,65 \leq \rho_{12} \leq 0,79$ \\
\hline Pesada & $0,80 \leq \rho_{12} \leq 0,95$ \\
\hline Muito pesada & $\rho_{12}>0,96$ \\
\hline
\end{tabular}

Tabela 3.40 - Retratibilidade - Sallenave

\begin{tabular}{c|c|c|c}
\hline \multirow{2}{*}{ CLASSE } & \multicolumn{3}{|c}{ RETRATIBILIDADE (\%) } \\
\cline { 2 - 4 } & Radial & Tangencial & Volumétrica \\
\hline Fraca contração & $<4$ & $<7$ & $<10$ \\
\hline Média contração & 5 a 7 & 8 a 11 & 11 a 15 \\
\hline Forte contração & $>8$ & $>12$ & $>16$ \\
\hline
\end{tabular}


Tabela 3.41 - Dureza JANKA normal às fibras - Sallenave

\begin{tabular}{c|c}
\hline CLASSE & $\begin{array}{c}\text { DUREZA JANKA NORMAL ÀS FIBRAS } \\
\left(\mathbf{d a N} / \mathbf{c m}^{2}\right)\end{array}$ \\
\hline Muito branda & 27 a 204 \\
\hline Branda & 205 a 409 \\
\hline Semidura & 410 a 817 \\
\hline Dura & 818 a 1226 \\
\hline Muito dura & 1227 a 2724 \\
\hline
\end{tabular}

Tabela 3.42 - Cota de dureza - Sallenave

\begin{tabular}{c|c|c}
\hline CLASSE & COTA DE DUREZA & APLICAÇÃO \\
\hline Pequena & $970 \leq C D \leq 1309$ & Madeira de Carpintaria \\
\hline Normal & $1310<C D \leq 1356$ & Madeira Industrial \\
\hline Forte & $1357<C D \leq 3012$ & Madeira de usos especiais \\
\hline
\end{tabular}

$C D=\frac{f d n}{\left(\rho_{12}\right)^{2}}$, onde:

$\mathrm{CD}=$ Cota de Dureza;

$\mathrm{fdn}=$ Dureza JANKA normal às Fibras $\left(\mathrm{daN} / \mathrm{cm}^{2}\right)$;

$\rho_{12}=$ Densidade Aparente com $U=12 \%\left(\mathrm{~g} / \mathrm{cm}^{3}\right)$.

Tabela 3.43 - Resistência ao fendilhamento - Sallenave

\begin{tabular}{c|c}
\hline CLASSE & $\begin{array}{c}\text { RESISTÊNCIA AO FENDILHAMENTO } \\
\left(\mathbf{d a N} / \mathbf{c m}^{2}\right)\end{array}$ \\
\hline Fraca & $<15$ \\
\hline Média & 16 a 30 \\
\hline Forte & $>31$ \\
\hline
\end{tabular}


Tabela 3.44 - Resistência à tração normal às fibras - Sallenave

\begin{tabular}{c|c}
\hline CLASSE & $\begin{array}{c}\text { RESISTÊNCIA À TRAÇÃO NORMAL ÀS } \\
\left.\text { FIBRAS (daN/cm })^{\mathbf{2}}\right)\end{array}$ \\
\hline Fraca & 10 a 25 \\
\hline Média & 26 a 45 \\
\hline Forte & 46 a 65 \\
\hline
\end{tabular}

Tabela 3.45 - Resistência ao cisalhamento - Sallenave

\begin{tabular}{c|c}
\hline CLASSE & $\begin{array}{c}\text { RESISTÊNCIA AO CISALHAMENTO } \\
\left(\mathbf{d a N} / \mathbf{c m}^{\mathbf{2}}\right)\end{array}$ \\
\hline Fraca & 50 a 70 \\
\hline Média & 71 a 100 \\
\hline Forte & 101 a 160 \\
\hline
\end{tabular}

Tabela 3.46 - Resistência à compressão paralela às fibras - Sallenave

\begin{tabular}{c|c}
\hline CLASSE & $\begin{array}{c}\text { RESISTÊNCIA À COMPRESSÃo } \\
\text { PARALELA ÀS FIBRAS }\left(\mathbf{d a N} / \mathbf{c m}^{\mathbf{2}}\right)\end{array}$ \\
\hline Fraca & $<450$ \\
\hline Média & 451 a 750 \\
\hline Forte & $>751$ \\
\hline
\end{tabular}

Tabela 3.47 - Resistência convencional na flexão estática - Sallenave

\begin{tabular}{c|c}
\hline CLASSE & MOR na FLEXÃO ESTÁTICA $\left(\mathbf{d a N} / \mathbf{c m}^{2}\right)$ \\
\hline Fraca & $\leq 1100$ \\
\hline Média & 1101 a 1800 \\
\hline Forte & $>1801$ \\
\hline
\end{tabular}




\subsection{3 - Critérios de Nahuz}

Nahuz (1974) estudou madeiras provenientes da região amazônica, mais precisamente da Bacia do Rio Paracuru. Em seu trabalho, entre outros tópicos, propôs vários critérios para fazer sua classificação final com base em parâmetros fisicos, de resistência, de rigidez, de durabilidade, de tratabilidade com substâncias preservativas e de trabalhabilidade.

Para determinação das propriedades mecânicas, os ensaios foram realizados com a madeira na condição de equilíbrio ao ar ( $\mathrm{U}=15 \%)$.

Nahuz (1974) propôs as seguintes propriedades físicas para a classificação das madeiras:
a. Densidade aparente, à umidade de $15 \%$;
b. Valores de contração (radial, tangencial e volumétrica);
c. Dureza JANKA paralela às fibras.

Dentre as propriedades mecânicas que permitem qualificar o comportamento das madeiras, por Nahuz (1974) foram selecionadas:
a. Resistência à compressão paralela às fibras;
b. Resistência ao cisalhamento;
c. Resistência convencional na flexão estática;
d. Módulo de elasticidade na flexão estática;
f. Tenacidade.

Outro parâmetro considerado por Nahuz, para a classificação das espécies com relação à trabalhabilidade (desempenho quando submetida ao processamento mecânico), se relaciona à proporção de peças livres de defeitos após o aplainamento.

$O$ aplainamento refere-se à regularidade das superficies de uma peça de madeira, assim como seu polimento natural, lustre e aspecto geral após ser trabalhada. Também se inclui neste item a facilidade das madeiras serem trabalhadas com cera, verniz, tintas, etc.

Os intervalos numéricos dos parâmetros propostos por Nahuz (1974), para a classificação de espécies de Dicotiledôneas, estão apresentados nas Tabelas a seguir: 
Tabela 3.48 - Densidade Aparente - Nahuz

\begin{tabular}{c|c}
\hline CLASSE & $\begin{array}{c}\text { DENSIDADE APARENTE A 15\% DE UMIDADE } \\
\left(\mathbf{g} / \mathbf{c m}^{\mathbf{3}}\right)\end{array}$ \\
\hline Leve & $\rho_{15}<0,575$ \\
\hline Semipesada & $0,575 \leq \rho_{15} \leq 0,805$ \\
\hline Pesada & $\rho_{15}>0,805$ \\
\hline
\end{tabular}

Tabela 3.49 - Retratibilidade - Nahuz

\begin{tabular}{c|c|c|c}
\hline \multirow{2}{*}{ CLASSE } & \multicolumn{3}{|c}{ RETRATIBILIDADE (\%) } \\
\cline { 2 - 4 } & Radial & Tangencial & Volumétrica \\
\hline Muito baixa & $<1,5$ & $<3,0$ & $<4,5$ \\
\hline Baixa & 1,6 a 2,5 & 3,1 a 5,0 & 4,6 a 7,5 \\
\hline Média & 2,6 a 4,5 & 5,1 a 9,0 & 7,6 a 13,5 \\
\hline Elevada & 4,6 a 6,5 & 9,1 a 13,0 & 13,6 a 19,5 \\
\hline Muito Elevada & $>6,6$ & $>13,1$ & $>19,6$ \\
\hline
\end{tabular}

Tabela 3.50 - Dureza JANKA paralela às fibras - Nahuz

\begin{tabular}{c|c}
\hline CLASSE & $\begin{array}{c}\text { DUREZA JANKA PARALELA ÀS FIBRAS } \\
\left(\mathbf{d a N} / \mathbf{c m}^{\mathbf{2}}\right)\end{array}$ \\
\hline Muito baixa & $<100$ \\
\hline Baixa & 101 a 400 \\
\hline Média & 401 a 900 \\
\hline Elevada & 901 a 1400 \\
\hline Muito elevada & $>1400$ \\
\hline
\end{tabular}


Tabela 3.51 - Resistência à Compressão Paralela às fibras - Nahuz

\begin{tabular}{c|c}
\hline CLASSE & $\begin{array}{c}\text { COMPRESSÄO PARALELA ÀS FIBRAS } \\
\left(\mathbf{d a N} / \mathbf{c m}^{\mathbf{2}}\right)\end{array}$ \\
\hline Muito baixa & $<200$ \\
\hline Baixa & 201 a 350 \\
\hline Média & 351 a 550 \\
\hline Elevada & 551 a 850 \\
\hline Muito elevada & $>851$ \\
\hline
\end{tabular}

Tabela 3.52 - Resistência ao Cisalhamento - Nahuz

\begin{tabular}{c|c}
\hline CLASSE & CISALHAMENTO $\left(\mathbf{d a N} / \mathbf{c m}^{2}\right)$ \\
\hline Muito baixa & $<50$ \\
\hline Baixa & 51 a 100 \\
\hline Média & 101 a 150 \\
\hline Elevada & 151 a 200 \\
\hline Muito elevada & $>201$ \\
\hline
\end{tabular}

Tabela 3.53 - Resistência convencional na flexão estática - Nahuz

\begin{tabular}{c|c}
\hline CLASSE & FLEXÃO ESTÁTICA $\left(\mathbf{d a N} / \mathbf{c m}^{2}\right)$ \\
\hline Muito baixa & $<500$ \\
\hline Baixa & 501 a 850 \\
\hline Média & 851 a 1200 \\
\hline Elevada & 1201 a 1750 \\
\hline Muito elevada & $>1751$ \\
\hline
\end{tabular}

Tabela 3.54 - MOE - Flexão Estática - Nahuz

\begin{tabular}{c|c}
\hline CLASSE & $\begin{array}{c}\text { MÓDULO DE ELASTICIDADE NA FLEXĀo } \\
\text { ESTÁTICA }\left(\mathbf{d a N} / \mathbf{c m}^{\mathbf{2}}\right)\end{array}$ \\
\hline Muito baixa & $<100000$ \\
\hline Baixa & 100001 a 120000 \\
\hline
\end{tabular}


Tabela 3.54 (continuação) - MOE - Flexão Estática - Nahuz

\begin{tabular}{c|c}
\hline Média & 120001 a 150000 \\
\hline Elevada & 150001 a 200000 \\
\hline Muito elevada & $>200001$ \\
\hline
\end{tabular}

Tabela 3.55 - Tenacidade - Nahuz

\begin{tabular}{c|c}
\hline CLASSE & TENACIDADE (daN x cm) \\
\hline Muito baixa & $<0,75$ \\
\hline Baixa & 0,76 a 2,25 \\
\hline Média & 2,26 a 3,75 \\
\hline Elevada & 3,76 a 5,25 \\
\hline Muito elevada & $>5,26$ \\
\hline
\end{tabular}

Tabela 3.56 - Trabalhabilidade - Nahuz

\begin{tabular}{c|c}
\hline \multirow{2}{*}{ CLASSE } & $\begin{array}{c}\text { APLAINAMENTO } \\
\end{array}$ \\
\hline Muito pobre & $<50$ \\
\hline Pobre & 51 a 60 \\
\hline Regular & 61 a 70 \\
\hline Boa & 71 a 90 \\
\hline Muito boa & 91 a 100 \\
\hline
\end{tabular}

\subsection{4 - Critérios de Nogueira}

Além dos critérios de Sallenave e de Nahuz foram utilizados alguns critérios complementares sugeridos por Nogueira (1991), com base na experiência acumulada no Laboratório de Madeiras e de Estruturas de Madeira, do Departamento de Engenharia de Estruturas, EESC-USP. 
Nogueira (1991) propôs para a classificação das madeiras as propriedades mecânicas que permitem completar a qualificação do comportamento das madeiras, considerando a umidade de $12 \%$.

As propriedades selecionadas por Nogueira, são:

a. Resistência à tração paralela às fibras;

b. Módulo de elasticidade na tração paralela às fibras;

c. Módulo de elasticidade na compressão paralela às fibras.

Os intervalos numéricos dos parâmetros propostos por Nogueira (1991), para complementar a classificação de espécies de Dicotiledôneas, estão apresentados nas Tabelas a seguir:

Tabela 3.57 - Resistência à Tração Paralela às Fibras - Nogueira

\begin{tabular}{c|c}
\hline CLASSE & $\begin{array}{c}\text { RESISTÊNCIA À TRAÇÃO PARALELA ÀS } \\
\text { FIBRAS (daN/cm }\end{array}$ \\
\hline Baixa & $\leq 750$ \\
\hline Média & 751 a 1000 \\
\hline Alta & $\geq 1001$ \\
\hline
\end{tabular}

Tabela 3.58 - MOE na Tração Paralela às Fibras - Nogueira

\begin{tabular}{c|c}
\hline CLASSE & $\begin{array}{c}\text { MOE na TRAÇÃo PARALELA ÀS FIBRAS } \\
\left(\mathbf{d a N} / \mathbf{c m}^{2}\right)\end{array}$ \\
\hline Baixa & $\leq 160000$ \\
\hline Média & 160001 a 200000 \\
\hline Alta & $\geq 200001$ \\
\hline
\end{tabular}

Tabela 3.59 - MOE na Compressão Paralela às fibras - Nogueira

\begin{tabular}{c|c}
\hline CLASSE & $\begin{array}{c}\text { MOE na COMPRESSÃo PARALELA ÀS } \\
\text { FIBRAS (daN/cm })\end{array}$ \\
\hline Baixa & 100000 a 150000 \\
\hline Média & 150001 a 180000 \\
\hline Alta & $\geq 180001$ \\
\hline
\end{tabular}




\subsection{5 - Classificação geral das aplicações na construção civil em função dos requisitos técnicos}

O IPT, em convênio com a SUDAM (1981), realizou um estudo de agrupamento de 148 espécies de madeiras tropicais da Amazônia brasileira consideradas de valor comercial, baseado em características como massa específica aparente, cor, durabilidade natural, e parâmetros mecânicos. O objetivo foi o de estabelecer requisitos para a definição dos usos principais a que se destinam as madeiras duras tropicais.

As espécies foram selecionadas tendo como base de informaç̃es o volume por unidade de área obtidos de inventários florestais realizados no Estado do Pará.

O agrupamento das 148 espécies fora feito segundo Nahuz, (1974).

No presente trabalho, para a indicação de usos finais foram selecionadas, dentre as classes e subdivisões adotadas pela SUDAM (1981), apenas aquelas de maior ênfase para classificação dos elementos estruturais, de aplicação na construção civil a partir da madeira serrada, a saber:

\subsection{Construção civil Pesada: - Externa;}

- Interna.

1.2 Construção civil Leve: - Externa;

- Interna (Decorativa, utilidade geral e estrutural).

2.1 Assoalhos: - Domésticos;

- Industriais.

Os elementos estruturais e respectivos requisitos técnicos, visando a classificação para os referidos itens 1 e 2 encontram-se apresentados nas Tabelas 3.60 a 3.67, a seguir: 
Tabela 3.60 - Construção civil pesada externa

\begin{tabular}{|l|l|}
\hline \multicolumn{2}{|c|}{ Construção civil pesada externa } \\
\hline \multicolumn{1}{|c|}{ Elementos estruturais } & \multicolumn{1}{c|}{ Requisitos técnicos necessários } \\
\hline$>\begin{array}{l}\text { Estacas maritimas, trapiches, pontes } \\
\text { obras imersas; }\end{array}$ & - Massa especifica alta (pesada); \\
$>\begin{array}{l}\text { Postes, cruzetas, estacas, escoras, } \\
\text { dormentes ferroviários; }\end{array}$ & - Propriedades mecânicas altas a \\
muito altas; \\
$>\begin{array}{l}\text { Estruturas pesadas, torres de } \\
\text { observação, vigamentos para pontes. }\end{array}$ & - Duráveis ou tratáveis; \\
\hline
\end{tabular}

Tabela 3.61 - Construção civil pesada interna

\begin{tabular}{|c|c|}
\hline \multicolumn{2}{|c|}{ Construção civil pesada interna } \\
\hline Elementos estruturais & Requisitos técnicos necessários \\
\hline $\begin{array}{l}>\text { Carpintaria resistente em geral; } \\
>\text { Tesouras, treliças; } \\
>\text { Estruturas internas; } \\
>\text { Plataformas, escadas. }\end{array}$ & 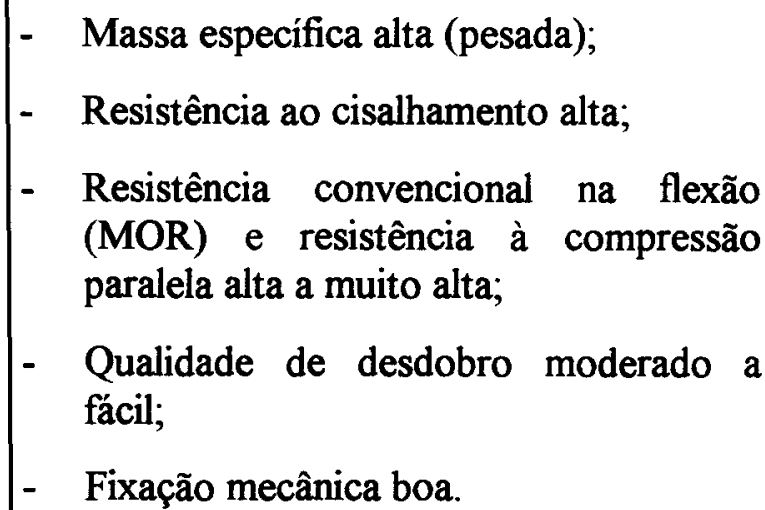 \\
\hline
\end{tabular}

Tabela 3.62 - Construção civil leve externa

\begin{tabular}{|c|c|}
\hline \multicolumn{2}{|c|}{ Construção civil leve externa } \\
\hline Elementos estruturais & Requisitos téenicos I \\
\hline $\begin{array}{l}\text { Moirões, pontaletes, porteiras; } \\
\text { Andaimes, longarinas, calhas, } \\
\text { elementos de cobertura; } \\
\text { Esquadrias em geral: portas, } \\
\text { venezianas, caixilhos, batentes; } \\
\text { Tabuado em geral; } \\
\text { Vigas. }\end{array}$ & $\begin{array}{l}\text { - } \quad \text { Massa específica média a baixa; } \\
\text { - } \quad \text { Resistência convencional na flexão alta; } \\
\text { - } \quad \text { Retratibilidade média a muito baixa; } \\
\text { - } \quad \text { Duráveis ou tratáveis; } \\
\text { - } \quad \text { Fixação mecânica regular a muito boa; } \\
\text { - } \quad \text { Trabalhabilidade regular a muito boa; } \\
\text { - } \quad \text { Qualidade de desdobro moderada fácil. }\end{array}$ \\
\hline
\end{tabular}


Tabela 3.63 - Construção civil leve interna - Decorativa

\begin{tabular}{|c|c|}
\hline \multicolumn{2}{|c|}{ Construção civil leve interna - Decorativa } \\
\hline Elementos estruturais & Requisitos técnicos necessários \\
\hline $\begin{array}{l}>\text { Lambris; } \\
>\text { Painéis; } \\
>\text { Molduras e perfilados; } \\
>\text { Guarnições. }\end{array}$ & $\begin{array}{l}\text { - Retratibilidade média a muito baixa; } \\
\text { - } \\
\text { - } \begin{array}{l}\text { Qcabamento regular a bom; } \\
\text { moderadamente dificil; }\end{array} \\
\text { - Tanto a aparência quanto a cor } \\
\text { devem estar boas; } \\
\text { - Condutividade média a baixa. } \\
\text { - Fixação mecânica regular a muito } \\
\text { boa; }\end{array}$ \\
\hline
\end{tabular}

Tabela 3.64 - Construção civil leve interna - Utilidade Geral

\begin{tabular}{|l|l|}
\hline \multicolumn{2}{|c|}{ Construção civil leve interna - Utilidade Geral } \\
\hline \multicolumn{1}{|c|}{ Elementos estruturais: } & Os requisitos técnicos necessários são: \\
\hline$>$ Cordões; & $-\begin{array}{l}\text { Massa específica média a leve; } \\
>\text { Forros; }\end{array}$ \\
$>$ Guarnições; & $-\begin{array}{l}\text { Retratibilidade e acabamento de } \\
\text { regular a bom; } \\
\text { Rodapés. }\end{array}$ \\
& $-\begin{array}{l}\text { Qualidade de desdobro de fácil a } \\
\text { muito fácil; } \\
\text { Qualidade de secagem ao ar de } \\
\text { moderadamente dificil a fácil; }\end{array}$ \\
\hline
\end{tabular}

Tabela 3.65 - Construção civil leve interna - Estrutural

\begin{tabular}{|c|c|}
\hline \multicolumn{2}{|c|}{ Construção civil leve interna - Estrutural } \\
\hline Elementos estruturais & Requisitos técnicos necessários \\
\hline $\begin{array}{l}>\text { Vigas; } \\
>\text { Caibros; } \\
>\text { Ripas. }\end{array}$ & $\begin{array}{l}\text { - Massa específica média; } \\
\text { - Resistência convencional na flexão } \\
\text { (MOR) e resistência ao cisalhamento } \\
\text { de média a muito alta; } \\
\text { - Fixação mecânica regular a boa; } \\
\text { - Qualidade de secagem de } \\
\text { moderadamente dificil a muito fácil; } \\
\text { - Qualidade de desdobro de moderada } \\
\text { a muito fácil. }\end{array}$ \\
\hline
\end{tabular}


Tabela 3.66 - Assoalhos Domésticos

\begin{tabular}{|c|c|}
\hline \multicolumn{2}{|c|}{ Assoalhos Domésticos } \\
\hline Elementos estruturais & Requisitos técnicos necessários \\
\hline $\begin{array}{l}>\text { Tacos; } \\
>\text { Tábuas; } \\
>\text { Parquete; }\end{array}$ & 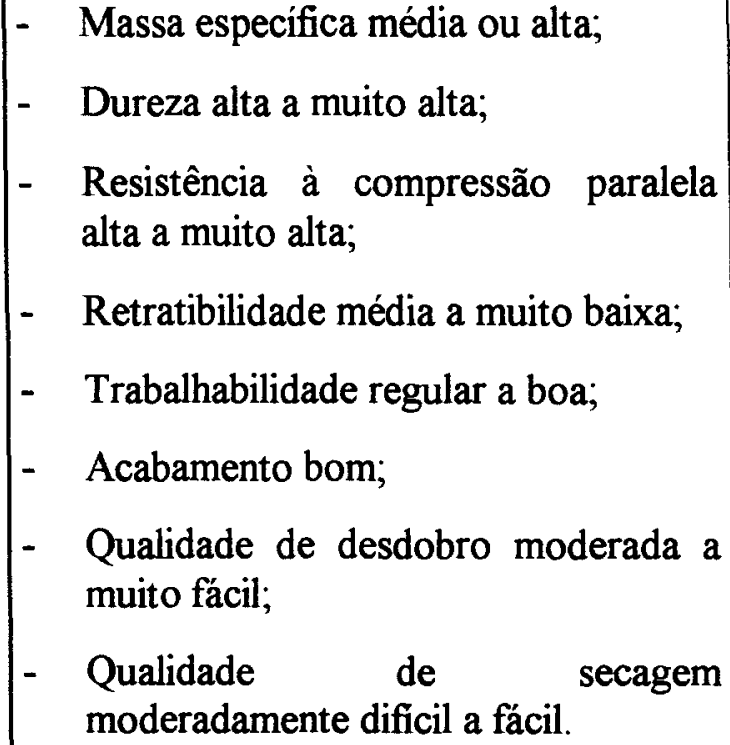 \\
\hline
\end{tabular}

Tabela 3.67 - Assoalhos Industriais

\begin{tabular}{|c|c|}
\hline \multicolumn{2}{|c|}{ Assoalhos Industriais } \\
\hline Elementos estruturais & Requisitos técnicos necessários \\
\hline $\begin{array}{l}>\text { Tacos; } \\
>\text { Tábuas; } \\
>\text { Blocos. }\end{array}$ & 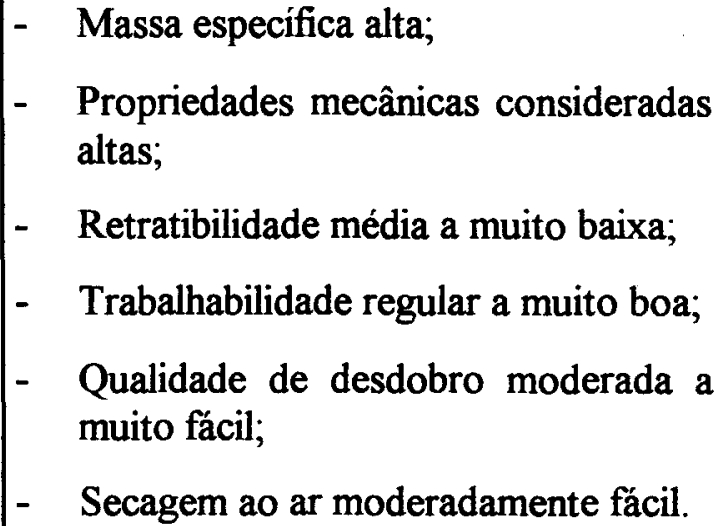 \\
\hline
\end{tabular}




\section{4 - APRESENTAÇÃO DOS RESULTADOS}

Neste capítulo são apresentados os resultados médios das propriedades físicas, de resistência e rigidez das trinta e quatro espécies de madeira da Amazônia Brasileira consideradas neste trabalho. Os resultados individuais dos ensaios são mostrados no Anexo 1. A análise dos resultados abrangeu apenas os valores médios das propriedades conforme os parâmetros dos critérios de Sallenave, Nahuz e Nogueira, adotados neste trabalho. Também são apresentados neste capítulo, aspectos referentes à secagem dos corpos-de-prova e características a respeito da trabalhabilidade.

As propriedades consideradas estão apresentadas na Tabela 4.1 e os resultados dos valores médios das respectivas propriedades apresentados na Tabela 4.2.

Tabela 4.1 - Propriedades Físicas de Resistência e Rigidez consideradas

\begin{tabular}{c|l|l}
\hline \multicolumn{3}{|c|}{ Propriedades Físicas de Resistência e Rigidez consideradas } \\
\hline$\rho_{\mathbf{a p}}$ & Densidade aparente & $\mathrm{g} / \mathrm{cm}^{3}$ \\
\hline$\varepsilon_{\mathbf{r}}$ & Retração Radial & $\%$ \\
\hline $\boldsymbol{\varepsilon}_{\mathbf{t}}$ & Retração Tangencial & $\%$ \\
\hline $\mathbf{f}_{\mathbf{c o}}$ & Resistência à Compressão Paralela às Fibras & $\mathrm{daN} / \mathrm{cm}^{2}$ \\
\hline $\mathbf{f}_{\mathrm{to}}$ & Resistência à Tração Paralela às Fibras & $\mathrm{daN} / \mathrm{cm}^{2}$ \\
\hline $\mathbf{f}_{\mathbf{t g 0}}$ & Resistência à Tração Normal às Fibras & $\mathrm{daN} / \mathrm{cm}^{2}$ \\
\hline $\mathbf{f}_{\mathrm{vo}}$ & Resistência ao Cisalhamento Paralelo às Fibras & $\mathrm{daN} / \mathrm{cm}^{2}$ \\
\hline $\mathbf{F}_{\mathbf{s}}$ & Resistência ao Fendilhamento & $\mathrm{daN} / \mathrm{cm}^{2}$ \\
\hline $\mathbf{f}_{\mathbf{M}}$ & Resistência Convencional no Ensaio de Flexão Estática & $\mathrm{daN} / \mathrm{cm}^{2}$ \\
\hline $\mathbf{E}_{\mathbf{c o}}$ & Módulo de Elasticidade Longitudinal na Compressão Paralela às Fibras & $\mathrm{daN} / \mathrm{cm}^{2}$ \\
\hline $\mathbf{E}_{\mathbf{t o}}$ & Módulo de Elasticidade Longitudinal na Tração Paralela às Fibras & $\mathrm{daN} / \mathrm{cm}^{2}$ \\
\hline $\mathbf{E}_{\mathbf{M}}$ & Módulo de Elasticidade Longitudinal no Ensaio de Flexão Estática & $\mathrm{daN} / \mathrm{cm}^{2}$ \\
\hline $\mathbf{f}_{\mathrm{H} 0}$ & Dureza Paralela às Fibras & $\mathrm{daN} / \mathrm{cm}^{2}$ \\
\hline $\mathbf{f}_{\mathrm{H} 90}$ & Dureza Normal às Fibras & $\mathrm{daN} / \mathrm{cm}^{2}$ \\
\hline$T$ & Tenacidade & $\mathrm{daN} \times \mathrm{m}$ \\
\hline & &
\end{tabular}


Tabela 4.2 - Propriedades Físicas de Resistência e Rigidez das espécies estudadas - Valores médios $\bar{X}$

\begin{tabular}{|c|c|c|c|c|c|c|c|c|c|c|c|c|c|c|c|}
\hline \multirow{2}{*}{$\begin{array}{c}\text { ESPÉCIES } \\
\text { ESTUDADAS } \\
\begin{array}{c}\text { UMIDADE } \\
12 \%\end{array}\end{array}$} & \multicolumn{15}{|c|}{ PROPRIEDADES FÍSICAS DE RESISTÊNCIA E DE RIGIDEZ - (VALORES MÉDIOS) } \\
\hline & $\begin{array}{c}\rho_{\text {ap }} \\
\left(\mathrm{g} / \mathrm{cm}^{3}\right)\end{array}$ & $\begin{array}{l}\boldsymbol{E}_{\mathbf{r}} \\
(\%)\end{array}$ & $\begin{array}{c}\boldsymbol{E}_{\mathbf{t}} \\
(\%)\end{array}$ & $\underset{\left(\mathrm{daN} / \mathrm{cm}^{2}\right)}{\mathbf{f}_{\mathbf{c o}}}$ & $\underset{\left(\mathrm{daN} / \mathrm{cm}^{2}\right)}{\mathbf{f}_{\text {to }}}$ & $\begin{array}{c}\mathbf{f}_{\mathbf{t 9 0}} \\
\left(\mathrm{daN} / \mathrm{cm}^{2}\right)\end{array}$ & $\underset{\left(\mathrm{daN} / \mathrm{cm}^{2}\right)}{\mathbf{f}_{\mathrm{vo}}}$ & $\begin{array}{c}\mathbf{f}_{\mathrm{so}} \\
\left(\mathrm{daN} / \mathrm{cm}^{2}\right)\end{array}$ & $\underset{\left(\mathrm{daN} / \mathrm{cm}^{2}\right)}{\mathbf{f}_{\mathbf{M}}}$ & $\underset{\left(\mathrm{daN} / \mathrm{cm}^{2}\right)}{\mathbf{E}_{\mathrm{co}}}$ & $\underset{\left(\mathrm{daN} / \mathrm{cm}^{2}\right)}{\mathbf{E}_{\mathrm{to}}}$ & $\frac{\mathbf{E}_{\mathbf{M}}}{\left(\mathrm{daN} / \mathrm{cm}^{2}\right)}$ & $\underset{\left(\mathrm{daN} / \mathrm{cm}^{2}\right)}{\mathbf{f}_{\mathrm{HO}}}$ & $\underset{\left(\mathrm{daN} / \mathrm{cm}^{2}\right)}{\mathbf{f}_{\mathbf{H} 90}}$ & $\frac{\mathbf{T}}{(\mathrm{daN} \times \mathrm{m})}$ \\
\hline $\begin{array}{c}\text { Angelim Amargoso } \\
\text { (Vataireia fusca) }\end{array}$ & 0,77 & 4,49 & 8,63 & 599 & 752 & 28 & 160 & 6 & 892 & 159403 & 160228 & 149472 & 996 & 606 & 0,959 \\
\hline $\begin{array}{c}\text { Angelim Araroba } \\
\text { (Vataireopsis } \\
\text { araroba) }\end{array}$ & 0,68 & 3,99 & 6,13 & 502 & 695 & 32 & 113 & 6 & 799 & 125254 & 118854 & 119433 & 612 & 398 & 0,689 \\
\hline $\begin{array}{c}\text { Angelim Ferro } \\
\text { (Hymenolobium sp) }\end{array}$ & 1,17 & 5,18 & 8,24 & 791 & 1179 & 38 & 200 & 8 & 1326 & 209463 & 197880 & 189384 & 1525 & 1356 & 1,602 \\
\hline $\begin{array}{c}\text { Angelim Pedra } \\
\text { (Hymenolobium } \\
\text { petraeum) }\end{array}$ & 0,69 & 4,30 & 7,00 & 655 & 780 & 35 & 146 & 7 & 300 & 14304 & 124677 & 141366 & 994 & 674 & 1,150 \\
\hline $\begin{array}{l}\text { Angelim Pedra } \\
\text { Verdadeiro } \\
\text { (Dinizia excelsa) }\end{array}$ & 1,13 & 5,10 & 8,42 & 775 & 1049 & 48 & 189 & 9 & 1102 & 166947 & 170243 & 152154 & 1458 & 1370 & 1,982 \\
\hline $\begin{array}{l}\text { Angelim Saia } \\
\text { (Vatairea } s p)\end{array}$ & 0,76 & 4,30 & 7,96 & 636 & 1005 & 30 & 146 & 9 & 1106 & 242494 & 209669 & 175610 & 843 & 620 & 4,544 \\
\hline $\begin{array}{l}\text { Angico Preto. } \\
\text { (Piptadenia } \\
\text { macrocarpa) } \\
\end{array}$ & 0,89 & 4,32 & 7,72 & 725 & 1104 & 50 & 245 & 10 & 1203 & 153748 & 160398 & 164977 & 1574 & 1446 & 1,461 \\
\hline $\begin{array}{c}\text { Branquilho } \\
\text { (Terminalia sp) }\end{array}$ & 0,81 & 4,87 & 9,08 & 485 & 879 & 32 & 160 & 7 & 829 & 138134 & 144388 & 154900 & 877 & 713 & 0,922 \\
\hline $\begin{array}{c}\text { Cafearana } \\
(\text { Andira } s p)\end{array}$ & 0,68 & 5,40 & 9,84 & 575 & 828 & 32 & 98 & 6 & 937 & 139661 & 135611 & 138497 & 810 & 479 & 0,735 \\
\hline $\begin{array}{c}\text { Canafistula } \\
\text { (Cássia ferruginea) }\end{array}$ & 0,86 & 4,43 & 7,71 & 520 & 849 & 60 & 185 & 11 & 886 & 146130 & 140872 & 147687 & - & $*$ & $*$ \\
\hline
\end{tabular}

"Dado desconsiderado, CP com defeito. 
Tabela 4.2 (continuação) - Propriedades Físicas de Resistência e Rigidez das espécies estudadas - Valores médios $\bar{X}$

\begin{tabular}{|c|c|c|c|c|c|c|c|c|c|c|c|c|c|c|c|}
\hline $\begin{array}{l}\text { UMIDADE } \\
12 \%\end{array}$ & $\underset{\left(\mathrm{g} / \mathrm{cm}^{3}\right)}{\rho_{\text {ap }}}$ & $\begin{array}{l}\varepsilon_{\mathbf{r}} \\
(\%)\end{array}$ & $\begin{array}{c}\boldsymbol{\varepsilon}_{\mathbf{t}} \\
(\%)\end{array}$ & $\underset{\left(\mathrm{daN} / \mathrm{cm}^{2}\right)}{\mathbf{f}_{\mathbf{c o}}}$ & $\underset{\left(\mathrm{daN} / \mathrm{cm}^{2}\right)}{\mathbf{f}_{\mathrm{to}}}$ & $\begin{array}{c}\mathbf{f}_{\mathbf{t g 0}} \\
\left(\mathrm{daN} / \mathrm{cm}^{2}\right)\end{array}$ & $\begin{array}{c}\mathbf{f v o}_{\text {vo }} \\
\left(\mathrm{daN} / \mathrm{cm}^{2}\right)\end{array}$ & $\frac{\mathbf{f}_{\mathbf{s o}}}{\left(\mathrm{daN} / \mathrm{cm}^{2}\right)}$ & $\underset{\left(\mathrm{daN} / \mathrm{cm}^{2}\right)}{\mathbf{f}_{\mathbf{M}}}$ & $\underset{\left(\mathrm{daN} / \mathrm{cm}^{2}\right)}{\mathbf{E}_{\mathbf{c o}}}$ & $\underset{\left(\mathrm{daN} / \mathrm{cm}^{2}\right)}{\mathbf{E}_{\mathrm{to}}}$ & $\frac{\mathbf{E}_{\mathbf{M}}}{\left(\mathrm{daN} / \mathrm{cm}^{2}\right)}$ & $\underset{\left(\mathrm{daN} / \mathrm{cm}^{2}\right)}{\mathbf{f}_{\mathbf{H O}}}$ & $\begin{array}{c}\mathbf{f H 9 O}_{\mathbf{H 9 0}} \\
\left(\mathrm{daN} / \mathrm{cm}^{2}\right)\end{array}$ & $\underset{(\mathrm{daN} \times \mathrm{m})}{\mathbf{T}}$ \\
\hline $\begin{array}{c}\text { Casca Grossa } \\
\text { (") }\end{array}$ & 0,79 & 6,04 & 11,65 & 585 & 1319 & 43 & 140 & 8 & 1067 & 165883 & 172459 & 163181 & 980 & 651 & 1,221 \\
\hline $\begin{array}{c}\text { Castelo } \\
\text { (Gossypiospermun) }\end{array}$ & 0,76 & 4,02 & 6,64 & 548 & 1036 & 70 & 213 & 14 & 1030 & 111048 & 131668 & 113748 & 1006 & 653 & 1,397 \\
\hline $\begin{array}{c}\text { Catanudo } \\
\text { (Callopyllum sp) }\end{array}$ & 0,80 & 5,41 & 8,37 & 506 & 677 & 36 & 164 & 6 & 831 & 130291 & 154987 & 147286 & 847 & 592 & 1,306 \\
\hline $\begin{array}{c}\text { Cedro Amargo } \\
\text { (Cedrella odorata) }\end{array}$ & 0,51 & 3,97 & 5,32 & 391 & 598 & 30 & 103 & 6 & 669 & 97253 & 104184 & 96251 & 542 & 329 & 0,460 \\
\hline $\begin{array}{c}\text { Cedrorana } \\
\text { (Cedrelinga } \\
\text { Catenaeformis) } \\
\end{array}$ & 0,57 & 3,49 & 6,44 & 413 & 617 & 31 & 119 & 6 & 605 & 102524 & 109697 & 100324 & 580 & 357 & 0,451 \\
\hline $\begin{array}{l}\text { Champanhe } \\
\text { (Dipteryx sp) }\end{array}$ & 1,09 & 3,95 & 6,38 & 950 & 1223 & 29 & 178 & 8 & 1648 & 230019 & 209533 & 251740 & 1381 & 1273 & " \\
\hline $\begin{array}{c}\text { Cupiúba } \\
\text { (Goupia Glabra) } \\
\end{array}$ & 0,85 & 4,27 & 7,13 & 537 & 735 & 33 & 179 & 7 & 786 & 131013 & 130991 & 126457 & 981 & 662 & 0,672 \\
\hline $\begin{array}{c}\text { Cutiúba } \\
\text { (Qualea paraensis) }\end{array}$ & 1,15 & 4,89 & 7,76 & 790 & 1075 & 35 & 179 & 9 & 1269 & 182378 & 165687 & 169842 & 1636 & 1184 & 1,623 \\
\hline $\begin{array}{c}\text { Garapa } \\
\text { (Apuleia leiocarpa) }\end{array}$ & 0,92 & 4,33 & 7,61 & 734 & 1161 & 73 & 196 & 10 & 1189 & 177182 & 166962 & 169233 & 1126 & 979 & 1,443 \\
\hline $\begin{array}{c}\text { Goiabão } \\
\text { (Planchonella } \\
\text { pachycarpa) }\end{array}$ & 0,94 & 8,90 & 18,84 & 485 & 1193 & 87 & 141 & 12 & 1065 & 187169 & 182674 & 183671 & $*$ & $*$ & * \\
\hline $\begin{array}{c}\text { Guaiçara } \\
\text { (Luetzelburgia sp) }\end{array}$ & 1,09 & 4,34 & 6,54 & 714 & 1165 & 42 & 208 & 7 & 1222 & 153017 & 163047 & 151264 & 2100 & 1113 & 2,282 \\
\hline $\begin{array}{l}\text { Guarucaia } \\
\text { (Peltophorum } \\
\text { vogelianum) }\end{array}$ & 0,92 & 4,13 & 8,09 & 624 & 749 & 56 & 201 & 10 & 956 & 162138 & 138700 & 150022 & 960 & 774 & 1,267 \\
\hline
\end{tabular}

\footnotetext{
"- Dado não conclusivo dos caracteres anatômicos da espécie estudada.

"Dado desconsiderado, CP com defeito.
} 
Tabela 4.2 (continuação) - Propriedades Físicas de Resistência e Rigidez das espécies estudadas - Valores médios $\bar{X}$

\begin{tabular}{|c|c|c|c|c|c|c|c|c|c|c|c|c|c|c|c|}
\hline $\begin{array}{c}\text { UMIDADE } \\
12 \%\end{array}$ & $\begin{array}{c}\rho_{\text {ap }} \\
\left(\mathrm{g} / \mathrm{cm}^{3}\right)\end{array}$ & $\begin{array}{l}\boldsymbol{E}_{\mathbf{r}} \\
(\%)\end{array}$ & $\begin{array}{c}\boldsymbol{E}_{\mathrm{t}} \\
(\%)\end{array}$ & $\frac{\mathbf{f}_{\mathrm{co}}}{\left(\mathrm{daN} / \mathrm{cm}^{2}\right)}$ & $\begin{array}{c}\mathbf{f}_{\mathbf{t o}} \\
\left(\mathrm{daN} / \mathrm{cm}^{2}\right)\end{array}$ & $\begin{array}{c}\mathbf{f}_{\mathbf{t} \mathbf{9 0}} \\
\left(\mathrm{daN} / \mathrm{cm}^{2}\right)\end{array}$ & $\begin{array}{c}\mathbf{f}_{\mathbf{v o}} \\
\left(\mathrm{daN} / \mathrm{cm}^{2}\right)\end{array}$ & $\underset{\left(\mathrm{daN} / \mathrm{cm}^{2}\right)}{\mathbf{f}_{\mathbf{s o}}}$ & $\underset{\left(\mathrm{daN} / \mathrm{cm}^{2}\right)}{\mathbf{f}_{\mathbf{M}}}$ & $\underset{\left(\mathrm{daN} / \mathrm{cm}^{2}\right)}{\mathbf{E}_{\mathrm{co}}}$ & $\underset{\left(\mathrm{daN} / \mathrm{cm}^{2}\right)}{\mathbf{E}_{\text {to }}}$ & $\underset{\left(\mathrm{daN} / \mathrm{cm}^{2}\right)}{\mathbf{E}_{\mathbf{M}}}$ & $\begin{array}{c}\mathbf{f}_{\mathbf{H O}} \\
\left(\mathrm{daN} / \mathrm{cm}^{2}\right)\end{array}$ & $\underset{\left(\mathrm{daN} / \mathrm{cm}^{2}\right)}{\left.\mathbf{f}_{\mathbf{H}}\right)}$ & $\underset{(\mathrm{daN} \times \mathrm{m})}{\mathbf{T}}$ \\
\hline $\begin{array}{c}\text { Itaúba } \\
\text { (Mezilaurus } \\
\text { itauba) } \\
\end{array}$ & 0,96 & 2,87 & 8,27 & 690 & 1037 & 21 & 188 & 5 & 1166 & 174430 & 176296 & 173448 & 765 & 739 & 1,453 \\
\hline $\begin{array}{c}\text { Louro Preto } \\
(\text { Octea sp })\end{array}$ & 0,68 & 4,11 & 7,95 & 569 & 705 & 33 & 150 & 6 & 927 & 142714 & 132209 & 139928 & 856 & 511 & 0,675 \\
\hline $\begin{array}{c}\text { Mandioqueira } \\
\text { (Qualea albiflora) }\end{array}$ & 0,85 & 4,72 & 9,34 & 708 & 910 & 28 & 170 & 6 & 1131 & 191433 & 187379 & 183025 & 1109 & 741 & 1,188 \\
\hline $\begin{array}{l}\text { Oiticica Amarela } \\
\text { (Clartsia } \\
\text { racemosa) }\end{array}$ & 0,76 & 2,47 & 6,21 & 700 & 858 & 39 & 178 & 6 & 1075 & 147188 & 146754 & 144913 & 957 & 589 & 1,338 \\
\hline $\begin{array}{c}\text { Oiuchu } \\
\text { (Pradosia sp) }\end{array}$ & 0,93 & 5,89 & 9,16 & 774 & 1300 & 30 & 201 & 6 & 1225 & 177179 & 181837 & 167088 & 1255 & 911 & 1,738 \\
\hline $\begin{array}{l}\text { Parinari (Parinari } \\
\text { excelsa sabine) }\end{array}$ & 0,79 & 5,37 & 9,00 & 603 & 1121 & $*$ & 134 & 10 & 1118 & 218812 & 188469 & 164565 & 876 & 677 & 3,738 \\
\hline $\begin{array}{c}\text { Piolho } \\
\text { (Tapirira sp) }\end{array}$ & 0,83 & 4,55 & 8,57 & 619 & 731 & 43 & 147 & 7 & 758 & 134036 & 134535 & 117896 & 992 & 722 & 1,446 \\
\hline $\begin{array}{c}\text { Quarubarana } \\
\text { (Erisma } \\
\text { uncinatum) }\end{array}$ & 0,54 & 3,61 & 7,16 & 378 & 581 & 26 & 96 & 4 & 674 & 87828 & 91723 & 88419 & 636 & 393 & 0,488 \\
\hline $\begin{array}{l}\text { Rabo de Arraia } \\
\text { (Vochysia sp) }\end{array}$ & 0,72 & 3,69 & 7,24 & 575 & 689 & 24 & 149 & 5 & 793 & 139798 & 136889 & 138584 & 854 & 508 & 0,737 \\
\hline $\begin{array}{c}\text { Tachi } \\
\text { (Sclerabium sp) } \\
\end{array}$ & 1,05 & 4,25 & 9,39 & 878 & 1381 & 53 & 208 & 13 & 1401 & 199005 & 194753 & 208126 & 1161 & 1285 & $*$ \\
\hline $\begin{array}{c}\text { Tatajuba (Bagassa } \\
\text { guianensis) }\end{array}$ & 0,94 & 4,28 & 5,78 & 802 & 929 & 40 & 200 & 9 & 1106 & 185712 & 168360 & 181141 & 1193 & 884 & 0,965 \\
\hline $\begin{array}{c}\text { Umirana } \\
\text { (Qualea retusa) }\end{array}$ & 0,71 & 3,58 & 6,25 & 538 & 539 & 29 & 145 & 6 & 668 & 101775 & 110437 & 107938 & 879 & 534 & 0,496 \\
\hline
\end{tabular}

"Dado desconsiderado, CP com defeito. 


\section{1 - ANÁLISE DOS RESULTADOS}

A partir dos resultados dos ensaios realizados, considerando as recomendações dos critérios propostos por Sallenave, Nahuz e Nogueira, adotou-se a simbologia, inicialmente apresentada por Nogueira, onde B - Baixa, M - Média, A - Alta. Adotou-se para os símbolos "B", "M" e "A" respectivamente, os fatores de multiplicação correspondentes a “1”, “ 3 ” e “5”, para interpretação conclusiva dos valores das propriedades, visando os usos finais das espécies.

Observa-se que serão classificadas separadamente as propriedades de resistência e rigidez. As propriedades foram selecionadas de acordo com as propriedades representativas empregadas na avaliação dos estados limites últimos, segundo o anexo B da NBR 7190/1997. No total, são cinco as propriedades de resistência e três as propriedades de rigidez consideradas, o que determinará sua classificação final, a partir do somatório destas e correspondência aos intervalos numéricos referente a cada símbolo.

Denomina-se por $C_{i}^{*}$ intervalo de classe, para $i=1,2,3$. Sendo $C_{1}=$ Classe Baixa, $\mathrm{C}_{2}=$ Classe Média e $\mathrm{C}_{3}=$ Classe Alta, estando estas apresentadas na Tabela 4.3 .

Os resultados finais para cada espécie, obtidos a partir da soma dos fatores de multiplicação adotados, são apresentados nas Tabelas 4.4 e 4.5. E na seqüência, a Tabela 4.6, apresenta a Classificação da densidade aparente, segundo Sallenave e Nahuz.

Tabela 4.3 - Intervalos correspondentes ao somatório dos valores numéricos dos símbolos - classificação

\begin{tabular}{c|c}
\hline$\left(\mathbf{C}_{\mathbf{i}-\mathbf{f}}\right) \rightarrow$ Resistência & $\left(\mathbf{C}_{\mathbf{i}-\mathbf{E}}\right) \rightarrow$ Rigidez \\
\hline$(0 \leftrightarrow 9) \rightarrow \mathrm{C}_{1}$ - BAIXA & $(0 \leftrightarrow 6) \rightarrow \mathrm{C}_{1}$ - BAIXA \\
\hline$(10 \leftrightarrow 16) \rightarrow \mathrm{C}_{2}$ - MÉDIA & $(7 \leftrightarrow 9) \rightarrow \mathrm{C}_{2}$ - MÉDIA \\
\hline$(17 \leftrightarrow 25) \rightarrow \mathrm{C}_{3}$ - ALTA & $(10 \leftrightarrow 15) \rightarrow \mathrm{C}_{3}$ - ALTA \\
\hline
\end{tabular}

\footnotetext{
${ }^{*}$ Onde $C_{i}$ não é uma distribuição de freqüência.
} 
Tabela 4.4 - Classificação - Propriedades de Resistência

\begin{tabular}{|c|c|c|c|c|c|c|}
\hline ESPÉCIES & $\mathbf{f}_{\mathbf{M}}$ & $\mathbf{f}_{\mathrm{co}}$ & $\mathbf{f}_{\mathbf{t 0}}$ & $\mathbf{f}_{\mathbf{9 0}}$ & $\mathbf{f}_{\mathrm{vo}}$ & $\left(\sum \Leftrightarrow C_{i-f}\right)$ \\
\hline Angelim Amargoso & $\mathrm{B}$ & $\mathrm{A}$ & $\bar{M}$ & M & $\bar{A}$ & $19=C_{3}-$ ALTA \\
\hline Angelim Araroba & $\mathrm{B}$ & $\mathrm{M}$ & $\mathrm{B}$ & $\mathrm{M}$ & $\bar{A}$ & $13=C_{2}-$ MÉDIA \\
\hline Angelim Ferro & $\mathbf{M}$ & $\mathrm{A}$ & A & $\mathrm{M}$ & $\mathrm{A}$ & $21=C_{3}-$ ALTA \\
\hline Angelim Pedra & A & $\mathrm{M}$ & $\mathbf{M}$ & $\mathbf{M}$ & A & $19=C_{3}-$ ALTA \\
\hline Angelim Pedra Verdadeiro & $\mathbf{M}$ & $\mathrm{A}$ & A & A & A & $23=C_{3}-A L T A$ \\
\hline Angelim Saia & $\mathbf{M}$ & $\mathbf{M}$ & $\mathrm{A}$ & $\mathbf{M}$ & $\mathrm{A}$ & $19=C_{3}-$ ALTA \\
\hline Angico Preto & $\mathbf{M}$ & $\mathbf{M}$ & $\mathrm{A}$ & $\mathrm{A}$ & A & $21=C_{3}-$ ALTA \\
\hline Branquilho & $\mathrm{B}$ & $\mathbf{M}$ & $\mathbf{M}$ & $\mathbf{M}$ & A & $15=C_{2}-$ MÉDIA \\
\hline Cafearana & $\mathbf{B}$ & $\mathbf{M}$ & $\mathrm{M}$ & $\mathrm{M}$ & $\mathbf{M}$ & $14=C_{2}-$ MÉDIA \\
\hline Canafistula & B & $\mathbf{M}$ & $\mathbf{M}$ & $\mathrm{A}$ & $\mathrm{A}$ & $17=C_{3}-$ ALTA \\
\hline Casca Grossa & B & $\mathbf{M}$ & $\mathbf{M}$ & A & A & $17=C_{3}-$ ALTA \\
\hline Castelo & $\mathrm{M}$ & $\mathrm{B}$ & $\mathbf{M}$ & $\mathrm{A}$ & $\mathrm{A}$ & $17=C_{3}-$ ALTA \\
\hline Catanudo & $\mathrm{B}$ & $M$ & $\mathrm{~B}$ & $\mathbf{M}$ & $\mathrm{A}$ & $13=C_{2}-$ MÉDIA \\
\hline Cedro Amargo & B & $\mathbf{B}$ & $\mathrm{A}$ & $\mathbf{M}$ & $\mathbf{B}$ & $11=C_{2}-$ MÉDIA \\
\hline Cedrorana & B & $\mathbf{M}$ & B & $\mathbf{M}$ & $\mathbf{M}$ & $11=C_{2}-$ MÉDIA \\
\hline Champanhe & $\mathrm{A}$ & A & $\mathrm{A}$ & $\mathbf{M}$ & $\mathrm{A}$ & $23=C_{3}-$ ALTA \\
\hline Cupiúba & $\mathrm{B}$ & $\mathbf{M}$ & $\mathbf{B}$ & $\mathbf{M}$ & $\mathbf{A}$ & $13=C_{2}$ - MÉDIA \\
\hline Cutiúba & B & A & $\mathrm{A}$ & $\mathbf{M}$ & A & $19=C_{3}-$ ALTA \\
\hline Garapa & $\mathbf{M}$ & $\mathrm{A}$ & $\overline{\mathrm{A}}$ & $\mathrm{A}$ & A & $23=C_{3}-$ ALTA \\
\hline Goiabão & $\mathbf{M}$ & A & A & $\mathbf{M}$ & & $16=C_{3}-A L T A$ \\
\hline Guaiçara & $\mathbf{M}$ & $\mathbf{M}$ & $\mathrm{A}$ & $\mathbf{M}$ & $\mathrm{A}$ & $19=C_{3}-$ ALTA \\
\hline Guarucaia & $\mathrm{B}$ & $\mathbf{M}$ & $\mathrm{B}$ & $\mathrm{A}$ & A & $15=C_{2}-$ MÉDIA \\
\hline Itaúba & $\mathrm{B}$ & $\mathbf{M}$ & A & B & $\bar{A}$ & $15=C_{2}-$ MÉDIA \\
\hline Louro Preto & $\mathbf{M}$ & $\mathbf{M}$ & $\mathrm{A}$ & $\mathbf{M}$ & $\mathbf{M}$ & $17=C_{3}-$ ALTA \\
\hline Mandioqueira & $\mathbf{M}$ & $\mathrm{A}$ & $\mathbf{M}$ & $\mathbf{M}$ & $\mathbf{A}$ & $19=C_{3}-$ ALTA \\
\hline Oiticica Amarela & $\mathbf{M}$ & $\mathrm{A}$ & $\mathrm{B}$ & $\mathbf{M}$ & $\mathrm{A}$ & $17=C_{3}-$ ALTA \\
\hline Oiuchu & $\mathbf{B}$ & $\mathrm{A}$ & A & $\mathbf{M}$ & A & $19=C_{3}-$ ALTA \\
\hline Parinari & $\mathbf{M}$ & $\mathbf{M}$ & A & $\mathbf{M}$ & $\mathbf{A}$ & $19=C_{3}-$ ALTA \\
\hline Piolho & $\mathrm{B}$ & $\mathbf{M}$ & $\mathrm{B}$ & $\mathbf{M}$ & $\mathrm{A}$ & $13=C_{2}-$ MÉDIA \\
\hline Quarubarana & B & $\mathbf{M}$ & $\mathrm{B}$ & $\mathbf{M}$ & B & $9=C_{1}-$ BAIXA \\
\hline Rabo de Arraia & $\mathrm{B}$ & $\mathbf{M}$ & B & $\mathbf{B}$ & $\mathrm{A}$ & $11=C_{2}-$ MÉDIA \\
\hline Tachi & B & A & A & $\mathrm{A}$ & A & $21=C_{3}-$ ALTA \\
\hline Tatajuba & $\mathbf{M}$ & A & $\mathbf{M}$ & $\mathbf{M}$ & A & $19=C_{3}-$ ALTA \\
\hline Umirana & $\mathrm{B}$ & $\mathbf{M}$ & B & $\mathbf{M}$ & $\bar{A}$ & $13=C_{2}-$ MÉDIA \\
\hline
\end{tabular}

* Dado desconsiderado, Cp com defeito. 
Tabela 4.5 - Classificação - Propriedades de Rigidez

\begin{tabular}{|c|c|c|c|c|}
\hline ESPÉCIES & $\mathbf{E}_{\mathbf{M}}$ & $\mathbf{E}_{\mathbf{c 0}}$ & $\mathbf{E}_{\mathbf{t} 0}$ & $\left(\sum \leftrightarrow C_{i-E}\right)$ \\
\hline AngelimAmargoso & $\mathbf{M}$ & $\mathbf{M}$ & $\mathbf{M}$ & $9=C_{2}-$ MÉDIA \\
\hline Angelim Araroba & $\mathrm{B}$ & $\mathrm{B}$ & $\mathrm{B}$ & $3=C_{1}-$ BAIXA \\
\hline Angelim Ferro & $\mathrm{A}$ & $\mathrm{A}$ & $\mathbf{M}$ & $13=C_{3}-$ ALTA \\
\hline Angelim Pedra & $\mathbf{M}$ & $\mathrm{B}$ & $\mathrm{B}$ & $5=C_{1}-$ BAIXA \\
\hline Angelim Pedra Verdadeiro & A & $\bar{M}$ & $\mathbf{M}$ & $11=C_{3}-$ ALTA \\
\hline Angelim Saia & A & A & $\mathrm{A}$ & $15=C_{3}-$ ALTA \\
\hline Angico Preto & A & $\mathbf{M}$ & $\mathrm{M}$ & $11=C_{3}-$ ALTA \\
\hline Branquilho & $\mathrm{A}$ & B & B & $7=C_{2}-$ MÉDIA \\
\hline Cafearana & $\mathbf{M}$ & B & B & $5=C_{1}-B A L A$ \\
\hline Canafistula & $\mathbf{M}$ & B & $\mathrm{B}$ & $5=C_{1}-$ BAIXA \\
\hline Casca Grossa & $\mathbf{A}$ & $\mathbf{M}$ & $\mathbf{M}$ & $11=C_{3}-$ ALTA \\
\hline Castelo & B & B & $\mathrm{B}$ & $3=C_{1}-$ BAIXA \\
\hline Catanudo & $\mathbf{M}$ & $\mathrm{B}$ & $\mathrm{B}$ & $5=C_{1}-$ BAIXA \\
\hline Cedro Amargo & $\mathrm{B}$ & B & $\mathrm{B}$ & $3=\mathrm{C}_{1}-\mathrm{BAIXA}$ \\
\hline Cedrorana & B & $\mathbf{B}$ & B & $3=C_{1}-$ BAIXA \\
\hline Champanhe & $\mathrm{A}$ & A & $\mathbf{A}$ & $15=C_{3}-$ ALTA \\
\hline Cupiúba & $\mathbf{M}$ & B & $\mathbf{B}$ & $5=C_{1}-$ BADXA \\
\hline Cutiúba & $\mathrm{A}$ & $\mathrm{A}$ & $\mathbf{M}$ & $13=C_{3}-A L T A$ \\
\hline Garapa & $\mathrm{A}$ & $\mathbf{M}$ & $\mathbf{M}$ & $11=C_{3}-$ ALTA \\
\hline Goiabão & $\mathrm{A}$ & $\mathbf{M}$ & $\mathbf{M}$ & $11=C_{3}-$ ALTA \\
\hline Guaiçara & $\mathrm{A}$ & $\mathbf{M}$ & $\mathbf{A}$ & $13=C_{3}-A L T A$ \\
\hline Guarucaia & $\mathrm{A}$ & $\mathbf{M}$ & B & $9=C_{2}-$ MÉDIA \\
\hline Itaúba & $\mathrm{A}$ & $\mathbf{M}$ & $\mathbf{M}$ & $11=C_{3}-$ ALTA \\
\hline Louro preto & $\mathbf{M}$ & $\mathrm{B}$ & $\mathrm{B}$ & $5=C_{1}-B A I X A$ \\
\hline Mandioqueira & $\mathrm{A}$ & $\mathbf{A}$ & $\mathbf{M}$ & $13=C_{3}-$ ALTA \\
\hline Oiticica Amarela & $\mathbf{M}$ & B & $\mathrm{B}$ & $5=C_{1}-$ BAIXA \\
\hline Oiuchu & $\mathrm{A}$ & $\mathbf{M}$ & $\mathbf{M}$ & $11=C_{3}-A L T A$ \\
\hline Parinari & $\mathbf{A}$ & $\mathrm{A}$ & $\mathbf{M}$ & $13=C_{3}-$ ALTA \\
\hline Piolho & $\mathrm{B}$ & $\mathrm{B}$ & $\mathrm{B}$ & $3=C_{1}-$ BAIXA \\
\hline Quarubarana & $\mathbf{B}$ & $\mathbf{B}$ & $\mathbf{B}$ & $3=C_{1}-$ BAIXA \\
\hline Rabo de Arraia & $\mathbf{M}$ & $\mathrm{B}$ & $\mathrm{B}$ & $5=C_{1}-$ BAIXA \\
\hline Tachi & A & A & $\mathbf{M}$ & $13=C_{3}-$ ALTA \\
\hline Tatajuba & $\mathbf{A}$ & $\mathbf{M}$ & $\mathbf{M}$ & $11=C_{3}-A L T A$ \\
\hline Umirana & B & B & B & $3=C_{1}-$ BAIXA \\
\hline
\end{tabular}


Tabela 4.6 - Classificação - Propriedade Física - Densidade aparente - Sallenave e Nahuz

\begin{tabular}{|c|c|c|}
\hline ESPÉCIES & $\rho_{a p}\left(\mathrm{~g} / \mathrm{cm}^{3}\right)-12 \%$ & $\rho_{a p}-$ Classificação \\
\hline Angelim Amargoso & 0,77 & MÉDIA \\
\hline Angelim Araroba & 0,68 & MÉDIA \\
\hline Angelim Ferro & 1,17 & ALTA \\
\hline Angelim Pedra & 0,69 & MÉDIA \\
\hline Angelim Pedra Verdadeiro & 1,13 & ALTA \\
\hline Angelim Saia & 0,76 & MÉDIA \\
\hline Angico Preto & 0,89 & ALTA \\
\hline Branquilho & 0,81 & ALTA \\
\hline Cafearana & 0,68 & MÉDIA \\
\hline Canafistula & 0,86 & ALTA \\
\hline Casca Grossa & 0,79 & MÉDIA \\
\hline Castelo & 0,76 & MÉDIA \\
\hline Catanudo & 0,80 & MÉDIA \\
\hline Cedro Amargo & 0,51 & BAIXA \\
\hline Cedrorana & 0,57 & BADXA \\
\hline Champanhe & 1,09 & ALTA \\
\hline Cupiúba & 0,85 & ALTA \\
\hline Cutiúba & 1,15 & ALTA \\
\hline Garapa & 0,92 & ALTA \\
\hline Goiabão & 0,94 & ALTA \\
\hline Guaiçara & 1,09 & ALTA \\
\hline Guarucaia & 0,92 & ALTA \\
\hline Itaúba & 0,96 & ALTA \\
\hline Louro preto & 0,68 & MEDIA \\
\hline Mandioqueira & 0,85 & ALTA \\
\hline Oiticica Amarela & $0, \overline{76}$ & MÉDIA \\
\hline Oiuchu & 0,93 & ALTA \\
\hline Parinari & 0,79 & MÉDIA \\
\hline Piolho & 0,83 & ALTA \\
\hline Quarubarana & 0,54 & BAIXA \\
\hline Rabo de Arraia & $0, \overline{72}$ & MÉDIA \\
\hline Tachi & 1,05 & ALTA \\
\hline Tatajuba & 0,94 & ALTA \\
\hline Umirana & 0,71 & MEDIA \\
\hline
\end{tabular}




\subsection{1 - Características de secagem}

Neste trabalho, foram objeto de secagem peças com as seguintes dimensões nominais:

a. $6 \mathrm{~cm} \times 6 \mathrm{~cm} \times 200 \mathrm{~cm}$

b. $6 \mathrm{~cm} \times 12 \mathrm{~cm} \times 200 \mathrm{~cm}$

Tais peças foram secas até próxima à umidade de $12 \%$, em secagem lenta (temperatura $\leq 50^{\circ} \mathrm{C}$ ), sem a preocupação de registrar o tempo decorrido no processo.

\subsection{2 - Características de trabalhabilidade}

Os critérios adotados para analisar a trabalhabilidade foram baseados nos critérios propostos por Nahuz e por Sallenave.

Nahuz considera para cada espécie a porcentagem de peças livres de defeitos no final do processo de aplainamento, (vide Tabela 3.56). As porcentagens para as espécies estudadas estão apresentadas na Tabela 4.7, a seguir.

Sallenave, considera a cota de dureza através do cálculo efetuado a partir das propriedades dureza JANKA normal às fibras, e densidade aparente em umidade 12\%, (vide Tabela 3.42). As classificações para as espécies estudadas da cota de dureza, estão apresentadas na Tabela 4.8 , na seqüência. 
Tabela 4.7 - Classificação - \% de defeitos no aplainamento - Nahuz

\begin{tabular}{|c|c|c|c|}
\hline NOME POPULAR - NOME CIENTÍFICO & $\begin{array}{l}\% \text { sem } \\
\text { defeitos }\end{array}$ & $\begin{array}{c}\% \text { com } \\
\text { defeitos }\end{array}$ & Classificação \\
\hline Angelim Amargoso - Vatairea fusca & 79 & 21 & Boa \\
\hline Angelim Araroba - Vataireopsis araroba & 76 & 24 & Boa \\
\hline Angelim Ferro - Hymenolobium $s p$ & 75 & 25 & Boa \\
\hline Angelim Pedra - Hymenolobium patraeum & 75 & 25 & Boa \\
\hline Angelim Pedra Verdadeiro - Dinisia excelsa & 83 & 17 & Boa \\
\hline Angelim Saia - Vatairea $s p$ & 83 & 17 & Boa \\
\hline Angico Preto - Piptadenia macrocarpa & 75 & 25 & Boa \\
\hline Branquilho - Terminalia $s p$ & 91 & 9 & Muito boa \\
\hline Cafearana - Andira $s p$ & 84 & 16 & Boa \\
\hline Canafistula-Cássia ferruginea & 80 & 20 & Boa \\
\hline Casca Grossa - $\left({ }^{* *}\right)$ & 76 & 24 & Boa \\
\hline Castelo-Gossypiospermun praecox & 90 & 10 & Boa \\
\hline Catanudo - Calophyllum sp & 83 & 17 & Boa \\
\hline Cedro Amargo - Cedrela odorata & 92 & 8 & Muito boa \\
\hline Cedrorana - Cedrelinga catenaeformis & 80 & 20 & Boa \\
\hline Champanhe - Dipteryx sp & 91 & 9 & Muito boa \\
\hline Cupiúba - Goupia glabra & 78 & 22 & Boa \\
\hline Cutiúba - Qualea paraensis & 75 & 25 & Boa \\
\hline Garapa - Apuleia leiocarpa & 78 & 22 & Boa \\
\hline Goiabão-Planchonella pachycarpa & 57 & 43 & Pobre \\
\hline Guaiçara - Luetzelburgia sp & 72 & 28 & Boa \\
\hline Guarucaia - Peltophorum vogelianum & 76 & 24 & Boa \\
\hline Itaúba - Mezilaurus itauba & 85 & 15 & Boa \\
\hline Louro Preto - Ocotea $s p$ & 88 & 17 & Boa \\
\hline Mandioqueira - Qualea $s p$ & 78 & 12 & Boa \\
\hline Oiticica amarela - Clarisia racemosa & & $*$ & - \\
\hline Oichu - Pradozia sp & 67 & 33 & Regular \\
\hline Parinari-Parinari excelsa sabine & 83 & 17 & Boa \\
\hline Piolho-Tapirira sp & 73 & 27 & Boa \\
\hline Quarubarana - Erisma uncinatum & 85 & 15 & Boa \\
\hline Rabo de Arraia - Vochysia sp & * & $*$ & - \\
\hline Tachi - Sclerolobium $s p$ & 78 & 22 & Boa \\
\hline Tatajuba - Bagassa guianensis & 84 & 16 & Boa \\
\hline Umirana-Qualea retusa & 70 & 30 & Boa \\
\hline
\end{tabular}

- Dado não conclusivo dos caracteres anatômicos da espécie estudada.

"Dado desconhecido. 
Tabela 4.8 - Classificação - Cota de Dureza - Sallenave

\begin{tabular}{|c|c|c|c|c|}
\hline $\begin{array}{l}\text { ESPÉCIES - } \\
\text { umidade } 12 \%\end{array}$ & $\underset{\left(\mathrm{g} / \mathrm{cm}^{3}\right)}{\rho_{\mathbf{a p}}}$ & $\begin{array}{c}f_{H 90} \\
\left(\mathrm{daN} / \mathrm{cm}^{2}\right)\end{array}$ & $\begin{array}{l}\text { COTA DE } \\
\text { DUREZA }\end{array}$ & $\begin{array}{l}\text { QUALIFICAÇÃO / } \\
\text { APLICAÇÕES }\end{array}$ \\
\hline $\begin{array}{l}\text { Angelim Amargoso } \\
\text { (Vataireia fusca) }\end{array}$ & 0,77 & 606 & 1022 & $\begin{array}{c}\text { NORMAL - } \\
\text { MADEIRA INDUSTRIAL }\end{array}$ \\
\hline $\begin{array}{c}\text { Angelim Araroba } \\
\text { (Vataireopsis araroba) }\end{array}$ & 0,68 & 398 & 861 & $\begin{array}{c}\text { NORMAL - } \\
\text { MADEIRA INDUSTRIAL } \\
\end{array}$ \\
\hline $\begin{array}{c}\text { Angelim Ferro } \\
\text { (Hymenolobium sp }\end{array}$ & 1,17 & 1356 & 991 & $\begin{array}{c}\text { NORMAL - } \\
\text { MADEIRA INDUSTRIAL }\end{array}$ \\
\hline $\begin{array}{c}\text { Angelim Pedra } \\
\text { (Hymenolobium } \\
\text { paetrum) }\end{array}$ & 0,69 & 674 & 1416 & $\begin{array}{c}\text { FORTE - } \\
\text { MADEIRA PARA USOS ESPECIAIS }\end{array}$ \\
\hline $\begin{array}{c}\text { Angelim Pedra } \\
\text { Verdadeiro (Dinizia } \\
\text { excelsa) }\end{array}$ & 1,13 & 1370 & 1073 & $\begin{array}{l}\text { NORMAL - } \\
\text { MADEIRA INDUSTRIAL }\end{array}$ \\
\hline $\begin{array}{c}\text { Angelim Saia } \\
\text { (Vatairea sp) }\end{array}$ & 0,76 & 620 & 1073 & $\begin{array}{c}\text { NORMAL - } \\
\text { MADEIRA INDUSTRIAL }\end{array}$ \\
\hline $\begin{array}{l}\text { Angico Preto } \\
\text { (Piptadenia } \\
\text { macrocarpa) }\end{array}$ & 0,89 & 1446 & 1826 & $\begin{array}{l}\text { FORTE - } \\
\text { MADEIRA PARA USOS ESPECIAIS }\end{array}$ \\
\hline $\begin{array}{l}\text { Branquilho } \\
\text { (Terminalia sp) }\end{array}$ & 0,81 & 713 & 1087 & $\begin{array}{c}\text { NORMAL - } \\
\text { MADEIRA INDUSTRIAL }\end{array}$ \\
\hline $\begin{array}{c}\text { Cafearana } \\
\text { (Andira sp) }\end{array}$ & 0,68 & 479 & 1036 & $\begin{array}{c}\text { NORMAL- } \\
\text { MADEIRA INDUSTRIAL }\end{array}$ \\
\hline $\begin{array}{c}\text { Canafistula } \\
\text { (Cássia ferruginea) }\end{array}$ & 0,86 & * & - & - \\
\hline $\begin{array}{c}\text { Casca Grossa } \\
(\stackrel{*}{*})\end{array}$ & 0,79 & 651 & 1043 & $\begin{array}{c}\text { NORMAL - } \\
\text { MADEIRA INDUSTRIAL } \\
\end{array}$ \\
\hline $\begin{array}{c}\text { Castelo } \\
\text { (Gossypiospermun) }\end{array}$ & 0,76 & 653 & 1131 & $\begin{array}{c}\text { NORMAL - } \\
\text { MADEIRA INDUSTRIAL }\end{array}$ \\
\hline $\begin{array}{c}\text { Catanudo } \\
\text { (Callophyllum sp) } \\
\end{array}$ & 0,80 & 592 & 925 & $\begin{array}{c}\text { NORMAL - } \\
\text { MADEIRA INDUSTRIAL }\end{array}$ \\
\hline $\begin{array}{c}\text { Cedro Amargo } \\
\text { (Cedrella odorata) }\end{array}$ & 0,51 & 329 & 1265 & $\begin{array}{c}\text { FORTE - } \\
\text { MADEIRA PARA USOS ESPECIAIS }\end{array}$ \\
\hline \begin{tabular}{|c|}
$\begin{array}{c}\text { Cedrorana (Cedrelinga } \\
\text { Catenaeformis) }\end{array}$ \\
\end{tabular} & 0,57 & 357 & 1099 & $\begin{array}{c}\text { NORMAL - } \\
\text { MADEIRA INDUSTRIAL } \\
\end{array}$ \\
\hline $\begin{array}{l}\text { Champanhe } \\
\text { (Dipteryx sp) } \\
\end{array}$ & 1,09 & 1273 & 1072 & $\begin{array}{c}\text { NORMAL - } \\
\text { MADEIRA INDUSTRIAL }\end{array}$ \\
\hline $\begin{array}{c}\text { Cupiúba } \\
\text { (Goupia Glabra) }\end{array}$ & 0,85 & 662 & 916 & $\begin{array}{c}\text { NORMAL - } \\
\text { MADEIRA INDUSTRIAL }\end{array}$ \\
\hline
\end{tabular}

"Dado desconsiderado, CP com defeitos.

"* Dado não conclusivo dos caracteres anatômicos da espécie estudada. 
Tabela 4.8 - (continuação) - Classificação - Cota de Dureza - Sallenave

\begin{tabular}{|c|c|c|c|c|}
\hline $\begin{array}{l}\text { ESPÉCIES - } \\
\text { umidade } 12 \%\end{array}$ & $\underset{.\left(g / \mathrm{cm}^{3}\right)}{\rho_{\text {ap }}}$ & $\begin{array}{c}\mathbf{f}_{\mathrm{H} 90} \\
\left(\mathrm{daN} / \mathrm{cm}^{2}\right)\end{array}$ & $\begin{array}{l}\text { COTA DE } \\
\text { DUREZA }\end{array}$ & QUALIFICAÇÃO / APLICAÇŌES \\
\hline $\begin{array}{c}\text { Cutiúba } \\
\text { (Qualea paraensis) } \\
\end{array}$ & 1,15 & 1184 & 895 & $\begin{array}{c}\text { NORMAL - } \\
\text { MADEIRA INDUSTRIAL } \\
\end{array}$ \\
\hline $\begin{array}{c}\text { Garapa } \\
\text { (Apuleia leiocarpa) } \\
\end{array}$ & 0,92 & 979 & 1157 & $\begin{array}{c}\text { NORMAL - } \\
\text { MADEIRA INDUSTRIAL }\end{array}$ \\
\hline $\begin{array}{c}\text { Goiabão (Planchonella } \\
\text { pachycarpa) }\end{array}$ & 0,94 & $*$ & - & - \\
\hline $\begin{array}{c}\text { Guaiçara } \\
\text { (Luetzelburgia sp) } \\
\end{array}$ & 1,09 & 1113 & 937 & $\begin{array}{c}\text { NORMAL - } \\
\text { MADEIRA INDUSTRIAL }\end{array}$ \\
\hline $\begin{array}{l}\text { Guarucaia } \\
\text { (Peltophorum } \\
\text { vogelianum }\end{array}$ & 0,92 & 774 & 915 & $\begin{array}{c}\text { NORMAL - } \\
\text { MADEIRA INDUSTRIAL }\end{array}$ \\
\hline $\begin{array}{c}\text { Itaúba (Mezilaurus } \\
\text { itauba) }\end{array}$ & 0,96 & 739 & 754 & $\begin{array}{c}\text { PEQUENA - } \\
\text { MADEIRA DE CARPINTARIA }\end{array}$ \\
\hline $\begin{array}{c}\text { Louro Preto } \\
\text { (Octea sp) }\end{array}$ & 0,68 & 511 & 1105 & $\begin{array}{c}\text { NORMAL - } \\
\text { MADEIRA INDUSTRIAL }\end{array}$ \\
\hline $\begin{array}{c}\text { Mandioqueira } \\
\text { (Qualea albiflora) }\end{array}$ & 0,85 & 741 & 1026 & $\begin{array}{c}\text { NORMAL - } \\
\text { MADEIRA INDUSTRIAL }\end{array}$ \\
\hline $\begin{array}{c}\text { Oiticica Amarela } \\
\text { (Clarisia racemosa) }\end{array}$ & 0,76 & 588,58 & 1019 & $\begin{array}{c}\text { NORMAL - } \\
\text { MADEIRA INDUSTRIAL }\end{array}$ \\
\hline $\begin{array}{c}\text { Oiuchu } \\
\text { (Pradosia sp) }\end{array}$ & 0,93 & 911 & 1053 & $\begin{array}{c}\text { NORMAL - } \\
\text { MADEIRA INDUSTRIAL } \\
\end{array}$ \\
\hline $\begin{array}{c}\text { Parinari (Parinari } \\
\text { excelsa sabine) }\end{array}$ & 0,79 & 677 & 1085 & $\begin{array}{c}\text { NORMAL - } \\
\text { MADEIRA INDUSTRIAL }\end{array}$ \\
\hline $\begin{array}{c}\text { Piolho } \\
\text { (Tapirira sp) } \\
\end{array}$ & 0,83 & 722 & 1048 & $\begin{array}{c}\text { NORMAL - } \\
\text { MADERA INDUSTRIAL } \\
\end{array}$ \\
\hline $\begin{array}{c}\text { Quarubarana } \\
\text { (Erisma uncinatum) }\end{array}$ & 0,54 & 393 & 1348 & $\begin{array}{c}\text { FORTE - } \\
\text { MADEIRA PARA USOS ESPECIAIS }\end{array}$ \\
\hline $\begin{array}{l}\text { Rabo de Arraia } \\
\text { (Vochysia sp) }\end{array}$ & 0,72 & 508 & 980 & $\begin{array}{c}\text { FORTE - } \\
\text { MADEIRA PARA USOS ESPECIAIS } \\
\end{array}$ \\
\hline $\begin{array}{c}\text { Tachi } \\
\text { (Sclerobiumsp) } \\
\end{array}$ & 1,05 & 1285 & 1166 & $\begin{array}{c}\text { FORTE - } \\
\text { MADEIRA PARA USOS ESPECIAIS } \\
\end{array}$ \\
\hline $\begin{array}{c}\text { Tatajuba } \\
\text { (Bagassa guianensis) } \\
\end{array}$ & 0,94 & 884 & 1001 & $\begin{array}{c}\text { FORTE - } \\
\text { MADEIRA PARA USOS ESPECIAIS } \\
\end{array}$ \\
\hline $\begin{array}{c}\text { Umirana } \\
\text { (Qualea retusa) }\end{array}$ & 0,71 & 534 & 1059 & $\begin{array}{c}\text { FORTE - } \\
\text { MADEIRA PARA USOS ESPECIAIS }\end{array}$ \\
\hline
\end{tabular}

* Dado desconsiderado, CP com defeitos. 


\section{2 - CLASSIFICAÇÃO FINAL DAS TRINTA E QUATRO ESPÉCIES DE MADEIRAS NATIVAS}

Apresentam-se, na Tabela 4.9, as características das madeiras requeridas por grupos de usos finais para emprego na construção civil e áreas afins das trinta e quatro espécies nativas, da região noroeste do Brasil, de acordo com a classificação geral sugerida pelo IPT-SUDAM, (1981).

Tabela 4.9 - Classificação final e indicações das trinta e quatro espécies nativas

\begin{tabular}{|c|c|c|c|c|c|c|}
\hline ESPÉCIES ANALISADAS & & GRUI & $\operatorname{POS} /$ & APLI & CAÇÕ & \\
\hline NOME POPULAR - NOME CIENTÍFICO & $1^{(* a)}$ & $2^{(* b)}$ & $3^{(* \mathrm{c})}$ & $4^{(* \mathrm{~d})}$ & $5 \mathbf{A}^{(* e)}$ & $5 \mathbf{B}^{(+1)}$ \\
\hline Angelim Amargoso - Vatairea fusca & & & & - & - & \\
\hline Angelim Araroba - Vataireopsis araroba & & & & $\bullet$ & $\bullet$ & \\
\hline Angelim Ferro - Hymenolobium sp & - & - & & & - & - \\
\hline Angelim Pedra - Hymenolobium paetrum & & & - & - & - & \\
\hline Angelim Pedra Verdadeiro - Dinísia excelsa & - & - & & & - & - \\
\hline Angelim Saia - Vatairea sp & & & - & - & - & \\
\hline Angico Preto - Piptadenia macrocarpa & - & - & $\bullet$ & & - & - \\
\hline Branquilho - Terminalia sp & & & • & - & - & \\
\hline Cafearana - Andira sp & & & - & - & & \\
\hline Canafístula - Cassia ferruginea & & & & - & - & \\
\hline Casca Grossa - ${ }^{\star \star}$ & & & & - & $\bullet$ & \\
\hline Castelo - Gossypiospermun praecox & & - & - & - & $\bullet$ & \\
\hline Catanudo-Calophyllum sp & & • & • & & - & \\
\hline Cedro Amargo - Cedrela odorata & & & & - & & \\
\hline Cedrorana - Cedrelinga catenaeformis & - & & - & - & & \\
\hline Champanhe - Dipteryx sp & - & - & & - & - & . \\
\hline Cupiúba - Goupia glabra & & & - & - & - & \\
\hline
\end{tabular}

"* Dado não conclusivo dos caracteres anatômicos da espécie estudada. 
Tabela 4.9 - (continuação) - Classificação final e indicações das trinta e quatro espécies nativas

\begin{tabular}{|c|c|c|c|c|c|c|}
\hline NOME POPULAR - NOME CIENTÍFICO & $1^{(* \mathrm{a})}$ & $2^{\left({ }^{*} \mathrm{~b}\right)}$ & $3^{(* \mathrm{c})}$ & $4^{(* \mathrm{~d})}$ & $5 \mathbf{A}^{(* \mathrm{e})}$ & $5 B^{(* n)}$ \\
\hline Cutiúba - Qualea paraensis & - & $\bullet$ & & - & - & - \\
\hline Garapa-Apuleia leiocarpa & - & - & - & & - & - \\
\hline Goiabão - Planchonella pachycarpa & & & - & - & & \\
\hline Guaiçara - Luetzelburgia sp & $\bullet$ & - & & & - & - \\
\hline Guarucaia - Peltophorum vogelianum & & & - & $\cdot$ & $\cdot$ & \\
\hline Itaúba-Mezilaurus itauba & & - & $\cdot$ & $\cdot$ & - & $\cdot$ \\
\hline Louro Preto - Ocotea sp & & & - & - & - & - \\
\hline Mandioqueira - Qualea sp & & - & - & & & - \\
\hline Oiticica amarela - Clarísia racemosa & & & $\cdot$ & - & - & \\
\hline Oichu - Pradozia sp & $\bullet$ & $\cdot$ & & - & - & $\cdot$ \\
\hline Parinari - Parinari excelsa sabine & & & - & $\cdot$ & - & $\cdot$ \\
\hline Piolho - Tapirira sp & & $\bullet$ & - & $\cdot$ & - & $\cdot$ \\
\hline Quarubarana - Erisma uncinatum & & & & $\cdot$ & & \\
\hline Rabo de Arraia - Vochysia sp & & & - & - & - & \\
\hline Tachi-Sclerolobium sp & $\bullet$ & $\bullet$ & & $\cdot$ & $\cdot$ & - \\
\hline Tatajuba - Bagassa guianensis & $\bullet$ & $\cdot$ & & $\cdot$ & $\cdot$ & $\cdot$ \\
\hline Umirana - Qualea retusa & & & $\cdot$ & $\cdot$ & $\cdot$ & \\
\hline
\end{tabular}

NOTA:

Os grupos aqui apresentados se referem às indicações da SUDAM (1981), estas se encontram detalhadas no Capítulo 4 desta dissertação.

$1^{\left({ }^{*}\right)} \quad-$ Construção civil pesada externa;

$2^{\left({ }^{*} \mathrm{~b}\right)} \quad-\quad$ Construção civil pesada interna;

$3^{\left({ }^{*}\right)} \quad$ - Construção civil leve externa;

$4^{\left({ }^{*} \mathrm{~d}\right)} \quad-\quad$ Construção civil leve interna;

$5 \mathbf{A}^{(* \mathrm{e})} \quad-$ Assoalhos - Domésticos;

$5 \mathrm{~B}^{\left({ }^{*} \mathrm{R}\right)} \quad-$ Assoalhos - Industriais. 


\section{5 - CONCLUSÕES}

A partir dos resultados e análises apresentados neste trabalho, pode-se concluir que, para as aplicações da madeira na construção civil e áreas afins, é possível a substituição de espécies consagradas, com o aproveitamento qualificado das espécies estudadas. Os parâmetros considerados são bons indicadores para se proceder à substituição das espécies, pois evidenciam com segurança, o comportamento da madeira ao ser solicitada pelos esforços de serviço.

As propriedades fisicas, de resistência e de rigidez, da maior parte do grupo das espécies estudadas, demonstraram ser bastante viáveis em termos de resistência estrutural, permitindo grandes possibilidades de expansão no mercado consumidor, melhorando e influenciando os padrões de consumo da madeira tropical, para eventualmente substituir ou dividir espaço com outras espécies de uso tradicional mas, que já se encontram em fase de extinção e por isso, de valor comercial muito elevado. Além disto, os resultados obtidos certamente contribuirão para a tão desejada desaceleração da exploração predatória, tão comum na Floresta Amazônica.

A análise feita a partir dos critérios propostos por Sallenave, Nahuz e Nogueira, demonstrada nas tabelas 3.39 a 3.60 , possibilita sumarizar o estudo e conduzir à indicação de usos mais convenientes, dentro do potencial de cada espécie, em particular.

O agrupamento, de espécies a partir dos resultados de suas propriedades, torna mais prático, do ponto de vista comercial, a indicação das potenciais aplicações da madeira, passando pela sua valorização em diversos setores, implicando uma economia de mercado, diante das opções oferecidas ao consumidor. 


\section{6 - ANEXO}

São apresentadas, a seguir, as tabelas referentes aos resultados dos ensaios realizados para a determinação das propriedades físicas, de resistência e de rigidez das trinta e quatro espécies de madeiras nativas estudadas. 
Tabela 6.1 - Ensaios - Angelim Amargoso

\begin{tabular}{|c|c|c|c|c|c|c|c|c|c|c|c|c|c|c|c|}
\hline $\begin{array}{c}\text { ESPECIE: } \\
\text { Angelim Amargoso } \\
\text { (Vataireia fusca) } \\
\end{array}$ & \multicolumn{15}{|c|}{ PROPRIEDADES FÍSICAS DE RESISTÊNCIA E DE RIGIDEZ } \\
\hline UMIDADE: $12 \%$ & $\underset{\left(\mathrm{g} / \mathrm{cm}^{3}\right)}{\boldsymbol{\rho}_{\mathbf{p}}}$ & $\begin{array}{l}\boldsymbol{E}_{\mathbf{r}} \\
(\%)\end{array}$ & $\begin{array}{c}\boldsymbol{E}_{\mathbf{t}} \\
(\%)\end{array}$ & $\begin{array}{c}\mathbf{f}_{\mathrm{co}} \\
\left(\mathrm{daN} / \mathrm{cm}^{2}\right)\end{array}$ & $\begin{array}{c}\mathbf{f}_{\mathrm{to}} \\
\left(\mathrm{daN} / \mathrm{cm}^{2}\right)\end{array}$ & $\begin{array}{c}\mathbf{f}_{\mathbf{t 9 0}} \\
\left(\mathrm{daN} / \mathrm{cm}^{2}\right)\end{array}$ & $\begin{array}{c}\mathbf{f}_{\mathbf{v o}} \\
\left(\mathrm{daN} / \mathrm{cm}^{2}\right)\end{array}$ & $\begin{array}{c}\mathbf{f}_{\mathrm{s} \mathbf{0}} \\
\left(\mathrm{daN} / \mathrm{cm}^{2}\right)\end{array}$ & $\underset{\left(\mathrm{daN} / \mathrm{cm}^{2}\right)}{\mathbf{f}_{\mathbf{M}}}$ & $\underset{\left(\mathrm{daN} / \mathrm{cm}^{2}\right)}{\mathbf{E}_{\mathbf{c o}}}$ & $\underset{\left(\mathrm{daN} / \mathrm{cm}^{2}\right)}{\mathbf{E}_{\mathrm{to}}}$ & $\underset{\left(\mathrm{daN} / \mathrm{cm}^{2}\right)}{\mathbf{E}_{\mathbf{M}}}$ & $\underset{\left(\mathrm{daN} / \mathrm{cm}^{2}\right)}{\mathbf{f}_{\mathbf{H o}}}$ & $\underset{\left(\mathrm{daN} / \mathrm{cm}^{2}\right)}{\mathbf{f}_{\mathbf{H 9 0}}}$ & $\underset{(\mathrm{daN} \times \mathrm{m})}{\mathbf{T}}$ \\
\hline N.01 - CP: 24 D 06 & 0,72 & 3,28 & 6,09 & 515 & 730 & 35 & 157 & 9 & 902 & 141195 & 175001 & 139068 & 980 & 542 & 0,449 \\
\hline N.02 - CP: 07 C 05 & 0,83 & 1,97 & 4,92 & 615 & 658 & 15 & 176 & 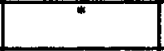 & 1026 & 136501 & 152204 & 164052 & 986 & 555 & $*$ \\
\hline N.03 - CP: 22 D 15 & 0,79 & 6,45 & 12,11 & 696 & 864 & 12 & 157 & 7 & 915 & 178874 & 192688 & 194121 & 1201 & 821 & 0,546 \\
\hline N.04 - CP: 10 C 09 & 0,79 & 5,55 & 8,53 & 493 & 1051 & 34 & 189 & 3 & 867 & 187400 & 183426 & 140421 & 937 & 705 & 0,603 \\
\hline N.05 - CP: 22 D 14 & 0,78 & 6,36 & 11,91 & 572 & 544 & 23 & 185 & 6 & 937 & 137648 & 162210 & 144668 & 1061 & 657 & 1,074 \\
\hline N.06 - CP: 29 F 01 & 0,77 & 3,70 & 8,91 & 575 & 459 & 22 & 133 & 8 & 737 & 132910 & 118039 & 151414 & 929 & 582 & 0,911 \\
\hline N.07 - CP: 22 D 16 & 0,76 & 4,86 & 9,13 & 625 & 876 & 46 & 120 & 6 & 934 & 180404 & 168866 & 136585 & 937 & 517 & 1,002 \\
\hline N.08 - CP: 09 C 06 & 0,74 & 4,05 & 7,14 & 651 & 524 & 27 & 151 & 5 & 856 & 154516 & 129360 & 127714 & 991 & 566 & 1,020 \\
\hline N.09 - CP: 01 & 0,75 & 3,88 & 6,37 & 665 & 680 & 30 & 131 & 4 & 991 & 151087 & 112316 & 136614 & 1018 & 479 & 0,993 \\
\hline N. $10-$ CP: 02 & 0,72 & 4,35 & 8,83 & 616 & 930 & 18 & 166 & 4 & 834 & 185825 & 167806 & 138128 & 927 & 579 & 1,393 \\
\hline N.11 - CP: 03 & 0,83 & 4,24 & 8,74 & 698 & 1041 & 31 & 168 & 6 & 956 & 170410 & 195984 & 139608 & 1029 & 743 & 1,715 \\
\hline N.12 - CP: 04 & 0,78 & 5,14 & 10,93 & 466 & 671 & 38 & 190 & 6 & 743 & 156060 & 164838 & 181276 & 954 & 528 & 0,838 \\
\hline MÉDIA & 0,77 & 4,49 & 8,63 & 599 & 752 & 28 & 160 & 6 & 892 & 159403 & 160228 & 149472 & 996 & 606 & 0,959 \\
\hline $\mathrm{N}^{2}$. DE AMOSTRA & 12 & 12 & 12 & 12 & 12 & 12 & 12 & 11 & 12 & 12 & 12 & 12 & 12 & 12 & 12 \\
\hline
\end{tabular}

"Dado desconsiderado, CP com defeito. 
Tabela 6.2 - Ensaios - Angelim Araroba

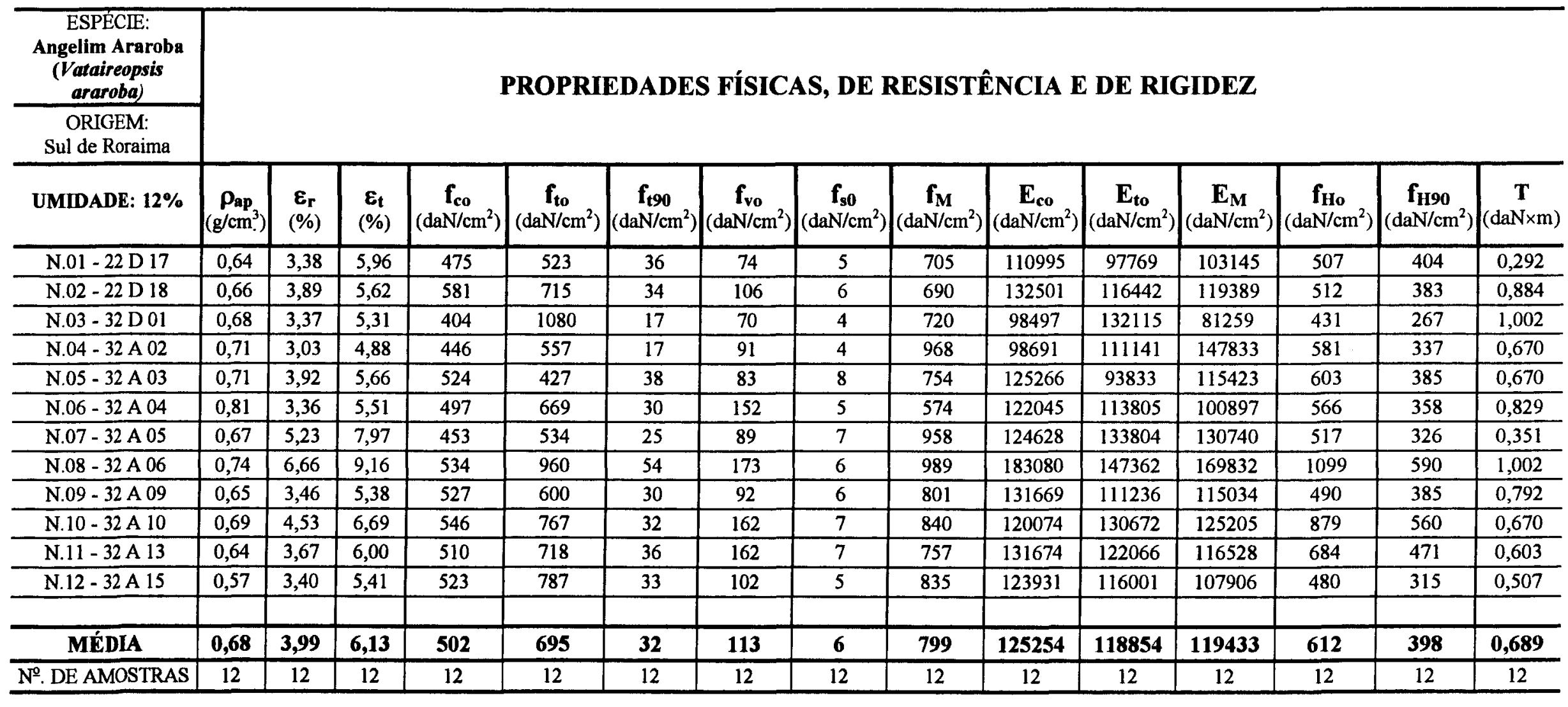


Tabela 6.3 - Ensaios - Angelim Ferro

\begin{tabular}{|c|c|c|c|c|c|c|c|c|c|c|c|c|c|c|c|}
\hline $\begin{array}{c}\text { ESPECIE: } \\
\text { Angelim Ferro } \\
\text { (Hymenolobium sp) } \\
\text { ORIGEM: }\end{array}$ & \multicolumn{15}{|c|}{ PROPRIEDADES FÍSICAS DE RESISTÊNCIA E DE RIGIDEZ } \\
\hline UMIDADE: $12 \%$ & $\underset{\left(\mathrm{g} / \mathrm{cm}^{3}\right)}{\rho_{\text {ap }}}$ & $\begin{array}{c}\boldsymbol{E}_{\mathbf{r}} \\
(\%)\end{array}$ & $\begin{array}{c}\boldsymbol{E}_{\mathrm{t}} \\
(\%)\end{array}$ & $\underset{\left(\mathrm{daN} / \mathrm{cm}^{2}\right)}{\mathbf{f}_{\mathbf{c o}}}$ & $\begin{array}{c}\mathbf{f}_{\mathbf{t o}} \\
\left(\mathrm{daN} / \mathrm{cm}^{2}\right)\end{array}$ & $\underset{\left(\mathrm{daN} / \mathrm{cm}^{2}\right)}{\mathbf{f}_{\mathbf{2}}}$ & $\begin{array}{c}\mathbf{f}_{\mathbf{v o}} \\
\left(\mathrm{daN} / \mathrm{cm}^{2}\right)\end{array}$ & $\begin{array}{c}\mathbf{f}_{\mathrm{s0}} \\
\left(\mathrm{daN} / \mathrm{cm}^{2}\right)\end{array}$ & $\underset{\left(\mathrm{daN} / \mathrm{cm}^{2}\right)}{\mathbf{f}_{\mathbf{M}}}$ & $\underset{\left(\mathrm{daN} / \mathrm{cm}^{2}\right)}{\mathbf{E}_{\mathbf{c o}}}$ & $\underset{\left(\mathrm{daN} / \mathrm{cm}^{2}\right)}{\mathbf{E}_{\text {to }}}$ & $\underset{\left(\mathrm{daN} / \mathrm{cm}^{2}\right)}{\mathbf{E}_{\mathbf{M}}}$ & $\begin{array}{c}\mathbf{f}_{\mathbf{H o}} \\
\left(\mathrm{daN} / \mathrm{cm}^{2}\right)\end{array}$ & $\begin{array}{c}\mathbf{f}_{\mathbf{H 9 0}} \\
\left(\mathrm{daN} / \mathrm{cm}^{2}\right)\end{array}$ & $\underset{(\mathrm{daN} \times \mathrm{m})}{\mathbf{T}}$ \\
\hline N.01 - CP: 09 C 04 & 1,23 & 4,66 & 6,80 & 706 & 870 & 28 & 160 & 8 & 1193 & 211951 & 181447 & 172320 & 1228 & 1117 & 2,226 \\
\hline N.02-CP: $09 \mathrm{C} 07$ & 1,14 & 5,98 & 8,29 & 886 & 1765 & 25 & 207 & 10 & 1402 & 232532 & 263541 & 172695 & 1616 & 1220 & 2,336 \\
\hline N.03 - CP: 09 C 08 & 1,24 & 4,74 & 7,36 & 530 & 691 & 27 & 178 & 10 & 1369 & 131348 & 135561 & 189401 & 1465 & 1225 & 1,723 \\
\hline N.04-CP: 09 C 09 & 1,18 & 5,25 & 7,81 & 741 & 741 & 41 & 189 & 5 & 1144 & 165544 & 208138 & 152699 & 1494 & 1293 & 1,240 \\
\hline N.05 - CP: $09 \mathrm{C} 10$ & 1,21 & 4,82 & 7,67 & 659 & 602 & 34 & 190 & 6 & 1174 & 170086 & 182255 & 174565 & 1476 & 1330 & 0,302 \\
\hline N.06 - CP: 09 C 11 & 1,15 & 5,54 & 8,28 & 781 & 1409 & 48 & 157 & 8 & 1080 & 194397 & 211159 & 155734 & 1223 & 1023 & 1,308 \\
\hline N.07-CP: 09 C 14 & 1,24 & 6,01 & 8,75 & 863 & 1970 & 34 & 215 & 11 & 866 & 222662 & 222792 & 175837 & 1599 & 1492 & 0,622 \\
\hline N.08-CP: $09 \mathrm{C} 16$ & 1,13 & 4,31 & 7,91 & 864 & 1681 & 44 & 202 & 7 & 1483 & 181885 & 185121 & 175082 & 1771 & 1662 & 2,912 \\
\hline N.09-CP:09 C 18 & 1,19 & 5,40 & 8,16 & 797 & 1372 & 22 & 265 & 7 & 1522 & 212473 & 195669 & 216473 & 1756 & 1435 & 2,285 \\
\hline N. $10-$ CP: 09 C 19 & 1,19 & 3,97 & 7,60 & 716 & 1538 & 56 & 246 & 7 & 1473 & 164007 & 187858 & 172529 & 1486 & 1507 & 1,443 \\
\hline N.11 - CP: 09 C 01 & 1,24 & 4,80 & 7,55 & 726 & 1004 & 11 & 210 & 8 & 915 & 169823 & 141398 & 170807 & 1524 & 1467 & 1,919 \\
\hline N.12 - CP: $09 \mathrm{C} 02$ & 1,20 & 5,00 & 7,35 & 786 & 1167 & 49 & 229 & 6 & 1265 & 192053 & 220584 & 188574 & 1551 & 1363 & 1,127 \\
\hline N.13-CP: 20 D 01 & 1,14 & 5,49 & 9,53 & 971 & 1271 & 28 & 220 & 6 & 1402 & 250561 & 250124 & 224969 & 1804 & 1702 & 2,703 \\
\hline N.14 - CP: 20 D 02 & 1,13 & 5,90 & 9,07 & 729 & 870 & 45 & 182 & 10 & 1403 & 210885 & 185168 & 188636 & 1314 & 1096 & 1,549 \\
\hline N.15 - CP: 20 D 03 & 1,12 & 5,34 & 9,19 & 712 & 987 & 62 & 193 & 11 & 1648 & 189306 & 155301 & 221010 & 1401 & 1314 & 0,948 \\
\hline N.16-CP: 20 D 04 & 1,13 & 4,63 & 7,29 & 881 & 1220 & 34 & 230 & 5 & 1658 & 242654 & 171350 & 209929 & 1519 & 1395 & 1,179 \\
\hline N.17-CP: 20 D 06 & 1,15 & 5,76 & 9,14 & 786 & 1146 & 54 & 210 & 9 & 1230 & 256040 & 208964 & 172316 & 1707 & 1694 & 2,259 \\
\hline N. 18 -CP: 20 D 07 & 1,12 & 5,25 & 9,19 & 658 & 1663 & 40 & 109 & 5 & 1270 & 265468 & 263351 & 203290 & 1617 & 1328 & 2,233 \\
\hline N. $19-\mathrm{CP}: 20 \mathrm{D} 08$ & 1,15 & 5,39 & 9,25 & 712 & 1128 & 26 & 200 & 12 & 1587 & 182493 & 201037 & 215339 & 1642 & 1325 & 2,452 \\
\hline N.20-CP: 20 D 09 & 1,18 & 4,90 & 8,21 & 907 & & 30 & 225 & 8 & 1542 & 261710 & $*$ & 179680 & 1373 & 1312 & 1,921 \\
\hline N.21-CP: 20 D 10 & 1,08 & 5,22 & 9,15 & 1053 & 859 & 65 & 142 & 9 & 1212 & 210147 & 199244 & 205280 & 1627 & 1489 & 2,416 \\
\hline N.22 - CP: 20 D 11 & 1,13 & 5,15 & 9,67 & 845 & 1150 & 56 & 201 & 10 & 1429 & 272304 & 241059 & 247800 & 1346 & 1039 & 0,764 \\
\hline N.23 - CP: $30 \mathrm{D} 15$ & 1,24 & 5,53 & 6,29 & 889 & 822 & 19 & 235 & 7 & 1221 & 227319 & 142239 & 170861 & $*$ & $*$ & $*$ \\
\hline MÉDIA & 1,17 & 5,18 & 8,24 & 791 & 1179 & 38 & 200 & 8 & 1326 & 209463 & 197880 & 189384 & 1525 & 1356 & 1,602 \\
\hline $\mathrm{N}^{2}$. DE AMOSTRAS & 23 & 23 & 23 & 23 & 22 & 23 & 23 & 23 & 23 & 23 & 22 & 23 & 22 & 22 & 22 \\
\hline
\end{tabular}

* Dado desconsiderado,CP com defeito 
Tabela 6.4 - ensaios - Angelim Pedra

\begin{tabular}{|c|c|c|c|c|c|c|c|c|c|c|c|c|c|c|c|}
\hline $\begin{array}{c}\text { ESPECIE: } \\
\text { Angelim Pedra } \\
\text { (Hymenolobium } \\
\text { petraeum) }\end{array}$ & \multicolumn{15}{|c|}{ PROPRIEDADES FISICAS DE RESISTÊNCIA E DE RIGIDEZ } \\
\hline UMDADE: 12\% & $\underset{\left({\left.\mathrm{g} / \mathrm{cm}^{3}\right)}^{\boldsymbol{\rho}_{2}}\right.}{\boldsymbol{\rho}}$ & $\begin{array}{c}\boldsymbol{E}_{\mathbf{r}} \\
(\%)\end{array}$ & $\begin{array}{c}\boldsymbol{E}_{\mathbf{t}} \\
(\%)\end{array}$ & $\begin{array}{c}\mathbf{f}_{\mathrm{co}} \\
\left(\mathrm{daN} / \mathrm{cm}^{2}\right)\end{array}$ & $\underset{\left(\mathrm{daN} / \mathrm{cm}^{2}\right)}{\mathbf{f}_{\mathrm{to}}}$ & $\begin{array}{c}\mathbf{f}_{\mathrm{tg0}} \\
\left(\mathrm{daN} / \mathrm{cm}^{2}\right)\end{array}$ & $\begin{array}{c}\mathbf{f v o}_{\mathbf{v o}} \\
\left(\mathrm{daN} / \mathrm{cm}^{2}\right)\end{array}$ & $\begin{array}{c}\mathbf{f}_{\mathbf{s 0}} \\
\left(\mathrm{daN} / \mathrm{cm}^{2}\right)\end{array}$ & $\underset{\left(\mathrm{daN} / \mathrm{cm}^{2}\right)}{\mathbf{f}_{\mathbf{M}}}$ & $\underset{\left(\mathrm{daN} / \mathrm{cm}^{2}\right)}{\mathbf{E}_{\mathbf{c o}}}$ & $\underset{\left(\mathrm{daN} / \mathrm{cm}^{2}\right)}{\mathbf{E}_{\mathrm{to}}}$ & $\underset{\left(\mathrm{daN} / \mathrm{cm}^{2}\right)}{\mathbf{E}_{\mathbf{M}}}$ & $\begin{array}{c}\mathbf{f}_{\mathbf{H o}} \\
\left(\mathrm{daN} / \mathrm{cm}^{2}\right)\end{array}$ & $\underset{\left(\mathrm{daN} / \mathrm{cm}^{2}\right)}{\left.\mathbf{f}_{\mathrm{H}}\right)}$ & $\underset{(\mathrm{daN} \times \mathrm{m})}{\mathbf{T}}$ \\
\hline N.01 - CP: 05 A 01 & 0,69 & 4,41 & 5,51 & 479 & 612 & \begin{tabular}{|l|}
23 \\
\end{tabular} & 127 & 6 & 872 & 111776 & 107468 & 109912 & 830 & 436 & 1,376 \\
\hline $\mathrm{N} .02-\mathrm{CP}: 05 \mathrm{~A} 02$ & 0,64 & 4,06 & 7,18 & 519 & 616 & 26 & 111 & 7 & 708 & 101546 & 97293 & 86237 & 776 & 490 & 0,536 \\
\hline N.03 - CP: 05 A 03 & 0,63 & 3,14 & 4,27 & 479 & 619 & 28 & 106 & 7 & 799 & 99322 & 99594 & 899566 & 695 & 549 & 0,736 \\
\hline N.04 - CP: 05 A 04 & 0,63 & 3,17 & 5,18 & 446 & 616 & 24 & 112 & 5 & 755 & 112927 & 93224 & 89368 & 674 & 420 & 0,745 \\
\hline N.05 - CP: 05 A 05 & 0,63 & 3,67 & 5,22 & 645 & 867 & 41 & 127 & 7 & 835 & 112487 & 139807 & 125693 & 770 & 453 & 0,651 \\
\hline N.06 - CP:05 A 06 & 0,62 & 3,42 & 5,24 & 522 & 473 & 36 & 89 & 8 & 678 & 93680 & 87035 & 86803 & 879 & 5547 & 0,911 \\
\hline N.07 - CP: 05 A 07 & 0,61 & 3,71 & 4,86 & 616 & 725 & 37 & 89 & 6 & 900 & 145400 & 122468 & 123904 & 813 & 453 & 0,498 \\
\hline N.08 - CP: 05 A 08 & 0,62 & 4,23 & 7,51 & 595 & 834 & 37 & 67 & 6 & 745 & 130874 & 131020 & 95861 & 732 & 507 & 0,641 \\
\hline N.09 - CP: 05 A 09 & 0,61 & 3,27 & 6,04 & 532 & 607 & 41 & 127 & 6 & 712 & 94968 & 109747 & 106924 & 856 & 512 & 0,584 \\
\hline N.10 - CP: 05 A 10 & 0,61 & 3,13 & 4,23 & 615 & 825 & 36 & 93 & 6 & 507 & 124243 & 119913 & 103791 & 808 & 420 & 0,594 \\
\hline $\mathrm{N} .11-\mathrm{CP}: 05 \mathrm{~A} 11$ & 0,69 & 3,78 & $5, \overline{54}$ & 568 & 626 & 28 & 97 & 6 & 711 & 113137 & 104951 & 93284 & 865 & 466 & 0,660 \\
\hline N.12 - CP: 05 A 12 & 0,65 & 4,12 & 6,83 & 528 & 579 & 27 & 137 & 6 & 762 & 102578 & 88319 & 110435 & 711 & 512 & 0,689 \\
\hline $\mathrm{N} .13-\mathrm{CP}: 12 \mathrm{C} 02$ & 0,73 & 4,82 & 6,62 & 503 & 765 & 55 & 142 & 8 & 1058 & 138748 & 126537 & 130689 & 701 & 485 & 0,764 \\
\hline N.14 - CP: $15 \mathrm{C} 01$ & 0,60 & 3,48 & 7,03 & 445 & 862 & 27 & 128 & 5 & 791 & 88722 & 85602 & 84008 & 657 & 393 & 0,708 \\
\hline $\mathrm{N} .15-\mathrm{CP}: 15 \mathrm{C} 02$ & 0,63 & 4,02 & 7,63 & 479 & 1085 & 18 & 138 & 5 & 935 & 104068 & 113144 & 101501 & 760 & 442 & 1,127 \\
\hline $\mathrm{N} .16-\mathrm{CP}: 15 \mathrm{C} 03$ & 0,80 & 6,52 & 8,36 & 810 & 664 & 29 & 166 & 8 & 778 & 164305 & 187584 & 145118 & 1184 & 652 & 1,074 \\
\hline N.17 - CP: $15 \mathrm{C} 04$ & 0,61 & 5,09 & 8,26 & 550 & 821 & 43 & 157 & 8 & 830 & 108931 & 107932 & 101223 & 760 & 431 & 0,449 \\
\hline $\mathrm{N} .18-\mathrm{CP}: 15 \mathrm{C} 05$ & 0,66 & 3,05 & 5,25 & 651 & 634 & 45 & 176 & 5 & 661 & 109657 & 91580 & 95340 & 786 & 399 & 0,632 \\
\hline $\mathrm{N} .19-\mathrm{CP}: 15 \mathrm{C} 06$ & 0,66 & 4,13 & 593 & 658 & 922 & 28 & 174 & 5 & 994 & 125821 & 115378 & 108511 & 840 & 498 & 0,498 \\
\hline $\mathrm{N} .20-\mathrm{CP}: 15 \mathrm{C} 07$ & 0,62 & 3,49 & 5,25 & 579 & 891 & 20 & 141 & $\overline{4}$ & 979 & 110634 & 120396 & 115882 & 813 & 466 & 0,565 \\
\hline $\mathrm{N} .21-\mathrm{CP}: 15 \mathrm{C} 09$ & 0,57 & 3,09 & 5,87 & 500 & 598 & 42 & 145 & 7 & 937 & 83673 & 88224 & 93326 & 684 & 415 & 0,232 \\
\hline N22-CP: $15 \mathrm{C} 09$ & 0,61 & 5,51 & 8,79 & 518 & 789 & 49 & 161 & 5 & 929 & 94346 & 119207 & 96583 & 781 & 410 & 0,527 \\
\hline
\end{tabular}


Tabela 6.4 - (Continuação) - ensaios - Angelim Pedra

\begin{tabular}{|c|c|c|c|c|c|c|c|c|c|c|c|c|c|c|c|}
\hline UMDADE: $12 \%$ & $\underset{\left(\mathrm{g} / \mathrm{cm}^{3}\right)}{\boldsymbol{\rho}_{\mathrm{ap}}}$ & $\begin{array}{c}\boldsymbol{E}_{\mathbf{r}} \\
(\%)\end{array}$ & $\begin{array}{c}\boldsymbol{E}_{\mathbf{t}} \\
(\%)\end{array}$ & $\begin{array}{c}\mathbf{f}_{\mathrm{co}} \\
\left(\mathrm{daN} / \mathrm{cm}^{2}\right)\end{array}$ & $\underset{\left(\mathrm{daN} / \mathrm{cm}^{2}\right)}{\mathbf{f}_{\mathrm{to}}}$ & $\begin{array}{c}\mathbf{f}_{\mathrm{tg0}} \\
\left(\mathrm{daN} / \mathrm{cm}^{2}\right)\end{array}$ & $\underset{\left(\mathrm{daN} / \mathrm{cm}^{2}\right)}{\mathbf{f}_{\mathbf{v}}}$ & $\begin{array}{c}\mathbf{f}_{\mathrm{s0}} \\
\left(\mathrm{daN} / \mathrm{cm}^{2}\right)\end{array}$ & $\underset{\left(\mathrm{daN} / \mathrm{cm}^{2}\right)}{\mathbf{f}_{\mathbf{M}}}$ & $\underset{\left(\mathrm{daN} / \mathrm{cm}^{2}\right)}{\mathbf{E}_{\mathbf{c o}}}$ & $\underset{\left(\mathrm{daN} / \mathrm{cm}^{2}\right)}{\mathbf{E}_{\mathbf{t o}}}$ & $\underset{\left(\mathrm{daN} / \mathrm{cm}^{2}\right)}{\mathbf{E}_{\mathbf{M}}}$ & $\underset{\left(\mathrm{daN} / \mathrm{cm}^{2}\right)}{\mathbf{f}_{\mathbf{H o}}}$ & $\begin{array}{c}\mathbf{f H}_{\mathbf{H} 90} \\
\left(\mathrm{daN} / \mathrm{cm}^{2}\right)\end{array}$ & $\underset{(\mathrm{daN} \times \mathrm{m})}{\mathbf{T}}$ \\
\hline N.23-CP: $15 \mathrm{C} 10$ & 0,57 & 2,73 & 5,54 & & 359 & 41 & 159 & 7 & 861 & $*$ & 82652 & 73700 & $*$ & $*$ & $*$ \\
\hline N.24-CP: 16 B 12 & 0,53 & 2,94 & 4,18 & 454 & 547 & 45 & 95 & 5 & 742 & 102411 & 83138 & 91188 & 593 & 431 & 0,325 \\
\hline N.25 - CP: 21 D 01 & 0,83 & 4,61 & 7,31 & 620 & 617 & 28 & 192 & 9 & 1049 & 121432 & 107335 & 124929 & 996 & 665 & 1,020 \\
\hline N.26 - CP: 21 D 03 & 0,87 & 4,87 & 8,15 & 855 & 1322 & 36 & 200 & 11 & 1438 & 166076 & 197790 & 175948 & 1228 & 794 & 1,409 \\
\hline N.27 - CP: 21 D 07 & 0,82 & 5,43 & 8,05 & 614 & 599 & 16 & 169 & 5 & 1093 & 177056 & 151334 & 148594 & 953 & 703 & 1,179 \\
\hline N.28-CP: 21 D 08 & 0,73 & 4,36 & 6,93 & 633 & 503 & 48 & 135 & 5 & 988 & 115692 & 93048 & 120765 & 959 & 740 & 1,274 \\
\hline N.29 - CP: 21 D 09 & 0,72 & 4,85 & 8,02 & 604 & 982 & 55 & 213 & 9 & 1173 & 130285 & 143344 & 154460 & 996 & 645 & 1,047 \\
\hline N.30 - CP: 21 D 11 & 0,86 & 5,01 & 7,75 & 747 & 658 & 25 & 199 & 7 & 980 & 162030 & 155788 & 145411 & 1018 & 625 & 0,939 \\
\hline N.31 - CP: 21 D 12 & 0,70 & 4,84 & 7,29 & 544 & 1076 & 36 & 181 & 10 & 1094 & 107746 & 164752 & 133119 & 900 & 542 & 1,118 \\
\hline N.32 - CP: 21 D 13 & 0,75 & 5,65 & 8,99 & 712 & 1163 & 36 & 202 & 7 & 1027 & 155361 & 174918 & 186969 & 886 & 609 & 1,557 \\
\hline N.34-CP: 21 D 10 & 0,67 & 4,23 & 7,19 & 740 & 732 & 50 & 173 & 10 & 999 & 140644 & 115338 & 132927 & 1018 & 649 & 0,829 \\
\hline N.33 - CP: 21 D 14 & 0,80 & 5,21 & 8,04 & 871 & 1051 & 43 & 234 & 9 & 1224 & 197422 & 149117 & 164249 & 1190 & 778 & 1,205 \\
\hline N.35 - CP: 16 B 12 & 0,78 & 4,48 & 6,86 & 607 & 762 & 29 & 141 & 8 & 1045 & 142593 & 138295 & 141884 & 1007 & 622 & 1,731 \\
\hline N.36 - CP: 21 D 01 & 0,81 & 5,44 & 8,13 & 605 & 1090 & 38 & 128 & 11 & 1237 & 160768 & 180107 & 164375 & 981 & 681 & 1,731 \\
\hline N.37 - CP: 21 D 03 & 0,76 & 5,35 & 7,36 & 463 & 867 & 33 & 119 & 7 & 937 & 117926 & 137136 & 127890 & 862 & 568 & 1,426 \\
\hline N.38-CP: 21 D 07 & 0,77 & 4,33 & 6,81 & 718 & 720 & 46 & 164 & 11 & 1444 & 123842 & 135975 & 179931 & 1120 & 676 & 0,536 \\
\hline N.39-CP: 21 D 08 & 0,72 & 5,21 & 8,36 & 578 & 1143 & 19 & 136 & 8 & 809 & 150840 & 163924 & 132680 & 959 & 699 & 1,368 \\
\hline N.40 - CP: 21 D 09 & 0,73 & 4,88 & 7,12 & 767 & 992 & 53 & 193 & 7 & 1096 & 159416 & 156647 & 151641 & 1236 & 1030 & 0,881 \\
\hline MÉDIA & 0,69 & 4,30 & 7 & 655 & 780 & 35 & 146 & 7 & 300 & 14304 & 124677 & 141366 & 994 & 674 & 1,150 \\
\hline №. DE AMOSTRAS & 40 & 40 & 40 & 39 & 40 & 40 & 40 & 40 & 40 & 39 & 40 & 40 & 39 & 39 & 39 \\
\hline
\end{tabular}

" Dado desconsiderado, CP com defeito. 
Tabela 6.5 - Ensaios - Angelim Pedra Verdadeiro

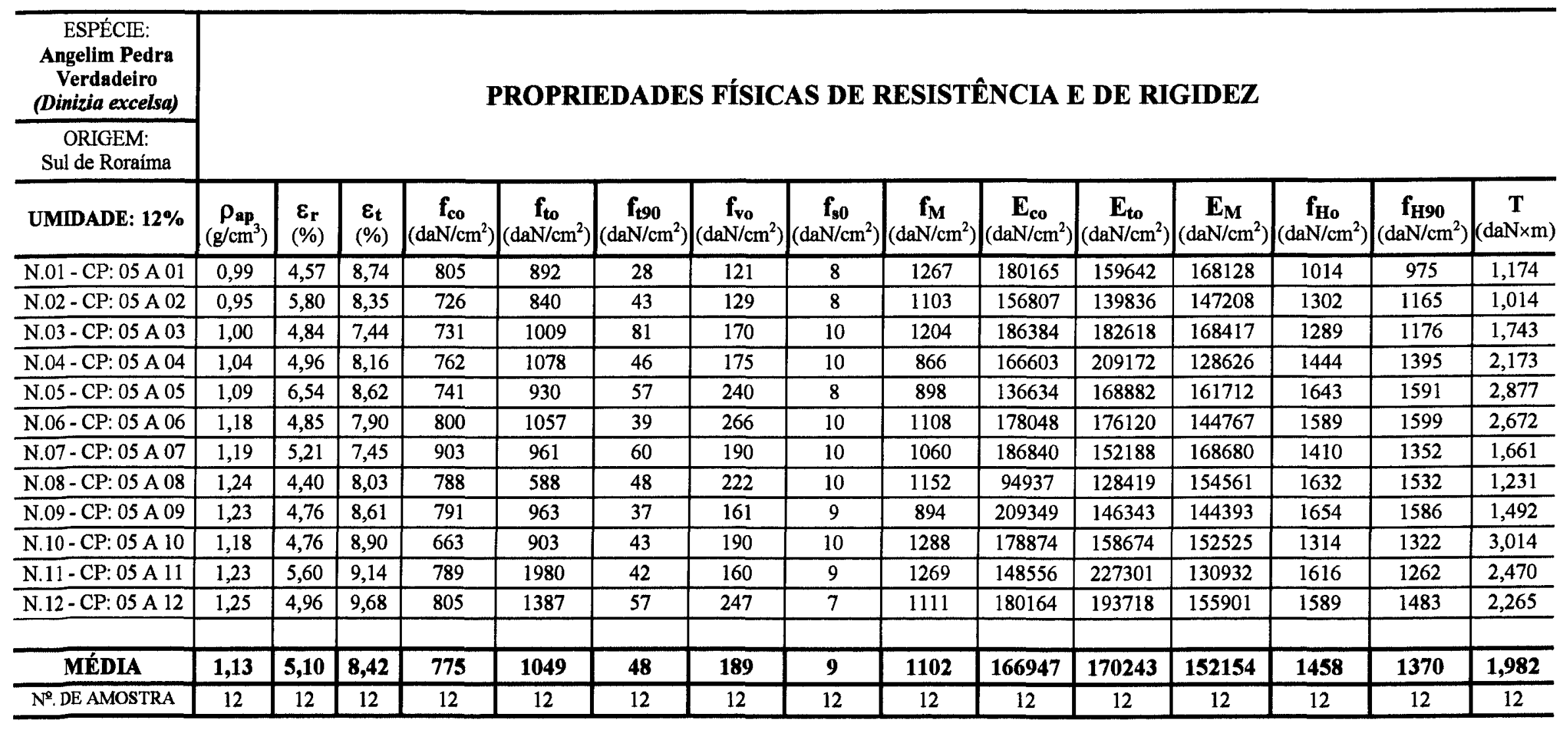


Tabela 6.6 - Ensaios - Angelim Saia

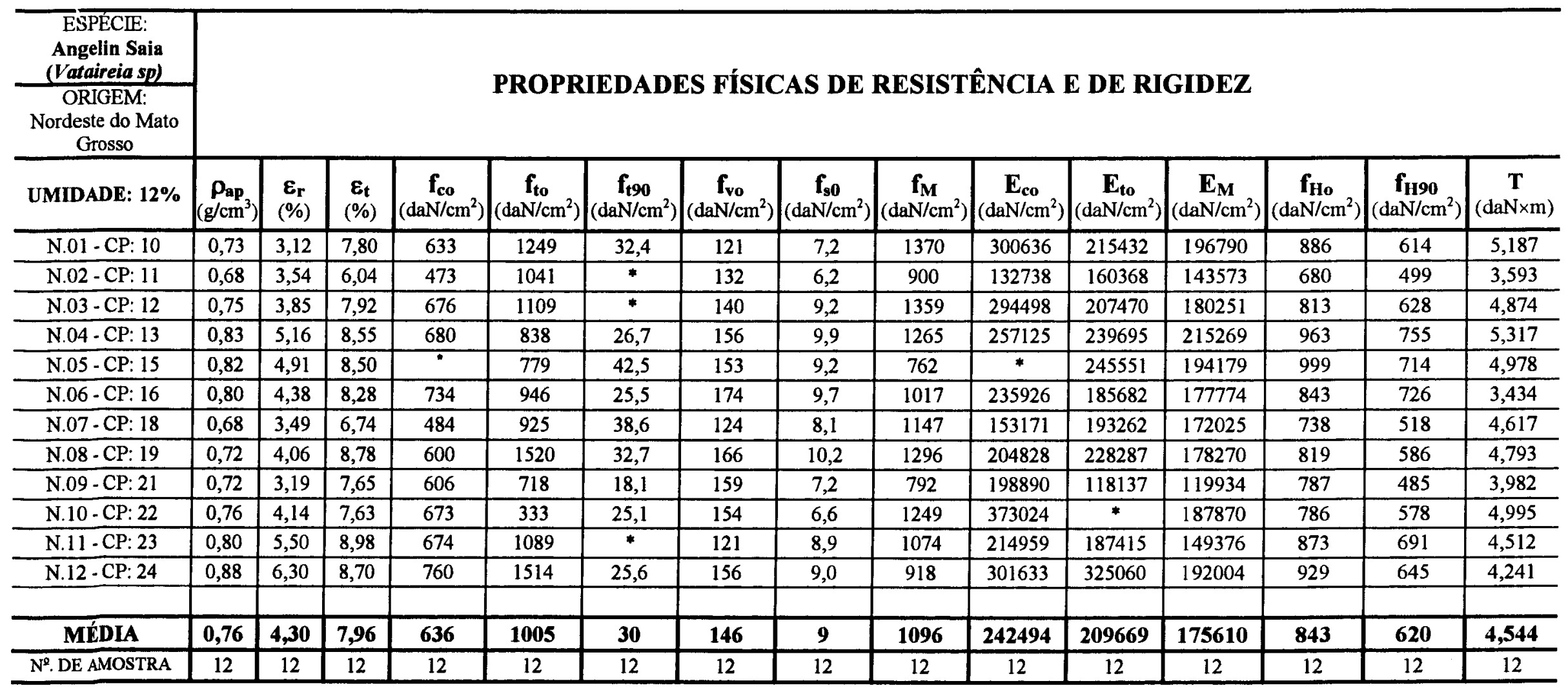

"Dado desconsiderado, CP com defeito. 
Tabela 6.7 - Ensaios - Angico Preto

\begin{tabular}{|c|c|c|c|c|c|c|c|c|c|c|c|c|c|c|c|}
\hline $\begin{array}{c}\text { ESPECIE: } \\
\text { Angico Preto } \\
\text { (Piptadenia macrocarpa) }\end{array}$ & \multicolumn{15}{|c|}{ PROPRIEDADES FISICAS DE RESISTÊNCIA E DE RIGIDEZ } \\
\hline UMDADE: $12 \%$ & $\underset{\left(\mathrm{g} / \mathrm{c} / \mathrm{m}^{3}\right)}{\rho_{\mathrm{ap}}}$ & $\begin{array}{c}\boldsymbol{E}_{\mathbf{r}} \\
(\%)\end{array}$ & $\begin{array}{c}\boldsymbol{\varepsilon}_{\mathbf{t}} \\
(\%)\end{array}$ & $\begin{array}{c}\mathbf{f}_{\mathbf{c o}} \\
\left(\mathrm{daN} / \mathrm{cm}^{2}\right)\end{array}$ & $\begin{array}{c}\mathbf{f}_{\text {to }} \\
\left(\mathrm{daN} / \mathrm{cm}^{2}\right)\end{array}$ & $\begin{array}{c}\mathbf{f}_{\mathrm{tg0}} \\
\left(\mathrm{daN} / \mathrm{cm}^{2}\right)\end{array}$ & $\begin{array}{c}\mathbf{f}_{\mathbf{v o}} \\
\left(\mathrm{daN} / \mathrm{cm}^{2}\right)\end{array}$ & $\begin{array}{c}\mathbf{f}_{\mathbf{s 0}} \\
\left(\mathrm{daN} / \mathrm{cm}^{2}\right)\end{array}$ & $\begin{array}{c}\mathbf{f}_{\mathbf{M}} \\
\left(\mathrm{daN} / \mathrm{cm}^{2}\right)\end{array}$ & $\begin{array}{c}\mathbf{E}_{\mathbf{c o}} \\
\left(\mathrm{daN} / \mathrm{cm}^{2}\right)\end{array}$ & $\underset{\left(\mathrm{daN} / \mathrm{cm}^{2}\right)}{\mathbf{E}_{\mathrm{to}}}$ & $\frac{\mathbf{E}_{\mathbf{M}}}{\left(\mathrm{daN} / \mathrm{cm}^{2}\right)}$ & $\begin{array}{c}\mathbf{f H o}_{\mathbf{H o}} \\
\left(\mathrm{daN} / \mathrm{cm}^{2}\right)\end{array}$ & $\begin{array}{c}\mathbf{f}_{\mathbf{H} 90} \\
\left(\mathrm{daN} / \mathrm{cm}^{2}\right)\end{array}$ & $\begin{array}{c}\mathbf{T} \\
(\mathrm{daN} \times \mathrm{m})\end{array}$ \\
\hline N.01 - CP: 05 A 01 & 0,92 & 4,62 & 8,27 & 903 & 1259 & 42 & 230 & 7 & 903 & 245660 & 167156 & 186094 & 1610 & 1392 & 2,793 \\
\hline N.02 - CP: 05 A 02 & 0,87 & 5,05 & 7,52 & 691 & 510 & 75 & 267 & 12 & 1280 & 100296 & 142303 & 162432 & 1495 & 1437 & 1,056 \\
\hline N.03 - CP: 05 A 03 & 0,90 & 3,87 & 7,79 & 568 & 935 & 43 & 200 & 10 & 992 & 104376 & 167022 & 156254 & 1560 & 1225 & 1,231 \\
\hline N.04 - CP: 05 A 04 & 0,80 & 4,44 & 10,65 & 543 & 855 & 25 & 198 & 6 & 1101 & 105644 & 135129 & 171713 & 1410 & 1407 & 1,127 \\
\hline N.65-CP: 05 A 05 & 0,93 & 4,13 & 7,70 & 752 & 1289 & 36 & 293 & 7 & 1595 & 116004 & 157805 & 167788 & 1625 & 1440 & 2,962 \\
\hline N.06 - CP: 05 A 06 & 0,89 & 3,42 & 7,09 & 568 & 1202 & 50 & 227 & 13 & 1772 & 162718 & 217119 & 193988 & 1260 & 1207 & 1,384 \\
\hline N.07-CP: 05 A 07 & 0,83 & 3,52 & 6,34 & 756 & 1613 & 65 & 316 & 13 & 1204 & 201397 & 195047 & 169576 & 1350 & 1332 & 2,723 \\
\hline N.08 - CP: 05 A 08 & 0,85 & 4,87 & 6,84 & 795 & 919 & 55 & 302 & 7 & 1222 & 147016 & 143673 & 138865 & 1710 & 1490 & 0,847 \\
\hline N.09-CP: 05 A 09 & 0,94 & 3,46 & 7,89 & 664 & 1273 & 53 & 282 & 9 & 1092 & 151065 & 162492 & 155587 & 1010 & 807 & 0,692 \\
\hline N.10-CP: 05 A 10 & 0,88 & 3,59 & 7,30 & 790 & 1396 & 34 & 262 & 11 & 1616 & 144076 & 141994 & 156698 & 1640 & 1422 & 1,082 \\
\hline N.11 - CP: 05 A 11 & 0,82 & 5,27 & 7,34 & 647 & 654 & 47 & 167 & 12 & 732 & 114335 & 114843 & 130295 & 1990 & 2055 & 0,641 \\
\hline N.12-CP: 05 A 12 & 1,03 & 5,54 & 7,91 & 1025 & 1342 & 70 & 191 & 13 & 921 & 252394 & 180190 & 190429 & 2225 & 2140 & 0,991 \\
\hline MÉDIA & 0,89 & 4,32 & 7,72 & 725 & 1104 & 50 & 245 & 10 & 1203 & 153748 & 160398 & 164977 & 1574 & 1446 & 1,461 \\
\hline $\mathrm{N}^{2}$. DE AMOSTRAS & 12 & 12 & 12 & 12 & 12 & 12 & 12 & 12 & 12 & 12 & 12 & 12 & 12 & 12 & 12 \\
\hline
\end{tabular}


Tabela 6.8 - Ensaios - Branquilho

\begin{tabular}{|c|c|c|c|c|c|c|c|c|c|c|c|c|c|c|c|}
\hline $\begin{array}{c}\text { ESPECIE: } \\
\text { Branquilho } \\
\text { (Terminalia sp) }\end{array}$ & \multicolumn{15}{|c|}{ PROPRIEDADES FÍSICAS DE RESISTÊNCIA E DE RIGIDEZ } \\
\hline UMIDADE: $12 \%$ & $\underset{\left(\mathrm{g} / \mathrm{c} / \mathrm{m}^{3}\right)}{\rho_{\text {ap }}}$ & $\begin{array}{c}\boldsymbol{\varepsilon}_{\mathbf{r}} \\
(\%)\end{array}$ & $\begin{array}{c}\boldsymbol{\varepsilon}_{\mathbf{t}} \\
(\%)\end{array}$ & $\begin{array}{c}\mathbf{f}_{\mathbf{c o}} \\
\left(\mathrm{daN} / \mathrm{cm}^{2}\right)\end{array}$ & $\begin{array}{c}\mathbf{f}_{\text {to }} \\
\left(\mathrm{daN} / \mathrm{cm}^{2}\right)\end{array}$ & $\begin{array}{c}\mathbf{f}_{\mathbf{t} 90} \\
\left(\mathrm{daN} / \mathrm{cm}^{2}\right)\end{array}$ & $\begin{array}{c}\mathbf{f}_{\mathbf{v o}} \\
\left(\mathrm{daN} / \mathrm{cm}^{2}\right)\end{array}$ & $\begin{array}{c}\mathbf{f}_{\mathbf{s 0}} \\
\left(\mathrm{daN} / \mathrm{cm}^{2}\right)\end{array}$ & $\underset{\left(\mathrm{daN} / \mathrm{cm}^{2}\right)}{\mathbf{f}_{\mathbf{M}}}$ & $\underset{\left(\mathrm{daN} / \mathrm{cm}^{2}\right)}{\mathbf{E}_{\mathbf{c o}}}$ & $\underset{\left(\mathrm{daN} / \mathrm{cm}^{2}\right)}{\mathbf{E}_{\mathbf{2}}}$ & $\frac{\mathbf{E}_{\mathbf{M}}}{\left(\mathrm{daN} / \mathrm{cm}^{2}\right)}$ & $\underset{\left(\mathrm{daN} / \mathrm{cm}^{2}\right)}{\mathbf{f}_{\mathrm{Ho}}}$ & $\begin{array}{c}\mathbf{f H}_{\mathbf{H} 90} \\
\left(\mathrm{daN} / \mathrm{cm}^{2}\right)\end{array}$ & $\underset{(\mathrm{daN} \times \mathrm{m})}{\mathbf{T}}$ \\
\hline N.01 - CP 01 & 0,79 & 4,8 & 8,9 & 510 & 965 & 23 & 127 & 6 & 984 & 149254 & 143820 & 142144 & 928 & 780 & 1,040 \\
\hline $\mathrm{N} .02-\mathrm{CP} 02$ & 0,89 & 5,7 & 9,9 & 541 & 1240 & 30 & 168 & 7 & 1031 & 156790 & 160477 & 158900 & 897 & 753 & 0,699 \\
\hline $\mathrm{N} .03-\mathrm{CP} 03$ & 0,76 & 4,8 & 9,4 & 486 & 888 & 33 & 172 & 9 & 751 & 126765 & 130090 & 123600 & 637 & 532 & 1,175 \\
\hline N.04 - CP 04 & 0,79 & 4,6 & 9,1 & 546 & 908 & 32 & 118 & 5 & 1020 & 145250 & 152278 & 160310 & 606 & 547 & 0,767 \\
\hline $\mathrm{N} .05-\mathrm{CP} 05$ & 0,80 & 4,9 & 7,7 & 490 & 681 & 33 & 175 & 6 & 662 & 123740 & 119804 & 133350 & 926 & 798 & 0,478 \\
\hline N.06 - CP 06 & 0,86 & 4,9 & 10,0 & 514 & 947 & 34 & 161 & 8 & 913 & 165950 & 187620 & 221204 & 1094 & 902 & 0,582 \\
\hline N.07 - CP 07 & 0,77 & 3,9 & 8,3 & 445 & 680 & 29 & 177 & 5 & 712 & 118350 & 132809 & 200420 & 805 & 593 & 0,850 \\
\hline N.08 - CP 08 & 0,80 & 5,0 & 9,3 & 484 & 801 & 36 & 157 & 8 & 713 & 116350 & 125810 & 139880 & 766 & 715 & 1,204 \\
\hline N.09- CP 09 & 0,85 & 4,3 & 8,1 & 469 & 729 & 43 & 156 & 10 & 641 & 152720 & 160928 & 139190 & 1400 & 965 & 1,201 \\
\hline N. $10-$ CP 10 & 0,79 & 4,9 & 9,0 & 438 & 672 & 25 & 173 & 8 & 816 & 123780 & 132058 & 140407 & 769 & 618 & 0,933 \\
\hline N.11 - CP 11 & 0,73 & 4,8 & 9,4 & 430 & 828 & 33 & 157 & 5 & 885 & 113940 & 118651 & 128800 & 825 & 669 & 1,418 \\
\hline N.12 - CP 12 & 0,89 & 5,8 & 9,8 & 464 & 1206 & 29 & 175 & 10 & 821 & 164720 & 168306 & 170600 & 874 & 678 & 0,713 \\
\hline MÉDIA & 0,81 & 4,87 & 9,08 & 485 & 879 & 32 & 160 & 7 & 829 & 138134 & 144388 & 154900 & 877 & 713 & 0,922 \\
\hline $\mathrm{N}^{2}$. DE AMOSTRA & 12 & 12 & 12 & 12 & 12 & 12 & 12 & 12 & 12 & 12 & 12 & 12 & 12 & 12 & 12 \\
\hline
\end{tabular}


Tabela 6.9 - Ensaios - Cafearana

\begin{tabular}{|c|c|c|c|c|c|c|c|c|c|c|c|c|c|c|c|}
\hline $\begin{array}{l}\text { ESPECIE: } \\
\text { Cafearama } \\
\text { (Andira sp) }\end{array}$ & \multicolumn{15}{|c|}{ PROPRIEDADES FÍSICAS DE RESISTÊNCIA E DE RIGIDEZ } \\
\hline UMIDADE: $12 \%$ & $\underset{\left(\mathrm{g} / \mathrm{cm}^{3}\right)}{\rho_{\mathbf{a p}}}$ & $\begin{array}{c}\boldsymbol{E}_{\mathbf{r}} \\
(\%)\end{array}$ & $\begin{array}{c}\boldsymbol{E}_{\mathrm{t}} \\
(\%)\end{array}$ & $\underset{\left(\mathrm{daN} / \mathrm{cm}^{2}\right)}{\mathbf{f}_{\mathbf{c o}}}$ & $\underset{\left(\mathrm{daN} / \mathrm{cm}^{2}\right)}{\mathbf{f}_{\mathrm{to}}}$ & $\begin{array}{c}\mathbf{f}_{\mathbf{t 9 0}} \\
\left(\mathrm{daN} / \mathrm{cm}^{2}\right)\end{array}$ & $\begin{array}{c}\mathbf{f}_{\mathrm{vo}} \\
\left(\mathrm{daN} / \mathrm{cm}^{2}\right)\end{array}$ & $\underset{\left(\mathrm{daN} / \mathrm{cm}^{2}\right)}{\mathbf{f}_{\mathrm{s0}}}$ & $\underset{\left(\mathrm{daN} / \mathrm{cm}^{2}\right)}{\mathbf{f}_{\mathbf{M}}}$ & $\underset{\left(\mathrm{daN} / \mathrm{cm}^{2}\right)}{\mathbf{E}_{\mathbf{c o}}}$ & $\underset{\left(\mathrm{daN} / \mathrm{cm}^{2}\right)}{\mathbf{E}_{\mathrm{to}}}$ & $\underset{\left(\mathrm{daN} / \mathrm{cm}^{2}\right)}{\mathbf{E}_{\mathbf{M}}}$ & $\begin{array}{c}\mathbf{f}_{\mathbf{H o}} \\
\left(\mathrm{daN} / \mathrm{cm}^{2}\right)\end{array}$ & $\underset{\left(\mathrm{daN} / \mathrm{cm}^{2}\right)}{\mathbf{f}_{\mathbf{H 9 0}}}$ & $\frac{\mathbf{T}}{(\mathrm{daN} \times \mathrm{m})}$ \\
\hline N.01 - CP: 02 A 10 & 0,75 & 6,70 & 11,45 & 678 & 1111 & 46 & 146 & 7 & 919 & 190208 & 159785 & 153090 & 1125 & 692 & 1,317 \\
\hline N.02 - CP: $13 \mathrm{C} 01$ & 0,64 & 4,59 & 8,76 & 341 & 587 & 18 & 81 & 4 & 538 & 100155 & 113504 & 116214 & 533 & 329 & 0,801 \\
\hline N.03 - CP: 13 C 02 & 0,66 & 5,36 & 9,97 & 619 & 970 & 18 & 79 & 4 & 806 & 135237 & 126872 & 132699 & 765 & 460 & 0,332 \\
\hline N.04 - CP: 13 C 03 & 0,61 & 4,41 & 8,24 & 638 & 729 & 25 & 65 & 4 & 900 & 124627 & 120614 & 136999 & 689 & 382 & 0,736 \\
\hline N.05-CP: $13 \mathrm{C} 05$ & 0,62 & 5,30 & 10,15 & 547 & 1093 & 37 & 68 & 4 & 931 & 146354 & 148093 & 135350 & 754 & 442 & 0,882 \\
\hline N.06 - CP: 13 C 06 & 0,62 & 4,98 & 9,70 & 561 & 580 & 29 & 68 & 6 & 793 & 114702 & 100794 & 125842 & 981 & 374 & 0,488 \\
\hline N.07 - CP: 13 C 07 & 0,67 & 6,12 & 10,08 & 419 & 585 & 35 & 96 & 6 & 902 & 97266 & 93347 & 112103 & 787 & 398 & 0,675 \\
\hline N.08 - CP: 13 C 08 & 0,78 & 5,65 & 9,78 & 781 & 1070 & 41 & 146 & 5 & 1273 & 207769 & 159721 & 177384 & 1090 & 690 & 1,188 \\
\hline N.09 - CP: 13 C 09 & 0,65 & 5,40 & 10,04 & 523 & 450 & 24 & 58 & 8 & 718 & 130080 & 122741 & 116598 & 523 & 380 & 0,498 \\
\hline N.10 - CP: 13 C 04 & 0,62 & 5,01 & 9,16 & 638 & 816 & 26 & 106 & 5 & 945 & 140328 & 136095 & 131359 & 738 & 433 & 0,651 \\
\hline N.11 - CP: 13 C 11 & 0,67 & 4,61 & 8,77 & 493 & 640 & 25 & 48 & 4 & 804 & 113402 & 119109 & 122610 & 598 & 509 & 0,641 \\
\hline N.12 - CP: 30 A 09 & 0,73 & 7,09 & 11,00 & 672 & 1020 & 63 & 178 & 10 & 1387 & 190606 & 184706 & 178481 & 1072 & 622 & 0,410 \\
\hline N.13 - CP 32 A 08 & 0,78 & 5,00 & 10,86 & 571 & 1108 & 29 & 134 & 9 & 1265 & 124862 & 177565 & 161736 & 878 & 520 & 0,939 \\
\hline MÉDIA & 0,68 & 5,40 & 9,84 & 575 & 828 & 32 & 98 & 6 & 937 & 139661 & 135611 & 138497 & 810 & 479 & 0,735 \\
\hline $\mathrm{N}^{2}$. DE AMOSTRA & 13 & 13 & 13 & 13 & 13 & 13 & 13 & 13 & 13 & 13 & 13 & 13 & 13 & 13 & 13 \\
\hline
\end{tabular}


Tabela 6.10 - Ensaios - Canafístula

\begin{tabular}{|c|c|c|c|c|c|c|c|c|c|c|c|c|c|c|c|}
\hline \multirow{2}{*}{$\begin{array}{c}\text { ESPECIE: } \\
\begin{array}{c}\text { Canafistula } \\
\text { (Cassia ferruginea) }\end{array} \\
\begin{array}{c}\text { ORIGEM: } \\
\text { Oeste do Mato Grosso }\end{array} \\
\text { UMIDADE: } 12 \%\end{array}$} & \multicolumn{15}{|c|}{ PROPRIEDADES FÍSICAS DE RESISTÊNCIA E DE RIGIDEZ } \\
\hline & $\underset{\left(\mathrm{g} / \mathrm{cm}^{3}\right)}{\rho_{\mathbf{a p}}}$ & $\begin{array}{c}\boldsymbol{E}_{\mathbf{r}} \\
(\%)\end{array}$ & $\begin{array}{c}\boldsymbol{\varepsilon}_{\mathbf{t}} \\
(\%)\end{array}$ & $\begin{array}{c}\mathbf{f}_{\mathbf{c o}} \\
\left(\mathrm{daN} / \mathrm{cm}^{2}\right)\end{array}$ & $\begin{array}{c}\mathbf{f}_{\mathbf{t o}} \\
\left(\mathrm{daN} / \mathrm{cm}^{2}\right)\end{array}$ & $\begin{array}{c}\mathbf{f}_{\mathbf{t 9 0}} \\
\left(\mathrm{daN} / \mathrm{cm}^{2}\right)\end{array}$ & $\begin{array}{c}\mathbf{f v o}_{\mathrm{vo}} \\
\left(\mathrm{daN} / \mathrm{cm}^{2}\right)\end{array}$ & $\begin{array}{c}\mathbf{f}_{\mathbf{s 0}} \\
\left(\mathrm{daN} / \mathrm{cm}^{2}\right)\end{array}$ & $\underset{\left(\mathrm{daN} / \mathrm{cm}^{2}\right)}{\mathbf{f}_{\mathbf{M}}}$ & $\underset{\left(\mathrm{daN} / \mathrm{cm}^{2}\right)}{\mathbf{E}_{\mathbf{c o}}}$ & $\underset{\left(\mathrm{daN} / \mathrm{cm}^{2}\right)}{\mathbf{E}_{\mathbf{t o}}}$ & $\underset{\left(\mathrm{daN} / \mathrm{cm}^{2}\right)}{\mathbf{E}_{\mathbf{M}}}$ & $\begin{array}{c}\mathbf{f}_{\mathbf{H o}} \\
\left(\mathrm{daN} / \mathrm{cm}^{2}\right)\end{array}$ & $\begin{array}{c}\mathbf{f}_{\mathbf{H 9 0}} \\
\left(\mathrm{daN} / \mathrm{cm}^{2}\right)\end{array}$ & $\underset{(\mathrm{daN} \times \mathrm{m})}{\mathbf{T}}$ \\
\hline N.01 - CP 01 & 0,91 & 4,68 & 9,02 & 567 & 1092 & 79 & 227 & 11 & 839 & 158543 & 170340 & 137470 & * & $*$ & * \\
\hline N.02 - CP 02 & 0,93 & 4,92 & 9,47 & 430 & 760 & 47 & 262 & 8 & 908 & 129040 & 141266 & 164128 & $*$ & $*$ & * \\
\hline N.03 - CP 03 & 0,92 & 5,36 & 8,68 & 619 & 1085 & 40 & 229 & 11 & 1025 & 172274 & 159348 & 182930 & $*$ & * & * \\
\hline N.04 - CP 04 & 0,92 & 4,12 & 7,90 & 647 & 801 & 50 & 195 & 13 & 1085 & 179824 & 162637 & 176429 & * & * & $*$ \\
\hline N.05 - CP 05 & 0,95 & 6,08 & 9,43 & 596 & 1004 & 58 & 241 & 14 & 852 & 175300 & 159842 & 167365 & $*$ & $*$ & $*$ \\
\hline N.06-CP 06 & 0,93 & 4,30 & 6,67 & 549 & 959 & 46 & 223 & 11 & 982 & 128307 & 126264 & 137918 & * & $*$ & * \\
\hline N.07-CP 07 & 0,78 & 3,47 & 5,92 & 386 & 720 & 47 & 120 & 10 & 780 & 124208 & 138493 & 132818 & $*$ & $*$ & $*$ \\
\hline N.08-CP 08 & 0,76 & 4,12 & 6,75 & 349 & 400 & 38 & 130 & 9 & 718 & 98817 & 90214 & 120118 & $*$ & $*$ & $*$ \\
\hline N.09-CP 09 & 0,74 & 4,39 & 7,62 & 430 & 540 & 42 & 126 & 9 & 800 & 112407 & 100771 & 105370 & $*$ & $*$ & $*$ \\
\hline N.10-CP 10 & 0,83 & 3,74 & 7,22 & 580 & 948 & 92 & 169 & 14 & 906 & 160951 & 150714 & 151800 & * & * & $*$ \\
\hline N. $11-$ CP 11 & 0,85 & 3,80 & 6,44 & 581 & 1004 & 104 & 182 & 13 & 937 & 170820 & 149675 & 159984 & $*$ & $*$ & $*$ \\
\hline N.12 - CP 12 & 0,80 & 4,15 & 7,39 & 501 & 877 & 75 & 119 & 9 & 797 & 143066 & 140894 & 135909 & $*$ & $*$ & $*$ \\
\hline MÉDIA & 0,86 & 4,43 & 7,71 & 520 & 849 & 60 & 185 & 11 & 886 & 146130 & 140872 & 147687 & * & * & $\star$ \\
\hline $\mathrm{N}^{2}$. DE AMOSTRAS & 12 & 12 & 12 & 12 & 12 & 12 & 12 & 12 & 12 & 12 & 12 & 12 & * & * & $*$ \\
\hline
\end{tabular}

"Dado desconsiderado, CP com defeito. 
Tabela 6.11 - Ensaios - Casca Grossa



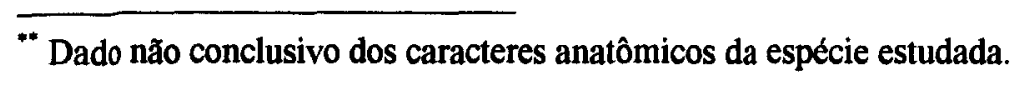


Tabela 6.11 - (Continuação) - Ensaios - Casca Grossa

\begin{tabular}{|c|c|c|c|c|c|c|c|c|c|c|c|c|c|c|c|}
\hline UMIDADE: $12 \%$ & $\underset{\left(\mathrm{g} / \mathrm{cm}^{3}\right)}{\rho_{\mathbf{a p}}}$ & $\begin{array}{l}\boldsymbol{E}_{\mathbf{r}} \\
(\%)\end{array}$ & $\begin{array}{c}\boldsymbol{E}_{\mathbf{t}} \\
(\%)\end{array}$ & $\begin{array}{c}\mathbf{f}_{\mathbf{c o}} \\
\left(\mathrm{daN} / \mathrm{cm}^{2}\right)\end{array}$ & $\underset{\left(\mathrm{daN} / \mathrm{cm}^{2}\right)}{\mathbf{f}_{\text {to }}}$ & $\underset{\left(\mathrm{daN} / \mathrm{cm}^{2}\right)}{\mathbf{f}_{\mathbf{2}}}$ & $\begin{array}{c}\mathbf{f}_{\mathbf{v o}} \\
\left(\mathrm{daN} / \mathrm{cm}^{2}\right)\end{array}$ & $\underset{\left(\mathrm{daN} / \mathrm{cm}^{2}\right)}{\left.\mathbf{f}_{\mathrm{g}}\right)}$ & $\underset{\left(\mathrm{daN} / \mathrm{cm}^{2}\right)}{\mathbf{f}_{\mathbf{M}}}$ & $\underset{\left(\mathrm{daN} / \mathrm{cm}^{2}\right)}{\mathbf{E}_{\mathbf{c o}}}$ & $\underset{\left(\mathrm{daN} / \mathrm{cm}^{2}\right)}{\mathbf{E}_{\text {to }}}$ & $\underset{\left(\mathrm{daN} / \mathrm{cm}^{2}\right)}{\mathbf{E}_{\mathbf{M}}}$ & $\underset{\left(\mathrm{daN} / \mathrm{cm}^{2}\right)}{\mathbf{f H o}_{\mathrm{H}}}$ & $\underset{\left(\mathrm{daN} / \mathrm{cm}^{2}\right)}{\mathbf{f}_{\mathrm{Hg0}}}$ & $\underset{(\operatorname{daN} \times m)}{\mathbf{T}}$ \\
\hline N.20 - CP: 18 D 05 & 0,78 & 10,07 & 17,98 & 429 & 1045 & 30 & 132 & 9 & 919 & 122967 & 126864 & 125302 & 839 & 587 & 1,936 \\
\hline N.21 - CP: 18 D 06 & 0,79 & 7,68 & 14,79 & 452 & 1171 & 25 & 106 & 6 & 1006 & 187696 & 192750 & 152274 & 840 & 544 & 1,194 \\
\hline N.22 - CP: 18 D 08 & 0,88 & 8,7 & 15,8 & 887 & 1629 & 55 & 120 & 11 & 1322 & 245937 & 204479 & 220595 & 1050 & 838 & 0,829 \\
\hline N.23 - CP: 31 A 01 & 0,78 & 4,64 & 8,54 & 564 & 867 & 57 & 148 & 10 & 834 & 133761 & 134045 & 122878 & 975 & 601 & 0,975 \\
\hline N.24 - CP: 31 A 02 & 0,75 & 12,52 & 16,19 & 570 & 823 & 43 & 209 & 11 & 1088 & 104817 & 130277 & 159538 & 915 & 644 & 1,274 \\
\hline N.25 - CP: 31 A 03 & 0,8 & 4,94 & 10,07 & 540 & 1359 & 55 & 114 & 9 & 855 & 121711 & 150561 & 128006 & 856 & 512 & 1,082 \\
\hline N.26 - CP: 31 A 04 & 0,78 & 5,17 & 10,85 & 546 & 925 & 42 & 164 & 7 & 1225 & 117843 & 154968 & 183244 & 1094 & 652 & 1,065 \\
\hline N.27 - CP: 31 A 05 & 0,8 & 5,05 & 10,19 & 657 & 1303 & 69 & 222 & 12 & 1353 & 179206 & 184627 & 198065 & 1082 & 776 & 1,384 \\
\hline N.28 - CP: 31 A 07 & 0,78 & 6,45 & 11,97 & 754 & 1204 & 36 & 146 & 10 & 1131 & 228140 & 220498 & 199613 & 948 & 759 & 1,443 \\
\hline N.29-CP: 31 A 08 & 0,8 & 7,14 & 11,97 & 681 & 976 & 37 & 101 & 9 & 1059 & 218926 & 168278 & 173737 & 953 & 644 & 0,488 \\
\hline N.30 - CP: 31 A 09 & 0,76 & 6,75 & 11,61 & 454 & 1081 & 45 & 131 & 8 & 981 & 101066 & 171874 & 133129 & 921 & 517 & 1,785 \\
\hline N.31 - CP: 31 A 10 & 0,77 & 5,92 & 10,87 & 595 & 885 & 48 & 177 & 7 & 1044 & 172947 & 120769 & 132108 & 1012 & 665 & 1,24 \\
\hline N 32 - CP: 31 A 11 & 0,73 & 4,78 & 9,48 & 439 & 1025 & 55 & 193 & 9 & 930 & 124831 & 148030 & 127238 & 850 & 579 & 1,277 \\
\hline N.33 - CP: 31 A 12 & 0,76 & 5,43 & 10,97 & 647 & 1205 & 62 & 148 & 8 & 888 & 181470 & 169742 & 136038 & 733 & 646 & 1,317 \\
\hline N.34 - CP: 31 A 13 & 0,78 & 6,01 & 10,84 & 476 & 1157 & 46 & 151 & 8 & 793 & 117263 & 136390 & 118785 & 948 & 633 & 1,144 \\
\hline MÉDIA & 0,79 & 6,04 & 11,65 & 585 & 1319 & 43 & 140 & 8 & 1067 & 165883 & 172459 & 163181 & 980 & 651 & 1,221 \\
\hline $\mathrm{N}^{9}$. DE AMOSTRAS & 34 & 34 & 34 & 34 & 34 & 34 & 34 & 34 & 34 & 34 & 34 & 34 & 34 & 34 & 34 \\
\hline
\end{tabular}


Tabela 6.12 - Ensaios - Castelo

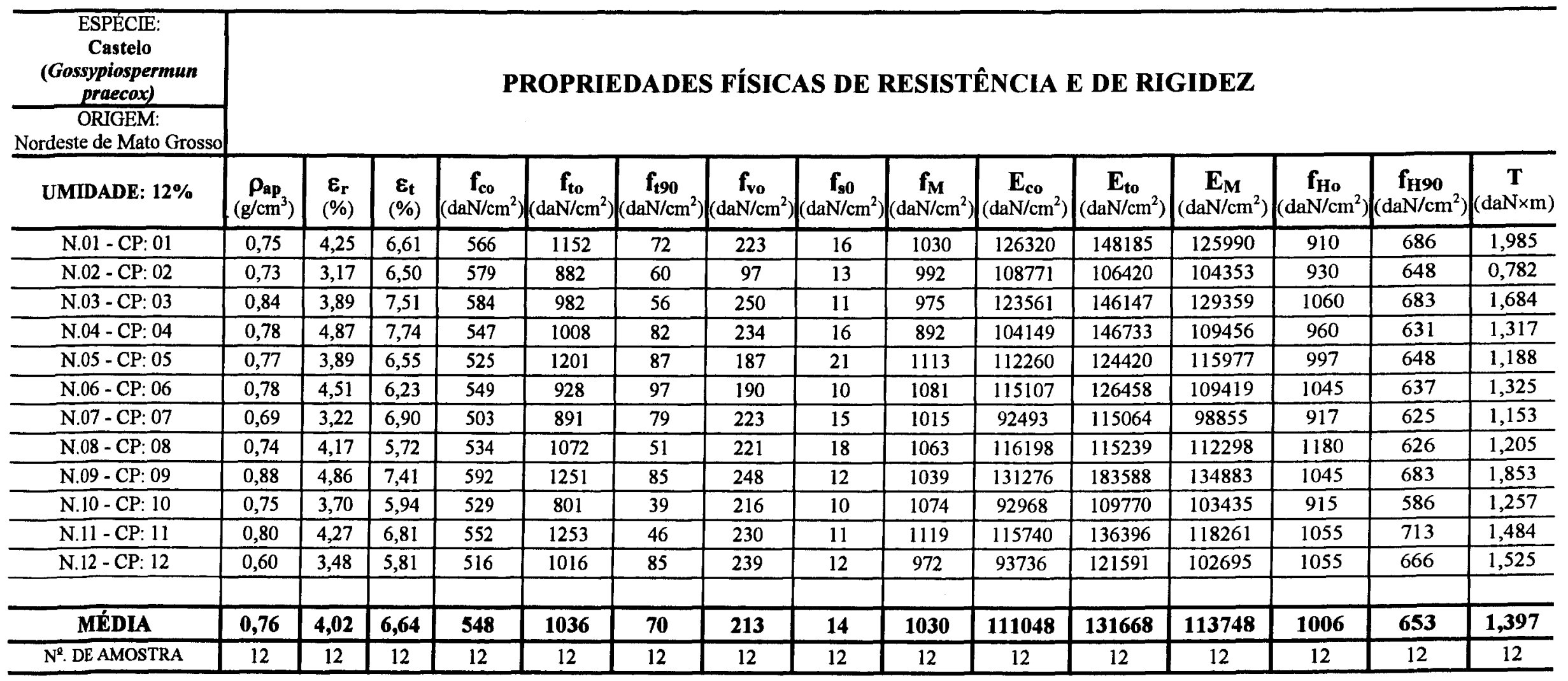


Tabela 6.13 - Ensaios - Catanudo

\begin{tabular}{|c|c|c|c|c|c|c|c|c|c|c|c|c|c|c|c|}
\hline $\begin{array}{c}\text { ESPECIE: } \\
\text { Catanudo } \\
\text { (Callophyllum sp) }\end{array}$ & \multicolumn{15}{|c|}{ PROPRIEDADES FÍSICAS DE RESISTÊNCIA E DE RIGIDEZ } \\
\hline UMIDADE: $12 \%$ & $\underset{\left(\mathrm{g} / \mathrm{cm}^{3}\right)}{\boldsymbol{\rho}_{\mathbf{a p}}}$ & $\begin{array}{c}\boldsymbol{E}_{\mathbf{r}} \\
(\%)\end{array}$ & $\begin{array}{c}\boldsymbol{E}_{\mathbf{t}} \\
(\%)\end{array}$ & $\underset{\left(\mathrm{daN} / \mathrm{cm}^{2}\right)}{\mathbf{f}_{\mathbf{c o}}}$ & $\begin{array}{c}\mathbf{f}_{\mathrm{to}} \\
\left(\mathrm{daN} / \mathrm{cm}^{2}\right)\end{array}$ & $\begin{array}{c}\mathbf{f}_{\mathbf{t 9 0}} \\
\left(\mathrm{daN} / \mathrm{cm}^{2}\right)\end{array}$ & $\begin{array}{c}\mathbf{f}_{\mathrm{vo}} \\
\left(\mathrm{daN} / \mathrm{cm}^{2}\right)\end{array}$ & $\begin{array}{c}\mathbf{f}_{\mathrm{s0}} \\
\left(\mathrm{daN} / \mathrm{cm}^{2}\right)\end{array}$ & $\underset{\left(\mathrm{daN} / \mathrm{cm}^{2}\right)}{\mathbf{f}_{\mathbf{M}}}$ & $\underset{\left(\mathrm{daN} / \mathrm{cm}^{2}\right)}{\mathbf{E}_{\mathbf{c o}}}$ & $\underset{\left(\mathrm{daN} / \mathrm{cm}^{2}\right)}{\mathbf{E}_{\text {to }}}$ & $\underset{\left(\mathrm{daN} / \mathrm{cm}^{2}\right)}{\mathbf{E}_{\mathbf{M}}}$ & $\underset{\left(\mathrm{daN} / \mathrm{cm}^{2}\right)}{\mathbf{f}_{\mathbf{H o}}}$ & $\underset{\left(\mathrm{daN} / \mathrm{cm}^{2}\right)}{\mathbf{f}_{\mathbf{H g O}}}$ & $\underset{(\mathrm{daN} \times \mathrm{m})}{\mathbf{T}}$ \\
\hline N.01 - CP: 01 & 0,79 & 6,35 & 7,19 & 547 & 666 & 14 & 227 & 4 & 943 & 155473 & 172047 & 159906 & 860 & 583 & 1,082 \\
\hline N.02 - CP: 02 & 0,80 & 5,15 & 8,16 & 494 & 582 & 54 & 123 & 4 & 985 & 136213 & 119792 & 150805 & 820 & 565 & 1,056 \\
\hline N.03 - CP: 03 & 0,87 & 6,09 & 9,43 & 567 & 1295 & 50 & 153 & 7 & 879 & 146145 & 174093 & 153889 & 895 & 658 & 1,645 \\
\hline N.04 - CP: 04 & 0,82 & 5,09 & 8,28 & 502 & 523 & 15 & 162 & 4 & 709 & 139086 & 139493 & 138838 & 855 & 550 & 1,056 \\
\hline N.05 - CP: 05 & 0,80 & 5,07 & 8,28 & 496 & 605 & 46 & 176 & 8 & 458 & 119871 & 151688 & 114438 & 885 & 568 & 1,188 \\
\hline N.06 - CP: 06 & 0,82 & 4,98 & 9,33 & 485 & 492 & 13 & 193 & 8 & 863 & 121298 & 157899 & 141252 & 860 & 633 & 1,351 \\
\hline N.07 - CP: 07 & 0,83 & 4,95 & 7,76 & 499 & 518 & 43 & 124 & 7 & 903 & 132756 & 160160 & 156040 & 890 & 581 & 1,434 \\
\hline N.08 - CP: 08 & 0,74 & 6,27 & 7,73 & 481 & 459 & 49 & 125 & 6 & 674 & 117084 & 132670 & 141495 & 793 & 546 & 0,829 \\
\hline N.09-CP: 09 & 0,78 & 5,45 & 8,09 & 481 & 464 & 22 & 142 & 3 & 941 & 98274 & 157012 & 162314 & 715 & 540 & 1,963 \\
\hline N.10 - CP: 10 & 0,74 & 4,01 & 7,06 & 456 & 677 & 23 & 190 & 5 & 653 & 87635 & 154987 & 122621 & 840 & 576 & 1,467 \\
\hline N.11 - CP: 11 & 0,83 & 5,84 & 9,61 & 555 & 935 & 54 & 135 & 7 & 1041 & 169503 & 208295 & 169310 & 805 & 608 & 1,153 \\
\hline N.12 - CP 12 & 0,83 & 5,61 & 9,47 & 506 & 907 & 47 & 220 & 11 & 923 & 140157 & 131706 & 156525 & 940 & 700 & 1,451 \\
\hline MÉDIA & $\mathbf{0 , 8 0}$ & 5,41 & 8,37 & 506 & 677 & 36 & 164 & 6 & 831 & 130291 & 154987 & 147286 & 847 & 592 & 1,306 \\
\hline$N^{2}$. DE AMOSTRAS & 12 & 12 & 12 & 12 & 12 & 12 & 12 & 12 & 12 & 12 & 12 & 12 & 12 & 12 & 12 \\
\hline
\end{tabular}


Tabela 6.14 - Ensaios - Cedro Amargo

\begin{tabular}{|c|c|c|c|c|c|c|c|c|c|c|c|c|c|c|c|}
\hline $\begin{array}{c}\text { ESPECIE: } \\
\text { Cedro Amargo } \\
\text { (Cedrella odorata) }\end{array}$ & \multicolumn{15}{|c|}{ PROPRIEDADES FISICAS DE RESISTÊNCIA E DE RIGIDEZ } \\
\hline UMIDADE: $12 \%$ & $\begin{array}{c}\boldsymbol{\rho}_{\text {ap }} \\
\left(\mathrm{g} / \mathrm{cm}^{3}\right)\end{array}$ & $\begin{array}{c}\boldsymbol{\varepsilon}_{\mathbf{r}} \\
(\%)\end{array}$ & $\begin{array}{c}\boldsymbol{E}_{\mathbf{t}} \\
(\%)\end{array}$ & $\begin{array}{c}\mathbf{f}_{\mathrm{co}} \\
\left(\mathrm{daN} / \mathrm{cm}^{2}\right)\end{array}$ & $\begin{array}{c}\mathbf{f}_{\mathrm{to}} \\
\left(\mathrm{daN} / \mathrm{cm}^{2}\right)\end{array}$ & $\begin{array}{c}\mathbf{f}_{\mathrm{tg0}} \\
\left(\mathrm{daN} / \mathrm{cm}^{2}\right)\end{array}$ & $\underset{\left(\mathrm{daN} / \mathrm{cm}^{2}\right)}{\mathbf{f}_{\text {vo }}}$ & $\begin{array}{c}\mathbf{f}_{\mathrm{s0}} \\
\left(\mathrm{daN} / \mathrm{cm}^{2}\right)\end{array}$ & $\underset{\left(\mathrm{daN} / \mathrm{cm}^{2}\right)}{\mathbf{f}_{\mathbf{M}}}$ & $\underset{\text { (daN/cm }{ }^{2} \text { ) }}{\mathbf{E}_{\mathbf{c o}}}$ & $\underset{\left(\mathrm{daN} / \mathrm{cm}^{2}\right)}{\mathbf{E}_{\mathrm{to}}}$ & $\underset{\left(\mathrm{daN} / \mathrm{cm}^{2}\right)}{\mathbf{E}_{\mathbf{M}}}$ & $\underset{\left(\mathrm{daN} / \mathrm{cm}^{2}\right)}{\mathbf{f}_{\mathbf{H o}}}$ & $\begin{array}{c}\mathbf{f}_{\mathbf{H 9 0}} \\
\left(\mathrm{daN} / \mathrm{cm}^{2}\right)\end{array}$ & $\underset{(\mathrm{daN} \times \mathrm{m})}{\mathbf{T}}$ \\
\hline N.01 - CP: $06 \mathrm{E} 13$ & 0,50 & 4,13 & 5,48 & 403 & 765 & 27 & 91 & 5 & 648 & 99970 & 103373 & 89476 & 630 & 334 & 0,507 \\
\hline N.02 - CP:16 B 01 & 0,46 & 3,97 & 5,26 & 340 & 565 & 40 & 110 & 5 & 583 & 74228 & 104992 & 89785 & 496 & 280 & 0,252 \\
\hline N.03 - CP: 16 B 02 & 0,53 & 4,18 & 5,32 & 421 & 498 & 33 & 131 & 5 & 568 & 90260 & 122003 & 87743 & 550 & 261 & 0,975 \\
\hline N.04 - CP: 16 B 03 & 0,52 & 3,85 & 5,27 & 397 & 748 & 13 & 105 & 5 & 658 & 73939 & 84420 & 94497 & 614 & 433 & 0,478 \\
\hline N.05 - CP: 16 B 04 & 0,52 & 4,05 & 5,10 & 442 & 538 & 35 & 94 & 6 & 651 & 93379 & 89511 & 91757 & 790 & 738 & 0,546 \\
\hline N.06-CP: 16 B 05 & 0,50 & 4,22 & 5,32 & 427 & 594 & 38 & 105 & 6 & 735 & 108450 & 93314 & 96014 & 711 & 512 & 0,440 \\
\hline N.07 - CP: $16 \mathrm{~B} 06$ & 0,48 & 3,93 & 5,05 & 424 & 530 & 30 & 142 & 4 & 646 & 103882 & 98598 & 93937 & 544 & 364 & 0,312 \\
\hline N.08 - CP: 16 B 08 & 0,52 & 5,13 & 6,02 & 447 & 371 & 29 & 115 & 6 & 553 & 94163 & 102564 & 85421 & 555 & 280 & 0,132 \\
\hline N.09-CP: 16 B 09 & 0,48 & 3,84 & 5,42 & 406 & 470 & 32 & 119 & 6 & 734 & 102188 & 73864 & 83169 & 512 & 321 & 0,381 \\
\hline N.10-CP: 16 B 10 & 0,51 & 3,29 & 6,37 & 309 & 880 & 30 & 89 & 5 & 873 & 103570 & 110450 & 97846 & 456 & 256 & 0,930 \\
\hline N.11 - CP: 16 B 11 & 0,50 & 3,35 & 5,03 & 315 & 548 & 29 & 79 & 4 & 593 & 93312 & 110485 & 102005 & 329 & 296 & 0,498 \\
\hline N.12 - CP: 16 B 13 & 0,49 & & $*$ & 418 & 684 & 35 & 98 & 6 & 760 & 115149 & 136493 & 112984 & 733 & 361 & 0,708 \\
\hline N.13-CP: 16 B 14 & 0,48 & 3,93 & 5,44 & 404 & 477 & 26 & 104 & 4 & 580 & 98603 & 96842 & 87177 & 463 & 296 & 0,081 \\
\hline N.14-CP: 16 B 15 & 0,67 & 3,86 & 4,87 & 319 & 793 & 30 & 74 & 7 & 430 & 97050 & 113892 & 89955 & 437 & 210 & 0,312 \\
\hline $\mathrm{N} .15-\mathrm{CP}: 17 \mathrm{~B} 01$ & 0,51 & 3,66 & 5,09 & 339 & 450 & 23 & 94 & 6 & 699 & 97619 & 103419 & 95527 & 490 & 261 & 0,517 \\
\hline N.16 - CP: 17 B 05 & 0,52 & 3,62 & 5,07 & 483 & 607 & 35 & 98 & 6 & 864 & 101999 & 108976 & 118229 & 550 & 302 & 0,884 \\
\hline N.17 - CP: 17 B 06 & 0,48 & 3,77 & 4,77 & 364 & 558 & 25 & 99 & 5 & 815 & 80871 & 110351 & 124310 & 447 & 256 & 0,381 \\
\hline N.18 - CP: $17 \mathrm{~B} 07$ & 0,52 & 4,41 & 5,24 & 411 & 626 & 36 & 97 & 8 & 543 & 107446 & 114557 & 92516 & 550 & 329 & 0,565 \\
\hline N.19-CP: 17 B 08 & 0,52 & 4,12 & 5,06 & 397 & 815 & 28 & 104 & 6 & 700 & 102125 & 112977 & 90502 & 560 & 280 & 0,536 \\
\hline N.20-CP: $17 \mathrm{~B} 09$ & 0,50 & 4,18 & 5,56 & 448 & 445 & 35 & 106 & 6 & 934 & 109652 & 109966 & 98803 & 474 & 270 & 0,162 \\
\hline N.21 - CP: 17B 13 & 0,44 & 3,96 & 5,63 & 304 & 602 & 26 & 106 & 5 & 477 & 94463 & 86825 & 99616 & 485 & 261 & 0,070 \\
\hline MÉDIA & $\mathbf{0 , 5 1}$ & 3,97 & 5,32 & 391 & 598 & 30 & 103 & 6 & 669 & 97253 & 104184 & 96251 & 542 & 329 & 0,460 \\
\hline $\mathrm{N}^{0}$. DE AMOSTRAS & 21 & 20 & 20 & 21 & 21 & 21 & 21 & 21 & 21 & 21 & 21 & 21 & 21 & 21 & 21 \\
\hline
\end{tabular}

"Dado desconsiderado, CP com defeito. 
Tabela 6.15 - Ensaios - Cedrorana

\begin{tabular}{|c|c|c|c|c|c|c|c|c|c|c|c|c|c|c|c|}
\hline $\begin{array}{l}\text { ESPECIE: } \\
\text { Cedrorana } \\
\text { (Cedrelinga } \\
\text { cateaformis) }\end{array}$ & \multicolumn{15}{|c|}{ PROPRIEDADES FÍSICAS DE RESISTÊNCIA E DE RIGIDEZ } \\
\hline UMIDADE: $12 \%$ & $\underset{\left(\mathrm{g} / \mathrm{cm}^{3}\right)}{\rho_{\mathbf{a p}}}$ & $\begin{array}{c}\boldsymbol{\varepsilon}_{\mathbf{r}} \\
(\%)\end{array}$ & $\begin{array}{c}\boldsymbol{\varepsilon}_{\mathbf{t}} \\
(\%)\end{array}$ & $\begin{array}{c}\mathbf{f}_{\mathbf{c o}} \\
\left(\mathrm{daN} / \mathrm{cm}^{2}\right)\end{array}$ & $\begin{array}{c}\mathbf{f}_{\mathbf{t o}} \\
\left(\mathrm{daN} / \mathrm{cm}^{2}\right)\end{array}$ & $\begin{array}{c}\mathbf{f}_{\mathbf{t 9 0}} \\
\left(\mathrm{daN} / \mathrm{cm}^{2}\right)\end{array}$ & $\begin{array}{c}\mathbf{f}_{\mathbf{v o}} \\
\left(\mathrm{daN} / \mathrm{cm}^{2}\right)\end{array}$ & $\begin{array}{c}\mathbf{f}_{\mathrm{s} \mathbf{0}} \\
\left(\mathrm{daN} / \mathrm{cm}^{2}\right)\end{array}$ & $\underset{\left(\mathrm{daN} / \mathrm{cm}^{2}\right)}{\mathbf{f}_{\mathbf{M}}}$ & $\underset{\left(\mathrm{daN} / \mathrm{cm}^{2}\right)}{\mathbf{E}_{\mathbf{c o}}}$ & $\underset{\left(\mathrm{daN} / \mathrm{cm}^{2}\right)}{\mathbf{E}_{\mathrm{to}}}$ & $\underset{\left(\mathrm{daN} / \mathrm{cm}^{2}\right)}{\mathbf{E}_{\mathbf{M}}}$ & $\underset{\left(\mathrm{daN} / \mathrm{cm}^{2}\right)}{\mathbf{f}_{\mathbf{H o}}}$ & $\underset{\left(\mathrm{daN} / \mathrm{cm}^{2}\right)}{\left.\mathbf{f}_{\mathbf{H}}\right)}$ & $\underset{(\mathrm{daN} \times \mathrm{m})}{\mathbf{T}}$ \\
\hline $26 \mathrm{D} 03$ & 0,64 & 3,43 & 7,03 & 471 & 463 & 22 & 172 & 5 & 605 & 97996 & 127210 & 93448 & 771 & 442 & 0,478 \\
\hline $12 \mathrm{C} 01$ & 0,56 & 5,20 & 7,30 & 530 & 472 & 28 & 140 & 7 & 852 & 129133 & 125133 & 123238 & 609 & 334 & 0,381 \\
\hline $07 \mathrm{C} 06$ & 0,58 & 2,87 & 7,10 & 311 & 689 & 12 & 69 & 5 & 471 & 107106 & 120895 & 85774 & 463 & 243 & 0,556 \\
\hline $31 \mathrm{~A} 15$ & 0,53 & 3,52 & 6,44 & 314 & 933 & 32 & 88 & 5 & 632 & 92421 & 100398 & 95025 & 318 & 323 & 0,381 \\
\hline 17 B 04 & 0,50 & 3,43 & 4,37 & 271 & 696 & 22 & 101 & 4 & 653 & 87445 & 98233 & 101919 & 329 & 269 & 0,782 \\
\hline $12 \mathrm{C} 04$ & 0,59 & 2,08 & 6,35 & 435 & 490 & 31 & 124 & 4 & 644 & 108167 & 89114 & 105325 & 679 & 361 & 0,342 \\
\hline $29 \mathrm{~F} 05$ & 0,63 & 2,27 & 5,41 & 408 & 478 & 37 & 149 & 5 & 407 & 84837 & 99543 & 84035 & 796 & 447 & 0,061 \\
\hline $29 \mathrm{~F} 08$ & 0,52 & 3,69 & 7,95 & 533 & 370 & 32 & 109 & 7 & 644 & 109693 & 81133 & 99533 & 856 & 393 & 0,507 \\
\hline $12 \mathrm{C} 03$ & 0,54 & 4,81 & 7,52 & 421 & 480 & 50 & 146 & 7 & 616 & 105593 & 103362 & 106360 & 566 & 342 & 0,381 \\
\hline $31 \times 14$ & 0,56 & 3,52 & 4,54 & 313 & 780 & 24 & 77 & 5 & 630 & 92641 & 133043 & 101432 & 367 & 321 & 0,594 \\
\hline $24 \mathrm{D} 08$ & 0,57 & 3,62 & 6,78 & 537 & 931 & 47 & 132 & 8 & 500 & 112728 & 128606 & 107471 & 630 & 447 & 0,498 \\
\hline MÉDIA & 0,57 & 3,49 & 6,44 & 413 & 617 & 31 & 119 & 6 & 605 & 102524 & 109697 & 100324 & 580 & 357 & 0,451 \\
\hline$N^{0}=$ DE AMOSTRA & 11 & 11 & 11 & 11 & 11 & 11 & 11 & 11 & 11 & 11 & 11 & 11 & 11 & 11 & 11 \\
\hline
\end{tabular}


Tabela 6.16 - Ensaios - Champanhe

\begin{tabular}{|c|c|c|c|c|c|c|c|c|c|c|c|c|c|c|c|}
\hline $\begin{array}{c}\text { ESPECIE: } \\
\text { Champanhe } \\
\text { (Dipteryx sp) }\end{array}$ & \multicolumn{15}{|c|}{ PROPRIEDADES FÍSICAS DE RESISTÊNCIA E DE RIGIDEZ } \\
\hline UMIDADE: $12 \%$ & $\underset{\left(\mathrm{g} / \mathrm{cm}^{3}\right)}{\rho_{\mathrm{ap}}}$ & $\begin{array}{c}\boldsymbol{E}_{\mathbf{r}} \\
(\%)\end{array}$ & $\begin{array}{c}\boldsymbol{\varepsilon}_{\mathbf{t}} \\
(\%)\end{array}$ & $\underset{\left(\mathrm{daN} / \mathrm{cm}^{2}\right)}{\mathbf{f}_{\mathrm{co}}}$ & $\begin{array}{c}\mathbf{f}_{\mathrm{to}} \\
\left(\mathrm{daN} / \mathrm{cm}^{2}\right)\end{array}$ & $\begin{array}{c}f_{t 90} \\
\left(\mathrm{daN} / \mathrm{cm}^{2}\right)\end{array}$ & $\begin{array}{c}\mathbf{f v o}_{\mathbf{v o}} \\
\left(\mathrm{daN} / \mathrm{cm}^{2}\right)\end{array}$ & $\begin{array}{c}\mathbf{f}_{\mathrm{s} 0} \\
\left(\mathrm{daN} / \mathrm{cm}^{2}\right)\end{array}$ & $\underset{\left(\mathrm{daN} / \mathrm{cm}^{2}\right)}{\mathbf{f}_{\mathbf{M}}}$ & $\begin{array}{c}\mathbf{E}_{\mathrm{co}} \\
\left(\mathrm{daN} / \mathrm{cm}^{2}\right)\end{array}$ & $\underset{\left(\mathrm{daN} / \mathrm{cm}^{2}\right)}{\mathbf{E}_{\mathrm{to}}}$ & $\underset{\left(\mathrm{daN} / \mathrm{cm}^{2}\right)}{\mathbf{E}_{\mathbf{M}}}$ & $\begin{array}{c}\mathbf{f H o}_{\mathbf{H o}} \\
\left(\mathrm{daN} / \mathrm{cm}^{2}\right)\end{array}$ & $\begin{array}{c}\mathbf{f}_{\mathrm{H} 90} \\
\left(\mathrm{daN} / \mathrm{cm}^{2}\right)\end{array}$ & $\underset{(\mathrm{daN} \times \mathrm{m})}{\mathbf{T}}$ \\
\hline N.01 - CP: 01 & 1,10 & 4,27 & 7,95 & 957 & 908 & 33 & 175 & 8 & 1486 & 246585 & 207912 & 266756 & 1148 & 1198 & " \\
\hline N.02 - CP: 02 & 1,06 & 4,27 & 6,08 & 909 & 967 & 21 & 112 & 6 & 2160 & 245442 & 217234 & 234009 & 1430 & 1088 & * \\
\hline N.03 - CP: 03 & 1,13 & 3,79 & 6,02 & 931 & 1129 & 32 & 147 & 9 & 922 & 184796 & 222098 & 225705 & 1430 & 1263 & $*$ \\
\hline N.04 - CP: 04 & 1,06 & 5,28 & 7,75 & 929 & 1231 & 32 & 209 & 7 & 1591 & 193979 & 231198 & 252376 & 1380 & 1240 & $*$ \\
\hline N.05 - CP: 05 & 1,14 & 4,53 & 7,76 & 1025 & 1733 & 23 & 204 & 7 & 2055 & 265497 & 184261 & 235880 & 1483 & 1405 & * \\
\hline N.06 - CP: 06 & 1,04 & 5,33 & 6,87 & 1025 & 1420 & 40 & 185 & 7 & 1570 & 265497 & 236795 & 272891 & 1375 & 1080 & $*$ \\
\hline N.07 - CP: 07 & 1,12 & 2,97 & 4,78 & 913 & 1524 & 21 & 218 & 8 & 1679 & 220871 & 209457 & 259145 & 1431 & 1390 & $*$ \\
\hline N.08 - CP: 08 & 1,07 & 3,65 & 4,98 & 911 & 873 & 26 & 177 & 9 & 1722 & 217480 & 167175 & 203822 & 1408 & 1478 & $*$ \\
\hline N.09 - CP: 09 & 1,12 & 3,03 & 5,42 & 849 & 1195 & 31 & 151 & 8 & 1821 & 240051 & 210984 & 285050 & 1125 & 1057 & $*$ \\
\hline N.10 - CP 10 & 1,07 & 4,01 & 6,93 & 905 & 1170 & 25 & 197 & 7 & 1629 & 218474 & 225341 & 242757 & 1490 & 1142 & $*$ \\
\hline N.11-CP: 11 & 1,11 & 3,27 & 6,19 & 1152 & 1237 & 28 & 184 & 8 & 1714 & 238421 & 201007 & 294631 & 1251 & 1353 & $*$ \\
\hline N.12 - CP: 12 & 1,06 & 3,02 & 5,79 & 894 & 1292 & 30 & 182 & 7 & 1428 & 223137 & 200929 & 247854 & 1617 & 1579 & * \\
\hline MÉDIA & 1,09 & 3,95 & 6,38 & 950 & 1223 & 29 & 178 & 8 & 1648 & 230019 & 209533 & 251740 & 1381 & 1273 & $*$ \\
\hline $\mathrm{N}^{2}$. DE AMOSTRA & 12 & 12 & 12 & 12 & 12 & 12 & 12 & 12 & 12 & 12 & 12 & 12 & 12 & 12 & * \\
\hline
\end{tabular}

"Dado desconsiderado, CP com defeito. 
Tabela 6.17 - Ensaios - Cupiúba

\begin{tabular}{|c|c|c|c|c|c|c|c|c|c|c|c|c|c|c|c|}
\hline \multirow{2}{*}{$\begin{array}{c}\begin{array}{c}\text { ESPÉCIE: } \\
\text { Cupiúba } \\
\text { (Goupia glabra) }\end{array} \\
\text { ORIGEM: } \\
\text { Sul de Roraima } \\
\text { UMIDADE: } 12 \%\end{array}$} & \multicolumn{15}{|c|}{ PROPRIEDADES FÍSICAS DE RESISTÊNCIA E DE RIGIDEZ } \\
\hline & $\underset{\left(\mathrm{g} / \mathrm{cm}^{3}\right)}{\rho_{\mathrm{ap}}}$ & $\begin{array}{c}\boldsymbol{\varepsilon}_{\mathbf{r}} \\
(\%)\end{array}$ & $\begin{array}{c}\varepsilon_{\mathbf{t}} \\
(\%)\end{array}$ & $\begin{array}{c}\mathbf{f}_{\mathbf{c o}} \\
\left(\mathrm{daN} / \mathrm{cm}^{2}\right)\end{array}$ & $\begin{array}{c}\mathbf{f}_{\mathbf{t o}} \\
\left(\mathrm{daN} / \mathrm{cm}^{2}\right)\end{array}$ & $\begin{array}{c}\mathbf{f}_{\mathbf{t g}} \\
\left(\mathrm{daN} / \mathrm{cm}^{2}\right)\end{array}$ & $\begin{array}{c}\mathbf{f}_{\mathbf{V O}} \\
\left(\mathrm{daN} / \mathrm{cm}^{2}\right)\end{array}$ & $\begin{array}{c}\mathbf{f}_{\mathrm{s0}} \\
\left(\mathrm{daN} / \mathrm{cm}^{2}\right)\end{array}$ & $\begin{array}{c}\mathbf{f}_{\mathbf{M}} \\
\left(\mathrm{daN} / \mathrm{cm}^{2}\right)\end{array}$ & $\underset{\left(\mathrm{daN} / \mathrm{cm}^{2}\right)}{\mathbf{E}_{\mathbf{c o}}}$ & $\underset{\left(\mathrm{daN} / \mathrm{cm}^{2}\right)}{\mathbf{E}_{\mathbf{t o}}}$ & $\underset{\left(\mathrm{daN} / \mathrm{cm}^{2}\right)}{\mathbf{E}_{\mathbf{M}}}$ & $\begin{array}{c}\mathbf{f}_{\mathbf{H o}} \\
\left(\mathrm{daN} / \mathrm{cm}^{2}\right)\end{array}$ & $\underset{\left(\mathrm{daN} / \mathrm{cm}^{2}\right)}{\mathbf{f}_{\mathbf{H O O}}}$ & $\underset{(\mathrm{daN} \times \mathrm{m})}{\mathbf{T}}$ \\
\hline N.01 - CP: 11 C 01 & 0,86 & 3,86 & 6,56 & 469 & 573 & 32 & 169 & 7 & 815 & 168328 & 149792 & 126795 & 959 & 630 & 1,091 \\
\hline $\mathrm{N} .02-\mathrm{CP}: 11 \mathrm{C} 02$ & 0,90 & 3,66 & 6,60 & 514 & 661 & 20 & 186 & 9 & 785 & 137863 & 109580 & 116029 & 1158 & 800 & 0,651 \\
\hline N.03-CP: $11 \mathrm{C} 03$ & 0,87 & 4,02 & 7,36 & 670 & 497 & 31 & 185 & 7 & 839 & 135886 & 113824 & 158344 & 1199 & 781 & 0,371 \\
\hline N.04-CP: 11 C 04 & 0,84 & 3,26 & 7,17 & 740 & 885 & 24 & 193 & 6 & 1141 & 172458 & 157101 & 160306 & 1007 & 695 & 0,921 \\
\hline N.05 - CP: 11 C 06 & 0,88 & 4,88 & 7,41 & 622 & 828 & 20 & 137 & 6 & 1051 & 168002 & 143900 & 147668 & 749 & 584 & 1,467 \\
\hline N.06-CP: 11 C 07 & 0,88 & 4,49 & 7,36 & 520 & 572 & 11 & $\overline{162}$ & 4 & 759 & 148025 & 148500 & 141750 & 765 & 571 & 1,109 \\
\hline N.07 - CP: 11 C 09 & 0,85 & 4,69 & 6,19 & 592 & 1026 & 36 & 156 & 8 & 1096 & 160535 & 153826 & 147741 & 851 & 601 & 0,847 \\
\hline N.08 - CP: 11 C 10 & 0,85 & 4,01 & 7,10 & 674 & 616 & 44 & 195 & 8 & 626 & 144982 & 137236 & 122862 & 1120 & 730 & 0,603 \\
\hline N.09-CP: 11 C 12 & 0,82 & 4,87 & 7,93 & 515 & 830 & 48 & 203 & 10 & 844 & 133713 & 177523 & 141081 & 1099 & 668 & 0,957 \\
\hline N.10-CP: $11 \mathrm{C} 13$ & 0,85 & 4,41 & 7,71 & 740 & 702 & 32 & 171 & 8 & 1014 & 190358 & 194871 & 166790 & 1136 & 719 & 0,679 \\
\hline N.11 - CP: 11 C 14 & 0,81 & 4,80 & 7,85 & 725 & 1000 & 28 & 210 & 4 & 812 & 188554 & 160250 & 157391 & 1136 & 719 & 0,856 \\
\hline N.12-CP: 11 C 15 & 0,77 & 4,13 & 7,55 & 602 & 753 & 12 & 143 & 4 & 814 & 153643 & 154301 & 142284 & 943 & 722 & 0,622 \\
\hline $\mathrm{N} .13-\mathrm{CP}: 13 \mathrm{C} 12$ & 0,84 & 4,56 & 7,44 & 618 & 1167 & 38 & 224 & 6 & 714 & 143390 & 165853 & 146747 & 1142 & 765 & 0,82 \\
\hline N.14 - CP: 17 B 12 & 0,82 & 3,93 & 9,92 & 308 & 295 & 42 & 166 & 4 & 685 & 70268 & 76505 & 106049 & 754 & 638 & 0,282 \\
\hline N.15 - CP: 19 D 02 & 0,87 & 5,12 & 6,52 & 476 & 502 & 34 & 197 & 5 & 671 & 90264 & 118531 & 125803 & 1018 & 789 & 0,764 \\
\hline $\mathrm{N} .16$ - CP: 19 D 03 & 0,85 & 3,38 & 5,14 & 567 & 1174 & 35 & 218 & 10 & 731 & 131649 & 94224 & 116194 & 1169 & 767 & 0,410 \\
\hline N.17 - CP: 19 D 04 & 0,90 & 5,08 & 6,88 & 644 & 520 & 47 & 201 & 10 & 731 & 116904 & 99993 & 100581 & 1239 & 795 & 0,651 \\
\hline
\end{tabular}


Tabela 6.17 - (continuação) - Ensaios - Cupiúba

\begin{tabular}{|c|c|c|c|c|c|c|c|c|c|c|c|c|c|c|c|}
\hline UMIDADE: $12 \%$ & $\underset{\left(\mathrm{g} / \mathrm{cm}^{3}\right)}{\boldsymbol{\rho}_{\mathbf{p}}}$ & $\begin{array}{c}\boldsymbol{\varepsilon}_{\mathbf{r}} \\
(\%)\end{array}$ & $\begin{array}{c}\boldsymbol{E}_{\mathrm{t}} \\
(\%)\end{array}$ & $\begin{array}{c}\mathbf{f}_{\mathrm{co}} \\
\left(\mathrm{daN} / \mathrm{cm}^{2}\right)\end{array}$ & $\begin{array}{c}\mathbf{f}_{\mathbf{t o}} \\
\left(\mathrm{daN} / \mathrm{cm}^{2}\right)\end{array}$ & $\begin{array}{c}\mathbf{f}_{\mathbf{t 9 0}} \\
\left(\mathrm{daN} / \mathrm{cm}^{2}\right)\end{array}$ & $\begin{array}{c}\mathbf{f}_{\mathbf{v o}} \\
\left(\mathrm{daN} / \mathrm{cm}^{2}\right)\end{array}$ & $\begin{array}{c}\mathbf{f}_{\mathbf{s 0}} \\
\left(\mathrm{daN} / \mathrm{cm}^{2}\right)\end{array}$ & $\begin{array}{c}\mathbf{f}_{\mathbf{M}} \\
\left(\mathrm{daN} / \mathrm{cm}^{2}\right)\end{array}$ & $\begin{array}{c}\mathbf{E}_{\mathbf{c o}} \\
\left(\mathrm{daN} / \mathrm{cm}^{2}\right)\end{array}$ & $\underset{\left(\mathrm{daN} / \mathrm{cm}^{2}\right)}{\mathbf{E}_{\mathrm{to}}}$ & $\underset{\left(\mathrm{daN} / \mathrm{cm}^{2}\right)}{\mathbf{E}_{\mathbf{M}}}$ & $\begin{array}{c}\mathbf{f H o}_{\mathrm{Ho}} \\
\left(\mathrm{daN} / \mathrm{cm}^{2}\right)\end{array}$ & $\begin{array}{c}\mathbf{f}_{\mathbf{H 9 0}} \\
\left(\mathrm{daN} / \mathrm{cm}^{2}\right)\end{array}$ & $\begin{array}{c}\mathbf{T} \\
(\mathrm{daN} \times \mathrm{m})\end{array}$ \\
\hline N.18 - CP: 19 D 05 & 0,87 & 4,85 & 7,02 & 517 & 506 & 46 & 163 & 6 & 779 & 117734 & 141660 & 119035 & 1077 & 652 & 0,322 \\
\hline N.19-CP: 19 D 07 & 0,86 & 4,30 & 5,33 & 503 & 889 & 52 & 181 & 9 & 763 & 103120 & 90958 & 101358 & 932 & 614 & 0,381 \\
\hline N.20 - CP: 19 D 08 & 0,85 & 4,43 & 6,32 & 425 & 777 & 47 & 207 & 11 & 631 & 107847 & 102381 & 102728 & 949 & 724 & 0,546 \\
\hline N.21 - CP: 19 D 09 & 0,86 & 5,02 & 7,92 & 428 & 691 & 38 & 200 & 11 & 696 & 95593 & 110819 & 97731 & 1390 & 698 & 0,312 \\
\hline N $22-C P: 19$ D 10 & 0,85 & 5,26 & 5,97 & 592 & 905 & 38 & 185 & 9 & 994 & 141418 & 179536 & 121942 & 1083 & 711 & 0,459 \\
\hline N.23 - CP: 27 F 02 & 0,78 & 3,63 & 6,76 & 420 & 897 & 23 & 65 & 7 & 549 & 106943 & 127132 & 105977 & 674 & 490 & 0,820 \\
\hline N.24 - CP: 27 F 03 & 0,84 & 3,69 & 8,54 & 394 & 987 & 40 & 133 & 9 & 886 & 101214 & 150919 & 126292 & 770 & 492 & 1,047 \\
\hline N.25 - CP: 27 F 04 & 0,82 & 3,91 & 7,70 & 353 & 709 & 30 & 212 & 6 & 619 & 85639 & 93446 & 97302 & 733 & 496 & 0,182 \\
\hline N.26 - CP: 27 F 05 & 0,84 & 3,33 & 6,77 & 477 & 482 & 28 & 204 & 5 & 710 & 108824 & 93576 & 119705 & 701 & 490 & 0,371 \\
\hline N.27-CP: 27 F 06 & 0,87 & 3,82 & 7,38 & 399 & 394 & 28 & 164 & 4 & 454 & 114193 & 90519 & 97847 & 743 & 533 & 0,613 \\
\hline MÉDIA & 0,85 & 4,27 & 7,13 & 537 & 735 & 33 & 179 & 7 & 786 & 131013 & 130991 & 126457 & 981 & 662 & 0,672 \\
\hline $\mathrm{N}^{2}$. DE AMOSTRAS & 27 & 27 & 27 & 27 & 27 & 27 & 27 & 27 & 27 & 27 & 27 & 27 & 27 & 27 & 27 \\
\hline
\end{tabular}


Tabela 6.18 - Ensaios - Cutiúba

\begin{tabular}{|c|c|c|c|c|c|c|c|c|c|c|c|c|c|c|c|}
\hline $\begin{array}{c}\text { ESPÉCIE: } \\
\text { Cutiúba } \\
\text { (Qualea Paraensis) }\end{array}$ & \multicolumn{15}{|c|}{ PROPRIEDADES FÍSICAS DE RESISTÊNCIA E DE RIGIDEZ } \\
\hline UMIDADE: $12 \%$ & $\underset{\left(\mathrm{g} / \mathrm{cm}^{3}\right)}{\boldsymbol{\rho}_{\mathrm{ap}}}$ & $\begin{array}{c}\boldsymbol{E}_{\mathbf{r}} \\
(\%)\end{array}$ & $\begin{array}{c}\boldsymbol{E}_{\mathbf{t}} \\
(\%)\end{array}$ & $\begin{array}{c}\mathbf{f}_{\mathrm{co}} \\
\left(\mathrm{daN} / \mathrm{cm}^{2}\right)\end{array}$ & $\begin{array}{c}\mathbf{f}_{\text {to }} \\
\left(\mathrm{daN} / \mathrm{cm}^{2}\right)\end{array}$ & $\begin{array}{c}\mathbf{f}_{\mathrm{tg0}} \\
\left(\mathrm{daN} / \mathrm{cm}^{2}\right)\end{array}$ & $\underset{\left(\mathrm{daN} / \mathrm{cm}^{2}\right)}{\mathbf{f}_{\mathbf{v o}}}$ & $\begin{array}{c}\mathbf{f}_{\mathrm{s0}} \\
\left(\mathrm{daN} / \mathrm{cm}^{2}\right)\end{array}$ & $\underset{\left(\mathrm{daN} / \mathrm{cm}^{2}\right)}{\mathbf{f}_{\mathbf{M}}}$ & $\underset{\left(\mathrm{daN} / \mathrm{cm}^{2}\right)}{\mathbf{E}_{\mathbf{c o}}}$ & $\underset{\left(\mathrm{daN} / \mathrm{cm}^{2}\right)}{\mathbf{E}_{\mathrm{to}}}$ & $\underset{\left(\mathrm{daN} / \mathrm{cm}^{2}\right)}{\mathbf{E}_{\mathbf{M}}}$ & $\begin{array}{c}\mathbf{f}_{\mathbf{H o}} \\
\left(\mathrm{daN} / \mathrm{cm}^{2}\right)\end{array}$ & $\begin{array}{c}\mathbf{f}_{\mathbf{H 9 0}} \\
\left(\mathrm{daN} / \mathrm{cm}^{2}\right)\end{array}$ & $\underset{(\mathrm{daN} \times \mathrm{m})}{\mathbf{T}}$ \\
\hline N.01 - CP: 22 D 07 & 1,08 & 5,17 & 7,88 & 561 & 888 & 39 & 141 & 11 & 959 & 121840 & 169129 & 142738 & 1530 & 1204 & 2,916 \\
\hline N.02 - CP: 23 D 01 & 1,21 & 5,00 & 8,50 & 840 & 849 & 26 & 116 & 11 & 904 & 175447 & 156712 & 126361 & 1702 & 1430 & 2,310 \\
\hline N.03 - CP: 23 D 02 & 1,16 & 6,15 & 7,23 & 876 & 1307 & 36 & 151 & 9 & 1623 & 245344 & 229702 & 186386 & 1998 & 1982 & 1,830 \\
\hline N.04 - CP: 23 D 03 & 1,20 & 5,94 & 9,01 & 989 & 1306 & 53 & 239 & 9 & 1842 & 214984 & 181243 & 250040 & 1621 & 1594 & 1,359 \\
\hline N.05 - CP: 23 D 04 & 1,17 & 5,06 & 7,86 & 933 & 1656 & 34 & 216 & 6 & 1485 & 204490 & 222592 & 212615 & 1643 & 1287 & 0,911 \\
\hline N.06 - CP: 23 D 05 & 1,16 & 4,70 & 7,17 & 761 & 867 & 37 & 189 & 10 & 824 & 188282 & 147515 & 114515 & 1362 & 814 & 0,670 \\
\hline N.07 - CP: 23 D 06 & 1,24 & 4,54 & 6,88 & 967 & 1553 & 20 & 220 & 11 & 1740 & 218653 & 181720 & 224053 & 1879 & 1345 & 2,193 \\
\hline N.08 - CP: 23 D 09 & 1,06 & 5,11 & 8,75 & 505 & 662 & 42 & 126 & 9 & 1291 & 138730 & 126291 & 168651 & 1476 & 706 & 1,020 \\
\hline N.09 - CP: 23 D 10 & 1,13 & 4,86 & 9,21 & 712 & 998 & 29 & 160 & 12 & 1096 & 182989 & 153059 & 144191 & 1487 & 1002 & 2,173 \\
\hline N.10 - CP: 23 D 11 & 1,23 & 2,66 & 5,93 & 880 & 1406 & 39 & 225 & 8 & 1334 & 195229 & 132259 & 159284 & 1551 & 814 & 2,252 \\
\hline N.11 - CP: 23 D 12 & 1,16 & 4,92 & 7,38 & 784 & 695 & 28 & 153 & 8 & 1224 & 175160 & 146760 & 180299 & 1605 & 1106 & 0,410 \\
\hline $\mathrm{N} .12-\mathrm{CP}: 23$ D 13 & 1,02 & 4,51 & 7,31 & 668 & 708 & 34 & 206 & 8 & 906 & 127387 & 141266 & 128973 & 1777 & 926 & 1,426 \\
\hline MÉDIA & 1,15 & 4,89 & $\mathbf{7 , 7 6}$ & 790 & 1075 & 35 & 179 & 9 & 1269 & 182378 & 165687 & 169842 & 1636 & 1184 & 1,623 \\
\hline $\mathrm{N}^{2}$. DE AMOSTRA & 12 & 12 & 12 & 12 & 12 & 12 & 12 & 12 & 12 & 12 & 12 & 12 & 12 & 12 & 12 \\
\hline
\end{tabular}


Tabela 6.19 - Ensaios - Garapa

\begin{tabular}{|c|c|c|c|c|c|c|c|c|c|c|c|c|c|c|c|}
\hline \multirow{2}{*}{$\begin{array}{c}\text { ESPÉCIE: } \\
\text { Garapa } \\
\text { (Apuleia leiocarpa) } \\
\text { ORIGEM: } \\
\text { Norte de Mato Grosso }\end{array}$} & \multicolumn{15}{|c|}{ PROPRIEDADES FÍSICAS DE RESISTÊNCIA E DE RIGIDEZ } \\
\hline & & & & & & & & & & & & & & & \\
\hline UMIDADE: $12 \%$ & $\underset{\left(\mathrm{g} / \mathrm{cm}^{3}\right)}{\boldsymbol{\rho}_{\text {ap }}}$ & $\begin{array}{c}\boldsymbol{E}_{\mathbf{r}} \\
(\%)\end{array}$ & $\begin{array}{c}\boldsymbol{E}_{\mathbf{t}} \\
(\%)\end{array}$ & $\begin{array}{c}\mathbf{f}_{\mathrm{co}} \\
\left(\mathrm{daN} / \mathrm{cm}^{2}\right)\end{array}$ & $\begin{array}{c}\mathbf{f}_{10} \\
\left(\mathrm{daN} / \mathrm{cm}^{2}\right)\end{array}$ & $\begin{array}{c}\mathbf{f}_{\mathrm{t} 90} \\
\left(\mathrm{daN} / \mathrm{cm}^{2}\right)\end{array}$ & $\begin{array}{c}\mathbf{f}_{\text {vo }} \\
\left(\mathrm{daN} / \mathrm{cm}^{2}\right)\end{array}$ & $\begin{array}{c}\mathbf{f}_{\mathrm{s0}} \\
\left(\mathrm{daN} / \mathrm{cm}^{2}\right)\end{array}$ & $\underset{\left(\mathrm{daN} / \mathrm{cm}^{2}\right)}{\mathbf{f}_{\mathbf{M}}}$ & $\underset{\left(\mathrm{daN} / \mathrm{cm}^{2}\right)}{\mathbf{E}_{\mathbf{c o}}}$ & $\underset{\left(\mathrm{daN} / \mathrm{cm}^{2}\right)}{\mathbf{E}_{\mathrm{to}}}$ & $\underset{\left(\mathrm{daN} / \mathrm{cm}^{2}\right)}{\mathbf{E}_{\mathbf{M}}}$ & $\underset{\left(\mathrm{daN} / \mathrm{cm}^{2}\right)}{\left.\mathbf{f}_{\mathrm{Ho}}\right)}$ & $\begin{array}{c}\mathbf{f H 9 0}_{\left(\mathrm{daN} / \mathrm{cm}^{2}\right)} \\
(\end{array}$ & $\frac{\mathbf{T}}{(\mathrm{daN} \times \mathrm{m})}$ \\
\hline N. 01 - CP: 01 & 0,86 & 4,27 & 7,95 & 644 & 1431 & 82 & 205 & 12 & 1210 & 173570 & 147772 & 112591 & 1110 & 922 & 1,205 \\
\hline N.02 - CP: 02 & 0,89 & 4,07 & 6,58 & 721 & 1087 & 71 & 209 & 13 & 1280 & 192588 & 185157 & 180406 & 1205 & 1067 & 2,070 \\
\hline $\mathrm{N} .03-\mathrm{CP} 03$ & 1,03 & 3,61 & 8,92 & 776 & 1204 & 78 & 199 & 8 & 1551 & 193344 & 206732 & 218248 & 1345 & 1240 & 2,006 \\
\hline N.04 - CP: 04 & 0,93 & 5,08 & 8,29 & 797 & 920 & 62 & 179 & 9 & 705 & 211205 & 182040 & 166312 & 1085 & 927 & 0,930 \\
\hline N.05 - CP: 05 & 0,94 & 4,63 & 7,96 & 871 & 1882 & 90 & 229 & 9 & 1514 & 193919 & 190367 & 196246 & 1230 & 1098 & 1,723 \\
\hline N.06-CP 06 & 0,9 & 4,23 & 7,07 & 614 & 882 & 72 & 195 & 13 & 834 & 144361 & 129943 & 163419 & 975 & 778 & 0,478 \\
\hline N.07 - CP: 07 & 0,85 & 4,19 & 6,90 & 763 & 990 & 62 & 197 & 11 & 1206 & 168022 & 156623 & 166710 & 1035 & 825 & 0,998 \\
\hline N.08-CP 08 & 1,00 & 4,32 & 7,85 & 676 & 1067 & 84 & 211 & 8 & 1208 & 125828 & 158259 & 144765 & 1090 & 990 & 1,100 \\
\hline N.09 - CP: 09 & 0,92 & 4,00 & 7,21 & 666 & 858 & 78 & 207 & 10 & 1364 & 154509 & 143894 & 157799 & 1110 & 1048 & 2,259 \\
\hline N.11 - CP: 11 & 0,94 & 4,44 & 7,65 & 862 & 1726 & 57 & 172 & 8 & 1448 & 212224 & 196100 & 189970 & 1210 & 1103 & 2,708 \\
\hline N. 12 - CP: 12 & 0,86 & 4,76 & 7,28 & 688 & 724 & 65 & 150 & 13 & 759 & 179433 & 139700 & 165092 & 995 & 775 & 0,391 \\
\hline MÉDIA & 0,92 & 4,33 & 7,61 & 734 & 1161 & 73 & 196 & 10 & 1189 & 177182 & 166962 & 169233 & 1126 & 979 & 1,443 \\
\hline $\mathrm{N}^{2}$. DE AMOSTRA & 11 & 11 & 11 & 11 & 11 & 11 & 11 & 11 & 11 & 11 & 11 & 11 & 11 & 11 & 11 \\
\hline
\end{tabular}


Tabela 6.20 - Ensaios - Goiabão

\begin{tabular}{|c|c|c|c|c|c|c|c|c|c|c|c|c|c|c|c|}
\hline $\begin{array}{c}\text { ESPÉCIE: } \\
\text { Goiabão } \\
\text { (Planchonella } \\
\text { pachicarpa) }\end{array}$ & & & & PRO & PRIEDA & IDES F] & ISICAS & DE RES & SISTÊNC & CIA E DJ & E RIGID & $\mathbf{E Z}$ & & & \\
\hline $\begin{array}{c}\text { ORIGEM: } \\
\text { Norte de Mato Grosso }\end{array}$ & & & & & & & & & & & & & & & \\
\hline UMIDADE: $12 \%$ & $\underset{\left(\mathrm{g} / \mathrm{cm}^{3}\right)}{\rho_{\mathbf{a p}}}$ & $\begin{array}{l}\boldsymbol{\varepsilon}_{\mathbf{r}} \\
(\%)\end{array}$ & $\begin{array}{c}\boldsymbol{E}_{\mathbf{t}} \\
(\%)\end{array}$ & $\underset{\left(\mathrm{daN} / \mathrm{cm}^{2}\right)}{\mathbf{f}_{\mathbf{c o}}}$ & $\begin{array}{c}\mathbf{f}_{\text {to }} \\
\left(\mathrm{daN} / \mathrm{cm}^{2}\right)\end{array}$ & $\underset{\left(\mathrm{daN} / \mathrm{cm}^{2}\right)}{\mathbf{f}_{\mathrm{t90}}}$ & $\underset{\left(\mathrm{daN} / \mathrm{cm}^{2}\right)}{\mathbf{f}_{\mathbf{v}}}$ & $\begin{array}{c}\mathbf{f}_{\mathbf{s 0}} \\
\left(\mathrm{daN} / \mathrm{cm}^{2}\right)\end{array}$ & $\underset{\left(\mathrm{daN} / \mathrm{cm}^{2}\right)}{\mathbf{f}_{\mathbf{M}}}$ & $\underset{\left(\mathrm{daN} / \mathrm{cm}^{2}\right)}{\mathbf{E}_{\mathbf{c o}}}$ & $\frac{\mathbf{E}_{\text {to }_{0}}}{\left(\mathrm{daN} / \mathrm{cm}^{2}\right)}$ & $\underset{\left(\mathrm{daN} / \mathrm{cm}^{2}\right)}{\mathbf{E}_{\mathbf{M}}}$ & $\underset{\left(\mathrm{daN} / \mathrm{cm}^{2}\right)}{\mathbf{f}_{\mathbf{H o}}}$ & $\underset{\left(\mathrm{daN} / \mathrm{cm}^{2}\right)}{\left.\mathbf{f}_{\mathrm{H}}\right)}$ & $\underset{(\mathrm{daN} \times \mathrm{m})}{\mathbf{T}}$ \\
\hline N.01 - CP: 01 & 0,86 & 9,4 & 19,2 & 409 & 744 & 74 & 136 & 9 & 1054 & 150382 & 156867 & 143608 & " & * & * \\
\hline N.02 - CP: 02 & 0,91 & 8,1 & 15,6 & 409 & 942 & 87 & 142 & 10 & 1264 & 135012 & 179498 & 152783 & $*$ & $*$ & $*$ \\
\hline N.03 - CP 03 & 0,80 & 10,6 & 18,9 & 508 & 657 & 62 & 174 & 14 & 843 & 197478 & 114678 & 165091 & $*$ & $*$ & $*$ \\
\hline N.04 - CP: 04 & 1,03 & 7,3 & 17,8 & 484 & 1786 & 52 & 112 & 19 & 986 & 184637 & 203104 & 185867 & * & $*$ & $*$ \\
\hline N.05 - CP: 05 & 0,98 & 10,8 & 20,3 & 434 & 1662 & 99 & 136 & 10 & 880 & 191980 & 165219 & 201840 & $*$ & $*$ & $*$ \\
\hline N.06-CP 06 & 1,04 & 9,7 & 19,1 & 533 & 1624 & 112 & 149 & 13 & 1240 & 203580 & 226850 & 184811 & 4 & $*$ & $*$ \\
\hline N.07 - CP: 07 & 0,98 & 7,9 & 17,2 & 608 & 1314 & 112 & 186 & 15 & 1166 & 227522 & 211375 & 262369 & $*$ & $*$ & $*$ \\
\hline N.08-CP 08 & 0,96 & 8,5 & 18,0 & 471 & 1178 & 74 & 132 & 10 & 1017 & 182004 & 152784 & 178466 & $*$ & $*$ & $*$ \\
\hline N.09 - CP: 09 & 0,98 & 8,9 & 19,8 & 546 & 1079 & 87 & 124 & 9 & 1141 & 225806 & 183106 & 187781 & * & $*$ & * \\
\hline N. 10 - CP: 10 & 0,90 & 10,4 & 22,0 & 434 & 992 & 99 & 124 & 10 & 1079 & 165161 & 197734 & 177492 & * & * & $*$ \\
\hline N.11 - CP: 11 & 0,93 & 8,3 & 19,3 & 508 & 1128 & 87 & 124 & 11 & 980 & 186551 & 195112 & 175079 & $*$ & $*$ & $*$ \\
\hline N. 12 - CP: 12 & 0,89 & 6,9 & 18,9 & 471 & 1215 & 99 & 149 & 10 & 1128 & 195912 & 205760 & 188860 & $*$ & " & $*$ \\
\hline MÉDIA & 0,94 & 8,90 & 18,84 & 485 & 1193 & 87 & 141 & 12 & 1065 & 187169 & 182674 & 183671 & * & * & * \\
\hline №. DE AMOSTRA & 12 & 12 & 12 & 12 & 12 & 12 & 12 & 12 & 12 & 12 & 12 & 12 & * & $*$ & $*$ \\
\hline
\end{tabular}

"Dado desconsiderado, CP com defeito. 
Tabela 6.21 - Ensaios - Guaiçara

\begin{tabular}{|c|c|c|c|c|c|c|c|c|c|c|c|c|c|c|c|}
\hline $\begin{array}{c}\text { ESPECIE: } \\
\text { Guaiçara } \\
\text { (Luetzelburgia sp) } \\
\end{array}$ & \multicolumn{15}{|c|}{ PROPRIEDADES FISICAS DE RESISTÊNCIA E DE RIGIDEZ } \\
\hline UMIDADE: $12 \%$ & $\underset{\left(\mathrm{g} / \mathrm{cm}^{3}\right)}{\boldsymbol{\rho}_{\mathbf{a p}}}$ & $\begin{array}{c}\boldsymbol{E}_{\mathbf{r}} \\
(\%)\end{array}$ & $\begin{array}{c}\varepsilon_{t} \\
(\%)\end{array}$ & $\begin{array}{c}\mathbf{f}_{\mathbf{c o}} \\
\left(\mathrm{daN} / \mathrm{cm}^{2}\right)\end{array}$ & $\begin{array}{c}\mathbf{f}_{\mathrm{to}} \\
\left(\mathrm{daN} / \mathrm{cm}^{2}\right)\end{array}$ & $\begin{array}{c}\mathbf{f}_{\mathbf{t g 0}} \\
\left(\mathrm{daN} / \mathrm{cm}^{2}\right)\end{array}$ & $\begin{array}{c}\mathbf{f}_{\mathbf{v o}} \\
\left(\mathrm{daN} / \mathrm{cm}^{2}\right)\end{array}$ & $\begin{array}{c}\mathbf{f}_{\mathrm{s} 0} \\
\left(\mathrm{daN} / \mathrm{cm}^{2}\right)\end{array}$ & $\begin{array}{c}\mathbf{f}_{\mathbf{M}} \\
\left(\mathrm{daN} / \mathrm{cm}^{2}\right)\end{array}$ & $\begin{array}{c}\mathbf{E}_{\mathbf{c o}} \\
\left(\mathrm{daN} / \mathrm{cm}^{2}\right)\end{array}$ & $\underset{\left(\mathrm{daN} / \mathrm{cm}^{2}\right)}{\mathbf{E}_{\text {to }}}$ & $\underset{\left(\mathrm{daN} / \mathrm{cm}^{2}\right)}{\mathbf{E}_{\mathbf{M}}}$ & $\underset{\left(\mathrm{daN} / \mathrm{cm}^{2}\right)}{\mathbf{f}_{\mathbf{H o}}}$ & $\begin{array}{c}\mathbf{f}_{\mathrm{H} 90} \\
\left(\mathrm{daN} / \mathrm{cm}^{2}\right)\end{array}$ & $\underset{(\mathrm{daN} \times \mathrm{m})}{\mathbf{T}}$ \\
\hline N.01 - CP: 01 & 1,12 & 4,26 & 6,50 & 613 & 1306 & 50 & 180 & 8 & 1273 & 169494 & 181007 & 163335 & 1215 & 1197 & 2,398 \\
\hline N.02 - CP: 02 & 1,08 & 4,28 & 6,28 & 814 & 693 & 55 & 232 & 7 & 801 & 179593 & 124229 & 169217 & 1180 & 1061 & 1,800 \\
\hline N.03 - CP: 03 & 1,11 & 3,65 & 5,81 & 772 & 862 & 28 & 175 & 4 & 1491 & 178684 & 155786 & 172251 & 1160 & 1120 & 2,139 \\
\hline N.04 - CP: 04 & 1,08 & 3,87 & 6,27 & 787 & 1209 & 35 & 220 & 9 & 1220 & 168159 & 164277 & 135833 & 1217 & 1135 & 1,830 \\
\hline N.05 - CP: 05 & 1,05 & 2,68 & 5,92 & 581 & 1240 & 42 & 216 & 7 & 1242 & 110728 & 174626 & 151494 & 1187 & 1070 & 2,361 \\
\hline N.06 - CP: 06 & 1,12 & 5,15 & 7,38 & 618 & 1151 & 49 & 184 & 8 & 1278 & 119447 & 136346 & 135079 & 1250 & 1182 & 1,393 \\
\hline N.07 - CP: 07 & 1,12 & 3,57 & 6,03 & 621 & 1369 & 53 & 213 & 9 & 1131 & 125888 & 163686 & 125209 & 1007 & 900 & 2,348 \\
\hline N.08 - CP: 08 & 1,06 & 6,80 & 7,06 & 837 & 1248 & 49 & 207 & 6 & 1467 & 165594 & 166884 & 166356 & 1250 & 1250 & 2,517 \\
\hline N.09 - CP: 09 & 1,06 & 4,55 & 7,51 & 750 & 1224 & 44 & 212 & 7 & 979 & 165127 & 189895 & 125491 & 1235 & 1062 & 3,097 \\
\hline N. 10 - CP: 10 & 1,08 & 4,36 & 5,63 & 785 & 982 & 31 & 199 & 7 & 1385 & 168324 & 139766 & 162018 & 1262 & 1200 & 2,529 \\
\hline N.11 - CP: 11 & 1,06 & 4,60 & 7,57 & 681 & 1536 & 28 & 245 & 7 & 1177 & 132152 & 197015 & 157616 & 11140 & 1070 & 2,687 \\
\hline MÉDIA & 1,09 & 4,34 & 6,54 & 714 & 1165 & 42 & 208 & 7 & 1222 & 153017 & 163047 & 151264 & 2100 & 1113 & 2,282 \\
\hline $\mathrm{N}^{0}$. DE AMOSTRA & 11 & 11 & 11 & 11 & 11 & 11 & 11 & 11 & 11 & 11 & 11 & 11 & 11 & 11 & 11 \\
\hline
\end{tabular}


Tabela 6.22 - Ensaios - Guarucaia

\begin{tabular}{c|c|c|c|c|c|c|c|c|c|c|c|c|c|c}
\hline $\begin{array}{c}\text { ESPECIE: } \\
\text { Guarucaia } \\
\begin{array}{c}\text { Peltophorum } \\
\text { vogelianum) }\end{array}\end{array}$ \\
$\begin{array}{c}\text { ORIGEM: } \\
\text { Norte de Mato Grosso }\end{array}$
\end{tabular}




\begin{tabular}{|c|c|c|c|c|c|c|c|c|c|c|c|c|c|c|c|}
\hline $\begin{array}{c}\text { ESPECIE: } \\
\text { Itaúba } \\
\text { (Mezilaurus itauba) }\end{array}$ & \multicolumn{15}{|c|}{ PROPRIEDADES FÍSICAS DE RESISTENNCIA E DE RIGIDEZ } \\
\hline UMWADE: $12 \%$ & $\underset{\left(\mathrm{g} / \mathrm{cm}^{3}\right)}{\rho_{\mathbf{a p}}}$ & $\begin{array}{c}\boldsymbol{\varepsilon}_{\mathbf{r}} \\
(\%)\end{array}$ & $\begin{array}{c}\boldsymbol{\varepsilon}_{\mathbf{t}} \\
(\%)\end{array}$ & $\underset{\left(\mathrm{daN} / \mathrm{cm}^{2}\right)}{\mathbf{f}_{\mathbf{c o}}}$ & $\underset{\left(\mathrm{daN} / \mathrm{cm}^{2}\right)}{\mathbf{f}_{\mathrm{to}}}$ & $\begin{array}{c}\mathbf{f}_{\mathrm{tg0}} \\
\left(\mathrm{daN} / \mathrm{cm}^{2}\right)\end{array}$ & $\underset{\left(\mathrm{daN} / \mathrm{cm}^{2}\right)}{\mathbf{f}_{\mathbf{v o}}}$ & $\begin{array}{c}\mathbf{f}_{\mathbf{s 0}} \\
\left(\mathrm{daN} / \mathrm{cm}^{2}\right)\end{array}$ & $\underset{\left(\mathrm{daN} / \mathrm{cm}^{2}\right)}{\mathbf{f}_{\mathbf{M}}}$ & $\underset{\left(\mathrm{daN} / \mathrm{cm}^{2}\right)}{\mathbf{E}_{\mathbf{c o}}}$ & $\underset{\left(\mathrm{daN} / \mathrm{cm}^{2}\right)}{\mathbf{E}_{\text {to }}}$ & $\underset{\left(\mathrm{daN} / \mathrm{cm}^{2}\right)}{\mathbf{E}_{\mathbf{M}}}$ & $\underset{\left(\mathrm{daN} / \mathrm{cm}^{2}\right)}{\mathbf{f}_{\mathbf{H o}}}$ & $\underset{\left(\mathrm{daN} / \mathrm{cm}^{2}\right)}{\mathbf{f}_{\mathrm{H} 90}}$ & $\underset{(\mathrm{daN} \times \mathrm{m})}{\mathbf{T}}$ \\
\hline N.01 - CP: 01 & 1,00 & 2,14 & 8,82 & 726 & 1151 & 11 & 217 & 2 & 1408 & 177376 & 175800 & 173829 & 775 & 765 & 1,581 \\
\hline N.02 - CP: 02 & 0,93 & 2,52 & 8,40 & 768 & 1084 & 31 & 206 & 1 & 1281 & 183977 & 194807 & 198101 & 840 & 820 & 1,573 \\
\hline N.03 - CP: 03 & 0,92 & 2,83 & 7,91 & 675 & 1540 & 40 & 188 & 5 & 876 & 166456 & 182768 & 161125 & 725 & 690 & 1,565 \\
\hline N.04 - CP: 04 & 0,89 & 3,62 & 8,47 & 656 & 579 & 28 & 217 & 7 & 1035 & 146186 & 162497 & 132919 & 865 & 802 & 1,144 \\
\hline N.05 - CP: 05 & 0,94 & 3,19 & 8,05 & 687 & 1153 & 13 & 184 & 4 & 1172 & 190586 & 186472 & 202737 & 840 & 832 & 1,248 \\
\hline N.06 - CP: 06 & 0,89 & 3,29 & 7,96 & 711 & 1056 & 12 & 163 & 4 & 1202 & 182983 & 188042 & 178637 & 745 & 705 & 1,565 \\
\hline N.07 - CP 07 & 0,88 & 2,84 & 7,94 & 617 & 1172 & 17 & 151 & 4 & 1090 & 149589 & 190473 & 174512 & 565 & 562 & 1,637 \\
\hline N.08 - CP: 08 & 0,86 & 2,56 & 8,62 & 683 & 563 & 18 & 174 & 8 & 1261 & 186500 & 151208 & 164193 & 815 & 725 & 1,308 \\
\hline N.09 - CP: 09 & 0,89 & 2,25 & 8,94 & 704 & 1425 & 17 & 210 & 7 & 1225 & 192425 & 140297 & 160423 & 884 & 890 & 1,286 \\
\hline N. 10 - CP: 10 & 0,94 & 3,29 & 8,12 & 652 & 1001 & 28 & 164 & 3 & 1342 & 170242 & 192225 & 184297 & 602 & 502 & 1,523 \\
\hline N.11 - CP: 11 & 0,95 & 2,54 & 8,04 & 663 & 825 & 18 & 179 & 5 & 1092 & 149929 & 175732 & 175753 & 742 & 739 & 1,694 \\
\hline N.12 - CP: 12 & 0,91 & 3,42 & 7,99 & 743 & 897 & 24 & 197 & 7 & 1003 & 196910 & 175230 & 174844 & 782 & 835 & 1,308 \\
\hline MÉDIA & 0,96 & 2,87 & 8,27 & 690 & 1037 & 21 & 188 & 6 & 1166 & 174430 & 176296 & 173448 & 765 & 739 & 1,453 \\
\hline $\mathrm{N}^{2}$. DE AMOSTRA & 12 & 12 & 12 & 12 & 12 & 12 & 12 & 12 & 12 & 12 & 12 & 12 & 12 & 12 & 12 \\
\hline
\end{tabular}


Tabela 6.24 - Ensaios - Louro Preto

\begin{tabular}{|c|c|c|c|c|c|c|c|c|c|c|c|c|c|c|c|}
\hline $\begin{array}{c}\text { ESPECIE: } \\
\text { Louro Preto } \\
\text { (Octea sp) }\end{array}$ & \multicolumn{15}{|c|}{ PROPRIEDADES FÍSICAS, DE RESISTÊNCIA E DE RIGIDEZ } \\
\hline UMDADE: $12 \%$ & $\underset{\left(\mathrm{g} / \mathrm{cm}^{3}\right)}{\rho_{\mathbf{a p}}}$ & $\begin{array}{c}\boldsymbol{\varepsilon}_{\mathbf{r}} \\
(\%)\end{array}$ & $\begin{array}{c}\boldsymbol{E}_{\mathrm{t}} \\
(\%)\end{array}$ & $\underset{\left(\mathrm{daN} / \mathrm{cm}^{2}\right)}{\mathbf{f}_{\mathbf{c o}}}$ & $\underset{\left(\mathrm{daN} / \mathrm{cm}^{2}\right)}{\mathbf{f}_{\text {to }}}$ & $\underset{\left(\mathrm{daN} / \mathrm{cm}^{2}\right)}{\mathbf{f t g 0}_{2}}$ & $\begin{array}{c}\mathbf{f}_{\mathrm{vo}} \\
\left(\mathrm{daN} / \mathrm{cm}^{2}\right)\end{array}$ & $\begin{array}{c}\mathbf{f}_{\mathrm{so}} \\
\left(\mathrm{daN} / \mathrm{cm}^{2}\right)\end{array}$ & $\underset{\left(\mathrm{daN} / \mathrm{cm}^{2}\right)}{\mathbf{f}_{\mathbf{M}}}$ & $\underset{\left(\mathrm{daN} / \mathrm{cm}^{2}\right)}{\mathbf{E}_{\mathbf{c o}}}$ & $\underset{\left(\mathrm{daN} / \mathrm{cm}^{2}\right)}{\mathbf{E}_{\mathrm{to}}}$ & $\underset{\left(\mathrm{daN} / \mathrm{cm}^{2}\right)}{\mathbf{E}_{\mathbf{M}}}$ & $\underset{\left(\mathrm{daN} / \mathrm{cm}^{2}\right)}{\mathbf{f}_{\mathbf{H o}}}$ & $\begin{array}{c}\mathbf{f}_{\mathbf{H 9 0}} \\
\left(\mathrm{daN} / \mathrm{cm}^{2}\right)\end{array}$ & $\underset{(\mathrm{daN} \times \mathrm{m})}{\mathbf{T}}$ \\
\hline N.01 - CP: $07 \mathrm{C} 01$ & 0,65 & 4,25 & 8,25 & 427 & 895 & 35 & 146 & 9 & 822 & 124183 & 129819 & 116721 & 690 & 399 & 1,281 \\
\hline N.02 - CP: $07 \mathrm{C} 02$ & 0,70 & 4,07 & 8,46 & 646 & 775 & 52 & 147 & 8 & 1952 & 162132 & 148423 & 157154 & 797 & 517 & 0,736 \\
\hline N.03 - CP: $07 \mathrm{C} 03$ & 0,69 & 4,32 & 7,13 & 671 & 749 & 31 & 109 & 7 & 1220 & 165549 & 160909 & 190255 & 830 & 509 & 0,764 \\
\hline N.04-CP: $07 \mathrm{C} 04$ & 0,74 & 4,13 & 8,22 & 636 & 609 & 29 & 128 & 5 & 801 & 151580 & 162094 & 135151 & 980 & 549 & 0,594 \\
\hline N.05-CP: 07 C 10 & 0,71 & 5,15 & 5,39 & 560 & 623 & 25 & 142 & 5 & 1080 & 141180 & 117248 & 170245 & 871 & 544 & 0,993 \\
\hline N.06 - CP: 07 C 11 & 0,68 & 4,40 & 8,62 & 620 & 831 & 32 & 130 & 6 & 896 & 166980 & 123445 & 138608 & 850 & 541 & 0,517 \\
\hline N.07-CP: 07 C 12 & 0,69 & 4,51 & 8,00 & 684 & 1002 & 40 & 167 & 8 & 935 & 172237 & 168835 & 125339 & 840 & 517 & 0,948 \\
\hline N.08-CP: 07 C 13 & 0,68 & 4,24 & 8,15 & 600 & 607 & 52 & 213 & 7 & 1362 & 145406 & 120424 & 193604 & 942 & 542 & 0,527 \\
\hline N.09 - CP: 07 C 14 & 0,66 & 4,23 & 8,31 & 685 & 683 & 25 & 104 & 6 & 1368 & 165566 & 148841 & 243231 & 902 & 621 & 0,773 \\
\hline N.10-CP: 07 C 15 & 0,70 & 3,32 & 8,34 & 602 & 675 & 21 & 172 & 7 & 857 & 152722 & 141672 & 130734 & 829 & 555 & 0,764 \\
\hline N.11 - CP: $08 \mathrm{C} 16$ & 0,64 & 4,29 & 8,21 & 527 & 851 & 31 & 154 & 9 & 827 & 140965 & 150702 & 120837 & 824 & 461 & 0,754 \\
\hline $\mathrm{N} .12-\mathrm{CP}: 08 \mathrm{C} 18$ & 0,67 & 4,49 & 8,29 & 541 & 588 & 40 & 115 & 5 & 823 & 133814 & 101656 & 113766 & 738 & 404 & 0,594 \\
\hline N.13-CP: 08 C 20 & 0,67 & 4,22 & 8,33 & 493 & 653 & 23 & 144 & 5 & 774 & 155959 & 122701 & 122365 & 909 & 474 & 0,957 \\
\hline N.14 - CP: 24 D 07 & 0,68 & 4,2 & 7,90 & 642 & 991 & 43 & 153 & 9 & 989 & 189553 & 167381 & 188648 & 921 & 670 & 0,507 \\
\hline $\mathrm{N} .15$ - CP: 26 D 02 & 0,67 & 4,36 & 8,59 & 549 & 689 & 32 & 133 & 5 & 701 & 94321 & 108107 & 101468 & 797 & 431 & 0,651 \\
\hline N.16-CP: 26 D 04 & 0,64 & 2,73 & 6,02 & 459 & 413 & 14 & 121 & 4 & 782 & 84058 & 85665 & 89440 & 827 & 455 & 0,142 \\
\hline N.17-CP: 26 D 05 & 0,63 & 2,77 & 6,32 & 486 & 419 & 25 & 104 & 5 & 546 & 93637 & 106492 & 80968 & 797 & 450 & 0,322 \\
\hline N.18-CP: 29 F 09 & 0,69 & 4,24 & 8,19 & 399 & 635 & 25 & 184 & 6 & 557 & 75937 & 101450 & 103230 & 910 & 571 & 0,393 \\
\hline N.19-CP: 29 F 10 & 0,69 & 3,98 & 8,58 & 675 & 628 & 47 & 170 & 7 & 759 & 169450 & 126929 & 122132 & 814 & 471 & 0,792 \\
\hline N.20-CP: 29 F 12 & 0,71 & 4,22 & 8,81 & 504 & 682 & 52 & 185 & 7 & 809 & 144066 & 134955 & 150193 & 958 & 487 & 0,302 \\
\hline N.21 - CP: $29 \mathrm{~F} 13$ & 0,76 & 4,26 & 8,87 & 538 & 800 & 22 & 219 & 6 & 600 & 167690 & 148641 & 144392 & 959 & 558 & 0,856 \\
\hline MEDIA & 0,68 & 4,11 & 7,95 & 569 & 705 & 33 & 150 & 6 & 927 & 142714 & 132209 & 139928 & 856 & 511 & 0,675 \\
\hline $\mathrm{N}^{2} . \mathrm{DE}$ AMOSTRAS & 21 & 21 & 21 & 21 & 21 & 21 & 21 & 21 & 21 & 21 & 21 & 21 & 21 & 21 & 21 \\
\hline
\end{tabular}


Tabela 6.25 - Ensaios - Mandioqueira

\begin{tabular}{|c|c|c|c|c|c|c|c|c|c|c|c|c|c|c|c|}
\hline $\begin{array}{c}\text { ESPECIE: } \\
\text { Mandioqueira } \\
\text { (Qualea albiflora) }\end{array}$ & \multicolumn{15}{|c|}{ PROPRIEDADES FÍSICAS, DE RESISTÊNCIA E DE RIGIDEZ } \\
\hline UMIDADE: $12 \%$ & $\underset{\left(\mathrm{g} / \mathrm{cm}^{3}\right)}{\boldsymbol{\rho}_{\text {ap }}}$ & $\begin{array}{l}\boldsymbol{E}_{\mathbf{r}} \\
(\%)\end{array}$ & $\begin{array}{c}\varepsilon_{t} \\
(\%)\end{array}$ & $\begin{array}{c}\mathbf{f}_{\mathrm{co}} \\
\left(\mathrm{daN} / \mathrm{cm}^{2}\right)\end{array}$ & $\begin{array}{c}\mathbf{f}_{\text {to }} \\
\left(\mathrm{daN} / \mathrm{cm}^{2}\right)\end{array}$ & $\begin{array}{c}\mathbf{f}_{\mathbf{t g 0}} \\
\left(\mathrm{daN} / \mathrm{cm}^{2}\right)\end{array}$ & $\begin{array}{c}\mathbf{f}_{\mathrm{vo}} \\
\left(\mathrm{daN} / \mathrm{cm}^{2}\right)\end{array}$ & $\begin{array}{c}\mathbf{f}_{\mathbf{8 0}} \\
\left(\mathrm{daN} / \mathrm{cm}^{2}\right)\end{array}$ & $\underset{\left(\mathrm{daN} / \mathrm{cm}^{2}\right)}{\mathbf{f}_{\mathbf{M}}}$ & $\underset{\left(\mathrm{daN} / \mathrm{cm}^{2}\right)}{\mathbf{E}_{\mathbf{c o}}}$ & $\underset{\left(\mathrm{daN} / \mathrm{cm}^{2}\right)}{\mathbf{E}_{\text {to }}}$ & $\underset{\left(\mathrm{daN} / \mathrm{cm}^{2}\right)}{\mathbf{E}_{\mathbf{M}}}$ & $\begin{array}{c}\mathbf{f}_{\mathbf{H o}} \\
\left(\mathrm{daN} / \mathrm{cm}^{2}\right)\end{array}$ & $\begin{array}{c}\mathbf{f}_{\mathbf{H 9 0}} \\
\left(\mathrm{daN} / \mathrm{cm}^{2}\right)\end{array}$ & $\underset{(\mathrm{daN} \times \mathrm{m})}{\mathbf{T}}$ \\
\hline N.01 - CP: 15 C 11 & 0,91 & 4,25 & 7,57 & 844 & 983 & 14 & 162 & 5 & 1233 & 219510 & 188250 & 193011 & 1616 & 1494 & 1,669 \\
\hline N.02 - CP: 22 D 19 & 0,82 & 6,5 & 11,09 & 683 & 611 & 49 & 216 & 10 & 808 & 154908 & 184975 & 175072 & 1093 & 773 & 0,866 \\
\hline N.03 - CP:22 D 01 & 0,79 & 4,44 & 10,56 & 537 & 407 & 57 & 175 & 6 & 805 & 191433 & 187379 & 183025 & 986 & 716 & 0,939 \\
\hline N.04 - CP: 28 F 01 & 0,86 & 5,61 & 10,94 & 934 & 851 & 19 & 122 & 5 & 1177 & 211832 & 170983 & 171536 & 846 & 601 & 1,231 \\
\hline N.05 - CP: 28 F 02 & 0,86 & 5,01 & 8,77 & 617 & 941 & 31 & 160 & 7 & 1106 & 192695 & 153754 & 155319 & 986 & 646 & 1,300 \\
\hline N.06 - CP: 28 F 03 & 0,87 & 4,19 & 8,46 & 649 & 501 & 22 & 143 & 7 & 1135 & 232969 & 163123 & 187190 & 1201 & 716 & 1,127 \\
\hline N.07 - CP: 28 F 04 & 0,90 & 4,03 & 7,34 & 646 & 1092 & 18 & 170 & 4 & 871 & 208661 & 203130 & 165186 & 980 & 638 & 1,192 \\
\hline N.08 - CP: 28 F 05 & 0,82 & 4,78 & 9,69 & 616 & 1044 & 16 & 167 & 5 & 1114 & 190616 & 204935 & 172768 & 1083 & 751 & 1,144 \\
\hline N.09-CP: 28 F 06 & 0,89 & 4,97 & 9,15 & 769 & 1400 & 32 & 213 & 4 & 1842 & 208651 & 213908 & 255259 & 674 & 455 & 1,359 \\
\hline N.10 - CP: 28 F 07 & 0,86 & 4,43 & 9,94 & 683 & 1170 & 14 & 156 & 7 & 1031 & 206256 & 183928 & 200494 & 1158 & 746 & 1,100 \\
\hline N.11 -CP: 28 F 08 & 0,82 & 4,65 & 9,73 & 717 & 892 & 26 & 170 & 7 & 1195 & 180491 & 180300 & 169602 & 1018 & 646 & 1,500 \\
\hline N.12 - CP: 28 F 09 & 0,83 & 4,76 & 9,56 & 605 & 1273 & 22 & 150 & 5 & 1382 & 141685 & 196107 & 147167 & 1465 & 846 & 0,856 \\
\hline N.13 - CP: 28 F 11 & 0,85 & 3,97 & 8,92 & 758 & 655 & 32 & 155 & 4 & 904 & 185451 & 169518 & 179021 & 1120 & 649 & 1,359 \\
\hline N.14 - CP: 28 F 12 & 0,84 & 4,45 & 8,28 & 739 & 638 & 20 & 195 & 4 & 1092 & 171798 & 191043 & 163672 & 1196 & 684 & 1,274 \\
\hline N.15 - CP: $28 \mathrm{~F} 13$ & 0,87 & 4,83 & 10,06 & 829 & 1197 & 55 & 196 & 6 & 1266 & 174541 & 219355 & 227058 & 1217 & 749 & 0,911 \\
\hline MÉDIA & 0,85 & 4,72 & 9,34 & 708 & 910 & 28 & 170 & 6 & 1131 & 191433 & 187379 & 183025 & 1109 & 741 & 1,188 \\
\hline $\mathrm{N}^{0}$. DE AMOSTRAS & 15 & 15 & 15 & 15 & 15 & 15 & 15 & 15 & 15 & 15 & 15 & 15 & 15 & 15 & 15 \\
\hline
\end{tabular}


Tabela 6.26 - Ensaios - Oiticica Amarela

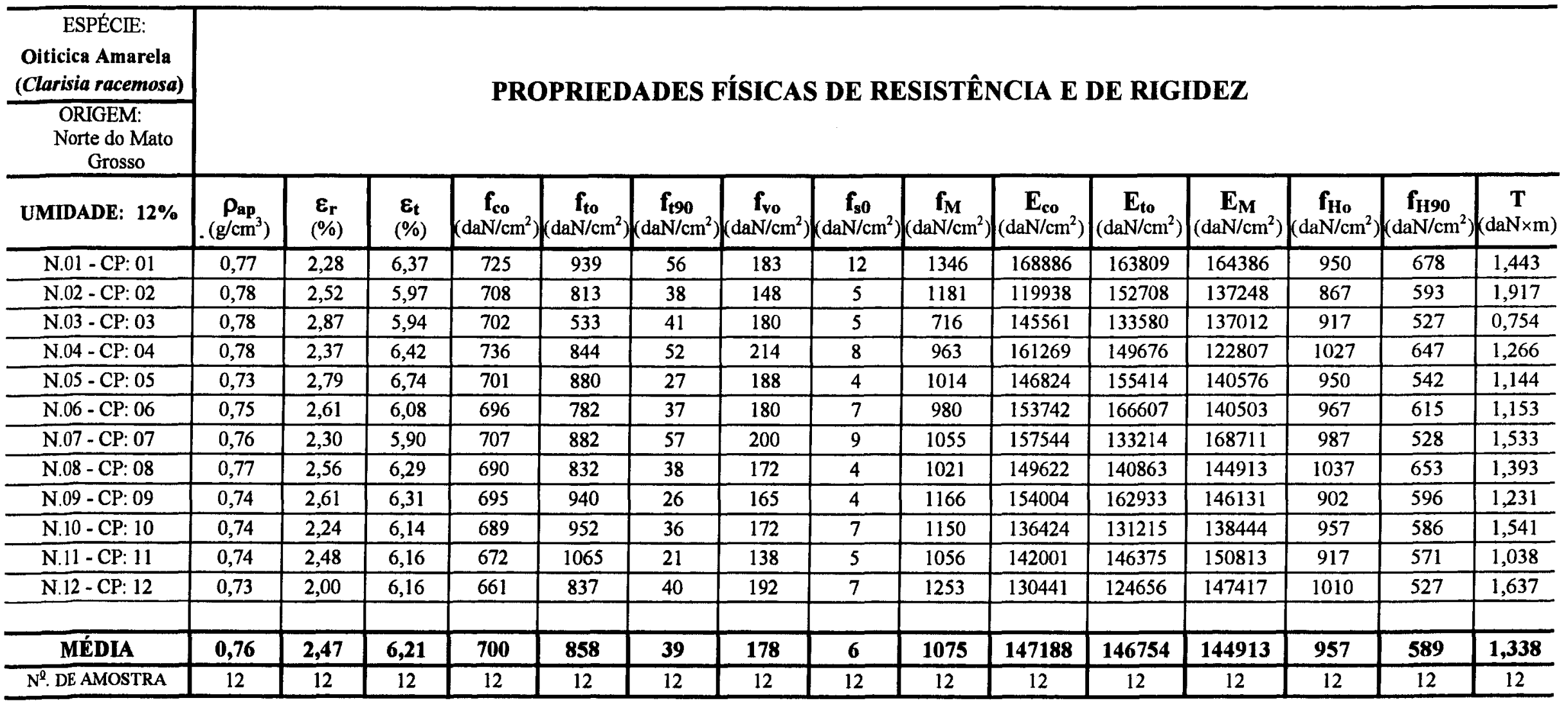


Tabela 6.27 - Ensaios - Oiuchu

\begin{tabular}{|c|c|c|c|c|c|c|c|c|c|c|c|c|c|c|c|}
\hline $\begin{array}{c}\text { ESPECIE: } \\
\text { Oiuchu } \\
\text { (Pradosia sp) } \\
\text { ORIGEM: } \\
\text { Nordeste do Mato } \\
\text { Grosso } \\
\end{array}$ & \multicolumn{15}{|c|}{ PROPRIEDADES FÍSICAS DE RESISTÊNCIA E DE RIGIDEZ } \\
\hline UMDADE: $12 \%$ & $\underset{\left(\mathrm{g} / \mathrm{cm}^{3}\right)}{\rho_{\mathrm{ap}}}$ & $\begin{array}{l}\boldsymbol{E}_{\mathbf{r}} \\
(\%)\end{array}$ & $\begin{array}{c}\boldsymbol{\varepsilon}_{\mathbf{t}} \\
(\%)\end{array}$ & $\begin{array}{c}\mathbf{f}_{\mathbf{c o}} \\
\left(\mathrm{daN} / \mathrm{cm}^{2}\right)\end{array}$ & $\begin{array}{c}\mathbf{f}_{\mathrm{to}} \\
\left(\mathrm{daN} / \mathrm{cm}^{2}\right)\end{array}$ & $\begin{array}{c}\mathbf{f}_{\mathrm{t90}} \\
\left(\mathrm{daN} / \mathrm{cm}^{2}\right)\end{array}$ & $\begin{array}{c}\mathbf{f}_{\mathrm{vo}} \\
\left(\mathrm{daN} / \mathrm{cm}^{2}\right)\end{array}$ & $\begin{array}{c}\mathbf{f}_{\mathrm{s0}} \\
\left(\mathrm{daN} / \mathrm{cm}^{2}\right)\end{array}$ & $\underset{\left(\mathrm{daN} / \mathrm{cm}^{2}\right)}{\mathbf{f}_{\mathbf{M}}}$ & $\begin{array}{c}\mathbf{E}_{\mathbf{c o}} \\
\left(\mathrm{daN} / \mathrm{cm}^{2}\right)\end{array}$ & $\underset{\left(\mathrm{daN} / \mathrm{cm}^{2}\right)}{\mathbf{E}_{\text {to }}}$ & $\underset{\left(\mathrm{daN} / \mathrm{cm}^{2}\right)}{\mathbf{E}_{\mathbf{M}}}$ & $\underset{\left(\mathrm{daN} / \mathrm{cm}^{2}\right)}{\mathbf{f}_{\mathbf{H o}}}$ & $\begin{array}{c}\mathbf{f}_{\mathrm{H} 90} \\
\left(\mathrm{daN} / \mathrm{cm}^{2}\right)\end{array}$ & $\underset{(\mathrm{daN} \times \mathrm{m})}{\mathbf{T}}$ \\
\hline N.01 - CP: 01 & 1,03 & 7,45 & 10,25 & 938 & 2016 & 20 & 234 & 8 & 1645 & 269098 & 233323 & 222192 & 1445 & 1185 & 2,291 \\
\hline N.02 - CP: 02 & 0,85 & 4,86 & 9,69 & 742 & 978 & 37 & 221 & 7 & 1161 & 181667 & 183753 & 168470 & 1155 & 746 & 1,621 \\
\hline N.03 - CP: 03 & 0,90 & 8,13 & 10,45 & 853 & 1381 & 39 & 183 & 5 & 1386 & 243974 & 268666 & 209798 & 1240 & 930 & 1,867 \\
\hline N.04 - CP: 04 & 0,84 & 5,06 & 9,23 & 721 & 1315 & 42 & 201 & 7 & 1020 & 157796 & 194765 & 168106 & 1075 & 721 & 1,443 \\
\hline N.05 - CP: 05 & 0,97 & 6,63 & 9,59 & 771 & 1617 & 27 & 202 & 8 & 1361 & 190244 & 205321 & 188893 & 1190 & 930 & 2,703 \\
\hline N.06 - CP: 06 & 0,90 & 4,31 & 8,19 & 650 & 1231 & 25 & 239 & 5 & 977 & 130794 & 149931 & 136967 & 1180 & 897 & 1,359 \\
\hline N.07 - CP: 07 & 0,98 & 8,54 & 10,53 & 790 & 2284 & 24 & 183 & 8 & 1432 & & $*$ & $*$ & 1495 & 1112 & 2,063 \\
\hline N.08 - CP: 08 & 1,01 & 6,67 & 9,35 & 893 & 1401 & 35 & 191 & 5 & 1484 & 185725 & 181422 & 196941 & 1377 & 1010 & 2,410 \\
\hline N.09 - CP: 09 & 0,91 & 4,50 & 7,65 & 703 & 642 & 27 & 148 & 4 & 790 & 147896 & 130160 & 122248 & 1152 & 767 & 1,359 \\
\hline N.10 - CP: 10 & 0,87 & 4,34 & 7,75 & 723 & 1092 & 21 & 130 & 5 & 1038 & 137647 & 161310 & 136799 & 1165 & 822 & 1,334 \\
\hline N.11 - CP: 11 & 0,93 & 5,22 & 9,11 & 702 & 802 & 29 & 239 & 7 & 1104 & 150284 & 152981 & 126499 & 1245 & 845 & 1,613 \\
\hline N. 12 - CP: 12 & 0,98 & 5,01 & 8,09 & 796 & 842 & 29 & 245 & 5 & 1300 & 153839 & 138572 & 161051 & 1340 & 962 & 0,795 \\
\hline MÉDIA & 0,93 & 5,89 & 9,16 & 774 & 1300 & 30 & 201 & 6 & 1225 & 177179 & 181837 & 167088 & 1255 & 911 & 1,738 \\
\hline $\mathrm{N}^{2}$. DE AMOSTRA & 12 & 12 & 12 & 12 & 12 & 12 & 12 & 12 & 12 & 11 & 11 & 11 & 12 & 12 & 12 \\
\hline
\end{tabular}

"Dado desconsiderado, CP com defeito. 
Tabela 6.28 - Ensaios - Parinari

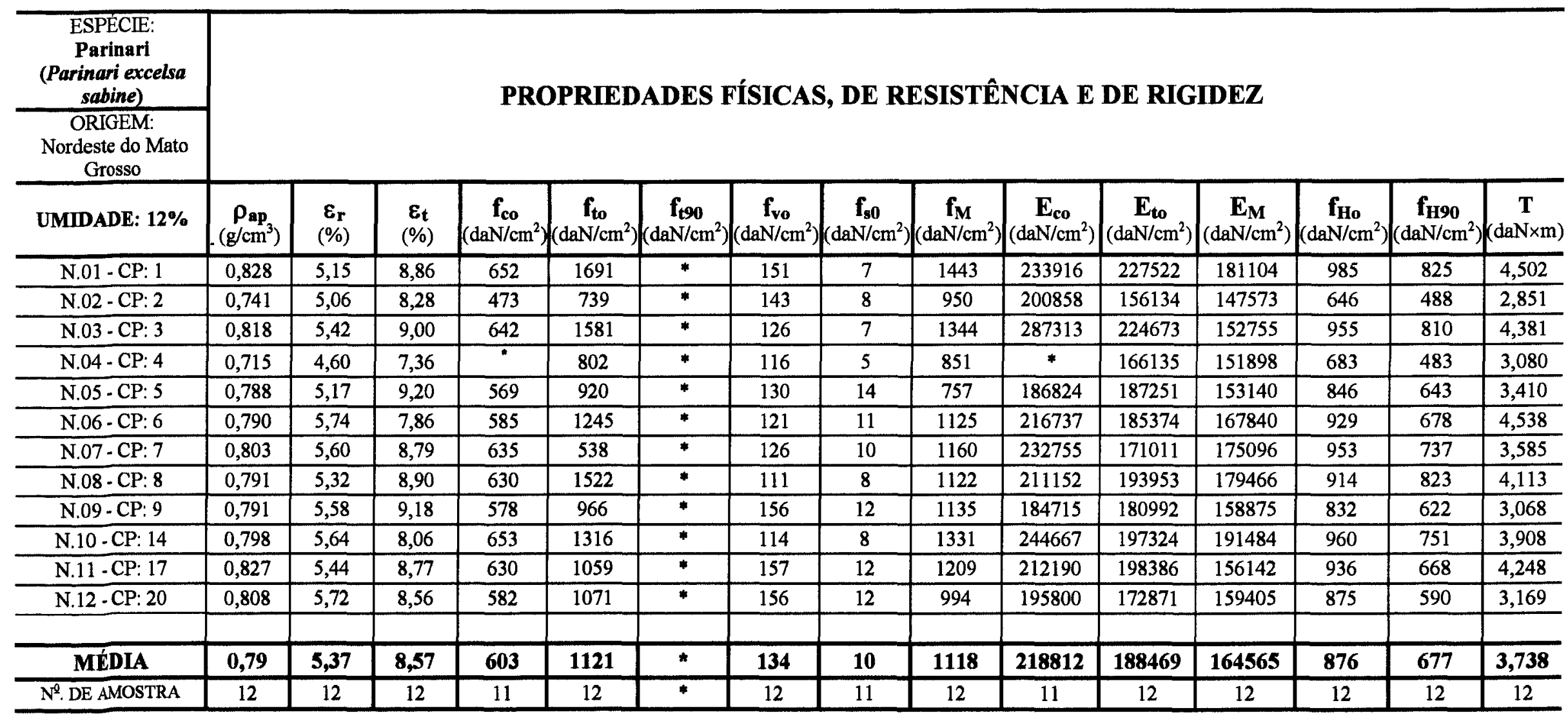

"Dados desconsiderado, CP com defeito. 
Tabela 6.29 - Ensaios - Piolho

\begin{tabular}{|c|c|c|c|c|c|c|c|c|c|c|c|c|c|c|c|}
\hline $\begin{array}{c}\text { ESPECIE: } \\
\text { Piolho } \\
\text { (Tapirira sp) }\end{array}$ & \multicolumn{15}{|c|}{ PROPRIEDADES FÍSICAS DE RESISTÊNCIA E DE RIGIDEZ } \\
\hline UMDDADE: $12 \%$ & $\underset{\left(\mathrm{g} / \mathrm{cm}^{3}\right)}{\rho_{\text {ap }}}$ & $\underset{(\%)}{\boldsymbol{E}_{\mathbf{r}}}$ & $\underset{(\%)}{\boldsymbol{E}_{\mathrm{t}}}$ & $\underset{\left(\mathrm{daN} / \mathrm{cm}^{2}\right)}{\mathbf{f}_{\mathbf{c o}}}$ & $\begin{array}{c}\mathbf{f}_{\text {to }} \\
\left(\mathrm{daN} / \mathrm{cm}^{2}\right)\end{array}$ & $\begin{array}{c}\mathbf{f}_{\mathrm{t} 90} \\
\left(\mathrm{daN} / \mathrm{cm}^{2}\right)\end{array}$ & $\underset{\left(\mathrm{daN} / \mathrm{cm}^{2}\right)}{\mathbf{f}_{\text {vo }}}$ & $\begin{array}{c}\mathbf{f}_{\mathbf{8 0}} \\
\left(\mathrm{daN} / \mathrm{cm}^{2}\right)\end{array}$ & $\underset{\left(\mathrm{daN} / \mathrm{cm}^{2}\right)}{\mathbf{f}_{\mathbf{M}}}$ & $\underset{\left(\mathrm{daN} / \mathrm{cm}^{2}\right)}{\mathbf{E}_{\mathbf{c o}}}$ & $\underset{\left(\mathrm{daN} / \mathrm{cm}^{2}\right)}{\mathbf{E}_{\mathrm{to}}}$ & $\underset{\left(\mathrm{daN} / \mathrm{cm}^{2}\right)}{\mathbf{E}_{\mathbf{M}}}$ & $\underset{\left(\mathrm{daN} / \mathrm{cm}^{2}\right)}{\mathbf{f}_{\mathrm{Ho}}}$ & $\begin{array}{c}f_{H 90} \\
\left(\mathrm{daN} / \mathrm{cm}^{2}\right)\end{array}$ & $\underset{(\mathrm{daN} \times \mathrm{m})}{\mathbf{T}}$ \\
\hline N.01 - CP: 01 & 0,76 & 4,98 & 10,21 & 737 & 881 & 26 & 138 & 8 & 831 & 146892 & 161993 & 126877 & 1137 & 832 & 1,807 \\
\hline N.02 - CP: 02 & 0,83 & 5,02 & 6,13 & 599 & 510 & 56 & 158 & 8 & 700 & 132940 & 102922 & 105275 & 970 & 647 & 0,957 \\
\hline N.03 - CP: 03 & 0,86 & 4,40 & 8,22 & 855 & 618 & 40 & 157 & 7 & 935 & 178856 & 114158 & 141391 & 1042 & 762 & 1,376 \\
\hline N.04 - CP: 04 & 0,81 & 4,65 & 9,16 & 720 & 994 & 29 & 148 & 5 & 911 & 176166 & 156723 & 141970 & 885 & 661 & 1,669 \\
\hline N.05 - CP: 05 & 0,86 & 3,67 & 6,61 & 398 & 643 & 78 & 127 & 7 & 760 & 91697 & 120197 & 104474 & 1050 & 816 & 1,231 \\
\hline N.06 - CP: 06 & 0,82 & 3,92 & 8,72 & 525 & 540 & 31 & 116 & 6 & 513 & 94411 & 117338 & 95865 & 892 & 665 & 1,002 \\
\hline N.07 - CP: 07 & 0,85 & 4,59 & 9,64 & 704 & 740 & 69 & 147 & 7 & 810 & 160557 & 149168 & 131897 & 972 & 763 & 1,549 \\
\hline N.08 - CP: 08 & 0,86 & 4,29 & 8,62 & 602 & 1023 & 22 & 165 & 6 & 632 & 130906 & 149377 & 104262 & 975 & 762 & 1,368 \\
\hline N.09 - CP: 09 & 0,75 & 4,62 & 9,69 & 406 & 1008 & 34 & 128 & 8 & 582 & 91648 & 161857 & 109370 & 822 & 653 & 1,8 \\
\hline N.10 - CP: 10 & 0,90 & 5,06 & 6,69 & 571 & 404 & 43 & 140 & 10 & 649 & 125738 & 118569 & 102758 & 1055 & 637 & 1,492 \\
\hline N.11 - CP: 11 & 0,81 & 4,68 & 10,68 & 653 & 987 & 48 & 187 & 7 & 880 & 155181 & 139630 & 130542 & 1065 & 775 & 1,525 \\
\hline N.12 - CP: 12 & 0,83 & 4,70 & 8,43 & 656 & 418 & 42 & 157 & 7 & 891 & 123441 & 122483 & 120075 & 1037 & 686 & 1,573 \\
\hline MÉDIA & 0,83 & 4,55 & $\mathbf{8 , 5 7}$ & 619 & 731 & 43 & 147 & 7 & 758 & 134036 & 134535 & 117896 & 992 & 722 & 1,446 \\
\hline $\mathrm{N}^{9}$. DE AMOSTRA & 12 & 12 & 12 & 12 & 12 & 12 & 12 & 12 & 12 & 12 & 12 & 12 & 12 & 12 & 12 \\
\hline
\end{tabular}


Tabela 6.30 - Ensaios - Quarubarana

\begin{tabular}{|c|c|c|c|c|c|c|c|c|c|c|c|c|c|c|c|}
\hline $\begin{array}{c}\text { ESPECIE: } \\
\text { Quarubarana } \\
\text { (Erisma uncinatum) }\end{array}$ & \multicolumn{15}{|c|}{ PROPRIEDADES FÍSICAS DE RESISTENCIA E DE RIGIDEZ } \\
\hline UMIDADE: $12 \%$ & $\underset{\left(\mathrm{g} / \mathrm{cm}^{3}\right)}{\boldsymbol{\rho}_{\mathbf{a p}}}$ & $\begin{array}{c}\boldsymbol{\varepsilon}_{\mathbf{r}} \\
(\%)\end{array}$ & $\begin{array}{c}\varepsilon_{t} \\
(\%)\end{array}$ & $\begin{array}{c}\mathbf{f}_{\mathrm{co}} \\
\left(\mathrm{daN} / \mathrm{cm}^{2}\right)\end{array}$ & $\begin{array}{c}\mathbf{f}_{\text {to }} \\
\left(\mathrm{daN} / \mathrm{cm}^{2}\right)\end{array}$ & $\begin{array}{c}\mathbf{f}_{\mathrm{t} 90} \\
\left(\mathrm{daN} / \mathrm{cm}^{2}\right)\end{array}$ & $\begin{array}{c}\mathbf{f}_{\mathbf{v o}} \\
\left(\mathrm{daN} / \mathrm{cm}^{2}\right)\end{array}$ & $\begin{array}{c}\mathbf{f}_{\mathrm{s0}} \\
\left(\mathrm{daN} / \mathrm{cm}^{2}\right)\end{array}$ & $\underset{\left(\mathrm{daN} / \mathrm{cm}^{2}\right)}{\mathbf{f}_{\mathbf{M}}}$ & $\underset{\left(\mathrm{daN} / \mathrm{cm}^{2}\right)}{\mathbf{E}_{\mathbf{c o}}}$ & $\underset{\left(\mathrm{daN} / \mathrm{cm}^{2}\right)}{\mathbf{E}_{\text {to }}}$ & $\underset{\left(\mathrm{daN} / \mathrm{cm}^{2}\right)}{\mathbf{E}_{\mathbf{M}}}$ & $\underset{\left(\mathrm{daN} / \mathrm{cm}^{2}\right)}{\mathbf{f}_{\mathbf{H o}}}$ & $\underset{\left(\mathrm{daN} / \mathrm{cm}^{2}\right)}{\mathbf{f}}$ & $\underset{(\mathrm{daN} \times \mathrm{m})}{\mathbf{T}}$ \\
\hline N.01 - CP: 07 C 01 & 0,53 & 4,66 & 7,13 & 398 & 711 & 37 & 91 & 3 & 892 & 115251 & 113455 & 117929 & 566 & 342 & 0,754 \\
\hline N.02 - CP: 07 C 01 & 0,53 & 3,81 & 7,29 & 489 & 441 & 33 & 97 & 4 & 627 & 78135 & 90604 & 93673 & 969 & 958 & 0,391 \\
\hline N.03 - CP: 08 C 01 & 0,52 & 2,45 & 6,11 & 337 & 327 & 25 & 120 & 3 & 560 & 72075 & 76470 & 70118 & 442 & 299 & 0,342 \\
\hline N.04 - CP: 08 C 04 & 0,55 & 3,12 & 6,38 & 277 & 649 & 29 & 111 & 3 & 598 & 62419 & 77781 & 75683 & 539 & 286 & 0,292 \\
\hline N.05 - CP: $08 \mathrm{C} 10$ & 0,53 & 2,44 & 6,37 & 272 & 658 & 17 & 112 & 5 & 621 & 56558 & 100165 & 73093 & 512 & 380 & 0,351 \\
\hline N.06 - CP: 08 C 12 & 0,47 & 3,42 & 6,85 & 293 & 548 & 18 & 111 & 4 & 721 & 81622 & 96904 & 94820 & 736 & 256 & 0,498 \\
\hline N.07 - CP: $08 C 14$ & 0,48 & 4,63 & 7,12 & 445 & 563 & 25 & 88 & 3 & 724 & 107194 & 76915 & 101978 & 469 & 226 & 0,381 \\
\hline N.08 - CP: 08 C 15 & 0,52 & 2,26 & 6,46 & 298 & 566 & 30 & 86 & 5 & 676 & 71542 & 85094 & 75484 & 808 & 458 & 0,488 \\
\hline N.09-CP: 08 C 19 & 0,55 & 3,4 & 8,38 & 360 & 691 & 18 & 117 & 4 & 755 & 79647 & 106093 & 81134 & 630 & 283 & 0,536 \\
\hline N.10 - CP: $10 C 09$ & 0,57 & 3,65 & 6,86 & 355 & 415 & 14 & 61 & 4 & 601 & 84507 & 80926 & 74247 & 582 & 334 & 0,371 \\
\hline N.11-CP: 12 C 03 & 0,61 & 4,14 & 7,32 & 427 & 633 & 38 & 94 & 2 & 788 & 93547 & 80464 & 93052 & 679 & 391 & 0,556 \\
\hline N. 12 - CP: 13 C 10 & 0,67 & 5,31 & 9,61 & 589 & 764 & 29 & 60 & 6 & 530 & 151441 & 115801 & 109815 & 695 & 506 & 0,893 \\
\hline MÉDIA & $\mathbf{0 , 5 4}$ & 3,61 & 7,16 & 378 & 581 & 26 & 96 & 4 & 674 & 87828 & 91723 & 88419 & 636 & 393 & 0,488 \\
\hline $\mathrm{N}^{0}$. DE AMOSTRAS & 12 & 12 & 12 & 12 & 12 & 12 & 12 & 12 & 12 & 12 & 12 & 12 & 12 & 12 & 12 \\
\hline
\end{tabular}


Tabela 6.31 - Ensaios - Rabo de Arraia

\begin{tabular}{|c|c|c|c|c|c|c|c|c|c|c|c|c|c|c|c|}
\hline $\begin{array}{c}\text { ESPECIE: } \\
\text { Rabo de Arraia } \\
\text { (Vochysia sp) }\end{array}$ & \multicolumn{15}{|c|}{ PROPRIEDADES FÍSICAS DE RESISTÊNCIA E DE RIGIDEZ } \\
\hline UMIDADE: $12 \%$ & $\underset{\left(\mathrm{g} / \mathrm{cm}^{3}\right)}{\rho_{\mathrm{ap}}}$ & $\begin{array}{c}\boldsymbol{E}_{\mathbf{r}} \\
(\%)\end{array}$ & $\begin{array}{c}\boldsymbol{E}_{\mathbf{t}} \\
(\%)\end{array}$ & $\begin{array}{c}\mathbf{f}_{\mathbf{c o}} \\
\left(\mathrm{daN} / \mathrm{cm}^{2}\right)\end{array}$ & $\begin{array}{c}\mathbf{f}_{\mathrm{to}} \\
\left(\mathrm{daN} / \mathrm{cm}^{2}\right)\end{array}$ & $\begin{array}{c}\mathbf{f}_{\mathrm{t} 90} \\
\left(\mathrm{daN} / \mathrm{cm}^{2}\right)\end{array}$ & $\begin{array}{c}\mathbf{f}_{\mathbf{v o}} \\
\left(\mathrm{daN} / \mathrm{cm}^{2}\right)\end{array}$ & $\begin{array}{c}\mathbf{f}_{\mathrm{s0}} \\
\left(\mathrm{daN} / \mathrm{cm}^{2}\right)\end{array}$ & $\frac{\mathbf{f}_{\mathbf{M}}}{\left(\mathrm{daN} / \mathrm{cm}^{2}\right)}$ & $\underset{\left(\mathrm{daN} / \mathrm{cm}^{2}\right)}{\mathbf{E}_{\mathbf{c o}}}$ & $\underset{\left(\mathrm{daN} / \mathrm{cm}^{2}\right)}{\mathbf{E}_{\text {to }}}$ & $\underset{\left(\mathrm{daN} / \mathrm{cm}^{2}\right)}{\mathbf{E}_{\mathbf{M}}}$ & $\begin{array}{c}\mathbf{f}_{\mathbf{H o}} \\
\left(\mathrm{daN} / \mathrm{cm}^{2}\right)\end{array}$ & $\begin{array}{c}\mathbf{f}_{\mathbf{H 9 0}} \\
\left(\mathrm{daN} / \mathrm{cm}^{2}\right)\end{array}$ & $\underset{(\mathrm{daN} \times \mathrm{m})}{\mathbf{T}}$ \\
\hline N.01 - CP: 08 C 01 & 0,72 & 3,48 & 7,50 & 541 & 823 & 19 & 175 & 7 & 912 & 125363 & 178818 & 131807 & 819 & 539 & 0,469 \\
\hline N.02 - CP: 08 C 02 & 0,69 & 3,39 & 6,57 & 462 & 562 & 23 & 135 & 4 & 687 & 120119 & 139476 & 107578 & 792 & 474 & 0,361 \\
\hline N.03 - CP: $08 \mathrm{C} 03$ & 0,79 & 3,81 & 7,85 & 529 & 703 & 15 & 149 & 5 & 678 & 135848 & 126204 & 127108 & 899 & 544 & 0,651 \\
\hline N.04 - CP: 08 C 04 & 0,73 & 2,58 & 5,25 & 540 & 551 & 16 & 137 & 3 & 769 & 160727 & 123458 & 120411 & 792 & 490 & 0,745 \\
\hline N.05 - CP: $08 \mathrm{C} 05$ & 0,70 & 3,46 & 7,25 & 716 & 650 & 26 & 117 & 5 & 1002 & 140815 & 135838 & 134818 & 882 & 507 & 0,517 \\
\hline N.0t - CP: 08 C 06 & 0,77 & 4,37 & 6,71 & 734 & 552 & 16 & 77 & 3 & 867 & 186203 & 161402 & 193029 & 776 & 523 & 0,556 \\
\hline N.07 - CP: $08 \mathrm{C} 07$ & 0,79 & 2,64 & 6,31 & 443 & 1101 & 21 & 146 & 5 & 951 & 124193 & 179850 & 160615 & 844 & 533 & 1,274 \\
\hline N.08 - CP: 08 C 08 & 0,63 & 3,21 & 7,33 & 438 & 484 & 18 & 114 & 3 & 928 & 135663 & 84827 & 102620 & 797 & 450 & 0,708 \\
\hline N.09 - CP: 08 C 09 & 0,72 & 2,63 & 5,52 & 496 & 628 & 11 & 111 & 4 & 244 & 119938 & 105976 & 143129 & 743 & 469 & 1,002 \\
\hline N.10 - CP: $08 \mathrm{C} 11$ & 0,73 & 4,60 & 8,54 & 762 & 894 & 46 & 468 & 5 & 531 & 123042 & 119897 & 125041 & 974 & 531 & 0,847 \\
\hline N.11 - CP: 08 C 12 & 0,69 & 5,58 & 9,83 & 606 & 589 & 19 & 167 & 4 & 856 & 111032 & 133759 & 126020 & 1055 & 582 & 0,856 \\
\hline N.12 - CP: 08 C 13 & 0,77 & 4,78 & 7,36 & 643 & 976 & 32 & 96 & 5 & 1077 & 165949 & 173522 & 154150 & 942 & 630 & 0,884 \\
\hline N.13 - CP: 08 C 14 & 0,71 & 3,89 & 7,52 & 745 & 970 & 25 & 62 & 4 & 1004 & 179760 & 158070 & 165452 & 931 & 450 & 0,782 \\
\hline N.14 - CP: 08 C 15 & 0,72 & 3,76 & 7,95 & 509 & 444 & 28 & 194 & 5 & 808 & 140741 & 124939 & 177844 & 936 & 557 & 1,056 \\
\hline N.15 - CP: 08 C 17 & 0,57 & 3,20 & 7,15 & 458 & 415 & 40 & 89 & 6 & 577 & 127573 & 107296 & 109133 & 630 & 347 & 0,351 \\
\hline MÉDLA & 0,72 & 3,69 & 7,24 & 575 & 689 & 24 & 149 & 5 & 793 & 139798 & 136889 & 138584 & 854 & 508 & 0,737 \\
\hline $\mathrm{N}^{2}$. DE AMOSTRAS & 15 & 15 & 15 & 15 & 15 & 15 & 15 & 15 & 15 & 15 & 15 & 15 & 15 & 15 & 15 \\
\hline
\end{tabular}


Tabela 6.32 - Ensaios - Tachi

\begin{tabular}{|c|c|c|c|c|c|c|c|c|c|c|c|c|c|c|c|}
\hline $\begin{array}{c}\text { ESPECIE: } \\
\text { Tachi } \\
\text { (Tachinalia } s p) \\
\end{array}$ & \multicolumn{15}{|c|}{ PROPRIEDADES FÍSICAS DE RESISTÊNCIA E DE RIGIDEZ } \\
\hline UMDADE: $12 \%$ & $\underset{\left(\mathrm{g} / \mathrm{cm}^{3}\right)}{\rho_{\mathbf{a p}}}$ & $\begin{array}{c}\boldsymbol{\varepsilon}_{\mathbf{r}} \\
(\%)\end{array}$ & $\begin{array}{c}\boldsymbol{\varepsilon}_{\mathbf{t}} \\
(\%)\end{array}$ & $\begin{array}{c}\mathbf{f}_{\mathrm{co}} \\
\left(\mathrm{daN} / \mathrm{cm}^{2}\right)\end{array}$ & $\begin{array}{c}\mathbf{f}_{\mathrm{to}} \\
\left(\mathrm{daN} / \mathrm{cm}^{2}\right)\end{array}$ & $\begin{array}{c}\mathbf{f}_{\mathbf{t g 0}} \\
\left(\mathrm{daN} / \mathrm{cm}^{2}\right)\end{array}$ & $\begin{array}{c}\mathbf{f}_{\mathbf{v o}} \\
\left(\mathrm{daN} / \mathrm{cm}^{2}\right)\end{array}$ & $\begin{array}{c}\mathbf{f}_{\mathrm{s0}} \\
\left(\mathrm{daN} / \mathrm{cm}^{2}\right)\end{array}$ & $\underset{\left(\mathrm{daN} / \mathrm{cm}^{2}\right)}{\mathbf{f}_{\mathbf{M}}}$ & $\underset{\left(\mathrm{daN} / \mathrm{cm}^{2}\right)}{\mathbf{E}_{\mathbf{c o}}}$ & $\underset{\left(\mathrm{daN} / \mathrm{cm}^{2}\right)}{\mathbf{E}_{\mathbf{t o}}}$ & $\underset{\left(\mathrm{daN} / \mathrm{cm}^{2}\right)}{\mathbf{E}_{\mathbf{M}}}$ & $\underset{\left(\mathrm{daN} / \mathrm{cm}^{2}\right)}{\mathbf{f}_{\mathbf{H}}}$ & $\begin{array}{c}\mathbf{f}_{\mathrm{Hg0}} \\
\left(\mathrm{daN} / \mathrm{cm}^{2}\right)\end{array}$ & $\underset{(\mathrm{daN} \times \mathrm{m})}{\mathbf{T}}$ \\
\hline N.01-CP: 01 & 0,99 & 2,14 & 7,44 & 833 & 594 & 41 & 229 & 10 & 1254 & 185921 & 164539 & 173309 & 1118 & 1161 & \\
\hline N.02 - CP: 02 & 1,1 & 2,99 & 8,59 & 961 & 1108 & 42 & 219 & 10 & 1192 & 252389 & 239672 & 213983 & 1354 & 1288 & * \\
\hline N.03 - CP: 03 & 1,08 & 4,56 & 8,78 & 968 & 4863 & 105 & 248 & 12 & 1788 & 232710 & 273146 & 248316 & 1278 & 1438 & $*$ \\
\hline N.04 - CP: 04 & 1,15 & 4,28 & 11,55 & 999 & 1470 & 62 & 216 & 13 & 2068 & 207531 & 255457 & 239751 & 1345 & 1594 & $*$ \\
\hline N.05 - CP: 05 & 1,13 & 4,54 & 11,51 & 950 & 615 & 51 & 216 & 15 & 1013 & 213552 & 152437 & 232869 & 1138 & 1301 & * \\
\hline N.06 - CP: 06 & 0,87 & 4,19 & 7,31 & 958 & 1180 & 55 & 178 & 12 & 1589 & 194687 & 193817 & 192782 & 1275 & 1248 & * \\
\hline N.07 - CP: 07 & 1,05 & 4,82 & 9,99 & 899 & 1479 & 44 & 131 & 10 & 1230 & 214629 & 192850 & 196022 & 1055 & 1154 & $*$ \\
\hline N.08 - CP: 08 & 1,02 & 3,96 & 8,37 & 746 & 1360 & 62 & 181 & 17 & 1450 & 163654 & 217198 & 208615 & 890 & 1064 & * \\
\hline N.09-CP: 09 & 1,07 & 5,78 & 9,56 & 729 & 514 & 41 & 230 & 10 & 937 & 147454 & 113023 & 147585 & 1065 & 1178 & $*$ \\
\hline N. 10 - CP: 10 & 1,06 & 6,16 & 9,96 & 880 & 954 & 37 & 304 & 18 & 1540 & 214718 & 176762 & 198850 & 1205 & 1614 & $*$ \\
\hline N.11 - CP: 11 & 1,03 & 3,33 & 10,24 & 734 & 1049 & 41 & 141 & 11 & 1355 & 161809 & 163379 & 237308 & 1048 & 1094 & * \\
\hline MÉDIA & 1,05 & 4,25 & 9,39 & 878 & 1381 & 53 & 208 & 13 & 1401 & 199005 & 194753 & 208126 & 1161 & 1285 & * \\
\hline $\mathrm{N}^{2}$. DE AMOSTRA & 11 & 11 & 11 & 11 & 11 & 11 & 11 & 11 & 11 & 11 & 11 & 11 & 11 & 11 & $*$ \\
\hline
\end{tabular}

* Dado desconsiderado, CP com defeito. 
Tabela 6.33 - Ensaios - Tatajuba

\begin{tabular}{|c|c|c|c|c|c|c|c|c|c|c|c|c|c|c|c|}
\hline $\begin{array}{c}\text { ESPECEE: } \\
\text { Tatajuba } \\
\text { (Bagassa guianensis) }\end{array}$ & \multicolumn{15}{|c|}{ PROPRIEDADES FÍSICAS DE RESISTÊNCIA E DE RIGIDEZ } \\
\hline UMIDADE: $12 \%$ & $\underset{\left(\mathrm{g} / \mathrm{cm}^{3}\right)}{\boldsymbol{\rho}_{\mathbf{p p}}}$ & $\begin{array}{c}\boldsymbol{E}_{\mathbf{r}} \\
(\%)\end{array}$ & $\begin{array}{c}\boldsymbol{\varepsilon}_{\boldsymbol{t}} \\
(\%)\end{array}$ & $\begin{array}{c}\mathbf{f}_{\mathbf{c o}} \\
\left(\mathrm{daN} / \mathrm{cm}^{2}\right)\end{array}$ & $\begin{array}{c}\mathbf{f}_{\mathbf{t o}} \\
\left(\mathrm{daN} / \mathrm{cm}^{2}\right)\end{array}$ & $\begin{array}{c}\mathbf{f}_{\mathbf{t} 90} \\
\left(\mathrm{daN} / \mathrm{cm}^{2}\right)\end{array}$ & $\underset{\left(\mathrm{daN} / \mathrm{cm}^{2}\right)}{\left.\mathbf{f}_{\mathbf{v o}}\right)}$ & $\begin{array}{c}\mathbf{f}_{\mathbf{s 0}} \\
\left(\mathrm{daN} / \mathrm{cm}^{2}\right)\end{array}$ & $\begin{array}{c}\mathbf{f}_{\mathbf{M}} \\
\left(\mathrm{daN} / \mathrm{cm}^{2}\right)\end{array}$ & $\underset{\left(\mathrm{daN} / \mathrm{cm}^{2}\right)}{\mathbf{E}_{\mathbf{c o}}}$ & $\underset{\left(\mathrm{daN} / \mathrm{cm}^{2}\right)}{\mathbf{E}_{\mathbf{t o}}}$ & $\underset{\left(\mathrm{daN} / \mathrm{cm}^{2}\right)}{\mathbf{E}_{\mathbf{M}}}$ & $\underset{\left(\mathrm{daN} / \mathrm{cm}^{2}\right)}{\mathbf{f}_{\mathrm{Ho}}}$ & $\begin{array}{c}\mathbf{f}_{\mathbf{H 9 0}} \\
\left(\mathrm{daN} / \mathrm{cm}^{2}\right)\end{array}$ & $\begin{array}{c}\mathbf{T} \\
(\mathrm{daN} \times \mathrm{m})\end{array}$ \\
\hline N.01 - CP: 25 D 01 & 0,96 & 3,54 & 5,27 & 987 & 981 & 42 & 217 & 8 & 1564 & 204018 & 185191 & 248284 & 1411 & 1015 & 1,248 \\
\hline N.02-CP: 25 D 02 & 0,95 & 4,24 & 5,81 & 994 & 895 & 42 & 193 & 6 & 1025 & 244245 & 186245 & 202826 & 1357 & 928 & 0,660 \\
\hline N.03 - CP: 25 D 03 & 0,96 & 5,37 & 6,59 & 786 & 1265 & 26 & 230 & 9 & 1084 & 211378 & 219403 & 206309 & 1276 & 949 & 1,661 \\
\hline N.04 - CP: 25 D 05 & 0,91 & 4,09 & 5,76 & 841 & 1041 & 19 & 208 & 8 & 1006 & 188661 & 175164 & 154033 & 1228 & 727 & 1,127 \\
\hline N.05-CP: 25 D 07 & 0,90 & 3,94 & 5,45 & 812 & 1160 & 35 & 183 & 10 & 1389 & 105657 & 142921 & 171030 & 1362 & 948 & 1,409 \\
\hline N.06 - CP: 25 D 08 & 0,83 & 4,49 & 5,37 & 900 & 970 & 28 & 210 & 9 & 694 & 182948 & 124819 & 136973 & 1325 & 899 & 0,764 \\
\hline N.07-CP: 45 A 01 & 1,06 & 4,25 & 5,27 & 870 & 915 & 71 & 196 & 12 & 1292 & 196328 & 179815 & 188837 & 1300 & 1167 & 0,763 \\
\hline N.08-CP: 45 A 02 & 0,91 & 4,59 & 7,03 & 452 & 480 & 45 & 190 & 9 & 785 & 172302 & 149221 & 156372 & 931 & 785 & 0,821 \\
\hline N.09-CP: 05 A 03 & 0,98 & 3,92 & 6,21 & 631 & 958 & 36 & 199 & 8 & 1014 & 185714 & 158429 & 173821 & 927 & 740 & 0,526 \\
\hline N.10 - CP: 05 A 04 & 0,96 & 4,4 & 5,01 & 742 & 628 & 58 & 171 & 10 & 1204 & 165864 & 162393 & 172929 & 809 & 683 & 0,675 \\
\hline MÉDIA & 0,94 & 4,28 & 5,78 & 802 & 929 & 40 & 200 & 9 & 1106 & 185712 & 168360 & 181141 & 1193 & 884 & 0,965 \\
\hline $\mathrm{N}^{2}$. DE AMOSTRA & 10 & 10 & 10 & 10 & 10 & 10 & 10 & 10 & 10 & 10 & 10 & 10 & 10 & 10 & 10 \\
\hline
\end{tabular}


Tabela 6.34 - Ensaios - Umirana

\begin{tabular}{|c|c|c|c|c|c|c|c|c|c|c|c|c|c|c|c|}
\hline $\begin{array}{c}\text { ESPECIE: } \\
\text { Umirana } \\
\text { (Qualea retusa) } \\
\end{array}$ & \multicolumn{15}{|c|}{ PROPRIEDADES FÍSICAS, DE RESISTÊNCIA E DE RIGIDEZ } \\
\hline UMDADE: $12 \%$ & $\underset{\left(\mathrm{g} / \mathrm{cm}^{3}\right)}{\rho_{\mathrm{ap}}}$ & $\begin{array}{l}\boldsymbol{E}_{\mathbf{r}} \\
(\%)\end{array}$ & $\begin{array}{c}\boldsymbol{\varepsilon}_{\mathbf{t}} \\
(\%)\end{array}$ & $\begin{array}{c}\mathbf{f}_{\mathbf{c o}} \\
\left(\mathrm{daN} / \mathrm{cm}^{2}\right)\end{array}$ & $\begin{array}{c}\mathbf{f}_{\mathbf{t o}} \\
\left(\mathrm{daN} / \mathrm{cm}^{2}\right)\end{array}$ & $\begin{array}{c}\mathbf{f}_{\mathbf{t 9 9}} \\
\left(\mathrm{daN} / \mathrm{cm}^{2}\right)\end{array}$ & $\begin{array}{c}\mathbf{f}_{\mathbf{v o}} \\
\left(\mathrm{daN} / \mathrm{cm}^{2}\right)\end{array}$ & $\left(\begin{array}{c}\mathbf{f}_{\mathbf{s} 0} \\
\left(\mathrm{daN} / \mathrm{cm}^{2}\right)\end{array}\right.$ & $\begin{array}{c}\mathbf{f}_{\mathbf{M}} \\
\left(\mathrm{daN} / \mathrm{cm}^{2}\right)\end{array}$ & $\underset{\left(\mathrm{daN} / \mathrm{cm}^{2}\right)}{\left.\mathbf{E}_{\mathbf{c o}}\right)}$ & $\begin{array}{c}\mathbf{E}_{\text {to }} \\
\left(\mathrm{daN} / \mathrm{cm}^{2}\right)\end{array}$ & $\underset{\left(\mathrm{daN} / \mathrm{cm}^{2}\right)}{\mathbf{E}_{\mathbf{M}}}$ & $\begin{array}{c}\mathbf{f}_{\mathbf{H o}} \\
\left(\mathrm{daN} / \mathrm{cm}^{2}\right)\end{array}$ & $\begin{array}{c}\mathbf{f}_{\mathrm{H}} \mathrm{Ho} \\
\left(\mathrm{daN} / \mathrm{cm}^{2}\right)\end{array}$ & $\underset{(\mathrm{daN} \times \mathrm{m})}{\mathbf{T}}$ \\
\hline N.01 - CP: 21 D 02 & 0,67 & 2,44 & 5,23 & 580 & 562 & 36 & 131 & 5 & 541 & 91584 & 86020 & 87078 & 776 & 501 & 0,381 \\
\hline N.02-CP: 21 D 04 & 0,72 & 3,05 & 4,97 & 610 & 592 & 29 & 172 & 6 & 439 & 99288 & 76200 & 73968 & 899 & 474 & 0,162 \\
\hline N.03-CP: 21 D 05 & 0,71 & 3,35 & 5,87 & 571 & 477 & 33 & 148 & 6 & 698 & 84510 & 112142 & 114963 & 872 & 501 & 0,562 \\
\hline N.04-CP: 21 D 10 & 0,70 & 3,76 & 5,69 & 492 & 670 & 23 & 144 & 7 & 771 & 121009 & 106204 & 93600 & 836 & 620 & 0,478 \\
\hline N.05 - CP: 21 D 16 & 0,73 & 4,86 & 9,13 & 528 & 440 & 49 & 112 & $\overline{6}$ & 529 & 85187 & 79105 & 79548 & 894 & 474 & 0,222 \\
\hline N.06 - CP: 21 D 17 & 0,68 & 3,44 & 6,01 & 527 & 326 & 21 & 164 & 5 & 679 & 108406 & 119877 & 103000 & 925 & 485 & 0,536 \\
\hline N.07-CP: 21 D 18 & 0,67 & 3,76 & 6,23 & 538 & 539 & 18 & 180 & 6 & 623 & 97212 & 121079 & 85900 & 943 & 498 & 0,679 \\
\hline N.08 - CP: 22 D 09 & 0,72 & 4,37 & 8,61 & 514 & 898 & 28 & 128 & 6 & 880 & 102097 & 104617 & 130998 & 878 & 579 & 0,546 \\
\hline N.09-CP: 22 D 10 & 0,71 & 2,97 & 6,08 & 466 & 406 & 22 & 143 & 5 & 628 & 72332 & 137070 & 125850 & 889 & 420 & 0,670 \\
\hline N.10 - CP: 22 D 11 & 0,73 & 3,16 & 5,50 & 555 & 596 & 22 & 101 & 5 & 656 & 103324 & 99431 & 163781 & 975 & 603 & 0,801 \\
\hline N.11 - CP: 22 D 13 & 0,73 & 3,87 & 6,24 & 504 & 412 & 33 & 142 & 5 & 639 & 118706 & 121293 & 91900 & 690 & 479 & 0,565 \\
\hline N.12 - CP: 22 D 20 & 0,69 & 3,96 & 5,45 & 572 & 544 & 29 & 180 & 6 & 937 & 137648 & 162210 & 144668 & 975 & 773 & 0,351 \\
\hline MÉDIA & 0,71 & $\mathbf{3 , 5 8}$ & 6,25 & 538 & 539 & 29 & 145 & 6 & 668 & 101775 & 110437 & 107938 & 879 & 534 & 0,496 \\
\hline$N^{0}$. DE AMOSTRAS & 12 & 12 & 12 & 12 & 12 & 12 & 12 & 12 & 12 & 12 & 12 & 12 & 12 & 12 & 12 \\
\hline
\end{tabular}




\section{7 - REFERÊNCIAS BIBLIOGRÁFICAS}

\section{1 - BIBLIOGRAFIA CONSULTADA}

ALENCAR, J. C.; LOUREIRO, A. A. \& SILVA, M. F. Essências Madeireiras da Amazônia. SUFRAMA-INPA, Manaus-Amazônia, v.2, 1979.

ASSOCIAÇÃO BRASILEIRA DE NORMAS TÉCNICAS - ABNT. NBR 7190/97: Projeto de estruturas de madeira. Rio de Janeiro, 1997.

BORTOLETTO, Jr., G.. Indicações para a utilização da madeira de seis espécies de pinus na construção civil. São Carlos. 1993. 127p. Dissertação (Mestrado) Departamento de Arquitetura e Planejamento, Escola de Engenharia de São Carlos, Universidade de São Paulo.

CAMARGOS,J. A. A. STERNADT, G.H. Novas perspectivas de utilização da cor da madeira Amazônica e seu aproveitamento comercial. LPF-SÉRIE TÉCNICA № 7. Brasília, 1989.

CARVALHO, G. M. ; MARTINS, V. A ; MELO, J. E. Espécies de madeiras substitutas do mogno. LPF- SÉRIE TÉCNICA №6. Brasília, 1989.

DIAS, A.A. Estudo da solicitação de compressão normal às fibras da madeira. São Carlos. 1994. 158p. Tese (Doutorado) - Departamento de Engenharia de Estruturas, Escola de Engenharia de São Carlos, Universidade de São Paulo.

DURLO, M.A; MARCHIORI, J. N. C. Tecnologia da madeira: Retratibilidade. Santa Maria, CEPEF/FATEC, 33 p. Série Técnica, 10, 1992.

FARIA, C. M. C. S. Madeiras da Amazônia - Identificação de 100 Espécies. Rede Ferroviária Federal, 1981. 
FLEISCHER, H. O. The impact of utilization research on thecomplete use of the forest. Wood Science and Technology, v.5, p.247-54, 1971.

FOREST PRODUCTS LABORATORY. Wood handbook: Wood as an engineering material. Washington; U.S. Departament of agriculture. 466p. (Agriculture handbook, 72), 1987.

FRÜWALD, A. Desenvolvimento técnico na produção da madeira. Brasil Madeira, v.4, n.4, p.32-43. Rever, 1980.

FREITAS, A.R. Probabilistic approach in the design of wood structures in Brasil based on the variability of 23 species. Dissertation submetted to the graduate Faculty of the Virginia Polytechnic Institute and State University in partial fulfillment of the requeriments for the degree of Doctor of Philosophy in Civil Engineering. IPT, São Paulo, Brasil, № 1198, 77p.1978.

FREITAS, J. A.; FREITAS, C. A. A. \& LOUREIRO, A. A. Essências Madeireiras da Amazônia. INPA, Manaus-Amazônia, v.3, 107p. 1997.

FURIATI, M. Classificação estrutural de peças de madeira. São Carlos, 1981. $131 \mathrm{p}$. Dissertação (Mestrado) - Departamento de Engenharia de Estruturas, Escola de Engenharia de São Carlos, Universidade de São Paulo.

GALVÃO, A. P. M.; JANKOWSSKY, I. P Secagem Racional da Madeira. São Paulo, Nobel, 1985.

HELLMEISTER, J. C. (1982). Sobre a determinação das características fisicas da madeira. Departamento de Engenharia de Estruturas. Laboratório de Madeiras e de Estruturas de Madeira. EESC - USP. 117p.

INSTITUTO FORESTAL - INFOR. Caracteristicas fisico mecânicas de eucalypus fastigata, eucalyptus nitens y pinus muricata crecidos no Chile. Chile, $\mathrm{n}^{-9}$ 97, 1983.

INSTITUTO NACIONAL DE PESQUISAS ESPACIAIS - INPE. Notícias. São José dos Campos, SP, Brasil, v.4, n.13, jan/fev, 1998.

INSTITUTO DE PESQUISAS TECNOLÓGICAS. Métodos de Ensaios / Tabela de Resultados / Nomenclatura das Madeiras Brasileiras. São Paulo, Boletim 31, $2^{\mathrm{a}}$ edição, 1956.

Madeira: Oque é e como pode ser processada e utilizada. São Paulo, Boletim ABPM, 36, 189p, 1985.

KOLLMAN, F.F.P.; CÔTÉ Jr., W.A. Principles of wood science and technology: I solid wood, Springer - Verlag. 560p. Berlin, 1968. 
LAHR, F.A. R. Sobre a determinação de propriedades de elasticidade da madeira. 216p. São Carlos, 1983. Tese (Doutorado) - Departamento de Engenharia de Estruturas, Escola de Engenharia de São Carlos, Universidade de São Paulo.

Considerações a respeito da variabilidade de propriedades de resistência e elasticidade da madeira. 175p. São Carlos, 1990. Tese (Livre docência) - Departamento de Engenharia de Estruturas, Escola de Engenharia de São Carlos, Universidade de São Paulo.

LOGSDON, N. B. Influência da umidade nas propriedades de resistência e rigidez da madeira. 174p. São Carlos, 1998. Tese (Doutorado) - Departamento de Engenharia de Estruturas Escola de Engenharia de São Carlos, Universidade de São Paulo.

LOUREIRO, A. A.; SILVA, M. F. Catálogo das madeiras da Amazônia. Superintendência do Desenvolvimento da Amazônia - SUDAM, Ministério do Interior. v.2, 411 p. Belém, 1968.

LABORATÓRIO DE PRODUTOS FLORESTAIS -LPF Madeiras da Amazônia: características e utilizações .Brasília, v.3, 1997.

MAINIERI, C. Manual de identificação das principais madeiras comerciais brasileiras. Publicação - IPT, n.1226, São Paulo, 1983.

MAINIERI, C \& CHIMELO, J. P. Fichas de características das madeiras brasileiras IPT - São Paulo, 489p. São Paulo, 1989.

MARTINS, V.A. et al. Secagem de madeiras ao ar livre na região do Distrito Federal. Boletim Técnico, n.35, 16p. São Paulo, 1985.

MARTINS, V.A. Secagem de madeira serrada. IBDF/DPQ-LPF, 56p. Brasília, 1988.

MENDES, A. P. Resistência da madeira ao cisalhamento. São Carlos, 1984. 157p. Dissertação (Mestrado) - Departamento de Engenharia de Estruturas, Escola de Engenharia de São Carlos, Universidade de São Paulo.

NAHUZ, M.A.R. Some aspects of the introduction of lesser known brazilian species to the european timber market. 1974. 243p. Department of Forestry and Wood Science University College of North Wales Bangor.

NOGUEIRA, M.C.J.A. Indicações para o emprego de dezesseis espécies de eucalipto na construção civil. São Carlos, 1991. 150p. Dissertação (Mestrado) - Departamento de Arquitetura e Planejamento, Escola de Engenharia de São Carlos, Universidade de São Paulo. 
PIGOZZO, J. C. Influência da umidade e da densidade na resistência à compressão da madeira. São Carlos, 1982. 142p. Dissertação (Mestrado) - Departamento de Engenharia de Estruturas, Escola de Engenharia de São Carlos, Universidade de São Paulo.

PRATA, D. G. Compressão paralela às fibras em peças de madeira. São Carlos, 1989. 151 p. Dissertação (Mestrado) - Departamento de Engenharia de Estruturas, Escola de Engenharia de São Carlos, Universidade de São Paulo.

REINALDO, H. P.; LUIZ, T.W. BRASIL. Ministério da Indústria e do Comércio Secretaria de Tecnologia Industrial. Manual de secagem da madeira. Brasília, DF, STF/IPT, 1985

RIZZINI, C. T. Árvores e madeiras úteis do Brasil - Manual de Dendrologia Brasileira, Editora Edgar Brúcher. 305p. São Paulo, 1971.

Árvores e madeiras úteis do Brasil - Manual de Dendrologia. 2.ed. Editora Edgar Brúcher, São Paulo, 1981.

ROCHA, J. S. Variabilidades de propriedades fisicas e mecânicas de madeiras Amazônicas nas condições verde e seca. Piracicaba, 1994. 132p. Dissertação (Mestrado) - Escola Superior de Agricultura "Luiz de Queiroz" da Universidade de São Paulo.

SALLENAVE, P. Propriétés physiques et mécaniques dês bois tropicaux de l'union française. Centre Technique Forestier Tropical, 128p. France, 1955.

Propriétés physiques et mécaniques dês bois tropicaux. Centre Technique Forestier Tropical. France, Premier Supplément. 79p. 1964.

Propriétés physiques et mécaniques dês bois tropicaux. Centre Technique Forestier Tropical. France, Deuxiéme Supplement. 123p. 1971.

SOUZA, M. H. Substituição da madeira de castanheira (Bertholletia excelsa Humb \& Bonpl.). Brasília, 1989.

SUDAM - Pesquisas e Informações sobre Espécies Florestais da Amazônia. Ministério do Interior, 111 p. Belém, 1979.

SUDAM/IPT - Grupamento de espécies tropicais da Amazônia por similaridade de características básicas e por utilização. 237p. Belém, 1981.

TANAAMI, R. G. Tração normal às fibras em peças de madeira. São Carlos, 1993. 127p. Tese (Doutorado) - Departamento de Estrutura, Escola de Engenharia de São Carlos, Universidade de São Paulo. 


\section{2 - BIBLIOGRAFIA COMPLEMENTAR}

AKACHUKU, A.E. The effects of some extrinsic and intrinsic factors on the proportions of vessels in Gmelina arborea Roxb. Wood Science and Thechnology, v. 19, n. $1,1985$.

BENEVENTE,V.A. Durabilidade em construções de madeira - uma questão de projeto. São Carlos, 1994. 231 p. Dissertação (Mestrado) - Escola de Engenharia de São Carlos, Universidade de São Paulo.

CARMO, A.P.T. Avaliação de algumas propriedades da madeira de seis espécies de eucalipto. Viçosa, 1996. 74 p. Dissertação (Mestrado) - Universidade Federal de Viçosa.

FOELKEL, C. E. B. Qualidade da madeira: teoria. Belo Oriente, s. ed, 1977.

GEMMEL, A. R. Anatomia do vegetal em desenvolvimento. São Paulo, Coleção Temas de Biologia, v.19, 1980.

HARLOW, W. M.; HARRAR, E. S. Textbook of dendrology. New York, Mc Graw Hill Book Company, 4. ed, 1958.

HELLMEISTER, J. C. Madeiras e suas características. In: Encontro Brasileiro em Madeiras e em Estruturas de Madeira, 1, São Carlos, SP, Brasil, 1983. Anais. São Carlos, USP-EESC, v.1, p.1-32.

KOLLMAN, F.F.P.; CÔTÉ Jr., W.A Principles of wood science and technology. v.1. solid wood. Reprint. Berlin, Heidelberg, New york, Tokyo. Springer-Verlag: 19681984.

KEENAN,F. J.; ENG, P. The utilization of wood as a construction material in tropical countries, University of Toroto. 30p. Toronto, 1979.

MAINIERI, C. Identificação das principais madeiras de comércio no Brasil. São Paulo, IPT, Boletim 31, 1956, 62p.

MOREY, P. R. O crescimento das árvores. São Paulo, Coleção Temas de Biologia, v.12, 1980 .

OLIVEIRA, J. T. S. Caracterização da madeira de eucalipto para a construção civil. São Paulo, 1997. v.1, 160p. \& v.2, 429p. Tese (Doutorado). Escola Politécnica da Universidade de São Paulo. 
PINHEIRO, R. V.; LAHR, F. A. R.. Influência da preservação contra demanda biológica em propriedades de resistência e de elasticidade da madeira. In: Encontro Brasileiro em Madeiras e em Estruturas de Madeira, 7. São Carlos, 2000. Anais. São Paulo, USP-EESC. CD-ROM, 2000.

RAWITSCHER, F. K. Elementos básicos de botânica. São Paulo, Brasil, Editora Centro Universitário, 1964. 